

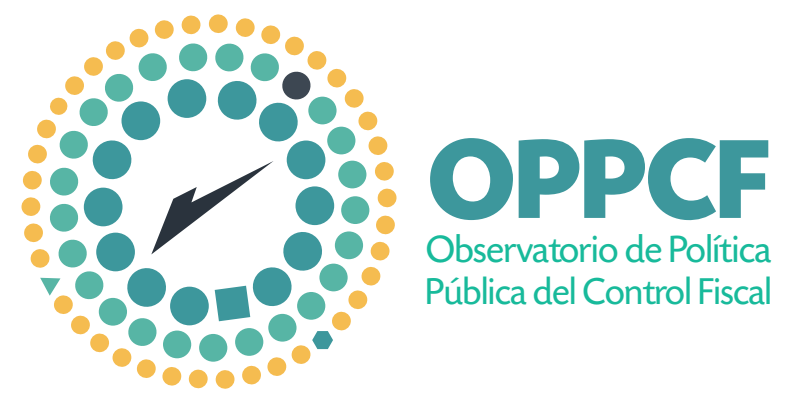

\section{PRESUPUESTOS PARA LA CONSTRUCCIÓN DE POLÍTICAS PÚBLICAS DE CONTROL FISCAL}




\section{PRESUPUESTOS PARA LA CONSTRUCCIÓN DE POLÍTICAS PÚBLICAS DE CONTROL FISCAL}

@ Auditoría General de la República, 2019

Dirección General: Carlos Hernán Rodriguez Becerra

Coordinación del Observatorio de Política Pública de Control Fiscal: Diana Carolina Villalba Erazo

Coordinación temática investigación: Manuel Fernando Moya Vargas

Coordinación editorial: Tatiana Ordoñez Vásquez

Comité Editorial: Carlos Hernán Rodriguez Becerra, Jaime Escobar Vélez, Diana Carolina Villalba Erazo, Manuel Fernando Moya Vargas, Diana Maite Bayona Aristizábal, Jhonny Marlon Cárdenas Arévalo, Tatiana Ordoñez Vásquez, Liliana Patricia Ortiz Ospino

Investigadores: Alexandra Paola González Zapata, Diana Maite Bayona Aristizábal, Tatiana Ordoñez Vásquez, Edgar Alfredo Restrepo Acevedo, Liliana Patricia Ortiz Ospino, José Lizardo Ortíz Cubillos, Jhonny Marlon Cárdenas Arévalo, Manuel Fernando Moya Vargas, Leyner Mosquera Perea, Juan Diego Doncel Ramírez, Armando Rodríguez Ángel, Ana Esther Tovar Porras, Ximena Salazar Quintero.

Colaboradores: Dalia Carreño Dueñas, María Margarita Bueno González, Luis Ricardo Martínez Ramírez, Cristian Orlando Daza Pérez, Donelia Adarme Jaimes.

Diseño y diagramación: Juan Pablo Dueñas Báez, Juan de Dios Cano Londoño

Impresión: Imprenta Nacional de Colombia

Impreso en Colombia

Bogotá, D.C., diciembre de 2019

Primera edición

500 ejemplares

ISBN: 978-958-57947-9-5 


\title{
Contenido
}

\author{
INTRODUCCIÓN $\quad 7$ \\ CAPÍTULO I \\ POLÍTICA PÚBLICA DEL CONTROL FISCAL. PRINCIPIOS CONSTITUCIONALES DE LA GESTIÓN \\ FISCAL 11
}

PRINCIPIOS CONSTITUCIONALES DEL CONTROL FISCAL 16

1.1. REFERENTES INSTITUCIONALES

16

1.2. PRINCIPIO DE ECONOMÍA: 19

1.3. PRINCIPIO DE EFICIENCIA 20

1.4. PRINCIPIO DE EFICACIA: 21

1.5. PRINCIPIO DE EQUIDAD: 22

1.6. VALORACIÓN DE COSTOS AMBIENTALES: 23

1.7. CONDICIONES PARA LA REALIZACIÓN DE LOS DERECHOS FUNDAMENTALES 26

1.8. CONCLUSIONES 26

1.9. BIBLIOGRAFÍA 27

CAPÍTULO II

CONTROL FISCAL: CADENA DE VALOR DEL PROCESO AUDITOR. 30

Introducción33

2.1. REFERENTES LEGALES DEL CONTROL FISCAL Y DEL PROCESO AUDITOR 34

2.2. GENERALIDADES DE LAS CONTRALORÍAS TERRITORIALES - CONTEXTO. 46

2.3. RENDICIÓN Y REVISIÓN DE CUENTAS 58

2.4. PLANEACIÓN Y EJECUCIÓN DE AUDITORÍAS. 64

2.5. CONCLUSIONES 79

2.6. BIBLIOGRAFIA 82

\section{CAPÍTULO III}

RESULTADOS DEL PROCESO AUDITOR: HALLAZGOS Y PROCESOS FISCALES

3.1. HALLAZGOS FISCALES COMO RESULTADO DEL PROCESO AUDITOR 2012-2017.

3.2. RESULTADO DE LOS PROCESOS DE RESPONSABILIDAD FISCAL 2012-2017.

3. EFICACIA DE LA ORALIDAD EN LOS PROCESOS DE RESPONSABILIDAD FISCAL TRAMITADOS ENTRE 2012 Y 2017. 101

3.4. RESULTADO DEL PROCESO DE JURISDICCIÓN COACTIVA.

104 


\section{Contenido}

3.5. HALLAZGOS Y PROCESOS DE RESPONSABILIDAD FISCAL DERIVADOS DE CONTROL FISCAL A LA GESTIÓN AMBIENTAL 2012-2017 105

3.6. CONCLUSIONES $\quad 110$

3.7. BIBLIOGRAFÍA $\quad 115$

CAPÍTULO IV

EFECTOS DEL CONTROL FISCAL EN EL APRENDIZAJE ORGANIZACIONAL DE LAS

CONTRALORÍAS 116

4.1. MARCO CONCEPTUAL

4.2. PRETENSIÓN 119

4.3. PROCEDIMIENTO EMPLEADO 120

4.4. RESULTADOS 120

4.5. CONCLUSIONES 133

4.6. BIBLIOGRAFÍA 134

CAPITULOV

CONTROL SOCIAL, RENDICIONES DE CUENTA A LA CIUDADANÍA Y NIVEL DE SATISFACCIÓN DE LOS USUARIOS: FACTORES DETERMINANTES EN LA VIGILANCIA FISCAL DE LAS CONTRALORÍAS TERRITORIALES EN COLOMBIA. 135

Introducción 137

5.1. RELACIÓN ENTRE NÚMERO DE HALLAZGOS FISCALES IDENTIFICADOS FRENTE A LA CAPACIDAD DE REALIZAR RENDICIONES DE CUENTA.

143

5.2. CAPACIDAD DE REALIZAR EJERCICIOS DE RENDICIONES DE CUENTA A LA CIUDADANÍA POR PARTE DE LAS CONTRALORÍAS TERRITORIALES 144

5.3. EL CONTROL SOCIAL, EL ROL DEL CONTROL INTERNO, Y SUS EFECTOS EN LA EFICACIA DEL CONTROL FISCAL. $\quad 146$

5.4. NIVEL DE SATISFACCIÓN DE LAS CONTRALORIAS RESPECTO DEL PROCESO AUDITOR DE LA AGR. 147

5.5. CONCLUSIONES 152

5.6. BIBLIOGRAFÍA 154

CAPÍTULO VI

ANÁLISIS SEMIÓTICO DE LA JUSTICIA FISCAL

Fundamentos teórico-prácticos de la culpabilidad fiscal como condición de la 


\section{Contenido}

responsabilidad derivada del ejercicio del control y vigilancia fiscal 156

Introducción 157

6.1. NATURALEZA DE LA JUSTICIA FISCAL 159

6.2. ORÍGENES HISTÓRICOS DE LA CULPABILIDAD 161

6.3. LA PUJA DOGMÁTICA Y EL ORIGEN DE LA VERSIÓN ESTANDARIZADA DE LA RESPONSABILIDAD SUBJETIVA COMO FUNDAMENTO DE LA SANCIÓN 169

6.4. CONSOLIDACIÓN DE LA RESPONSABILIDAD SANCIONATORIA BASADA EN LA CULPABILIDAD 177

6.5. EFECTOS DE LA HEGEMONÍA KANTIANA 180

6.6. CONCRECIÓN DE UN ABORDAJE SEMIÓTICO Y SU INFLUENCIA SOBRE LA JUSTICIA FISCAL 190

6.7. CONCLUSIONES 201

\section{CAPITULO VII}

ESTRUCTURA Y FORTALECIMIENTO DEL CONTROL FISCAL TERRITORIAL - DIAGNÓSTICO Y PROPUESTA210

Introducción 213

7.1. CONTEXTO Y DIAGNÓSTICO 216

7.2. DIAGNÓSTICO Y PROPUESTAS DE SOLUCIÓN 220

7.3. CONCLUSIONES 243

7.4. BIBLIOGRAFÍA 245

CAPÍTULO VIII

LA DESIGUALDAD, LOS HALLAZGOS, LAS BRECHAS SOCIO ECONÓMICAS Y SU RELACIÓN CON LAS POLÍTICAS PÚBLICAS DEL CONTROL Y VIGILANCIA FISCAL 248

Introducción 249

8.1. CONTEXTO 256

8.2. METODOLOGÍA Y DESCRIPCIÓN DE DATOS 267

Gráfico 17. Descriptiva de las 5 variables de interés para Cesar $\quad 274$

8.3. RESULTADOS Y ANÁLISIS 278

8.4. CONCLUSIONES 280

8.5. REFERENCIAS BIBLIOGRÁFICAS 


\section{Agradecimientos}

Los investigadores agradecen la colaboración del Ingeniero Cristian Orlando Daza Pérez y del economista Ricardo Martínez Ramírez, en la obtención de los datos del Sistema de Información de la Auditoría General de la República (SIA-SIREL), sus comentarios y aportes al proceso de análisis estadístico. 


\section{INTRODUCCIÓN}

El Observatorio de Política Pública del Control Fiscal (OPPCF) fue creado al interior de la Auditoría General de la República, para contribuir al fortalecimiento de su misión constitucional.

Surgió como herramienta de investigación científica, de divulgación y de formación, tanto para el sector público como para el sector privado, involucrando a particulares y funcionarios, los primeros, con fortalezas investigativas y los segundos con la experiencia de los procesos de gestión fiscal, sectores que son a la vez expertos y legos. Esta simbiosis permite construir una alternativa para el desarrollo integral del control y vigilancia fiscal.

Si bien hay diversas concepciones de lo que debe ser un observatorio, uno de los propósitos del OPPCF es, generar conocimiento científico. Tal orientación ha implicado que, en su plan de acción, se mantenga la meta de desarrollar procesos investigativos como el que aquí se presenta.

De ahí que las investigaciones que nutren al observatorio, se formulan mediante proyectos provenientes del Grupo de Investigación "Altos Estudios de Control fiscal, Derechos Humanos y Convivencia Pacífica", reconocido y categorizado por Colciencias.

Para el año 2018 se propuso el proyecto que lleva por título, Presupuestos para una política pública del control fiscal, el cual, se sujetó a las condiciones de ciencia y tecnología procedentes de la comunidad científica, y que para el contexto colombiano son promovidas por Colciencias. De esta manera y teniendo en cuenta que las políticas públicas son el conjunto de intervenciones formuladas por el Estado para atender o resolver las problemáticas de una nación y "el reflejo de los ideales y anhelos de la sociedad, que expresan objetivos de bienestar colectivo y permiten entender hacia dónde se quiere orientar el desarrollo y cómo hacerlo, evidenciando lo que se pretende conseguir con la intervención pública y cómo se distribuyen las responsabilidades y

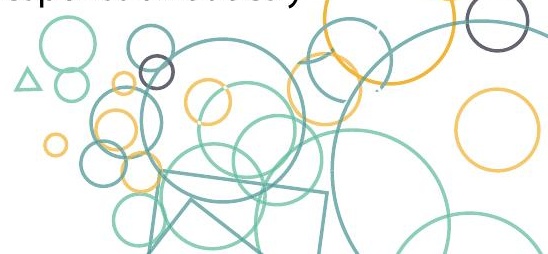


recursos entre los actores sociales" (Torres-Melo \& Santander, 2013) esta investigación aborda algunas de las bases que constituyen punto de partida para el diseño y análisis de políticas públicas de la vigilancia de la gestión fiscal en Colombia, acervo informativo oportuno para la toma de decisiones en materia de control fiscal.

En este sentido el texto también contiene insumos surgidos en el marco del convenio suscrito con la Universidad Santo Tomás, y en cuyo desarrollo muy particularmente se consideró la situación actual que vive el país, evidenciada en parte, por la ausencia de un programa de política pública del control fiscal, declarado y fundamentado. Significando con ello que a través de la investigación, se busca aportar elementos de estudio, que sirvan de fundamento para mejorar el entorno específico de la realidad social de Colombia, al proporcionar elementos importantes para la construcción de las políticas públicas que se echan de menos.

A tal fin, se consideraron como presupuesto esencial del estado de la cuestión, las directrices para la evaluación de las políticas públicas impartidas por la Organización Internacional de Entidades Fiscalizadoras Superiores (INTOSAI), en la norma INTOSAI GOV 9400, y de allí se derivó la importancia de revisar la fundamentación vigente, y la realidad del sistema de control y vigilancia fiscal nacional.

Sobre la base de información y conocimiento previamente producido en ejecución del OPPCF, se verificó el plexo de principalidad en que descansa dicho sistema, para proceder a dar cuenta de sus condiciones constitucionales, abordadas a título de principios en el capítulo I.

Luego, en la medida en que las políticas públicas no puede ni debe desprenderse de la realidad del entorno, se expone en los capítulos II a V, un estudio detallado, procedente de las entrañas de la Auditoría General de la República, elaborado por especialistas de la entidad, que da cuenta empírica de los resultados obtenidos en los últimos años, por la vigilancia y el control fiscal en el país, en desarrollo de la cadena de valor del proceso auditor, la gestión de los procesos de responsabilidad fiscal, oralidad y cobro coactivo; la medición del efecto del control fiscal en el aprendizaje organizacional de las contralorías; y en materia de control social y rendición de cuentas a la ciudadanía.

Se trata de una aproximación a una realidad tangible que, como lo recomienda la disposición internacional, se precisa considerar para poder orientar el sentido que debe adquirir dicha función pública, a través de las políticas requeridas.

El proceso que mantuvo como indicadores fundamentales los principios en que se basa el sistema de control y vigilancia fiscal, esto es, los de economía, eficacia, eficiencia, equidad y 
valoración de costos ambientales, es polivalente y por ello, se hallará que la justicia fiscal es, así mismo, un aspecto determinante en la construcción de políticas públicas de la vigilancia y control fiscal.

De tal suerte, se asumió el estudio de la estructura básica de la responsabilidad fiscal, considerada la base constitucional y legal prevista para los procesos en que se verifica, de conformidad con el modelo comúnmente reconocido como de responsabilidad subjetiva. Estos últimos resultados se hallan en el capítulo VI.

En el capítulo VII se propone un orden de temas estructurales que legal y constitucionalmente están en la agenda pública para debate, a título de diagnóstico y propuesta de los presupuestos técnicos de construcción de una política pública del control y vigilancia fiscal, apoyados en estudios ejecutados por especialistas de la Auditoría General de la República.

Finalmente, en el capítulo VIII se consigna un análisis reflexivo acerca del deber ser de las políticas públicas en Colombia, su necesidad y su práctica, así como un ejercicio asociado a un estudio de caso.

Si bien a medida que se avanza en el cuerpo del informe integrado en formato de libro de divulgación, y se van haciendo precisiones de orden metodológico, es importante distinguir que la metodología atiende a la prevista en el OPPCCF., y que a metodología empleada considera aspectos cuantitativos y cualitativos, conforme al diseño pensado, en los fundamentos generales del OPPCF, y de cada ventana en particular.

Como se indicó, el Observatorio no cesa con este proyecto sus funciones. Al contrario, cada proceso cumplido de investigación, de estudio, de análisis y de aporte ilustrado, se erige en el presupuesto para la formulación de uno nuevo, conforme al plan anual que prescribe en sus estatutos.

En este sentido, sobre la base de los resultados que aquí se presentan, se deja en manos del próximo Auditor General, la formulación de un proyecto de investigación que dé continuidad a la actividad del OPPCF y permita abordar nuevos desafíos frente a las problemáticas del control fiscal que pretende resolver el diseño y análisis de políticas públicas, y ofrecer insumos para la toma de decisiones en la materia.

\section{CARLOS HERNÁN RODRÍGUEZ BECERRA}

Director General del Observatorio de Política Pública de Control Fiscal

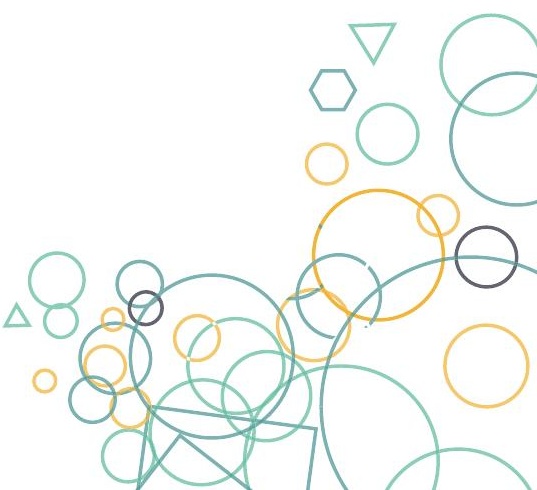


$\because 1 \%$

:8:

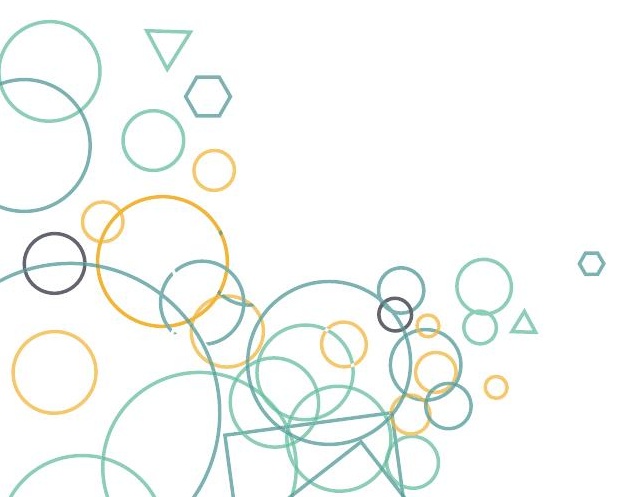




\section{CAPÍTULO I}

POLÍTICA PÚBLICA DEL CONTROL FISCAL

PRINCIPIOS CONSTITUCIONALES DE LA GESTIÓN FISCAL

Condiciones esenciales para garantizar los derechos fundamentales

CONSTITUTIONAL PRINCIPLES OF FISCAL MANAGEMENT

Essential conditions to guarantee fundamental rights

Alexandra González Zapata'

\section{Resumen}

Los principios rectores del control fiscal establecidos en la Constitución de 1991 tienen la función de guiar la gestión fiscal tanto de instituciones públicas como de privados que administren recursos de la nación, para que esta se realice de manera económica, eficaz, eficiente, con equidad y teniendo en cuenta la valoración de costos ambientales. De igual forma, los entes de control que ejercen la vigilancia sobre la gestión fiscal deben realizar un ejercicio de auditoría y control que les permita evaluar el cumplimiento de los mismos.

El presente capítulo pretende presentar una lectura de los desarrollos de cada uno de estos principios constitucionales, a partir de la jurisprudencia, la doctrina y normas aplicables. Lo anterior, en aras de promover una reflexión sobre los retos ante los eventuales ajustes a nivel normativo de la política pública de control fiscal y los procedimientos que en ella se aplican.

Politóloga y magister en Políticas Públicas de la Universidad Nacional de Colombia. Experiencia en análisis de política pública, política criminal y derechos humanos. Investigadora del Observatorio de Política Pública del Control Fiscal. 


\section{Abstract}

The guiding principles of fiscal control established in the 1991 Constitution have the function of guiding the fiscal management of both public and private institutions that administer resources of the nation, so that this is carried out in an economic, effective, efficient manner, with equity and taking into account the assessment of environmental costs. Likewise, the control entities that exercise oversight over fiscal management must perform an audit and control exercise that allows them to assess their compliance.

This chapter aims to present a reading of the developments of each of these constitutional principles, based on jurisprudence, doctrine and applicable norms. The aforementioned, in order to promote a reflection on the challenges before the possible adjustments at the regulatory level of the public policy of fiscal control and the procedures that apply therein.

Palabras clave: control fiscal, eficiencia, eficacia, economía, valoración de costos ambientales.

Key words: fiscal control, efficiency, effectiveness, economy, valuation of environmental costs.

Temario: Introducción. 1.1. Referentes institucionales. 1.2. Principio de economía. 1.3. Principio de Eficiencia. 1.4. Principio de Eficacia. 1.5. Principio de Equidad. 1.6. Valoración de costos ambientales. 1.7. Condiciones para la realización de los derechos fundamentales. 1.8. Conclusiones. 1.9. Bibliografía.

\section{Introducción}

La Asamblea Nacional Constituyente (ANC) y la Constitución Política de 1991 (CP) fueron la síntesis de un proceso de transformación que años atrás venía reformulando los principios sobre los cuales había sido edificado el Estado colombiano a nivel político, económico, administrativo y social. La disposición de los sectores políticos, tradicionales y emergentes, de modernizar la República a la luz de principios liberales, se dio con el interés de responder a algunos problemas que estaban arraigados en la Nación, incluso antes de la Constitución conservadora de 1886, "tales como el autoritarismo, la intolerancia religiosa, la discriminación étnica y cultural, y los límites a la participación política de los ciudadanos" (JARAMILLO, 2016, pág. 72).

La CP propendió por la creación de un régimen constitucional garantista, a través de la creación de órganos como la Corte Constitucional y mecanismos jurídicos para la protección de los derechos (UPRIMNY \& SÁNCHEZ, 2012), como la tutela, el derecho de petición, la acción de grupo, entre otros. De otro lado, ante la crisis de legitimidad de la restringida democracia 
representativa, se propuso su fortalecimiento a través de la apertura del sistema político y de la consagración de mecanismos de participación, tales como el plebiscito, el referendo, el cabildo abierto, la iniciativa popular, la revocatoria del mandato y la consulta popular.

De manera particular, la Constitución de 1991 siguió la tradición latinoamericana que generó una oleada de reformismo y reformulación constitucional desde la década de los 80's, y buscó "reforzar las instancias estatales de control, fortaleciendo la autonomía y la capacidad fiscalizadora de las mismas" (UPRIMNY, 2011, pág. 118).

Lo anterior, teniendo en cuenta que una de las características de un Estado considerado democrático no es únicamente su origen, es decir su proceso de elección y consolidación, sino depende intrínsecamente de su funcionamiento, el cual debe responder a garantizar los derechos de interés general, y a su vez, a tener una práctica correcta y transparente. Para ello, el desarrollo de un sistema autónomo que permita hacer un ejercicio de control, es decir, de pesos y contrapesos, es fundamental en un Estado democrático (GUIJARRO, J., 2005).

La Constitución reorientó y rediseñó la política de control fiscal, dado el descontento social que existía sobre la misma. Para ello, optó por la organización de los órganos que tienen competencias en la política pública de control fiscal en el país, creando nuevas entidades como la Auditoría General de la Republica (1992); y reformulando el carácter y mandato legal de otras que existían en el país hace décadas, como la Procuraduría General de la Nación (1819), la Contraloría General de la República (1923) y las Contralorías Territoriales (1945)².

En la Asamblea Nacional Constituyente se decidió excluir la figura del control previo ejercida por los entes de control, la cual se aplicaba siguiendo lo dispuesto por la Ley 20 de 1975, por considerarla ineficaz y nociva, dado que según los imaginarios construidos, este procedimiento se había convertido en un sistema de coadministración arbitraria, razón por la cual el control fiscal pasó ser posterior y selectivo. Esto implicó abandonar el modelo de control que se había desarrollado en el país desde la segunda década del siglo XX.

El proceso constituyente llevado a cabo en 1991 partió sobre un consenso generalizado de suprimir de nuestro ordenamiento el control previo, y para ello, los principales ponentes de las reformas en materia de control fiscal señalaron:

El control previo, generalizado en Colombia, ha sido funesto para la administración pública pues ha desvirtuado el objetivo de la Contraloría al permitirle ejercer abusivamente una

2 El Acto Legislativo 1 de 1945 estableció que era responsabilidad de las Asambleas Departamentales organizar la Contraloría Departamental y elegir el Contralor para un período de dos años. Actualmente, pese a que la Contraloría General de la República es el máximo órgano de control fiscal, no es superior jerárquico de ninguna de las contralorías territoriales, las cuales conservan la autonomía e independencia.

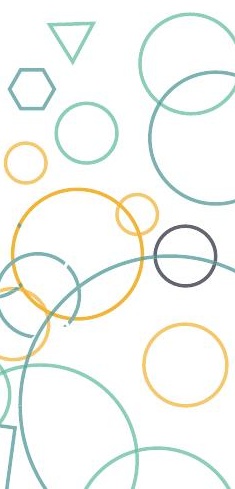


cierta coadministración que ha redundado en un gran poder unipersonal del contralor y se ha prestado también para una engorrosa tramitomanía que degenera en corruptelas (NORIEGA, GONZALEZ, \& HERRÁN, 1991).

Producto de lo anterior, el texto constituyente contempla un marco normativo general el cual supone que el control fiscal no se limita a un mero control numérico y de legalidad, sino que "la vigilancia de la gestión fiscal comprende un control financiero, de legalidad, de gestión, de resultados, la revisión de cuentas y la evaluación del control interno" (Ley 42, 1992, art. 9). Lo anterior, con base en criterios de:

Eficiencia, economía, equidad y valoración de los costos ambientales, de tal manera que permita determinar en la administración, en un período determinado, que la asignación de recursos sea la más conveniente para maximizar sus resultados; que en igualdad de condiciones de calidad los bienes y servicios se obtengan al menor costo; que sus resultados se logren de manera oportuna y guarden relación con sus objetivos y metas. Así mismo, que permita identificar los receptores de la acción económica y analizar la distribución de costos y beneficios entre sectores económicos y sociales y entre entidades territoriales y cuantificar el impacto por el uso o deterioro de los recursos naturales y el medio ambiente y evaluar la gestión de protección, conservación, uso y explotación de los mismos (Corte Constitucional, Sentencia C-103, 2015).

A partir de la reconfiguración del Estado Social de Derecho en 1991, el control fiscal pasa de ser numérico, a ser un control de evaluación de los resultados globales de la gestión fiscal administrativa del Estado y de los particulares que manejen fondos o bienes de la Nación. Ahora bien, lo anterior desde una perspectiva enunciativa de principios y del deber ser, teniendo en cuenta que:

La Constitución de 1991 no es un texto que mire hacia atrás ("backward looking") sino que quiso proyectarse hacia el futuro ("forward looking") (Teitel, 1997: 2014) pues, más que intentar codificar las relaciones de poder existentes al momento de su adopción, fue un documento jurídico que quería delinear un modelo de sociedad a construir. Es pues, en la terminología de otros autores, una constitución "aspiracional" (García, 2006) (...). Es pues un texto lleno de promesas de derechos y bienestar para todos (UPRIMNY \& SÁNCHEZ, Constitución de 1991, justicia constitucional y cambio democrático: un balance dos décadas después. , 2012).

El constitucionalista Rodrigo Uprimny (2012) caracteriza a Colombia como un Estado de Derecho Constitucional. Para él, el texto constitucional colombiano es denso en derecho pero normativo. Es decir, se reconocen derechos y valores, pero establece un orden social a ser realizado y de alguna forma, una garantía constitucional de que eso se va a lograr por medio de distintas formas de justicia constitucional.

En ese sentido, la Constitución establece, de manera deóntica, los principios que deben regir 
la gestión fiscal administrativa del nuevo Estado Social de Derecho en Colombia. Para ello re direcciona el control fiscal en aras de que éste permita salvaguardar el patrimonio de la Nación y ofrecer claridad y transparencia por la correcta utilización de los recursos públicos, tanto de las entidades públicas como de los particulares que manejan fondos o bienes de la Nación (Corte Constitucional, Sentencia C-167, 1995). Por lo anterior, define una transformación de las instituciones encargadas de cumplir las metas y derechos establecidos.

No obstante, transcurridos ya casi treinta años después de promulgada la Constitución, en materia de control fiscal aún existen retos normativos y procedimentales para garantizar que los principios plasmados en la carta magna se materialicen de manera íntegra y oportuna, desde una lectura positivista de la norma. Lo anterior se debe, en parte, a que el texto Constitucional es en últimas un marco de referencia deóntica, es decir, plasma el funcionamiento de la sociedad que queremos llegar a ser. De acuerdo a lo plasmado por Aguiló:

La constitución formal pretende cumplir funciones normativas ex-ante, pretende fundar o refundar (hacia el futuro) la identificación, la unidad y la permanencia (la estabilidad, en definitiva) de un sistema jurídico-político y lo hace determinando qué va a contar (hacia el futuro) como fundamental en ese sistema. De ahí no se sigue, sin embargo, que transcurrido el tiempo ella opere de hecho como la constitución (en el sentido positivista de la expresión) de la comunidad de referencia. En este sentido, el éxito de una constitución formal se medirá ex - post en función de que ella sea el factor principal en la explicación de la estabilización de la conducta jurídica y política de esa comunidad, en definitiva de su unidad y permanencia (AGUILÓ, 2001, pág. 14).

Las principales transformaciones que se adoptaron en materia de control fiscal en la Constituyente fue la transformación del control previo y perceptivo, a uno posterior y selectivo, para evitar la figura de la coadministración; de igual forma, la Contraloría General de la República se convirtió en uno de los órganos autónomos e independientes del Estado, junto con las demás entidades del Ministerio Público, el Consejo Nacional Electoral, el Banco de la República y la Comisión Nacional de Televisión. De otro lado, la elección del Contralor General y los contralores territoriales pasó a ser realizada por el poder legislativo en pleno, dependiendo de cada jurisdicción.

De igual forma, el texto constitucional de 1991 definió los valores y principios que rigen actualmente el control fiscal. Para ello, se estableció que la Contraloría General de la República (art. 267), las contralorías territoriales (art. 272) y la Auditoría General de la República (art. 274) realizan un proceso de vigilancia de la gestión fiscal. 
La vigilancia de la gestión fiscal del Estado incluye el ejercicio de un control financiero, de gestión y de resultados, fundado en la eficiencia, la economía, la equidad y la valoración de los costos ambientales. En los casos excepcionales, previstos por la ley, la Contraloría podrá ejercer control posterior sobre cuentas de cualquier entidad territorial (CONSTITUCIÓN POLÍTICA [C.P.], ART. 267).

\section{PRINCIPIOS CONSTITUCIONALES DEL CONTROL FISCAL}

Los principios constitucionales funcionan, a la luz del derecho, como un indicador que permite establecer el nivel de cumplimiento que se logra de una disposición, en este caso, suprema.

Los principios, es decir los indicadores, tienen por tanto tres funciones principales: guiar a los órganos públicos para que los desarrollos normativos posteriores en la materia, estén acordes con dicho principio; ser un asidero para la interpretación de las normas, tanto de los órganos judiciales como de los funcionarios y órganos encargados de la aplicación de la norma; y permitir suplir las insuficiencias que las normas escritas tienen, generando así un criterio de integración de todas las normas.

Para comprender la interpretación de los principios, es preciso hacer un análisis de los referentes institucionales.

\subsection{REFERENTES INSTITUCIONALES}

Los constituyentes de 1991 establecieron en el artículo 267 de la Constitución, que:

El control fiscal es una función pública que ejercerá la Contraloría General de la República, la cual vigila la gestión fiscal de la administración y de los particulares o entidades que manejen fondos o bienes de la Nación.

Dicho control se ejercerá en forma posterior y selectiva conforme a los procedimientos, sistemas y principios que establezca la ley. Esta podrá, sin embargo, autorizar que, en casos especiales, la vigilancia se realice por empresas privadas colombianas escogidas por concurso público de méritos, y contratadas previo concepto del Consejo de Estado.

La vigilancia de la gestión fiscal del Estado incluye el ejercicio de un control financiero, de gestión y de resultados, fundado en la eficiencia, la economía, la equidad y la valoración de los costos ambientales. En los casos excepcionales, previstos por la ley, la Contraloría podrá ejercer control posterior sobre cuentas de cualquier entidad territorial.

La Contraloría es una entidad de carácter técnico con autonomía administrativa y presupuestal. No tendrá funciones administrativas distintas de las inherentes a su propia organización.

El Contralor será elegido por el Congreso en pleno en el primer mes de sus sesiones para un período igual al del Presidente de la República, de terna integrada por candidatos presentados a razón de uno por la Corte Constitucional, la Corte Suprema de Justicia y el Consejo de Estado, y no podrá ser reelegido para el período inmediato ni continuar en ejercicio de sus funciones al vencimiento del mismo. Quien haya ejercido en propiedad este cargo no podrá desempeñar empleo público alguno del orden nacional, salvo la docencia, ni aspirar a cargos de elección popular sino un año después de haber cesado en sus funciones. 
Sólo el Congreso puede admitir las renuncias que presente el Contralor y proveer las vacantes definitivas del cargo; las faltas temporales serán provistas por el Consejo de Estado.

Para ser elegido Contralor General de la República se requiere ser colombiano de nacimiento y en ejercicio de la ciudadanía; tener más de 35 años de edad; tener título universitario o haber sido profesor universitario durante un tiempo no menor de 5 años; y acreditar las calidades adicionales que exija la ley.

No podrá ser elegido Contralor General quien sea o haya sido miembro del Congreso $u$ ocupado cargo público alguno del orden nacional, salvo la docencia, en el año inmediatamente anterior a la elección. Tampoco podrá ser elegido quien haya sido condenado a pena de prisión por delitos comunes.

En ningún caso podrán intervenir en la postulación o elección del Contralor personas que se hallen dentro del cuarto grado de consanguinidad, segundo de afinidad y primero civil o legal respecto de los candidatos.

Dicho artículo estuvo vigente sin transformación desde el 13 de junio de 1991 hasta el 30 de junio de 2015, cuando fue modificado a través de la denominada reforma de equilibrio de poderes, la cual estableció que la elección del Contralor debía hacerse a través de una convocatoria e inscripción pública, para posteriormente hacer una aplicación de un examen de conocimientos, y finalmente, a partir de los 20 mejores resultados, la elección sería realizada por el Congreso en pleno.

Sin embargo, más allá del mecanismo de elección del Contralor General y los contralores territoriales, a nivel constitucional el artículo base del control fiscal (at. 267) no ha sufrido modificaciones profundas, más si interpretaciones constitucionales y desarrollos normativos.

Así pues, en el año 1995 la Corte Constitucional estableció que la función pública del control fiscal debe orientarse a la aplicación de cuatro principios:

Con la promulgación de la Carta Política de 1991, la función pública del control fiscal adquiere una nueva dimensión en la medida de que la actividad debe orientarse dentro de la filosofía del nuevo Estado Social de Derecho en general, y especialmente dirigida a la aplicación de los principios de eficacia económica, equidad y valoración de los costos ambientales (...). En efecto, la Carta Política en el artículo 267 determina como función pública a cargo de la Contraloría General de la República el control fiscal de la gestión de la administración y de los particulares que manejen fondos o bienes de la Nación. Es así como, en el Estado social de derecho, se han concebido dentro de un largo proceso histórico sistemas articulados de controles y contrapesos que procuran prevenir y sancionar las fallas o extralimitaciones en el ejercicio del poder público. Es bajo este orden de ideas que el constituyente colombiano institucionalizó varios sistemas de controles entre los cuales se destaca el control fiscal, que comprende la "gestión fiscal de la administración" que no sólo se limita a la Rama Ejecutiva del 
poder público, sino que se hace extensivo a todos los órganos del Estado y a los particulares que manejen fondos o bienes de la Nación (Sentencia C - 167, 1995).

Es necesario para el contexto de la publicación traer a colación conceptos que se desprenden del articulado de la Ley 610 de 2000, tales como:

Gestión fiscal: Conjunto de actividades económicas, jurídicas y tecnológicas, que realizan los servidores públicos y las personas de derecho privado que manejen o administren recursos o fondos públicos, tendientes a la adecuada y correcta adquisición, planeación, conservación, administración, custodia, explotación, enajenación, consumo, adjudicación, gasto, inversión y disposición de los bienes públicos, así como a la recaudación, manejo e inversión de sus rentas en orden a cumplir los fines esenciales del Estado, con sujeción a los principios de legalidad, eficiencia, economía, eficacia, equidad, imparcialidad, moralidad, transparencia, publicidad y valoración de los costos ambientales. (Ley 610, 2000, art. 3)

Responsabilidad Fiscal: Tiene por objeto el resarcimiento de los daños ocasionados al patrimonio público como consecuencia de la conducta dolosa o culposa de quienes realizan gestión fiscal mediante el pago de una indemnización pecuniaria que compense el perjuicio sufrido por la respectiva entidad estatal (Ley 610, 2000, art. 4)

Daño Patrimonial al Estado: Lesión del patrimonio público, representada en el menoscabo, disminución, perjuicio, detrimento, pérdida, o deterioro de los bienes o recursos públicos, o a los intereses patrimoniales del Estado, producida por una gestión fiscal antieconómica, ineficaz, ineficiente e inoportuna, que en términos generales, no se aplique al cumplimiento de los cometidos y de los fines esenciales del Estado, particularizados por el objetivo funcional y organizacional, programa o proyecto de los sujetos de vigilancia y control de las contralorías. Dicho daño podrá ocasionarse por acción u omisión de los servidores públicos o por la persona natural o jurídica de derecho privado, que en forma dolosa o culposa produzcan directamente o contribuyan al detrimento al patrimonio público (Ley 610,2000 , art. 6)

La función pública de control fiscal evalúa que la gestión de los sujetos vigilados se hubiera adelantado "con sujeción a los principios de legalidad, eficiencia, economía, eficacia, equidad, imparcialidad, moralidad, transparencia, publicidad y valoración de los costos ambientales" (Ley 610, 2000, art. 3). Lo anterior a través de unos sistemas y unos métodos, dentro de los cuales se incluyen los procesos auditores. 
Figura 1. Relación de los principios de la vigilancia de la gestión fiscal

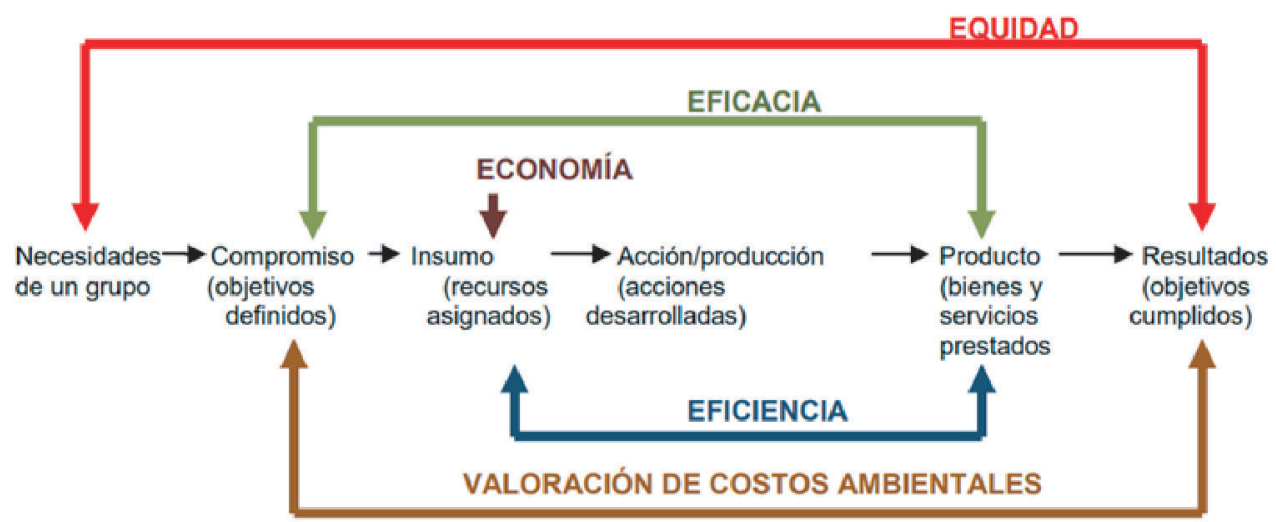

Fuente. ISSAI 3000/1.4 y del Manual de Auditoría de Rendimiento de la Unión - Brasil

Fuente: Contraloría General de la República de Colombia (2017) Guía Auditoría de desempeño - GAD, Recuperado de: http://cort. as/-M007 (Pág. 18)

\subsection{PRINCIPIO DE ECONOMÍA:}

El principio de economía es entendido como la adecuada adquisición y asignación de los recursos humanos, físicos, técnicos y naturales en los diferentes procesos, para maximizar sus resultados (Contraloría General de la República, 2017).

Sin embargo, su concepción no ha sido homogénea desde la Constitución, puesto que, la Ley 42 de 1993, la cual organiza el sistema de control fiscal financiero y los organismos que lo ejercen, reorienta el sentido de dicho principio. Como lo señala Salazar:

Este principio vario con la Ley 42 de 1993, ya que antes se concebía como simple aspecto contable al ordenar que las operaciones de la administración del Estado se hiciesen al mínimo costo. Con este principio se busca establecer que la asignación de recursos ha sido el más provechoso para maximizar los resultados desde la óptica social, lo cual viene a darle un nuevo enfoque a la labor de la Contraloría General de la República (SALAZAR, s.f.).

En el Congreso de la República, en el año 2004 se tramitó un proyecto de ley el cual establecía que el principio de economía debía implementarse

(...) a través del desarrollo de políticas de austeridad y de mesura del gasto; de la medición racional de costos, y al propiciar el equilibrio en la inversión para garantizar la adecuada proporcionalidad y conformidad de los resultados, en términos de la relación costo-beneficio (Congreso de la República, Proyecto de Ley No. 181 Senado del 16 de marzo de 2004) 
Dicho proyecto de ley, el cual tenía por objeto reglamentar los organismos de control fiscal y derogar la Ley 610 de 2000, buscaba propiciar una comprensión normativa de los principios que rigen la gestión fiscal, los cuales hasta la fecha no cuentan con un profundo desarrollo normativo legal, más allá de la comprensión que los propios organismos de control han desarrollado de los mismos a partir del artículo 8 de la Ley 42 de 1993. No obstante, el proyecto fue archivado y no tuvo posteriores desarrollos.

Por lo anterior, ateniéndonos a las fuentes existentes a la fecha, una gestión se considera económica cuando al evaluarla se comprueba, siguiendo la doctrina de Estupiñan Gaitán (2006, págs. 247-250), que:

Se hizo en forma racional la adquisición de los insumos requeridos en el proceso de producción

o de prestación de servicios, o sea que no se utilizó más de lo que realmente se necesitaba.

Se estableció si la asignación de los recursos disponibles era lo más conveniente para maximizar los resultados.

Se estudió y analizó la planeación y programación de necesidades y utilización de los recursos de manera tal que estos se entregan oportunamente y no fueron causas de mora en la elaboración de los bienes o servicios que suministra la entidad.

Se evaluó el costo de adquisición de los insumos.

Se evaluó el beneficio o pérdida social derivados de los diferentes proyectos y/o programas realizados por las entidades.

El cumplimiento del principio de economía en la gestión fiscal por parte de las instituciones públicas y de los privados que manejen fondos de la nación permite fortalecer la legitimidad del control fiscal, siguiendo lo expuesto por la Corte Constitucional en su sentencia C-167 de 1995, en la medida que permite proteger el patrimonio de la Nación, que es a su vez el patrimonio colectivo de los ciudadanos producto de su aporte individual a la construcción del fisco.

Una actuación económica por parte de las entidades que administran recursos públicos debe propender por la protección del interés general de la ciudadanía, y cuando ello se comprueba a partir de la protección del patrimonio, se gesta legitimidad no sólo a los organismos de control que vigilan esta actividad, sino al conjunto del Estado.

\subsection{PRINCIPIO DE EFICIENCIA}


La eficiencia, desde las teorías tradicionales para el análisis de las políticas públicas, hace referencia a la relación de medios y fines, la cual también se comprende desde la típica ecuación de costos y resultados. Se supone, desde esta noción, que "...un sistema eficiente obtiene más productos con un determinado conjunto de recursos, insumos o logra niveles comparables de productos con menos insumos, manteniendo a lo demás igual" (LECKHEED \& HANUSHEK, 1994, en: MOKATE, 2001, pág. 5).

Teniendo en cuenta la doctrina, la eficiencia se ocupa de la relación entre los costes asumidos (medios/recursos) y el fin perseguido (beneficio/éxito). Su contenido mínimo es la obligación de conseguir el fin fijado con la menor cantidad posible de medios y su objetivo máximo consiste en aspirar al mayor beneficio posible con los medios de que se dispone (SCHMIDTASSAMANN, 2003, pág. 47).

El principio de eficiencia no sólo se desarrolla dentro de los procedimientos de la vigilancia de la gestión fiscal, sino que es uno de los pilares del nuevo modelo de control fiscal desarrollado por la Constitución de 1991. El modelo de control fiscal previo y perceptivo era considerado en su estructura como ineficiente, dado que los resultados obtenidos eran escasos, en relación con el trabajo y los recursos invertidos. Por esta razón, se considera la inclusión de este principio como un aspecto central para evaluar la óptima utilización de recursos públicos. La finalidad de establecer si los costos en que incurren las entidades públicas, incluidas aquellas que ejercen el control fiscal, son eficientes, permite identificar el oportuno cumplimiento de sus objetivos y resultados, otro de los aspectos incluidos en el control fiscal a partir de la Constitución de 1991.

Según los Postulados Básicos de la Fiscalización Pública desarrollados por las ISSAI 100 dentro de las Normas Internacionales de las Entidades Fiscalizadoras Superiores (ISSAI) y emitidas por la Organización Internacional de Entidades Fiscalizadoras Superiores (INTOSAI), la auditoría en materia de eficiencia comprende:

(...) el control de la eficiencia en la utilización de los recursos humanos, financieros y de cualquier otro tipo, junto con el examen de los sistemas de información, de las medidas de rendimiento y control, y de los procedimientos seguidos por las entidades fiscalizadas para corregir las deficiencias encontradas. (...) (INTOSAI, 1992, Numeral 40).

\subsection{PRINCIPIO DE EFICACIA:}

Pese a que la Constitución Política en el artículo 267 no señala la eficacia como uno de los principios de la vigilancia de la gestión fiscal, posteriormente se convierte en un principio de naturaleza legal a partir de la Ley 42 de $1993^{3}$, y además, es a su vez un principio de la gestión

3 El artículo 8 de la Ley 42 de 1993 establece que: "la vigilancia de la gestión fiscal del Estado se fundamenta en la eficiencia, la economía, la eficacia, 
fiscal, según el artículo 3 de la Ley 610 de 2000.

De otra parte, la Constitución determina como una de las atribuciones del Contralor General de la República: "Revisar y fenecer las cuentas que deben llevar los responsables del erario y determinar el grado de eficiencia, eficacia y economía con que hayan obrado" (Numeral 2, artículo 268).

De igual forma, establece en el artículo 209 que"la función administrativa está al servicio de los intereses generales y se desarrolla con fundamento en los principios de igualdad, moralidad, eficacia, economía, celeridad, imparcialidad y publicidad, mediante la descentralización, la delegación y la desconcentración de funciones" (C.P., 1991).

Una aproximación a una definición de este principio, sería aquella que comprende "el concepto de eficacia [como] la capacidad de la gestión para alcanzar los objetivos inmediatos, traducidos en metas de la producción o de atención" (TRIBUNAL DE CUENTAS DE LA UNIÓN BRASIL "TCU", 2010, pág. 8).

En materia de políticas públicas el concepto de eficacia está asociado al logro de resultados. Es decir, que su evaluación consiste ya no en analizar los medios utilizados, sino que los logros obtenidos se correspondan con la planeación inicial realizada. "Por tanto, una iniciativa resulta eficaz si cumple los objetivos esperados en el tiempo previsto y con la calidad esperada" (MOKATE, 2001, pág. 2).

El artículo 3 de la ley 1437 de 2011, Código del Procedimiento Administrativo y de lo Contencioso Administrativo, referencia que:

las autoridades buscarán que los procedimientos logren su finalidad y, para el efecto, removerán de oficio los obstáculos puramente formales, evitarán decisiones inhibitorias, dilaciones o retardos y sanearán las irregularidades procedimentales que se presenten, en procura de la efectividad del derecho material objeto de la actuación administrativa (Art. 3, Numeral 11).

\subsection{PRINCIPIO DE EQUIDAD:}

Mediante la aplicación de este principio [equidad] la administración debe permitir identificar los receptores de la acción económica y el análisis sobre la distribución de los costos y beneficios entre sectores económicos y sociales y entre entidades territoriales. Este principio se encuentra poco desarrollado en los organismos de control, pues no se han diseñado aun las herramientas básicas que permitan su medición (VASQUEZ, 2000, pág. 67).

la equidad y la valoración de los costos ambientales". 
Al respecto es importante establecer que, en la medida en que se trata de aplicar la equidad a la gestión fiscal de las entidades públicas y privados que manejan recursos de la nación, este principio, es tal vez el que menos desarrollo normativo, interpretativo y doctrinal tiene. El artículo 8 de la Ley 42 establece que la equidad debe permitir "identificar los receptores de la acción económica y analizar la distribución de costos y beneficios entre sectores económicos y sociales y entre entidades territoriales" (Ley 42, 1993).

Teniendo en cuenta que, según la definición aportada por el Diccionario de la Real Academia Española (RAE), equidad hace referencia a la "disposición del ánimo que mueve a dar a cada uno lo que merece", su implicación en materia de gestión fiscal debe permitir analizar que los resultados esperados de un proyecto o intervención pública debe medirse en cuanto a la evaluación y transformación de la situación considerada como problemática. Por tanto, de manera hipotética, una población que tiene profundos problemas de desnutrición, acceso a educación básica y primaria, entre otras, no tiene como necesidad esencial un programa de bilingüismo, el cual, si bien es importante en el establecimiento y fortalecimiento de la educación primaria y la competitividad, no tiene una relación directa con las necesidades básicas insatisfechas.

El principio de equidad debe permitir evaluar que los resultados esperados se correspondan con un efectivo y oportuno análisis de la situación problemática, y que las acciones emprendidas, así como sus resultados, permitan la superación de dicha situación. Es así como la aplicación de este principio busca, ante todo, que la práctica administrativa, en su planeación, gestión y alcance de resultados, esté encaminada a la realización de una vida en condiciones de dignidad, entendida esta, según lo establecido por la Corte Constitucional como (i) vivir bien, (ii) vivir como se quiere y (iii) vivir sin discriminación.

\subsection{VALORACIÓN DE COSTOS AMBIENTALES:}

La Constitución Política de 1991 integra un concepto de desarrollo sostenible, en el cual contempla el impulso de los derechos colectivos y de ambiente en el Capítulo 3 del Título 2 de la carta magna. Allí establece en el artículo 80 que "el Estado planificará el manejo y aprovechamiento de los recursos naturales, para garantizar su desarrollo sostenible, su conservación, restauración o sustitución" (C.P., 1991)

La incorporación del principio de valoración de costos ambientales, como función del control fiscal, refleja un principio de "equidad intergeneracional" (LÓPEZ-OBREGÓN, 2006, pág. 72). 


\section{OPPCF}

La vigilancia de la gestión fiscal de la administración debe permitir la cuantificación del impacto por el uso o deterioro de los recursos naturales y del medio ambiente y evaluar la gestión que desarrolla la administración para la protección, conservación, uso y aceptación de los mismos (Ley 42, 1993, art. 8).

El principio faculta y obliga a las contralorías territoriales y a la General a evaluar el impacto de la gestión fiscal sobre el medio ambiente y los recursos naturales de la nación, como bien público del pueblo y patrimonio común de la humanidad. En ese sentido, es deber de los sujetos de control, tener en cuenta esta variable para la gestión de proyectos de desarrollo y la realización de obras públicas.

El artículo 46 de la Ley 42 de 1993 establece que "el Contralor debe presentar al Congreso de la República un informe anual sobre el estado de los recursos naturales y del medio ambiente", para lo cual debe:

Reglamentar la obligatoriedad de toda entidad vigilada de incluir en todo proyecto de inversión, convenio, contrato o autorización de explotación de recursos, la valoración en términos cuantitativos del costo-beneficio sobre la conservación, restauración, sustitución, manejo en general de los recursos naturales y degradación del medio ambiente, así como su contabilización y el reporte oportuno a la Contraloría (Ley 42, 1993, artículo 46).

Para el caso de las contralorías territoriales, no es la Ley 42 de 1993, sino el artículo 272 constitucional y la Ley 330 de 1996 los que les establecen el deber de presentar el informe anual sobre el estado de los recursos naturales y del medio ambiente, a las asambleas departamentales y concejos municipales, según el caso.

La valoración de costos ambientales implica "cuantificar el impacto por el uso o deterioro de los recursos naturales y el medio ambiente, y evaluar la gestión de protección, conservación, uso y explotación de los mismos" (Ley 42, 1993, art. 8), que realizan actores públicos y privados en el desarrollo de funciones, bienes o servicios públicos.

Teniendo en cuenta el carácter posterior y selectivo del control fiscal, la Contraloría General de la República ha expedido un guía para realizar un "Procedimiento Especializado de Auditoria a la aplicación del Principio de Valoración de Costos Ambientales", en ella se establece que:

Si bien las auditorías son posteriores y selectivas, es decir, actúan especialmente sobre hechos cumplidos en el ambiente, se propone que en los procesos auditores, bajo el enfoque del PVCA, se evalúe la forma en que los gestores fiscales identificaron y calificaron los riesgos de generación de afectaciones ambientales desde la planificación de las políticas, planes, programas, proyectos y presupuestos, de manera que esto permita identificar en los informes de la CGR el tratamiento dado a las acciones de prevención, reducción o mitigación de impactos y la valoración (cualitativa o cuantitativa) de los mismos. Por esta razón, el procedimiento especializado se ha estructurado considerando el contexto nacional de la gestión ambiental y las guías de auditoría vigente, así como la articulación con las Normas Internacionales de Entidades Fiscalizadoras Superiores (ISSAI's). (Contraloría General de la República, 2018, pág. 4). 
Respecto del papel del control en la Protección del Medio Ambiente, Botero (s.f.) ha señalado que (pág. 11 y 12):

(...) uno de los objetivos de la Contraloría General de la República es el de evaluar los resultados obtenidos por las diferente organizaciones y entidades del Estado en la correcta, eficiente, económica, eficaz y equitativa administración del patrimonio público de los recursos naturales y del medio ambiente, podemos afirmar que para el cumplimiento de ese objetivo, la Contraloría está llamada a ejercer vigilancia y control fiscal en tres frentes distintos y claramente definidos así:

Fiscalización de las Autoridades Ambiental es del orden nacional, institutos de investigación y demás organismos del Sistema Nacional Ambiental a que se refiere la Ley 99 de 1993 exceptuando las autoridades ambientales urbanas que son de competencia de las contralorías territoriales respectivas.

Fiscalización de las demás entidades estatales;

Fiscalización a los Particulares que manejen fondos de la Nación y que utilicen en su actividad económica los recursos naturales.

Para el desarrollo efectivo del control fiscal, el artículo 5 de la Ley 99 de 1993, por medio de la cual "se crea el Ministerio del Medio Ambiente, se reordena el Sector Público encargado de la gestión y conservación del medio ambiente y los recursos naturales renovables, se organiza el Sistema Nacional Ambiental, SINA y se dictan otras disposiciones", establece que es deber del Ministerio: "Establecer técnicamente las metodologías de valoración de los costos económicos del deterioro y de la conservación del medio ambiente y de los recursos naturales renovables" (Ley 99, 1993, artículo 5).

El control fiscal ejercido por las entidades del Sistema de Control Fiscal, y liderado por la Contraloría General de la República, "está llamado a velar por que se apliquen, implemente $y$, eventualmente, señalar las deficiencias que puedan presentar dichas metodologías hasta construir un instrumento idóneo de valoración" (BOTERO, s.f., pág. 13).

La vigilancia de la gestión fiscal en relación con la valoración de los costos ambientales incluye la verificacion del cumplimiento de la aplicación de la legislación ambiental en el desarrollo de la gestión ambiental o de las actividades relacionadas con el uso, disfrute o explotación del ambiente, preservación, conservación y uso adecuado, por parte de los sujetos vigilados.

La doctrina define el control fiscal y la valoración de costos ambientales como:

Una herramienta de evaluación de la gestión de las entidades públicas, con el fin de proteger las inversiones en materia ambiental y evaluar las acciones encaminadas al mejoramiento del ambiente, y a su vez, que se dé un uso racional a los recursos naturales y al ambiente. Es una función de naturaleza pública, que se desarrolla a través de un conjunto de técnicas y procedimientos que tienen por objetivo vigilar y controlar las entidades de carácter público, privadas y mixtas que intervienen en el uso, conservación, protección y explotación de los recursos naturales y el ambiente. (ESCUDERO, 2015, pág. 28) 


\subsection{CONDICIONES PARA LA REALIZACIÓN DE LOS DERECHOS FUNDAMENTALES}

Existe un vínculo estrecho entre el control fiscal y los derechos fundamentales, vínculo que sobrepasa las características propias de una relación entre entes independientes, para determinar así un lugar de dependencia entre entidades que no se pueden entender ni desarrollar la una sin la otra.

"La reciente doctrina entiende el control fiscal como un asunto que supera los límites de la economía, pues posibilita significativamente los fines esenciales del Estado" (Moya, 2018), en la medida en que el control fiscal verifica que la gestión de las entidades públicas o de terceros que gestionan recursos públicos sea no sólo eficiente y eficaz, sino que se corresponda con las necesidades propias de la población, y permita una redistribución de los recursos públicos para garantizar así un orden político, económico y social justo, el goce efectivo de derechos y profundizar la dignidad humana, y por ende, la democracia, aludiendo por tanto al principio constitucional de equidad de la gestión fiscal, como se ha señalado anteriormente.

Sin una gestión fiscal equitativa, eficiente, eficaz, económica y que tenga en cuenta los costos ambientales, es improbable la materialización de los derechos fundamentales, entre ellos los humanos, pues implica que el accionar del Estado no está encaminado a sus fines esenciales, a saber: asegurar a sus integrantes la vida, la convivencia, el trabajo, la justicia, la igualdad, el conocimiento, la libertad y la paz. El control fiscal, por tanto, realiza una suerte de evaluación de resultados para determinar que el fisco público no se destine a acciones que van en contravía de esos presupuestos.

Es inevitable concluir que el control fiscal es en sí mismo un derecho fundamental y, en tanto tal, es tan partícipe de él el Estado como la sociedad (Moya, 2018), en la medida en que la sociedad no sólo tiene la posibilidad de participar en el control fiscal, sino que, de su garantía, depende que sus derechos consagrados en la carta política se materialicen.

\subsection{CONCLUSIONES}

El establecimiento de los cinco principios constitucionales de la gestión fiscal explicados: economía, eficiencia, eficacia, equidad y valoración de costos ambientales constituye en Colombia una apuesta por la materialización a través del ejercicio del control fiscal de derechos fundamentales, toda vez que la vigilancia de la gestión fiscal no sólo está encaminada a determinar posibles daños patrimoniales, sino establecer, en últimas, que las actuaciones públicas del Estado permitan superar las necesidades reales de las poblaciones atendidas. 
Pese a que existe una regulación normativa de los principios a través de la Ley 42 de 1993, en el desarrollo metodológico posterior por parte de los organismos de control, particularmente de la Contraloría General de la República y la Auditoría General de la República, no es posible identificar una metodología única que permita evaluar cada uno de estos de manera independiente, a excepción del principio de valoración de costos ambientales, el cual por su connotación y la responsabilidad que en él tiene el Ministerio de Ambiente, cuenta con más desarrollos dogmáticos y metodológicos.

De otra parte, se considera que el principio de equidad tiene diferentes acepciones, sin embargo, en aras de comprender la relación del control fiscal con la materialización de los derechos fundamentales, se considera que este principio representa grandes oportunidades en la medida en que puede evaluar no sólo el medio y logro establecido, sino determinar si la planeación de la gestión fiscal responde de manera fehaciente a una real evaluación de necesidades y situaciones percibidas socialmente como insatisfactorias, razón por la cual el principio de equidad podría ser orientador en evaluar si la gestión fiscal del Estado si está contribuyendo a la superación de estados de pobreza, desigualdad y vulnerabilidad. Por ello, se sugiere en el marco de elaboración de una política pública de control fiscal, incluir la entrega de un informe anual sobre el estado de la equidad en la gestión fiscal al Congreso de la República y demás cuerpos legislativos del país, por parte de la Contraloría General de la República y las contralorías territoriales.

Finalmente, es importante profundizar en el desarrollo de metodologías al interior de los procedimientos de auditoría que permitan evaluar de manera más profunda todos los principios del control fiscal, en particular, los principios de economía, equidad y valoración de costos ambientales.

\subsection{BIBLIOGRAFÍA}

AGUILÓ, J. (2001). Sobre la Constitución del Estado constitucional.

BOTERO, R. (s.f.). Marco legal del control fiscal ambiental en Colombia. Bogotá: Contraloría General de la República y Universidad Tecnológica de Pereira.

CONGRESO DE COLOMBIA (1993) Ley 99.

CONGRESO DE COLOMBIA (2000) Ley 610.

CONGRESO DE COLOMBIA (2011) Ley 1437.

CONGRESO DE LA REPÚBLICA (2004) Proyecto de Ley No. 181 Senado del 16 de marzo de 2004 


\section{OPPCF}

CONTRALORÍA GENERAL DE LA REPÚBLICA. (2017). Principios, fundamentos y aspectos generales para las auditorías en la Contraloría General de la República. Bogotá: Contraloría General de la República.

CONTRALORÍA GENERAL DE LA REPÚBLICA. (2018). Procedimiento Especializado de Auditoría a la aplicación del principio de valoración de costos ambientales. Macroproceso: Control Fiscal Micro. Bogotá.

CORTE CONSTITUCIONAL (1995). Sentencia C - 167. M.P. Fabio Morón Díaz

CORTE CONSTITUCIONAL (2015). Sentencia C-103. MP María Victoria Calle Correa.

ESCUDERO, G. (2015). Marco legal del control fiscal ambiental. Bogotá.

ESTUPIÑAN, R. \& ESTUPIÑAN, O. (2006). Análisis financiero y de gestión. Bogotá: Editorial Ecoe ediciones.

GUIJARRO, J. M. (2005). La legitimidad de las instituciones superiores de control. Revista española de control externo, 7(19), 13-42.

INTOSAI (1992) Normas de Auditoría.

JARAMILLO, J. (2016). La Constitución de 1991: un análisis de sus aportes desde una perspectiva histórica. En J. Jaramillo, M. García, A. Rodríguez, R. Uprimny, \& D. Güiza, Constitución, democracia y derechos (págs. 27 - 60). Bogotá: Centro de Estudios de Derecho, Justicia y Sociedad, Dejusticia.

LÓPEZ-OBREGÓN, C. (2006). Control fiscal territorial: fundamentos de reforma.

MOKATE, K. M. (2001). Eficacia, eficiencia, equidad y sostenibilidad: ¿qué queremos decir? Inter-American Development Bank.

MOYA, M. (2018). La cuestión epistemológica en torno al Observatorio de Política Pública del Control Fiscal. En OPPCF, Transformaciones y continuidades en las instituciones de control fiscal (págs. 2 - 29). Bogotá: Auditoría General de la República.

SALAZAR, J. (s.f.). Revisión, análisis y estado del arte del control fiscal en Colombia. Bogotá: Auditoría General de la República.

SCHMIDT-ASSAMANN, E. (2003). La teoría general del derecho administrativo como sistema: objeto y fundamentos de la construcción sistemática. Marcial Pons.

TRIBUNA DE CUENTAS DE LA UNIÓN. (2010). Manual de Auditoría de Rendimiento. Brasilia: TCU. 
UPRIMNY, R. (2011). Las trasformaciones constitucionales recientes en América Latina: tendencias y desafíos. En C. Rodríguez Garavito, El derecho en América Latina, un mapa para el pensamiento jurídico del siglo XXI. Buenos Aires: Siglo XXI Ed.

UPRIMNY, R., \& SÁNCHEZ, L. (2012). Constitución de 1991, justicia constitucional y cambio democrático: un balance dos décadas después. Cahiers des Amériques latines (71), 33-53.

VÁSQUEZ, W. (2000). Control fiscal y auditoría de estado en Colombia. Bogotá: U. Jorge Tadeo Lozano.

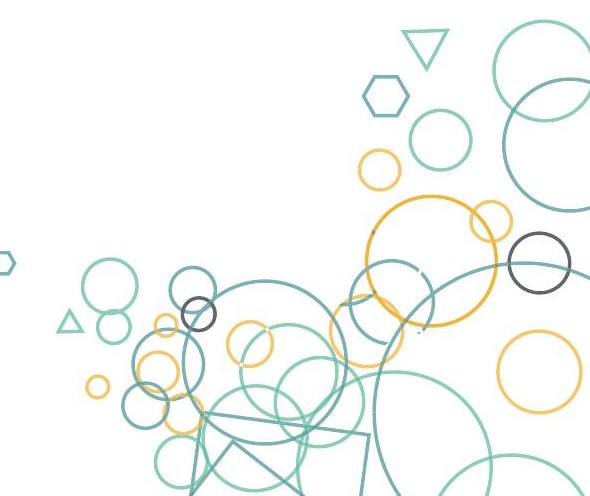




\section{CAPÍTULO II}

\section{CONTROL FISCAL: CADENA DE VALOR DEL PROCESO AUDITOR FISCAL CONTROL: AUDIT PROCESS VALUE CHAIN}

\section{Coautores:}

Diana Maite Bayona Aristizábal, Abogada de la Universidad Santo Tomás - Bogotá y actual Coordinadora de la Maestría en Derecho Penal de dicha institución; Especialista en Ciencias Penales y Criminológicas de la Universidad Externado de Colombia. Candidata a Magíster en Derecho Penal de la Universidad Santo Tomás. Docente universitaria de pregrado y posgrado, e investigadora del "Observatorio de Política Pública del Control Fiscal" adscrito -según convenioa la Auditoría General de la República y la Universidad Santo Tomás de Bogotá.

Edgar Alfredo Restrepo Acevedo. Administrador Público de la Escuela Superior de Administración Pública. Magister en Liderazgo y Dirección Pública de la Universidad Internacional Menéndez Pelayo Madrid-España. Magister en Estudios Políticos de la Universidad Nacional de Colombia. Especialista en Alta Gerencia de la Universidad Industrial de Santander. Especialista en Gobernabilidad y Desarrollo Institucional de la Universidad de Alcalá de Henares- España. Profesional Especializado Gerencia Seccional Medellín AGR e investigador "Observatorio de Política Pública del Control Fiscal" adscrito -según convenio- a la Auditoría General de la República y la Universidad Santo Tomás de Bogotá.

José Lizardo Ortiz Cubillos. Administrador público de la Escuela Superior de Administración Pública. Especialista en control fiscal de la Universidad Externado de Colombia. Profesional Especializado Dirección de Recursos Físicos AGR. Investigador del "Observatorio de Política Pública del Control Fiscal" adscrito -según convenio- a la Auditoría General de la República y la 
Universidad Santo Tomás de Bogotá.

Liliana Patricia Ortiz Ospino, Ingeniera Industrial de la Universidad del Norte, Magíster en Políticas Públicas de la Universidad de los Andes y Especialista en Gerencia y Gestión Cultural de la Universidad del Rosario. Docente investigador del campo cultural y Profesional Especializado Oficina de Estudios Especiales y Apoyo Técnico de la AGR e investigadora del "Observatorio de Política Pública del Control Fiscal" adscrito -según convenio- a la Auditoría General de la República y la Universidad Santo Tomás de Bogotá

Tatiana Ordóñez Vásquez. Abogada de la Universidad del Rosario. Magister en Derecho Administrativo de la Universidad Militar, Especialista en Instituciones Jurídico-Procesales de la Universidad Nacional de Colombia y Especialista en Derecho Administrativo de la Universidad Santo Tomás. Profesional Especializado Auditoría Auxiliar AGR. Docente de posgrado, e investigadora del "Observatorio de Política Pública del Control Fiscal" adscrito -según convenioa la Auditoría General de la República y la Universidad Santo Tomás de Bogotá.

\section{Resumen}

Como preámbulo a los elementos cardinales necesarios para la construcción de políticas públicas de control fiscal, se propone en este capítulo primero un referente legal y de regulación del control fiscal colombiano; y después los resultados concretos obtenidos de manera empírica en desarrollo de la cadena de valor del proceso auditor.

La gestión fiscal constituye uno de los fundamentos del Estado Social de Derecho. Se encamina a la protección, vigilancia, monitoreo y control de los recursos públicos que son invertidos en actividades de naturaleza económica, jurídica y tecnológica en el país y que se administran por servidores públicos y/o particulares encomendados a tales propósitos. Esta, debe velar por el cumplimiento de las condiciones normativas y operacionales de los recursos del erario en el marco de los principios orientadores de legalidad, eficiencia, economía, eficacia, equidad y valoración de los costos ambientales, entre otros.

Con la intención de determinar empíricamente los resultados obtenidos por los órganos de control fiscal, se realizó un abordaje de datos de índole cualitativa y cuantitativa a la labor de las contralorías en el periodo comprendido entre 2012 y 2017, primero siguiendo la cadena del proceso auditor. Se ha seleccionado este marco temporal, en razón a que el reporte de la información de datos se genera con un año de posterioridad a la vigencia fiscal. En consecuencia, los datos emitidos por las contralorías territoriales para los años 2018 y 2019 aún se encuentran en proceso de consolidación. Se plantean como resultado, conclusiones 
y análisis de la realidad operacional del control fiscal con la esperanza que sirvan de insumo a otras investigaciones y constituyan un objeto de monitoreo por parte del Observatorio de Política Pública de Control Fiscal de la Auditoría General de la República (En adelante, AGR).

\begin{abstract}
As a preamble to the cardinal elements necessary for the construction of fiscal control policies, this chapter initially proposes a legal and regulatory reference for Colombian fiscal control; and then the concrete results obtained empirically in the development of the value chain of the audit process.

Fiscal management is one of the foundations of the Social State of Law. It is aimed at the protection, surveillance, monitoring and control of public resources that are invested in activities of an economic, legal and technological nature in the country and that are administratered by public servants and/or individual entrusted to such purposes. This ensures compliance with the regulatory and operational conditions of the treasury resources within the framework of the guiding principles of legality, efficiency, economy, effectiveness, equity and valuation of environmental costs, among others.

With the intention of determining the impact generated by the public audit management bodies, a qualitative and quantitative data approach was made the work of the comptrollership in the period between 2012 and 2017, first following the audit process chain, the compensation of damage public assets in fiscal management, and later, with practical analyzes on specific issues of perception of corruption, social control, and organizational learning, with emphasis on territorial comptrollers. This time frame has been selected, because the report of the data information is generated one year after the fiscal period. Consequently, the data issued by the territorial comptrollers for the years 2018 and 2019 are still in the process of consolidation. As a result, conclusions and analysis of the operational reality of public audit management are raised with the aim that they will serve as input to other investigations and constitute an object of monitoring by the Public Policy Observatory of Fiscal Control of the General Audit of the Republic (In go ahead, AGR).
\end{abstract}

\title{
Palabras clave
}

Auditoría General de la República (AGR), Contraloría General de la República (CGR). Gestión de Auditoría Pública, Control fiscal, Rendición de cuentas.

\section{Key words}


General Audit of the Republic (AGR), General Comptroller of the Republic (CGR), Public Audit Management, Fiscal control, accountability

Temario: 2.1. Referentes legales del control fiscal y del proceso auditor. 2.2. Generalidades de las contralorías territoriales - contexto. 2.3. Rendición y revisión de cuentas. 2.4. Planeación y ejecución de auditorías. 2.5. Conclusiones. 2.6. Bibliografía.

\section{Introducción}

Reconocidos investigadores del fenómeno de la corrupción afirman que la estructura de las instituciones gubernamentales y los procesos políticos son factores determinantes para aumentarla o disminuirla, y que esas circunstancias explican por qué en los países menos desarrollados la corrupción resulta altamente costosa para su proceso de desarrollo (Tullock, 1989; Klitgaard, 1991; Schleifer \& Vishny, 1993 y Mauro, 1993).

Esta reflexión conlleva a pensar tanto en la estructura de las instituciones gubernamentales que controlan el erario, como en los resultados e impacto de su gestión.

En Colombia, no obstante que cada entidad gubernamental procura la existencia de oficinas de control interno y de sistemas de gestión de calidad, existen organismos nacionales y locales que de manera externa ejercen control sobre sus finanzas y resultados, tarea que se posibilitó gracias a la Carta Política de 1991.

Las premisas normativas instituidas en la Constitución Política de Colombia de 1991, el Decreto 272 de 2000 y la Ley 42 de 1993, le confieren competencia a las agencias gubernamentales que controlan el fisco colombiano y constituyen el principal sustento para preguntarse: ¿Qué procesos son necesarios para realizar un ejercicio efectivo de la vigilancia y el control fiscal en Colombia? En ese entendido cobran relevancia las preguntas sobre el impacto de la vigilancia de la gestión fiscal que ejercen la Contraloría General de la República, la Auditoría General de la República y las contralorías territoriales.

Tales órganos del orden nacional y local ejercen control fiscal a través de distintos sistemas de control: financiero, de legalidad, de gestión y de resultados, de revisión de cuentas y la evaluación de control interno, de conformidad con el artículo 9º de la Ley 42 de 1993.

De ahí que, tanto la estructura del capítulo como su distribución temática se hayan concretado a la cadena del proceso auditor desde lo empírico, teniendo en cuenta que su práctica redunda tanto en el mejoramiento de la gestión de los vigilados, como en los beneficios de auditoria cuantificables y no cuantificables, para continuar en los siguientes capítulos con la gestión 
frente al resarcimiento del patrimonio público dañado en ejercicio de gestión fiscal, y después a algunos análisis empíricos sobre percepción de la corrupción, la transparencia, la visibilidad y el control ciudadano, centrados en las contralorías territoriales, temas estos abordados en este y los capítulos siguientes.

En consecuencia, después del contexto legal general, se abordan primero indicadores en materia de recursos humanos y presupuesto destinados por las contralorías del país a adelantar el proceso auditor. Luego, se desarrollan indicadores sobre la rendición y revisión de cuentas; y finalmente como culminación de la cadena a de valor del proceso auditor, lo concerniente a la planeación y ejecución de auditorías. El cuarto, el quinto y el sexto capítulos abordan los resultados en términos de hallazgos fiscales, procesos de responsabilidad fiscal y procesos de jurisdicción coactiva. Un séptimo subcapítulo refiere al control fiscal efectuado a la gestión ambiental. El octavo explica el mejoramiento de los sujetos vigilados tanto de la Auditoría General de la República AGR, como de las contralorías; el noveno, analiza el control social frente a la capacidad de rendición de cuenta de las contralorías territoriales a la ciudadanía, los hallazgos fiscales, visibilidad y percepción y en un último subcapítulo, la percepción de las contralorías territoriales respecto del proceso auditor de la Auditoría General de la República.

En ese contexto, se exponen al final del capítulo, las conclusiones obtenidas en el estudio, con la ilusión de que sean monitoreadas por el Observatorio de Política Pública de Control Fiscal AGR, tanto en su materia, como en el análisis empírico de datos y hechos que las soportan.

\subsection{REFERENTES LEGALES DEL CONTROL FISCAL Y DEL PROCESO AUDITOR}

Descrito como quedó a la luz de los artículos fundamento constitucional del control fiscal que adelantan las contralorías (General y territoriales) y la Auditoria General de la República, artículos 267, 268, 271, 272 y 274, es menester ofrecer, las referencias legales más importantes a título de contexto de la cadena de valor del proceso auditor cuyos resultados se explican en detalle más adelante en este mismo capítulo.

Lejos de la intención de hacer una reconstrucción histórica o del control fiscal colombiano, a título puramente descriptivo se proponen como preámbulo a los capítulos posteriores, algunas referencias generales de contexto.

Previo a ello, es de precisar que en materia de derecho comparado y evolución histórica del control fiscal en Colombia, por lo menos hasta 2007, es un referente muy importante el estudio aportado en el texto "Eficacia del Control Fiscal en Colombia: Derecho comparado, historia, macroorganizaciones e instituciones" (Naranjo, Rodrigo, 2007). 
Ahora bien, de manera muy general y puramente descriptiva, se tiene que los orígenes del control fiscal en Colombia remontan a la colonia, antes del periodo independista y republicano, con figuras unipersonales o colegiadas asignadas a verificar el gasto público, tales como: los lugartenientes, los Contadores Mayores de Castilla (1.492), Real y Supremo Consejo de Indias (1.524), Real Audiencia de Santafé de Bogotá (1.550), los visitadores de territorios, Oficiales Reales (1.593) y el Tribunal de Contadores de Cuentas o Contaduría Mayor (1.605.) (GOMEZ LEE, 2006, págs. 29-30)

A lo largo de la historia, el control fiscal se institucionalizó en una figura denominada,según el mismo autor, como: Tribunal Superior de Cuentas (1.819), Contaduría General de Hacienda (1.821), Dirección General de Hacienda y Rentas Nacionales (1.824); Contaduría General de Hacienda (1.832) alternamente creada con la Tesoreria General de la de la República, separando funciones. Luego, se denominó Oficina General de Cuentas (1.850), Corte de Cuentas (1.860), nuevamente Oficina General de Cuentas (1.866); y otra vez Corte de Cuentas (1.898).

De la misma manera que las instituciones, las funciones de control fiscal se fueron adicionando en ese tiempo. Primero, la fiscalización de bienes y rentas de la corona española, luego el enjuiciamiento y sanción de los responsables de un mal manejo; imposición de multas; revisión y fenecimiento de las cuentas anuales; el examen, glosa y fenecimiento de cuentas, y el cobro ejecutivo de las deudas a favor del Estado.

Luego, por recomendación que hizo la Misión Kemmerer tras su visita a Colombia, para lograr un control fiscal mas efectivo, se expidió la Ley 42 de 19 de julio de 1923, que reorganizó la contabilidad oficial y creó el Departamento de Contraloría, como entidad independiente y a cargo de un Contralor General, al que asignó sus funciones.

El control fiscal obtuvo rango constitucional con un acto legislativo de 1945, que modificó la Constitución Política de 1886, y el siguiente texto:

Artículo 93. El artículo 209 de la Constitución quedará así:

\section{ARTÍCULO 209}

La vigilancia de la gestión fiscal de la Administración corresponde a la Contraloría General de la República.

La Contraloría será una oficina de contabilidad y de vigilancia fiscal, y no ejercerá funciones administrativas distintas de las inherentes al desarrollo de su propia organización.

El Contralor General de la República será elegido por la Cámara de Representantes para períodos de dos años. (Acto Legislativo 1, 1945)

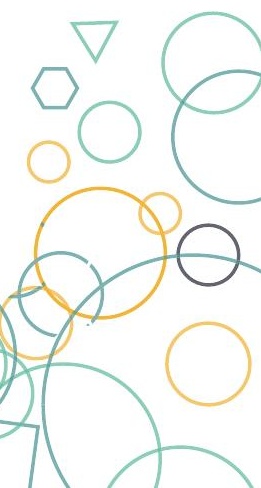


Fue transformado despues con la reforma constitucional de 1968, y en 1975 con la expedición de la ley "Por la cual se modifican y adicionan las normas orgánicas de la Contraloría General de la República, se fijan sistemas y directrices para el ejercicio del control fiscal y se dictan otras disposiciones". (Ley 20, 1975)

Así, despues de no pocos intentos de modernización y mejora del control fiscal nacional y territorial debido a los bajos resultados obtenidos, fue con la Constitución Política de 1991 cuando se consolidó, en los artículos 267, 268, 271, 272 y 274, lo que hoy por hoy constituye el fundamento constitucional del control fiscal en Colombia, explicado en detalle en el capítulo anterior.

A finales de 1993 se organizó la estructura orgánica y funcional de la Contraloría General de la República; de la audioría externa (hoy Auditoría General de la República) y del Fondo de Bienestar Social de la CGR: y entre otras cosas,se creó la tarifa de control fiscal para los organismos y entidades fiscalizadas, a favor de la CGR. (Ley 106, 1993)

Luego, con el Estatuto de Control Fiscal, Ley 42 de 1993 publicada en el Diario Oficial No. 40.732 de ese año, en 110 artículos se organizó el sistema de control fiscal financiero ${ }^{4}$, se establecieron los preceptos, los principios, los sistemas, los procedimientos y los órganos de control fiscal de los niveles nacional y territorial. Se resalta que en esta ley:

Se retomó la definición constitucional de control fiscal, como "una función pública, la cual vigila la gestión fiscal de la administración y de los particulares o entidades que manejen fondos o bienes del Estado en todos sus órdenes y niveles" (Art.4º)

Se definieron los principios y sistemas de la vigilancia de la gestión fiscal, dejando abierta la posibilidad de que la Contraloría General de la República (CGR) adoptara otros por reglamento especial, expuestos al inicio de éste capítulo.

Se identificaron como órganos de control fiscal, autónomos e independientes la CGR y las contralorías territoriales.

Se determinaron los sujetos de control fiscal, y se fijaron las funciones y competencias del Contralor General de la República, y de los contralores departamentales, distritales y municipales, en materia de vigilancia de la gestión fiscal.

Se definieron las características de posterior y selectivo del control fiscal, que le había otorgado

4 La expresión "control financiero" es una imprecisión legislativa (GOMEZ LEE, 2006) en la medida en que el control financiero es solo uno de los sistemas de control que se pueden aplicar para el ejercicio del control fiscal a la luz del artículo $9^{\circ}$ de la misma ley: "financiero, de legalidad, de gestión, de resultados, la revisión de cuentas y la evaluación del control interno". 
la Constitución Política de 1991, así:

“Para efecto del artículo 267 de la Constitución Nacional se entiende por control posterior la vigilancia de las actividades, operaciones y procesos ejecutados por los sujetos de control y de los resultados obtenidos por los mismos. Por control selectivo se entiende la elección mediante un procedimiento técnico de una muestra representativa de recursos, cuentas, operaciones o actividades para obtener conclusiones sobre el universo respectivo en el desarrollo del control fiscal. Para el ejercicio del control posterior y selectivo las contralorías podrán realizar las diligencias que consideren pertinentes." (Negrilla fuera del texto) (Ley 42, 1923. Art. 5)

Se establecieron los procesos de responsabilidad fiscal y jurisdicción coactiva y la facultad sancionatoria de los contralores, como se explica ampliamente en el capítulo siguiente de esta misma publicación, a propósito de los resultados del control fiscal en materia de procesos fiscales y de cobro coactivo.

Por otro lado, es importante el hecho que uno de los dos órganos de control fiscal del orden nacional -la Auditoría General de la República- fue inicialmente considerado dentro de la organización de la Contraloría General de la República, como una dependencia de carácter técnico adscrita al Despacho del Contralor, denominada Auditoría de la Contraloría General de la República y cuyo objetivo era únicamente "ejercer la vigilancia de la gestión fiscal de la Contraloría General de la República, de acuerdo con la Constitución y la ley". (Ley 106, 1993)

Luego, en 1996 y en desarrollo del artículo 308 constitucional, la legislación reguló la función pública de control fiscal que ejercen las contralorías departamentales, en cabeza de los contralores departamentales, se asignó la vigilancia de su gestión fiscal a la Auditoría General de la República. (Ley 330, 1996).

En 1998, la Corte Constitucional quitó a la AGR la naturaleza de adscrita al Despacho del Contralor General, sentencia C-499; y se pronunció sobre la competencia de la AGR para ejercer control fiscal a las contralorías departamentales, distritales y municipales, sentencia C-110 de ese año.

Luego, con el Decreto-Ley 267 de 2000, que modificó parcialmente la Ley 106 de 1993, se efectuó una gran reforma a la estructura orgánica de la Contraloría General de la Republica orientada a la profesionalización del control fiscal nacional.

También se modificó la Ley 106 de 1993 con el Decreto 272 de 2000, al darle a la Auditoría General de la República (AGR) la naturaleza de órgano de control fiscal, con la autonomía jurídica,

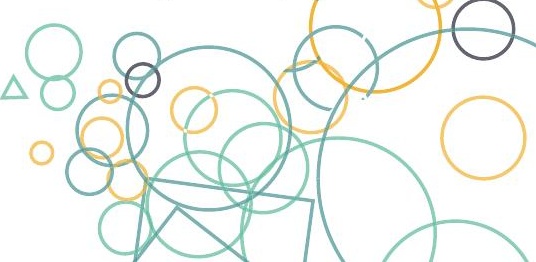




\section{OPPCF}

presupuestal, administrativa y contractual que aún conserva, se organizó como entidad. Entre otras cosas, se le amplió la competencia de la vigilancia de la gestión fiscal de la Contraloría General de la República a la de las contralorías departamentales y se le atribuyó de manera excepcional la vigilancia de la gestión fiscal "sobre las cuentas de las contralorías municipales y distritales, sin perjuicio del control que les corresponde a las contralorías departamentales, previa solicitud del gobierno departamental, distrital o municipal", excluyendo expresamente a la Contraloría Distrital de Bogotá de dicho control. (Decreto-Ley 272, 2000)

Al respecto, la Sala Plena de la Corte Constitucional al hacer un extenso análisis de constitucionalidad de la autonomía y funciones de la Auditoría General de la República, concluyó entre otras muchas cosas, que la vigilancia de la gestión fiscal de la AGR a las contralorías municipales y distritales no es excepcional, y que no había razón para excluir a la Contraloría Distrital de su control. (Sentencia C-1339, 2000)

Ese mismo año, uno de los más fructíferos en el desarrollo normativo del control fiscal colombiano, se expidió la Ley 610 de 2000 que derogó todo lo relacionado con el proceso de responsabilidad fiscal que traía la Ley 42 de 1993; y en su lugar definió conceptos como el de gestión fiscal y daño patrimonial al Estado, los principios de la acción fiscal, el objeto y los elementos sine qua non de la responsabilidad fiscal, la prescripción de la responsabilidad fiscal, la caducidad de la acción fiscal y el procedimiento ordinario del proceso de responsabilidad fiscal. Conceptos que, en los próximos capítulos se abordan de manera empírica.

Esta ley, entre otras cosas, también asignó a la CGR el deber de publicar trimestral de un boletín de responsables fiscales -artículo 60-, para que no pudieran ser nombrados, posesionados o contratados por representantes legales o nominadores de entidades públicas, mientras no hubieran acreditado el pago correspondiente al fallo con responsabilidad fiscal ejecutoriado en su contra, o no hubieran sido retirados del boletín por alguna otra razón

También en el año 2000 se dispuso la supresión de numerosas contralorías. Las de los municipios y distritos que, según la Contaduría General de la Nación, no contaban con la capacidad de financiar sus gastos de funcionamiento; y se impusieron nuevas reglas para la creación de nuevas contralorías territoriales, condicionadas a que fuera en municipios y distritos de categoría especial, $1^{\text {a }}$ y $2^{\text {a }}$ (y en ésta última categoría solo los de más de cien mil habitantes). Adicionalmente, se asignó a las contralorías departamentales la vigilancia de la gestión fiscal de los municipios y distritos que no tienen contraloría municipal. (Ley 617, 2000). Volviendo al tema del boletín de responsables fiscales, en 2002 fue incluido como causal taxativa de inhabilidad para desempeñar cargos públicos el “haber sido declarado responsable 
fiscalmente" (Ley 734 , 2002), causal que, valga precisar, se repite en el artículo 42 de la Ley 1912 de $2019^{5}$ junto con el parágrafo que traía desde antes:

10. Quien haya sido declarado responsable fiscalmente será inhábil para el ejercicio de cargos públicos y para contratar con el Estado durante los cinco (5) años siguientes a la ejecutoria del fallo correspondiente. Esta inhabilidad cesará cuando la Contraloría competente declare haber recibido el pago o, si este no fuere procedente, cuando la Contraloría General de la República excluya al responsable del boletín de responsables fiscales.

Si pasados cinco años desde la ejecutoria de la providencia, quien haya sido declarado responsable fiscalmente no hubiere pagado la suma establecida en el fallo ni hubiere sido excluido del boletín de responsables fiscales, continuará siendo inhábil por cinco años si la cuantía, al momento de la declaración de responsabilidad fiscal, fuere superior a 100 salarios mínimos legales mensuales vigentes; por dos años si la cuantía fuere superior a 50 sin exceder de 100 salarios mínimos legales mensuales vigentes; por un año si la cuantía fuere superior a 10 salarios mínimos legales mensuales vigentes sin exceder de 50, y por tres meses si la cuantía fuere igual o inferior a 10 salarios mínimos legales mensuales vigentes.

Más adelante, respecto de las contralorías territoriales, en dos artículos se fortaleció el ejercicio del control fiscal acerca de la denominada cuota de fiscalización y se estableció un incremento en el porcentaje límite de gastos de funcionamiento de las contralorías distritales y municipales. (Ley 1416, 2010)

En 2011, con el Estatuto Anticorrupción, dentro de las "normas orientadas a fortalecer los mecanismos de prevención, investigación y sanción de actos de corrupción y la efectividad del control de la gestión pública", se introdujeron cambios importantes en materia de control fiscal (Ley 1474, 2011), dentro de los que se resaltan:

El Contralor General de la República y el Auditor General de la República hacen parte de la Comisión Nacional para la Modernización, creada por la misma ley.

Representantes de la Contraloría General de la República, y las contralorías departamentales, municipales y distritales hacen arte de las Comisiones Regionales de Moralización, establecidas a nivel departamental.

Todo el capítulo VIII describe, en 33 artículos, varias "medidas para la eficiencia y eficacia del control fiscal en la lucha contra la corrupción". Se destacan:

- La creación del proceso verbal de responsabilidad fiscal, explicado en el capítulo Ill de esta publicación conceptual y empíricamente, en un estudio sobre la eficacia de la oralidad en proceso de responsabilidad fiscal, tomando como base la información rendida por los distintos órganos de control fiscal del país, a la AGR, entre 2012 hasta 2017.

5 El plazo de vigencia fue prorrogado hasta el $1^{\circ}$ de julio de 2021 por el artículo 140 de la Ley 1955 de 2019 por la cual se expidió el Plan Nacional de Desarrollo 2018-2022.

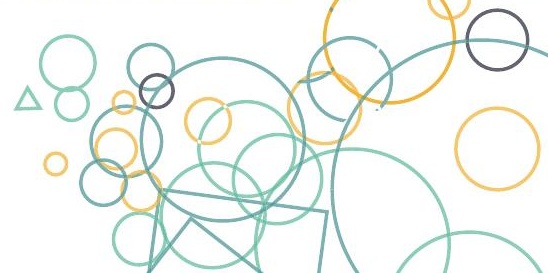


- Las modificaciones al procedimiento ordinario de responsabilidad fiscal de que trata la Ley 610 de 2000.

- La realización de alianzas estratégicas entre las contralorías territoriales y la academia para ejercer control fiscal social preventivo; el control excepcional de la CGR a solicitud del Congreso; la articulación con el ejercicio de control político.

- Se somete la medición de beneficios del control fiscal que hacen las contralorías, a la verificación por parte de la AGR.

- La gran reforma a la estructura interna de la CGR, orientada a su fortalecimiento institucional. Se crearon las contralorías delegadas intersectoriales y las gerencias colegiadas departamentales. Se crearon como adscritas al despacho del contralor general, la Unidad de Investigaciones Especiales contra la Corrupción, la Unidad de Cooperación nacional e Internacional de Prevención, Investigación e Incautación de Bienes, la Unidad de Apoyo Técnico al Congreso y la Unidad de Seguridad y Aseguramiento Tecnológico e Informático.

- En materia de fortalecimiento del control fiscal territorial, la adopción de medidas para asegurar la planeación estratégica de las contralorías territoriales, la implantación del modelo estándar de control interno - $\mathrm{MECl}$ el sistema de gestión de calidad en la gestión pública. Además, que le impone a la CGR facilitar a las contralorías territoriales guías actualizadas de auditoria, adaptadas a sus necesidades, con su capacitación respectiva, tarea ésta que según la misma ley será verificada por la AGR.

En 2011, la Corte Constitucional reiteró lo que había precisado antes en las sentencias C-1176 de 2004 y C-499 de 1998 al afirmar que el control fiscal que efectúa la AGR a la CGR, "debe llevarse a cabo con la misma intensidad y de conformidad con los principios que rigen el control fiscal ejercido por la Contraloría frente a las restantes entidades y organismos del Estado"; y lo más importante, es que aportó los argumentos que la llevaron a concluir que es la Auditoría General de la República el órgano de control fiscal que debe efectuar control fiscal a la gestión del Fondo de Bienestar Social de la Contraloría General de la República, y no ella misma a su fondo como venía ocurriendo hasta entonces. (Sentencia C-599, 2011).

Por lo mismo, los fondos de bienestar social de las contralorías territoriales, salvo la de Bogotá D.C., creados bien como establecimientos públicos con personería jurídica o bien como fondos cuenta, cuyos recursos están conformados por traslados o transferencia, totales o parciales de los presupuestos de las contralorías, así como de donaciones y/o aportes, también 
son responsables de rendir cuentas y son sujetos de vigilancia de la AGR.

En 2012, varios aportes al desarrollo normativo del control fiscal colombiano. Se resalta el haber facultado a la CGR "para ejercer control posterior excepcional sobre el manejo de los recursos propios del municipio o departamento, cuando estos provengan del Fondo Nacional de Gestión del Riesgo de Desastres, los cuales estuviesen destinados para la atención de desastres", en el marco de la política nacional de gestión del riesgo de desastres. (Ley 1523, 2012).

También, el haberle otorgado a la CGR la vigilancia y el ejercicio del control fiscal sobre los recursos del Sistema General de Regalías (Ley 1530, 2012); y la creación de empleos de la planta temporal necesaria en la CGR para hacerlo. (Decreto 1539, 2012).

En 2013, al decidir un conflicto positivo de competencias administrativas entre la Auditoría General de la República y la Auditoría Fiscal ante la Contraloría Distrital de Bogotá Distrito Capital, la Sala de Consulta y Servicio Civil del Consejo de Estado concluyó que la competente para vigilar la gestión fiscala de la Contraloría de Bogotá D.C. es de manera expresa por la ley la Auditoría Fiscal, "sin que sea posible deducir o atribuir dicha competencia a la AGR por analogía, conexidad, extensión o afinidad." (Concepto Sala de Consulta y Servicio Civil, 2013). Desde entonces, la de Bogotá D.C. es la única contraloría del país que no es sujeto vigilado de la AGR. Justamente por esta razón, no hace parte de los resultados del análisis empírico de la información rendida por las contralorías (Ley Estatutaria 1757, 2015) del país, en el capítulo de resultados del control fiscal en materia de hallazgos y procesos de responsabilidad fiscal y cobro coactivo, adelante en esta misma publicación.

Por su parte, tanto la Contraloría General de la República, como la Auditoría General de la República intervinieron frente a la Corte solicitando la inexequibilidad de algunos apartes de los artículos 19, 22 y 23 del Proyecto de Ley Estatutaria número 156 de 2011 Senado, 228 de 2012 Cámara, "por medio de la cual se crea la Ley Estatutaria de Transparencia y del Derecho al acceso a la Información Pública Nacional y se dictan otras disposiciones". Su intervención fue concretamente respecto de la oponibilidad y término de la reserva legal de información relacionada con sus procesos misionales. (Ley 1712 , 2014)

Por su parte, el Estatuto de la Participación Democrática en Colombia (Ley Estatutaria 1757, 2015) fortaleció de manera importante el control fiscal:

Definió en el artículo 69 la denuncia en el control fiscal, así:

La denuncia está constituida por la narración de hechos constitutivos de presuntas irregularidades por el uso indebido de los recursos públicos, la mala prestación de los servicios

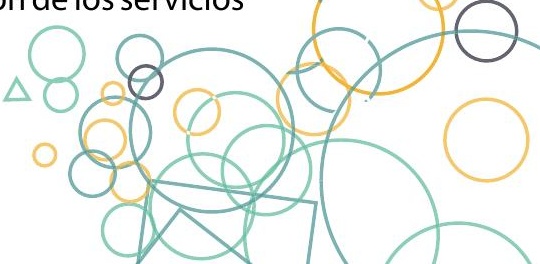




\section{OPPCF}

públicos en donde se administren recursos públicos y sociales, la inequitativa inversión pública o el daño al medio ambiente, puestos en conocimiento de los organismos de control fiscal, y podrá ser presentada por las veedurías o por cualquier ciudadano.

Estableció en el artículo 70 el procedimiento para la atención de las denuncias de control fiscal, y fijó el término para darles respuesta. Lo hizo adicionando un artículo a la Ley 850 de 2003 que reglamenta las veedurías ciudadanas:

La atención de las denuncias en los organismos de control fiscal seguirá un proceso común, así:

a) Evaluación y determinación de competencia;

b) Atención inicial y recaudo de pruebas;

c) Traslado al proceso auditor, responsabilidad fiscal o entidad competente;

d) Respuesta al ciudadano.

PARÁGRAFO 1o. La evaluación y determinación de competencia, así como la atención inicial y recaudo de pruebas, no podrá exceder el término establecido en el Código Contencioso Administrativo para la respuesta de las peticiones.

\section{El proceso auditor dará respuesta definitiva a la denuncia durante los siguientes seis (6) meses posteriores a su recepción. <Inciso CONDICIONALMENTE exequible>}

PARÁGRAFO 2o. Para el efecto, el Contralor General de la República en uso de sus atribuciones constitucionales armonizará el procedimiento para la atención y respuesta de las denuncias en el control fiscal. <Parágrafo CONDICIONALMENTE exequible> (Negrilla fuera del texto)

- También, la misma Ley Estatutaria impuso a los órganos de control (como la AGR, la CGR y las contralorías territoriales) la obligación de destinar recursos financieros para actividades de fortalecimiento de los mecanismos de control social.

- E incluyó, como uno de los instrumentos de acción para las veedurías, el que puedan solicitar por escrito a la CGR el control excepcional; poder que sí tenía la ciudadanía desde la Ley 42 de 1993.

En esta relación normativa es menester referir a la creación, en la Contraloría General de la República, del Centro de Estudios Fiscales con el objetivo de "realizar y fomentar la investigación que soporte el conocimiento en ciencia y tecnología y a través de ella la formación de alta calidad en materia de vigilancia de la gestión y control de los recursos públicos (...)" (Ley 1807, 2016)

En el año 2018 se establecieron nuevas reglas para la elección del Contralor General de la República, requisitos y procedimientos, en desarrollo de unas etapas del proceso de selección, dentro de las cuales convocatoria pública, inscripción, prueba de conocimientos y entrevista. (Ley 1904, 2018) 
- Por su parte, en materia de control fiscal, la Ley 1955 de 2019“Por la cual se expide el Plan Nacional de Desarrollo 2018-2022 "Pacto por Colombia, Pacto por la Equidad", entre otras cosas:

- Estableció que el Plan Plurianual de Inversiones para la paz, es sujeto de control fiscal, según las competencias de los distintos órganos.

- Asignó a la CGR el control fiscal de los recursos destinados al desarrollo del Proyecto del Aeropuerto del Café (AEROCAFÉ), ejecutados a través de un patrimonio autónomo.

En materia de acceso a la información, instituyó en el artículo 136, que:

La Contraloría General de la República para el cumplimiento de sus funciones, tendrá acceso sin restricciones a los sistemas de Información o bases de datos de las entidades públicas y privadas que dispongan o administren recursos y/o ejerzan funciones públicas.

La reserva legal de información o documentos no le será oponible a la Contraloría General de la República y se entenderá extendida exclusivamente para su uso en el marco de sus funciones constitucionales y legales.

Parágrafo $1^{\circ}$. Cada entidad deberá disponer de lo necesario para garantizar el suministro oportuno y en tiempo real de la información requerida por la Contraloría General de la República.

Parágrafo $\mathbf{2}^{\circ}$. Además de las sanciones ya previstas en la ley, la Contraloría General de la República podrá suspender en el ejercicio del cargo, hasta por el término de 180 días y con el fin de impulsar el correcto ejercicio del control fiscal, a los servidores públicos que impidan o entorpezcan el acceso a la información, previo agotamiento del procedimiento legal administrativo correspondiente, en el cual se garantizará el derecho al debido proceso. El Contralor General de la República reglamentará la materia. (Ley 1955, 2019)

En efecto, la Contraloría General de la República reglamentó todo lo relacionado con la potestad sancionatoria fiscal de esa entidad. (Resolución Reglamentaria Orgánica REF-ORG-0029-2019, 2019)

Es propio referir en este punto, que también el Contralor General de la República reglamentó la facultad irrestricta de acceso a los sistemas de información o bases de datos de las entidades públicas y privadas que le dio la misma ley a la CGR, y le estableció los responsables, los competentes para elevar requerimientos y el término mínimo de 5 días para dar respuesta. (Resolución Reglamentaria Orgánica REG-ORG-030-2019, 2019) 


\section{OPPCF}

- Asimismo, con esa Ley se transfirió al Ministerio de Hacienda y Crédito Público la competencia para liquidar y recaudar la tarifa de control fiscal a que se hizo referencia líneas atrás en éste capítulo, creada por la Ley 106 de 1993.

Y, se revistió al Presidente de la República de facultades extraordinarias -durante 6 meses, es decir hasta noviembre de 2019- para reestructurar jerárquica y funcionalmente algunas dependencias específicas de la Contraloría General de la República. (Ley 1955, 2019)

- El Acto Legislativo Nro. 04 de 18 de septiembre de $2019^{6}$, cuyo proyecto nació a iniciativa del Contralor General de la República en desarrollo del numeral $8^{\circ}$ del artículo 268 constitucional, introdujo reformas importantes al régimen del control fiscal colombiano, con la modificación de los artículos 267, 268, 27, 272 y 274 de la Constitución Política, dentro de las que se resaltan:

Amplió el concepto de función pública de control fiscal, al de vigilancia.

- Trasladó a la ley el deber de definir y reglamentar lo referente a las competencias entre contralorías, en observancia de los principios de coordinación, concurrencia y subsidiaridad, el control prevalente y preferente de la CGR, el control fiscal preventivo y concomitante, y las funciones de policía judicial en ejercicio de la vigilancia y el control fiscal.

- Estableció un control fiscal concomitante y preventivo, complementario al posterior y selectivo existente, y recuperó la función de advertencia de la CGR.

- Evolucionó el concepto de sistema de valoración de costos ambientales, al de sostenibilidad ambiental.

- Dispuso que el control jurisdiccional de los fallos con responsabilidad fiscal no debe superar un año, y sometió si ejercicio a regulación legal.

- Modificó la forma de elección Auditor General de la República, en un sistema de mérito por convocatoria pública, y le amplió el periodo a 4 años.

- Determinó que las faltas temporales del Contralor General de la República ya no las suple en todos los casos el Consejo de Estado, sino que en el evento de ser mayores a 45 días, le corresponde hacerlo al Congreso.

- Elevó a rango constitucional el Sistema Nacional de Control Fiscal -SINACOF- para la Proyecto de Acto Legislativo 39 de 2019 Senado, 355 de 32019 Cámara "Por medio del cual se reforma el régimen de control fiscal" (Primera vuelta). Con Decreto 1275 de 18 de julio de 2019 se ordenó la publicación del texto definitivo, con el que se busca reformar el régimen de control fiscal, en los artículos 267, 268, 271, 272 y 274 de la Constitución Política. 
unificación y estandarización de la vigilancia y del control fiscal de la gestión fiscal.

- Estableció el control de advertencia como función constitucional de la CGR.

- Elevó a rango constitucional la posibilidad de imponer sanciones - del artículo 101 de la Ley 42 de 1993- a quienes no suministren información, impidan u obstaculicen el ejercicio de la vigilancia y control fiscal.

\section{Procedimientos de Auditoría}

Los procedimientos de auditoria de control fiscal que hoy desarrolla la Contraloría General de la República están actualizados en cuatro guías adoptadas y elaboradas conforme a los International Standards of Supreme Audit Institutions (ISSAI), de la International Organization of Supreme Audit Institutions (INTOSAI); es decir, conforme a las Normas Internacionales de Auditoría para Entidades Fiscalizadoras Superiores (EFS), que recomiendan el uso especializado de los distintos sistemas de control.

Para el efecto, es importante tener en cuenta que desde hace varias décadas Colombia es país miembro de la Organización Latinoamericana y del Caribe de Entidades Fiscalizadoras Superiores (OLACEFS), grupo regional coordinado con la INTOSAI. Incluso, entre 2009 y 2010 la presidencia de la OLACEFS fue ejercida por el Contralor General de la República, que representa a Colombia en dicha organización.

En consecuencia, de acuerdo con los tres tipos de auditoria de control fiscal que desarrolla la INTOSAI (Auditoría de Cumplimiento, Auditoría de Desempeño y Auditoría Financiera), la Contraloría General de la República actualizó en 2017 sus procedimientos de auditoría conforme a las Normas Internacionales de Auditoría para Entidades Fiscalizadoras Superiores (EFS), elaboró, adoptó y puso en funcionamiento cuatro guías, así:

Principios, fundamentos y aspectos generales para las auditorias en la CGR En el marco de las normas de auditoria de las entidades Fiscalizadoras ISSAI. (Resolución Reglamentaria Orgánica REG - ORG- 0012-2017, 2017)

\section{Guía de Auditoría de Cumplimiento como instrumento de control fiscal posterior} y selectivo, en el marco de las Normas Internacionales de Auditoría para las Entidades Fiscalizadoras Superiores- ISSAI. La versión inicial (Resolución Reglamentaria Orgánica REGORG-0014-2017, 2017), fue derogada por la Resolución (Resolución Reglamentaria Orgánica REG-ORG-022-2018, 2018), que contiene una nueva versión de la guía.

Guía de Auditoría de Desempeño, en concordancia con las Normas Internacionales de Auditoría para las Entidades Fiscalizadoras Superiores- ISSAI. Una versión inicial (Resolución

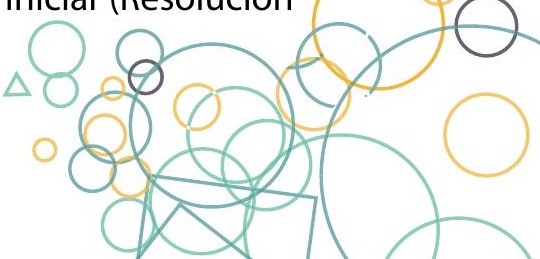


Reglamentaria Orgánica REG-ORG-0015-2017,2017), derogada por la (Resolución Reglamentaria Orgánica RES-ORG-023-2018, 2018), que contiene una nueva versión de la guía.

Guía de Auditoría Financiera como instrumento de control fiscal posterior y selectivo, dentro de los parámetros de las Normas Internacionales de Auditoría para las Entidades Fiscalizadoras Superiores - ISSAI.

Por otro lado, en materia de procedimientos de auditoría, las contralorías territoriales en su mayoría han adoptado y adaptado a sus necesidades desde 2012, la Guía de Auditoría para las Contralorías Territoriales - GAT, construida por la Contraloría General de la República en cumplimiento del artículo 130 del Estatuto Anticorrupción, (Contraloría General de la República, 2012). Actualmente, en un trabajo conjunto, la CGR, la AGR y las contralorías territoriales están actualizando dicha guía a las Normas Internacionales de Auditoría para Entidades Fiscalizadoras Superiores (EFS).

Finalmente, la Auditoría General de la República cuenta desde hace casi dos décadas, con instrumentos metodológicos propios de la AGR plasmados en el Manual de Proceso Auditor, los procedimientos y los formatos debidamente documentados en el Sistema de Gestión de Calidad de la entidad, en proceso de actualización a las normas internacionales referidas.

\subsection{GENERALIDADES DE LAS CONTRALORÍAS TERRITORIALES - CONTEXTO.}

En el presente apartado se identifica la organización administrativa de que disponen las contralorías territoriales del país, para realizar la vigilancia de los recursos públicos que le han sido encomendados, haciendo un comparativo de las variaciones en la estructura en los periodos 2012 - 2017, teniendo en cuenta el tamaño de la tarea encomendada, medida según el número de entidades y la cantidad de recursos que son sujetos receptores del control fiscal. Se circunscribe a un análisis de la estructura de las contralorías territoriales, que no incluye a la Contraloría General de la República, ni a la Contraloría Distrital de Bogotá.

\subsubsection{La institucionalidad del control fiscal territorial.}

En el país existen 66 contralorías, a las que les corresponde vigilar y controlar los recursos de la Nación, departamentos, entidades descentralizadas de cada nivel de gobierno y de los particulares que manejen fondos o bienes públicos, a saber;

La Contraloría General de la República para vigilar los recursos de origen de la Nación.

32 contralorías Departamentales para la vigilancia de los recursos de todos los 
departamentos y sus entidades descentralizadas y de 1090 Municipios ${ }^{7}$ que no tienen contraloría municipal.

- 5 contralorías distritales para la vigilancia de los recursos de los distritos de Bogotá D.C., Barranquilla, Cartagena, Buenaventura y Santa Marta, $y$,

- 28 contralorías municipales para la vigilancia de los recursos de origen de los municipios donde fueron creadas.

Por disposición constitucional, en cada departamento existe una contraloría departamental, que les corresponde vigilar las finanzas del respectivo departamento, las entidades descentralizadas que dependen de estos; además ejercen el control de los recursos en aquellos municipios que no tienen contraloría, es decir las contralorías departamentales tienen jurisdicción de control fiscal en 1088 municipios en los que no existen contralorías. Las 32 contralorías distritales y municipales ejercen vigilancia y control a los recursos de los municipios de su jurisdicción y sus entidades descentralizadas, así como a los particulares que manejan recursos públicos.

Las obligaciones constitucionales y legales que tienen las contralorías territoriales en la vigilancia del recurso público se sintetizan en:

- Vigilancia y control de la gestión de los responsables del manejo del recurso y de los particulares que manejen fondos o bienes públicos.

- Resarcir los daños al patrimonio y recaudar su monto.

- Administrar los asuntos propios de su funcionamiento.

Para el desarrollo de las anteriores funciones el esquema organizacional de las contralorías territoriales está compuesto por unidades administrativas o dependencias con funciones administrativas o misionales orientadas a lograr el cumplimiento de los objetivos y metas establecidas en los planes de la entidad. Las áreas misionales desarrollan las actividades de vigilancia fiscal a través del ejercicio auditory el trámite de los procesos de responsabilidad fiscal, con el fin de evaluar la gestión y ejecución del recurso público y procurar por el resarcimiento de los daños causados al patrimonio público, y el área administrativa que brinda el apoyo y soporte requerido por la Entidad para el cumplimiento de las obligaciones constitucionales.

A las corporaciones públicas territoriales (asambleas departamentales y concejos municipales) que cuentan con contralorías, les corresponde dotarlas de estructura organizativa, distribución

Según cifras del Departamento Administrativo Nacional de Estadística a diciembre de 2011, en el país existían 1.120 municipios, en 34 de ellos existe contraloría municipal, en el estudio no se incluye la Contraloría Distrital de Bogotá D.C.

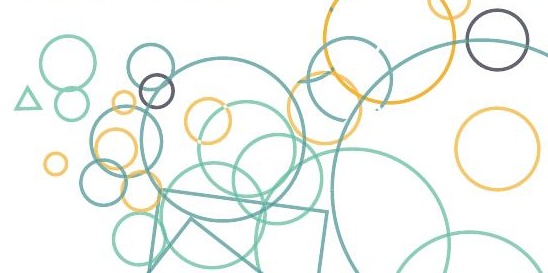


interna de las diferentes dependencias con las funciones requeridas para cumplir con su misión constitucional y legal, así mismo, determinarles la planta de personal y escalas de remuneración correspondientes a las distintas categorías de empleo.

\subsubsection{Tamaño de las contralorías territoriales y alcance del control fiscal ejercido.}

Las 64 contralorías territoriales ${ }^{9}$ ejecutaron en la vigencia 2017 un presupuesto de \$293.008.886.461, para vigilar a $3.708^{10}$ entes territoriales y entidades descentralizadas que ejecutaron en la vigencia un presupuesto por $\$ 127.151 .490 .643 .247$. Para realizar este ejercicio de control, las contralorías cuentan con 3.293 cargos en sus plantas de personal, de los cuales 2.147 están asignados a las áreas misionales del proceso auditor y de los procesos de responsabilidad fiscal.

Tabla No. 1. Contralorías territoriales vs sujetos de control. Vigencias 2012 - 2017

\begin{tabular}{|c|c|c|c|c|}
\hline Vigencia & $\begin{array}{c}\text { Presupuesto de } \\
\text { la Contraloría, } \\
\text { compromisos (\$) }\end{array}$ & $\begin{array}{c}\text { No. Total, de } \\
\text { cargos de la } \\
\text { Contraloría }\end{array}$ & $\begin{array}{c}\text { No. Total, } \\
\text { sujetos de } \\
\text { control }\end{array}$ & $\begin{array}{c}\text { Presupuesto ejecutado } \\
\text { de gastos sujetos de } \\
\text { control (\$) }\end{array}$ \\
\hline $\mathbf{2 0 1 2}$ & 213.335 .386 .837 & 3.229 & 4.968 & 94.466 .500 .689 .722 \\
\hline $\mathbf{2 0 1 3}$ & 230.524 .923 .307 & 3.264 & 4.564 & 93.059 .892 .697 .717 \\
\hline $\mathbf{2 0 1 4}$ & 239.481 .331 .815 & 3.254 & 4.204 & 76.055 .176 .941 .138 \\
\hline $\mathbf{2 0 1 5}$ & 251.212 .278 .217 & 3.238 & 3.657 & 115.501 .571 .433 .991 \\
\hline $\mathbf{2 0 1 6}$ & 269.539 .058 .745 & 3.241 & 3.646 & 137.225 .447 .503 .513 \\
\hline $\mathbf{2 0 1 7}$ & 293.008 .886 .461 & 3.293 & 3.708 & 127.151 .490 .643 .247 \\
\hline
\end{tabular}

Tabla No. 1. Elaboración propia. Fuente. Análisis de información reportada por las contralorías en el módulo SIA-SIREL de la AGR.

El presupuesto ejecutado por las contralorías territoriales no ha tenido variaciones significativas desde el año 2012, presentando un crecimiento promedio de 7,5\%, al pasar de $\$ 213.335 .386 .837$ en la vigencia 2012 a $\$ 293.008 .886 .461$ en el 2017. Por su parte el presupuesto de los sujetos de control sobre los cuales recae el control fiscal territorial, en promedio, presentó un aumento $6.9 \%$ por vigencia, similar al aumento en el presupuesto de las contralorías. Sin embargo, ha disminuido en el número de entidades sujetas de control, debido a la depuración en la reglamentación interna que vienen realizando varias contralorías, al catalogar a las instituciones educativas como puntos de control y no como entidades sujetas de control ${ }^{11}$, incidiendo en la contabilización de estos.

Las 10 contralorías de mayor presupuesto ${ }^{12}$ concentran el $54 \%$ de los recursos totales

$8 \quad$ Artículo 650 de la Ley 42 de 1993, Diario Oficial №. 40.732, de 27 de enero de 1993

9 No se incluye en el análisis la Contraloría de Bogotá D.C., que no es su sujeto vigilado de la AGR.

10 Información sustentada en las resoluciones internas de cada contraloría que establecen el número de sujetos y puntos de control por auditar en cada vigencia.

A través de reglamentación interna cada organismo de control fiscal territorial determina los puntos y sujetos de control sobre los cuales tiene competencia en el ejercicio de control fiscal.

12 Corresponde a las contralorías territoriales de Antioquia, Medellín, Cali, Cundinamarca, Valle del Cauca, Santander, Barranquilla, Cartagena de 
asignados al control fiscal territorial y le corresponde vigilar el 55\% del total de los recursos de competencia de las contralorías territoriales, por su parte, las 10 contralorías con menor presupuesto $^{13}$ tienen el $3 \%$ del total asignado y vigilan el $2 \%$ de los recursos por auditar de todas las contralorías. Indicando que existen entes de control que concentran la mayor cantidad de recursos destinados al control fiscal territorial mientras las contralorías pequeñas solo funcionan con un mínimo presupuesto.

La financiación del control fiscal territorial le corresponde a la entidad territorial donde exista contraloría a través de transferencias del sector central y cuotas de auditaje fijadas a las entidades descentralizadas. Según los datos de la tabla No. 1, para la vigencia 2017, por cada $\$ 434$ ejecutados en el nivel territorial, en promedio se destinó 1 peso para el ejercicio del control fiscal.

Según la información contenida en la rendición de cuenta, el Departamento de la Guajira es el que dedica menores recursos para el control fiscal, al asignar 1 peso por cada 1.607 de presupuesto territorial, seguido por los municipios de Cúcuta y Medellín ${ }^{14}$ y los Departamentos de Arauca y Meta, que asignan un peso por cada 800 pesos de ejecución territorial. Por su parte, los que más asignan recursos para el control fiscal son los municipios de Yumbo (Valle), Girón (Santander) y el Departamento de San Andrés, Providencia y Santa Catalina, que asignan 1 peso por cada 100 de ejecución territorial.

\subsubsection{Estructura de las plantas de personal.}

La Constitución Política de Colombia define el control fiscal como una función pública ${ }^{15}$ que vigila la gestión fiscal de la administración y de los particulares o entidades que manejen fondos o bienes del Estado, además establece que dicha función debe ser ejercida por entidades (contralorías) de carácter técnico, mandato que le demanda a las contralorías un trabajo profesional y especializado para fundamentar sus evaluaciones, en técnicas y procedimientos confiables, medibles y comprobables (Restrepo, 2017, p. 78).

Para cumplir con eficiencia y eficacia la disposición constitucional, las contralorías requieren de personal calificado, que actúe con independencia profesional frente al auditado, sea objetivo e imparcial en los conceptos y opiniones que emita. Así se ha definido en la legislación internacional, en lo que concierne al equipo de auditoría, al establecer como principios Indias, Bolívar y Tolima,

13 Corresponde a las contralorías territoriales de Girón, Vaupés, Vichada, Guainía, Dosquebradas, Soledad - Atlántico, Amazonas, Sincelejo, Popayán y Guaviare

14 En los sujetos de control de la Contraloría General de Medellín, se incluye el holding empresarial de Empresas Públicas de Medellín que el año 2017 ejecutaron recursos por 16,8 billones de pesos.

15 Artículo 267 de la Constitución Política de Colombia.

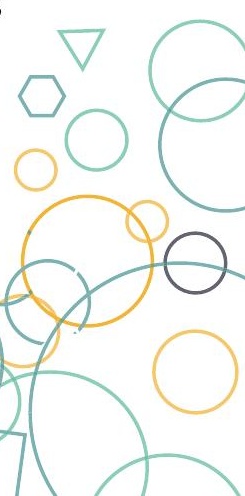


generales de la labor de auditoría en el sector público; “Los miembros del equipo que lleve a cabo una auditoría en el sector público deberán contar con las competencias profesionales, la experiencia necesaria y los conocimientos técnicos o especializados requeridos por el objeto de la auditoría," (Bayona, 2018, p.28)

En el periodo analizado se evidencia que las corporaciones públicas han modificadola estructura organizativa de la respectiva contraloría territorial, con la justificación de profesionalizarlas y ponerlas acorde con las políticas de modernización del Estado, sin variaciones significativas en el número total de cargos.

Tabla No. 2. Composición y variaciones en las plantas de personal de las contralorías territoriales. Vigencias 2012 - 2017

\begin{tabular}{|c|c|c|c|c|c|c|c|}
\hline \multirow[t]{2}{*}{ Vigencia } & \multirow[t]{2}{*}{$\begin{array}{l}\text { Total, de } \\
\text { cargos } \\
\text { de las }\end{array}$} & \multicolumn{2}{|c|}{$\begin{array}{l}\text { Cargos áreas misionales } \\
\text { (Proceso Auditor) }\end{array}$} & \multicolumn{2}{|c|}{$\begin{array}{l}\text { Cargos de carrera } \\
\text { administrativa }\end{array}$} & \multicolumn{2}{|c|}{$\begin{array}{c}\text { Cargos de libre } \\
\text { nombramiento y } \\
\text { remoción }\end{array}$} \\
\hline & & 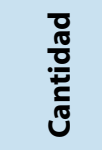 & $\begin{array}{c}\text { \% Respecto } \\
\text { del total de } \\
\text { cargos }\end{array}$ & 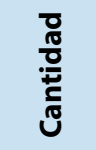 & $\begin{array}{c}\text { \% Respecto } \\
\text { del total de } \\
\text { cargos }\end{array}$ & 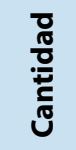 & $\begin{array}{c}\text { \% Respecto } \\
\text { del total de } \\
\text { cargos }\end{array}$ \\
\hline 2012 & 3.229 & 1,598 & $49.5 \%$ & 1,194 & $37 \%$ & 708 & $22 \%$ \\
\hline 2013 & 3,264 & 1,622 & $49.7 \%$ & 1,164 & $36 \%$ & 720 & $22 \%$ \\
\hline 2014 & 3,254 & 1,598 & $49.1 \%$ & 1,106 & $34 \%$ & 730 & $22 \%$ \\
\hline 2015 & 3,238 & 1,569 & $48.5 \%$ & 1,631 & $50 \%$ & 706 & $22 \%$ \\
\hline 2016 & 3,241 & 1,568 & $48.4 \%$ & 2,022 & $62 \%$ & 722 & $22 \%$ \\
\hline 2017 & 3,293 & 1,581 & $48.0 \%$ & 2,003 & $61 \%$ & 747 & $23 \%$ \\
\hline
\end{tabular}

Tabla No. 2. Elaboración propia. Fuente. Análisis de información reportada por las contralorías en el módulo SIA-SIREL de la AGR.

En las vigencias analizadas, las plantas de cargos de las contralorías no han presentado variaciones significativas en el número de cargos, al igual que el personal destinado al ejercicio de tareas misionales de proceso auditor, sin embargo, en los cargos de carrera administrativa se presentó un incremento positivo al pasar de representar el $37 \%$ del total de la planta al 61\%, reflejado por los concursos de carrera administrativa en las vigencias 2014 y 2015.

Los cargos de libre nombramiento y remoción representan el $23 \%$ de la planta de personal, sin embargo, en las contralorías territoriales de Soledad, Guainía, Itagüí, Girón, Floridablanca, Soacha y Envigado más del $60 \%$ de los cargos de la entidad son de libre nombramiento y remoción, generando alta rotación del personal al servicio de la Contraloría, situación que impide responden al fortalecimiento del control fiscal como organismos técnicos y especializados. 
En el $72 \%$ de las contralorías, más del $60 \%$ del personal cumple funciones misionales de las contralorías, dando prioridad en el ejercicio del control fiscal, sin embargo, en las contralorías territoriales de Palmira, San Andrés, Providencia y Santa Catalina, Floridablanca, Tuluá, Atlántico, Buenaventura y Sincelejo, el personal que se dedica al control fiscal es menos del $50 \%$.

En promedio, el $49 \%$ del personal de las contralorías están asignados a la labor misional del proceso auditor, sobre ellos recae la responsabilidad del desarrollo y ejecución de los procesos auditores en las entidades sujetas de control, aplicando los conocimientos propios de la carrera profesional requerida y las competencias exigidas en las labores de auditoría, en ese sentido, les corresponde realizar las actividades operativas para la definición de los métodos y forma de rendir cuentas a los responsables del manejo de fondos o bienes de las entidades sujetas de control, establecer y desarrollar los criterios de evaluación financiera, operativa y de resultados logrados por los sujetos vigilados; aplicar los instrumentos y herramientas de análisis en la revisión y fenecimiento de cuentas que rinden los responsables del erario, y son quienes llevan a cabo los análisis y estudios para determinar el grado de eficiencia, eficacia y economía dado al manejo de los bienes y recursos públicos.

En promedio cada funcionario asignado al área misional, le corresponde auditar 2 sujetos de control, sin embargo, en las contralorías territoriales de Arauca es de 11, Chocó de 4 Guajira de 4, Putumayo de 4 y Casanare con 4, con presupuestos mayores que el promedio nacional.

Según la naturaleza de sus funciones, las competencias y los requisitos exigidos para su desempeño, los empleos de las entidades territoriales, al igual que el de las contralorías, se clasifican en niveles jerárquicos: nivel directivo, asesor, profesional, técnico y asistencial. ${ }^{16}$

El nivel profesional con 1,457 cargos representa el 44\% de la planta de personal las contralorías territoriales, los niveles asistencial y técnico representan el $34 \%$ y los niveles directivo y asesor el $22 \%$, sin embargo en las contralorías territoriales de Antioquia, Cali, Palmira y Envigado existen más cargos en el nivel directivo y asesor que en el nivel profesional responsable del desarrollo de la tarea misional, por ello se presenta que en la Contraloría General de Antioquia existen 134 cargos directivos para dirigir 18 dependencias de la estructura organizacional de la entidad (Restrepo, 2017, p. 76), generando riesgo en la intensidad del control fiscal que ejercen a los recursos públicos, afectando de manera sensible la finalidad de las normas constitucionales y legales que rigen la naturaleza de los empleos del Estado.

\subsubsection{Capacidad instalada de las contralorías frente a sus hallazgos administrativos.}

En el análisis se estimaron dos datos de la capacidad instalada respecto de los hallazgos

16 Artículo $3^{\circ}$ del Decreto 785 de 2005. Diario 0ficial 45.855 de marzo 19 de 2005

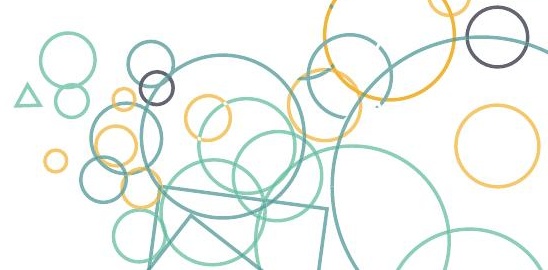


administrativos (entendiendo por tales, el conjunto de todos los hallazgos independientemente de las connotaciones penal, disciplinaria y fiscal que puedan tener) por año: el promedio del número de hallazgos por auditor asignado (indicador de cantidad) y el promedio de la cuantía de los hallazgos por auditor asignado (indicador de volumen).

Tabla No. 3. Promedio del número de hallazgos por auditor asignado y de cuantía de los hallazgos por auditor asignado.

\begin{tabular}{|r|r|r|r|r|}
\hline Año & $\begin{array}{c}\text { Promedio } \\
\text { de número } \\
\text { de hallazgos } \\
\text { por auditor } \\
\text { (cantidad) }\end{array}$ & $\begin{array}{c}\text { Promedio de la cuantía de } \\
\text { los hallazgos por auditor } \\
\text { (volumen) } \mathbf{( \$ )}\end{array}$ & $\begin{array}{c}\text { Variación Anual } \\
\text { en Cantidad }\end{array}$ & $\begin{array}{c}\text { Variación } \\
\text { Anual en } \\
\text { Volumen }\end{array}$ \\
\hline $\mathbf{2 0 1 2}$ & 0,88 & 154.186 .918 & & \\
\hline $\mathbf{2 0 1 3}$ & 0,49 & 103.409 .884 & $-44,42$ & $-32,93$ \\
\hline $\mathbf{2 0 1 4}$ & 0,28 & 81.806 .976 & $-42,84$ & $-20,89$ \\
\hline $\mathbf{2 0 1 5}$ & 0,27 & 70.032 .987 & $-3,76$ & $-14,39$ \\
\hline $\mathbf{2 0 1 6}$ & 0,60 & 265.061 .850 & 124,09 & 278,48 \\
\hline $\mathbf{2 0 1 7}$ & 0,50 & 118.173 .439 & $-16,43$ & $-55,42$ \\
\hline
\end{tabular}

Tabla No. 3. Elaboración propia. Fuente. Análisis de información reportada por las contralorias en el módulo SIA-SIREL de Ia AGR.

La evidencia arroja que para el período analizado el promedio de hallazgos por auditor ha ido disminuyendo, y la cuantía de los hallazgos por auditor también presenta disminución, esto sugiere de que pese a que no disminuye al mismo ritmo, ambas capacidades siguen disminuyendo en el tiempo, a excepción del 2016, confirmando que las contralorías en promedio van perdiendo capacidad instalada para cumplir con su misión, lo cual resulta un desafío importante en la efectividad del desempeño de las contralorías.

\subsubsection{Ejecución presupuestal de las contralorías territoriales.}

La ejecución presupuestal en las entidades públicas es un indicador de eficiencia utilizado con frecuencia en el cual se evidencia la manera en que se usan los recursos que se asignan a una institución, política, plan o proyecto teniendo en una anualidad.

La Ley 819 de 2003 "por la cual se dictan normas orgánicas en materia de presupuesto, responsabilidad y transparencia fiscal y se dictan otras disposiciones", establece:

“Artículo $8^{\circ}$. Reglamentación a la programación presupuestal. La preparación y elaboración del Presupuesto General de la Nación y el de las Entidades Territoriales, deberá sujetarse a los correspondientes Marcos Fiscales de Mediano Plazo de manera que las apropiaciones presupuestales aprobadas por el Congreso de la República, las Asambleas y los Concejos, puedan ejecutarse en su totalidad durante la vigencia fiscal correspondiente". (Resaltado fuera del texto) 
Así, la ejecución presupuestal es un principio que se contempla en la normativa colombiana como una medida deseable de uso sobre las apropiaciones del presupuesto.

Por su parte, el Decreto 1957 de 2007, dispuso:

"Artículo $1^{\circ}$. Los compromisos presupuestales legalmente adquiridos, se cumplen o ejecutan, tratándose de contratos o convenios, con la recepción de los bienes y servicios, y en los demás eventos, con el cumplimiento de los requisitos que hagan exigible su pago. (...) Artículo $2^{\circ}$. De conformidad con lo previsto en el artículo $9^{\circ}$ de la Ley 225 de 1995 y el artículo 31 de la Ley 344 de 1996, en cada vigencia, el Gobierno Nacional reducirá el presupuesto en el $100 \%$ del monto de las reservas presupuestales constituidas sobre el presupuesto del año inmediatamente anterior, que excedan el $2 \%$ de funcionamiento y el $15 \%$ de las apropiaciones de inversión del presupuesto de dicho año (Artículo 1 y 2, Decreto 1957 de 2007).

En el ejercicio realizado con las contralorías si bien se observan altas ejecuciones presupuestales, al analizar la construcción de reservas presupuestales en donde se tienen en cuentan no solo los compromisos al presupuesto, sino también las obligaciones y pagos correspondientes se evidencia rezagos presupuestales superiores establecidos en la normativa.

Frente a esta disposición el Ministerio de Hacienda y Crédito Público ha analizado en sus conceptos jurídicos presupuestales, el concepto de reserva presupuestal de la siguiente manera:

"De conformidad con lo expuesto se puede concluir: Los órganos que hacen parte del Presupuesto General de la Nación sólo podrán adquirir compromisos cuya ejecución, entendida como entrega de bienes o prestación de servicios, se realice en la respectiva vigencia fiscal. Si se requiere exceder la anualidad, esto es, cuando la ejecución de la obligación se inicie con presupuesto de la vigencia en curso y su objeto también se lleve a cabo en la (s) anualidad (es) siguiente (s), se debe solicitar autorización al CONFIS o a quien este delegue, para asumir dichas obligaciones con cargo a presupuestos de vigencias futuras. Los compromisos legalmente adquiridos para ser ejecutados durante la respectiva vigencia, que no se hayan podido ejecutar a 31 de diciembre, se deberán constituir como reservas presupuestales de conformidad con el artículo 89 del Estatuto Orgánico de Presupuesto. Una vez constituidas dichas reservas, se aplicará lo dispuesto por el artículo 9 de la Ley 225 de 1995 y el artículo 31 de la Ley 344 de 1996, si se excede el 2\% de las apropiaciones de funcionamiento y el 15\% de las apropiaciones de inversión" (Minhacienda, 2011, p. 65-68)

Así, los altos rezagos presupuestales no son deseables pues constituyen un riesgo inminente para la apropiación futura de recursos, lo cual ante una situación de escasez de financiamiento, pondría en peligro la sostenibilidad de la implementación de políticas públicas y un retroceso en los avances realizados en materia de ejecución (Ortiz, 2017).

Respecto de la ejecución del presupuesto las Contralorías exhiben en general un alto porcentaje, salvo en contadas oportunidades para el período 2012-2016 muestran una ejecución inferior al $90 \%$. No obstante, en la revisión de los requisitos de la Ley de Presupuesto Nacional donde se exige que las entidades del Estado deben ejecutar su presupuesto con 
rezagos inferiores al 15\% se encontró que en general este cálculo es inferior a esa proporción. Algunas de las contralorías no cumplen con este precepto legal en el período como es el caso de las contralorías de Buenaventura, Cauca, Casanare, Soledad y el Fondo de Bienestar de la Contraloría General de la República.

Estos indicadores reflejan que pese a que la generalidad de las contralorías, son eficientes en relación con la ejecución de su presupuesto, existen contralorías con rezagos presupuestales lo que no es coherente con sus solicitudes y necesidades de aumento en los presupuestos asignados.

A continuación, se presentan el cálculo de la ejecución presupuestal del período:

Tabla No.4. Ejecución presupuestal de las contralorías territoriales vigencias 2012-2016

\begin{tabular}{|l|r|r|r|r|r|}
\hline \multicolumn{1}{|c|}{ Contraloría } & $\begin{array}{r}\text { \% } \\
\text { ejecución } \\
\mathbf{2 0 1 2}\end{array}$ & $\begin{array}{c}\text { \% } \\
\text { ejecución } \\
\mathbf{2 0 1 3}\end{array}$ & $\begin{array}{c}\text { \% } \\
\text { ejecución } \\
\mathbf{2 0 1 4}\end{array}$ & $\begin{array}{c}\text { \% } \\
\text { ejecución } \\
\mathbf{2 0 1 5}\end{array}$ & $\begin{array}{c}\text { \% } \\
\text { ejecución } \\
\mathbf{2 0 1 6}\end{array}$ \\
\hline Amazonas & 99,6 & 100,0 & 100,0 & 99,8 & 98,7 \\
\hline Antioquia & 94,5 & 97,6 & 94,0 & 99,6 & 100,0 \\
\hline Arauca & 99,1 & 99,2 & 99,1 & 99,1 & 100,0 \\
\hline Armenia & 92,7 & 100,0 & 97,8 & 94,7 & 100,0 \\
\hline Atlántico & 99,4 & 100,0 & 100,0 & 99,7 & 98,3 \\
\hline Barrancabermeja & 99,9 & 99,8 & 100,0 & 100,0 & 99,8 \\
\hline Barranquilla & 100,0 & 100,0 & 100,0 & 100,0 & 100,0 \\
\hline Bello & 99,6 & 99,2 & 99,4 & 99,5 & 97,0 \\
\hline Bolívar & 95,6 & 92,6 & 87,5 & 96,5 & 99,9 \\
\hline Boyacá & 100,0 & 100,0 & 100,0 & 99,9 & 99,9 \\
\hline Bucaramanga & 92,8 & 98,8 & 99,8 & 99,6 & 98,6 \\
\hline Buenaventura & 100,0 & 100,0 & 97,2 & 100,0 & 95,4 \\
\hline Caldas & 96,3 & 96,8 & 98,1 & 100,0 & 93,5 \\
\hline Cali & 99,7 & 99,9 & 99,7 & 99,9 & 99,8 \\
\hline Caquetá & 99,6 & 99,2 & 97,8 & 99,5 & 98,7 \\
\hline Cartagena de Indias & 99,9 & 100,0 & 100,0 & 100,0 & 100,0 \\
\hline Casanare & 93,5 & 92,5 & 96,1 & 92,0 & 89,0 \\
\hline Cauca & 92,6 & 87,1 & 80,9 & 72,4 & 68,7 \\
\hline Cúcuta & 99,9 & 100,0 & 98,1 & 97,0 & 97,2 \\
\hline Cesar & 98,9 & 100,0 & 100,0 & 99,0 & 100,0 \\
\hline
\end{tabular}




\begin{tabular}{|c|c|c|c|c|c|}
\hline Contraloría & $\begin{array}{c}\% \\
\text { ejecución } \\
2012\end{array}$ & $\begin{array}{c}\% \\
\text { ejecución } \\
2013\end{array}$ & $\begin{array}{c}\% \\
\text { ejecución } \\
2014\end{array}$ & $\begin{array}{c}\% \\
\text { ejecución } \\
2015\end{array}$ & $\begin{array}{c}\% \\
\text { ejecución } \\
2016\end{array}$ \\
\hline Chocó & 91,7 & 100,0 & 100,0 & 100,0 & 100,0 \\
\hline Cundinamarca & 98,0 & 98,1 & 98,7 & 98,7 & 98,3 \\
\hline Dosquebradas & 100,0 & 100,0 & 100,0 & 100,0 & 100,0 \\
\hline Envigado & 96,9 & 100,0 & 100,0 & 100,0 & 100,0 \\
\hline Floridablanca & 99,9 & 100,0 & 99,4 & 95,5 & 96,9 \\
\hline General de la República & 94,0 & 92,5 & 96,0 & 94,5 & 96,3 \\
\hline Guainía & 99,8 & 99,7 & 99,8 & 99,8 & 99,9 \\
\hline Guajira & 95,9 & 90,6 & 95,0 & 84,0 & 92,6 \\
\hline Guaviare & 100,0 & 100,0 & 100,0 & 100,0 & 100,0 \\
\hline Huila & 90,3 & 97,8 & 95,4 & 99,8 & 99,8 \\
\hline lbagué & 98,6 & 100,0 & 100,0 & 100,0 & 98,6 \\
\hline Itagüúí & 97,8 & 99,8 & 99,7 & 98,6 & 100,0 \\
\hline Magdalena & 95,5 & 99,4 & 99,7 & 98,6 & 95,3 \\
\hline Manizales & 100,0 & 99,7 & 100,0 & 95,5 & 100,0 \\
\hline Medellín & 100,0 & 100,0 & 100,0 & 99,9 & 100,0 \\
\hline Meta & 99,6 & 99,3 & 96,5 & 98,6 & 99,0 \\
\hline Montería & 100,0 & 100,0 & 100,0 & 100,0 & 100,0 \\
\hline Nariño & 100,0 & 100,0 & 100,0 & 100,0 & 98,0 \\
\hline Neiva & 100,0 & 99,3 & 100,0 & 100,0 & 100,0 \\
\hline Norte de Santander & 99,1 & 95,7 & 99,4 & 94,4 & 99,6 \\
\hline Palmira & 92,1 & 100,0 & 100,0 & 99,5 & 100,0 \\
\hline Pasto & 100,0 & 100,0 & 100,0 & 100,0 & 100,0 \\
\hline Pereira & 100,0 & 100,0 & 100,0 & 100,0 & 100,0 \\
\hline Popayán & 100,0 & 99,7 & 99,9 & 97,9 & 99,5 \\
\hline Putumayo & 99,6 & 95,5 & 99,2 & 98,1 & 100,0 \\
\hline Quindío & 92,1 & 98,7 & 100,0 & 94,0 & 100,0 \\
\hline Risaralda & 93,1 & 89,6 & 91,6 & 100,0 & 100,0 \\
\hline $\begin{array}{l}\text { San Andrés, Providencia y } \\
\text { Santa Catalina }\end{array}$ & 100,0 & 100,0 & 100,0 & 100,0 & 92,2 \\
\hline Santa Marta & 93,2 & 98,9 & 98,6 & 98,5 & 99,6 \\
\hline Santander & 97,3 & 96,3 & 99,9 & 98,1 & 99,4 \\
\hline Soacha & 100,0 & 99,5 & 100,0 & 99,5 & 99,2 \\
\hline Soledad & 100,0 & 89,6 & 100,0 & 100,0 & 100,0 \\
\hline
\end{tabular}




\begin{tabular}{|l|r|r|r|r|r|}
\hline \multicolumn{1}{|c|}{ Contraloría } & $\begin{array}{c}\text { \% } \\
\text { ejecución } \\
\mathbf{2 0 1 2}\end{array}$ & $\begin{array}{c}\text { \% } \\
\text { ejecución } \\
\mathbf{2 0 1 3}\end{array}$ & $\begin{array}{c}\text { \% } \\
\text { ejecución } \\
\mathbf{2 0 1 4}\end{array}$ & $\begin{array}{c}\text { \% } \\
\text { ejecución } \\
\mathbf{2 0 1 5}\end{array}$ & $\begin{array}{c}\text { \% } \\
\text { ejecución } \\
\mathbf{2 0 1 6}\end{array}$ \\
\hline Sucre & 100,0 & 100,0 & 100,0 & 100,0 & 100,0 \\
\hline Tolima & 99,4 & 100,0 & 100,0 & 99,7 & 100,0 \\
\hline Tunja & 100,0 & 100,0 & 100,0 & 100,0 & 100,0 \\
\hline Valle del Cauca & 96,9 & 96,9 & 98,6 & 99,2 & 99,8 \\
\hline Valledupar & 93,1 & 99,8 & 99,4 & 99,7 & 100,0 \\
\hline Vaupés & 100,0 & 100,0 & 100,0 & 100,0 & 100,0 \\
\hline Vichada & 99,6 & 100,0 & 100,0 & 99,9 & 99,9 \\
\hline Villavicencio & 99,6 & 99,5 & 100,0 & 100,0 & 100,0 \\
\hline Yumbo - Valle & 100,0 & 100,0 & 100,0 & 100,0 & 100,0 \\
\hline
\end{tabular}

Tabla No. 4. Elaboración propia. Fuente. Análisis de información reportada por las contralorías en el módulo SIA-SIREL de la AGR.

La siguiente tabla presenta los rezagos presupuestales de las contralorías del país, a los que se hizo referencia anteriormente.

Tabla No.5. Rezagos presupuestales de las contralorías territoriales vigencias 2012-2016.

\begin{tabular}{|l|r|r|r|r|r|}
\hline \multicolumn{1}{|c|}{ Contraloría } & $\begin{array}{r}\text { Rezago } \\
\mathbf{2 0 1 2}\end{array}$ & \multicolumn{1}{c|}{$\begin{array}{r}\text { Rezago } \\
\mathbf{2 0 1 3}\end{array}$} & $\begin{array}{c}\text { Rezago } \\
\mathbf{2 0 1 4}\end{array}$ & $\begin{array}{c}\text { Rezago } \\
\mathbf{2 0 1 5}\end{array}$ & $\begin{array}{c}\text { Rezago } \\
\mathbf{2 0 1 6}\end{array}$ \\
\hline Amazonas & 0,4 & 5,9 & 0,7 & 1,2 & 5,6 \\
\hline Antioquia & 11,8 & 6,5 & 8,8 & 2,0 & 8,4 \\
\hline Arauca & 1,0 & 3,5 & 0,9 & 0,9 & 1,0 \\
\hline Armenia & 7,8 & 1,0 & 2,9 & 5,3 & 0,0 \\
\hline Atlántico & 4,5 & 2,9 & 5,7 & 14,0 & 18,6 \\
\hline Barrancabermeja & 0,1 & 0,2 & 0,0 & 0,0 & 0,2 \\
\hline Barranquilla & 3,5 & 5,6 & 2,9 & 0,7 & 2,0 \\
\hline Bello & 18,9 & 7,0 & 5,4 & 6,7 & 13,6 \\
\hline Bolívar & 7,6 & 15,9 & 21,9 & 11,3 & 4,2 \\
\hline Boyacá & 3,9 & 3,4 & 3,2 & 3,6 & 1,6 \\
\hline Bucaramanga & 9,3 & 1,3 & 5,9 & 13,3 & 10,7 \\
\hline Buenaventura & 22,0 & 14,4 & 16,1 & 8,8 & 19,5 \\
\hline Caldas & 7,0 & 8,5 & 9,3 & 8,8 & 13,5 \\
\hline Cali & 11,4 & 7,3 & 6,6 & 9,6 & 11,0 \\
\hline Caquetá & 0,4 & 1,5 & 8,5 & 0,5 & 1,3 \\
\hline Cartagena de Indias & 5,0 & 5,2 & 0,2 & 2,0 & 5,4 \\
\hline Casanare & 23,4 & 21,6 & 16,5 & 12,0 & 14,9 \\
\hline
\end{tabular}




\begin{tabular}{|c|c|c|c|c|c|}
\hline Contraloría & $\begin{array}{l}\text { Rezago } \\
2012\end{array}$ & $\begin{array}{l}\text { Rezago } \\
2013\end{array}$ & $\begin{array}{l}\text { Rezago } \\
2014\end{array}$ & $\begin{array}{l}\text { Rezago } \\
2015\end{array}$ & $\begin{array}{l}\text { Rezago } \\
2016\end{array}$ \\
\hline Cauca & 12,0 & 17,5 & 28,3 & 32,2 & 40,7 \\
\hline Cúcuta & 0,1 & 0,0 & 1,9 & 3,0 & 2,8 \\
\hline Cesar & 10,6 & 6,0 & 4,3 & 9,3 & 10,7 \\
\hline Chocó & 11,8 & 4,3 & 3,5 & 0,3 & 7,1 \\
\hline Cundinamarca & 2,0 & 1,9 & 1,3 & 1,3 & 1,7 \\
\hline Dosquebradas & 4,6 & 6,8 & 5,4 & 0,0 & 0,0 \\
\hline Envigado & 7,4 & 8,0 & 3,4 & 3,5 & 1,8 \\
\hline Floridablanca & 8,5 & 14,2 & 11,2 & 9,2 & 6,3 \\
\hline General de la República & 11,2 & 11,3 & 7,6 & 25,3 & 9,4 \\
\hline Guainía & 2,5 & 2,5 & 0,8 & 0,7 & 0,4 \\
\hline Guajira & 7,7 & 13,6 & 7,8 & 16,3 & 12,4 \\
\hline Guaviare & 0,0 & 2,7 & 3,7 & 0,5 & 1,1 \\
\hline Huila & 13,0 & 6,3 & 7,3 & 3,3 & 3,4 \\
\hline Ibagué & 16,6 & 6,2 & 0,0 & 3,1 & 4,4 \\
\hline Itagüí & 5,1 & 3,6 & 3,6 & 2,8 & 7,0 \\
\hline Magdalena & 11,6 & 0,8 & 2,6 & 1,4 & 4,7 \\
\hline Manizales & 9,5 & 8,2 & 13,0 & 12,4 & 7,4 \\
\hline Medellín & 1,7 & 1,7 & 1,9 & 2,2 & 2,3 \\
\hline Meta & 2,2 & 2,5 & 4,3 & 2,6 & 1,1 \\
\hline Montería & 6,8 & 4,4 & 1,3 & 2,8 & 4,9 \\
\hline Nariño & 11,9 & 14,8 & 10,5 & 11,9 & 17,9 \\
\hline Neiva & 5,8 & 5,6 & 9,8 & 6,2 & 7,7 \\
\hline Norte de Santander & 7,9 & 10,9 & 9,4 & 13,1 & 9,7 \\
\hline Palmira & 13,1 & 7,4 & 11,6 & 5,7 & 9,2 \\
\hline Pasto & 3,2 & 2,0 & 2,2 & 2,5 & 2,3 \\
\hline Pereira & 7,6 & 3,5 & 2,9 & 0,0 & 5,3 \\
\hline Popayán & 7,3 & 7,4 & 4,0 & 7,6 & 6,0 \\
\hline Putumayo & 11,4 & 13,8 & 9,2 & 7,1 & 12,1 \\
\hline Quindío & 7,9 & 1,7 & 0,0 & 6,0 & 0,0 \\
\hline Risaralda & 9,4 & 13,6 & 12,3 & 2,9 & 6,1 \\
\hline $\begin{array}{l}\text { San Andrés, Providencia y Santa } \\
\text { Catalina }\end{array}$ & 0,8 & 0,2 & 0,0 & 1,8 & 11,7 \\
\hline Santa Marta & 14,4 & 4,5 & 1,4 & 1,9 & 6,1 \\
\hline Santander & 2,7 & 3,7 & 0,1 & 1,9 & 0,6 \\
\hline Soacha & 1,9 & 0,5 & 1,3 & 0,5 & 6,7 \\
\hline Soledad & 5,4 & 16,8 & 7,6 & 14,6 & 22,0 \\
\hline
\end{tabular}




\begin{tabular}{|c|c|c|c|c|c|}
\hline Contraloría & $\begin{array}{c}\text { Rezago } \\
2012\end{array}$ & $\begin{array}{c}\text { Rezago } \\
2013\end{array}$ & $\begin{array}{c}\text { Rezago } \\
2014\end{array}$ & $\begin{array}{c}\text { Rezago } \\
2015\end{array}$ & $\begin{array}{c}\text { Rezago } \\
2016\end{array}$ \\
\hline Sucre & 11,4 & 4,8 & 2,1 & 3,2 & 5,9 \\
\hline Tolima & 12,4 & 3,8 & 0,8 & 0,5 & 3,7 \\
\hline Tunja & 0,0 & 0,0 & 0,0 & 0,0 & 0,0 \\
\hline Valle del Cauca & 16,5 & 9,6 & 9,8 & 8,3 & 13,8 \\
\hline Valledupar & 11,7 & 0,3 & 1,0 & 0,3 & 6,0 \\
\hline Vaupés & 0,0 & 0,0 & 0,0 & 0,0 & 0,0 \\
\hline Vichada & 4,4 & 0,2 & 0,2 & 0,2 & 2,1 \\
\hline Villavicencio & 7,6 & 4,9 & 4,1 & 4,4 & 5,1 \\
\hline Yumbo - Valle & 3,7 & 4,9 & 2,2 & 5,1 & 12,9 \\
\hline
\end{tabular}

Tabla No. 5. Elaboración propia. Fuente. Análisis de información reportada por las contralorías en el módulo SIA-SIREL de la AGR.

\subsection{RENDICIÓN Y REVISIÓN DE CUENTAS}

El control fiscal es una función pública, que vigila la gestión fiscal de la administración y de los particulares o entidades que manejen fondos o bienes del Estado en todos sus órdenes y niveles (Constitución Política de Colombia, 1991, art. 267) ${ }^{17}$.

La ley determina quienes son sujetos de control fiscal según el nivel al que pertenecen. Son sujetos de control fiscal del orden nacional los órganos que integran las ramas legislativa y judicial, los órganos autónomos e independientes como los de control y electorales, los organismos que hacen parte de la estructura de la administración nacional y demás entidades nacionales, los organismos creados por la Constitución Nacional y la ley que tienen régimen especial, las sociedades de economía mixta, las empresas industriales y comerciales del Estado, los particulares que manejen fondos o bienes del Estado, las personas jurídicas y cualquier otro tipo de organización o sociedad que maneje recursos del Estado en lo relacionado con éstos y el Banco de la República. (Ley 43, 1993, art. 2), y son sujetos de control fiscal en el orden territorial los organismos que integran la estructura de la administración departamental y municipal y las entidades de este orden enumeradas en el artículo anterior. (Ley 42, 1993, art. 3).

Por mandato constitucional, dentro de las atribuciones del Contralor General de la República, están las de prescribir los métodos y la forma de rendir cuentas los responsables del manejo de fondos o bienes de la Nación; y revisar y fenecer las cuentas que deben llevar los responsables del erario (Const., 1991, art. 268); y los contralores territoriales tienen tales facultades en virtud del inciso sexto del artículo 272 del texto constitucional y los numerales $1^{\circ}$ y $2^{\circ}$ del artículo $9^{\circ}$ de la Ley 330 de 1996.

17 Texto igual al del artículo 40 de la Ley 42 de 1993 
La revisión de cuentas es un sistema de control (Ley 42, 1993, art. 9), que consiste en el estudio especializado de los documentos que soportan legal, técnica, financiera y contablemente las operaciones realizadas por los responsables del erario durante un período determinado, con miras a establecer la economía, la eficacia, la eficiencia y la equidad de sus actuaciones (Ley 42,1993 , art. 14). La ley define una cuenta como el informe acompañado de los documentos que soportan legal, técnica, financiera y contablemente las operaciones realizadas por los responsables del erario (Ley 42, 1993, art. 15). En este punto es necesario precisar que la rendición de cuentas a la que se hace referencia es la fiscal, es decir que no es la misma rendición de cuentas a la ciudadanía, figura de control social que se aborda ampliamente en un capítulo posterior de este mismo estudio.

En la medida en que la revisión de cuentas de los órganos de control fiscal exige la rendición de cuenta de sus sujetos vigilados, para efectos de concluir sobre los resultados del control fiscal objeto del capítulo se efectuó un análisis empírico de las 43.566 rendiciones de cuenta realizadas entre el $1^{\circ}$ de enero de 2012 y el 31 de diciembre de 2017 por los sujetos vigilados, según información reportada por las contralorías del país en el módulo SIA-SIREL de la Auditoría General de la República.

Gráfico No.1. Numero de sujetos de control Vs número de cuentas rendidas

por vigencia

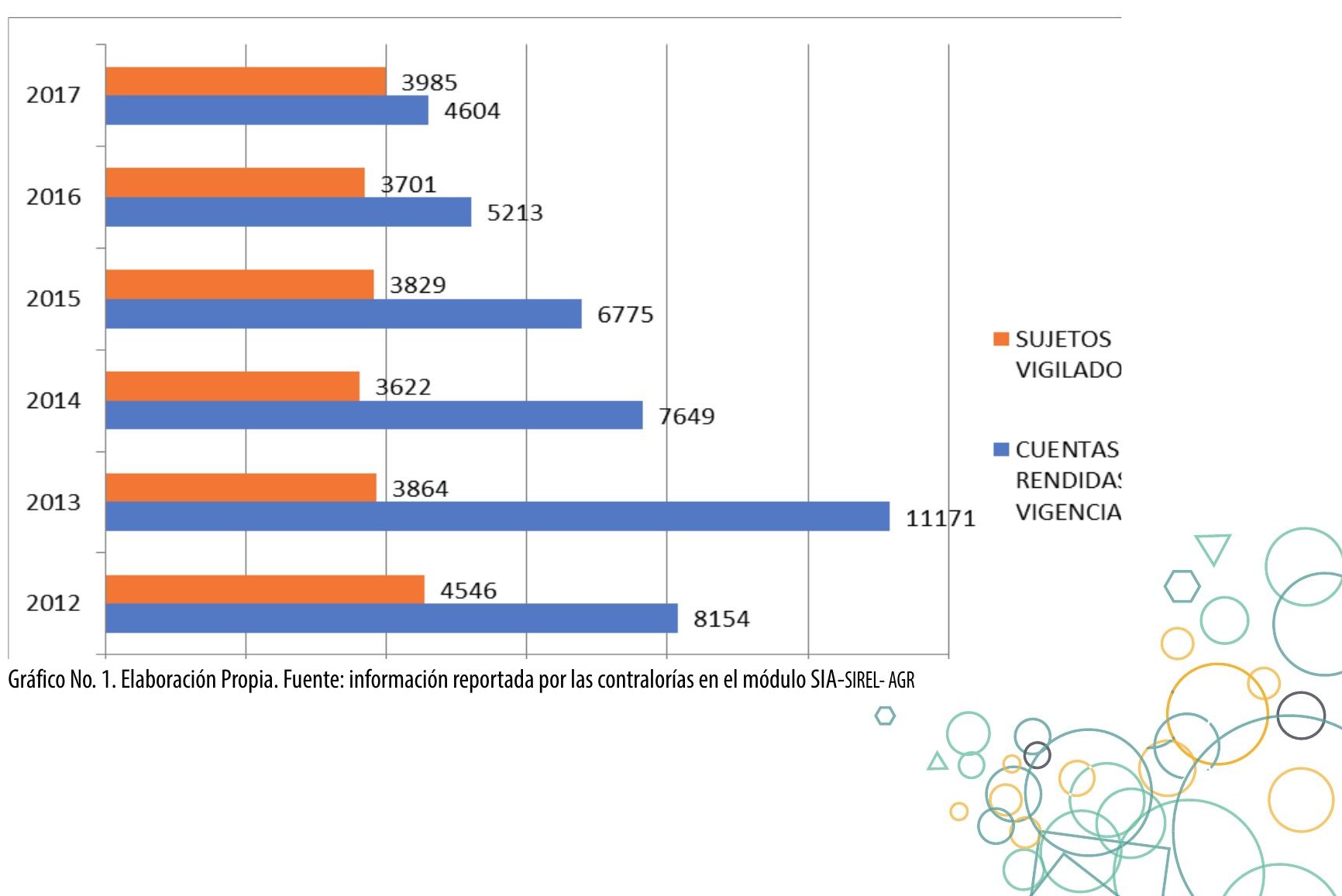




\section{OPPCF}

Como se aprecia en la gráfica anterior, el número de cuentas rendidas por vigencia es mayor que el de sujetos vigilados; que en total fue de 23.547. Se calcula que cerca el número de cuentas rendidas supera al de sujetos de control, en un 46\% durante el periodo de estudio, 2012-2017. Esa relación porcentual puede ser atribuible a varias razones, i) Los sujetos vigilados presentan durante la vigencia, complementos, ajustes o correcciones a rendiciones de cuentas de años anteriores; ii) Los sujetos vigilados presentan rendición de cuentas de años anteriores (de forma extemporánea) durante la vigencia que es posterior; iii) Las contralorías efectúan solicitudes de rendición de cuentas adicionales. Al respecto, es de tener en cuenta que, aunque cada contraloría prescribe de forma autónoma, las políticas, procedimientos métodos y periodicidad con que sus sujetos vigilados rinden su cuenta, de las cuentas rendidas en el periodo de estudio se puede concluir que, por lo general los sujetos vigilados rinden cuenta anual o semestralmente, e incluso de forma trimestral en una contraloría territorial, y bienal en otra.

No obstante, no derivarse de la información reportada por las contralorías a la Auditoria General de la República en el módulo SIA SIREL el grado de cumplimiento del deber de rendir cuentas, la tendencia del porcentaje en el que el número de cuentas rendidas supera el de sujetos vigilados entre 2012 y 2017, indica en términos generales que los sujetos de control cumplen el deber de hacerlo.

Por otro lado, el estudio especializado que efectúan las contralorías a los documentos que soportan legal, técnica, financiera y contablemente las operaciones realizadas por sus vigilados durante un período determinado -es decir de las cuentas- supone un pronunciamiento con el cual se califique la gestión fiscal por los sujetos vigilados, en condiciones de economía, eficiencia, eficacia, equidad y valoración de los costos ambientales. Es lo que se denomina pronunciamiento de la cuenta, que puede ser de fenecimiento o no fenecimiento. Si con posterioridad a la revisión de cuentas de los responsables del erario aparecieran pruebas fraudulentas o irregulares relacionadas con ellas, se levantará el fenecimiento. (Ley 42, 1993, art. 17).

Las contralorías también dictaminan sobre la ejecución presupuestal, estados financieros, y esa opinión puede ser con razonabilidad o no razonabilidad según la conformidad con la normatividad presupuestal aplicable; y con abstención, o con salvedades según el grado de incorrecciones o limitaciones al control encontradas.

\subsubsection{Cobertura y capacidad instalada de las contralorías territoriales para la revisión de las cuentas recibidas.}

Respecto de la cobertura y capacidad instalada de las contralorías territoriales para la revisión de las cuentas recibidas se observó que durante el período analizado hubo un aumento sostenido en la proporción promedio de revisión de las cuentas por parte de las contralorías a 
sus sujetos vigilados, pese a esto la media de la capacidad de las contralorías en el volumen de revisión de las cuentas, solo alcanza el 50\%.

De otro lado, los dictámenes razonables no superan el $30 \%$ de las cuentas revisadas, lo cual resulta preocupante no solo por la capacidad instalada de las contralorías, que se nota insuficiente, sino también por los resultados de los sujetos vigilados que controlan. En condiciones mejores, frente al flagelo de la corrupción, este indicador como mínimo debería superar el 50\%, sin embargo, en Colombia existe un desafío de las entidades territoriales en conseguir dictámenes razonables por parte de los entes de control que las vigilan.

Tabla No.6. Cuentas revisadas y fenecidas del total de las cuentas revisadas

\begin{tabular}{|c|r|r|r|r|r|r|}
\hline & $\mathbf{2 0 1 2}$ & \multicolumn{1}{|c|}{$\mathbf{2 0 1 3}$} & \multicolumn{1}{|c|}{$\mathbf{2 0 1 4}$} & \multicolumn{1}{|c|}{$\mathbf{2 0 1 5}$} & \multicolumn{1}{c|}{$\mathbf{2 0 1 6}$} & \multicolumn{1}{c|}{$\mathbf{2 0 1 7}$} \\
\hline \% Cuentas Revisadas & 45,6 & 43,6 & 40,4 & 43,3 & 48,1 & 50,4 \\
\hline \% Cuentas Fenecidas & 23,4 & 19,8 & 21,1 & 25,9 & 25,6 & 28,3 \\
\hline
\end{tabular}

Tabla No. 6. Elaboración propia. Fuente. Análisis de información reportada por las contralorias en el módulo SIA-SIREL de la AGR.

\section{Gráfica No.2. Cuentas fenecidas y no fenecidas del total de las cuentas revisadas}

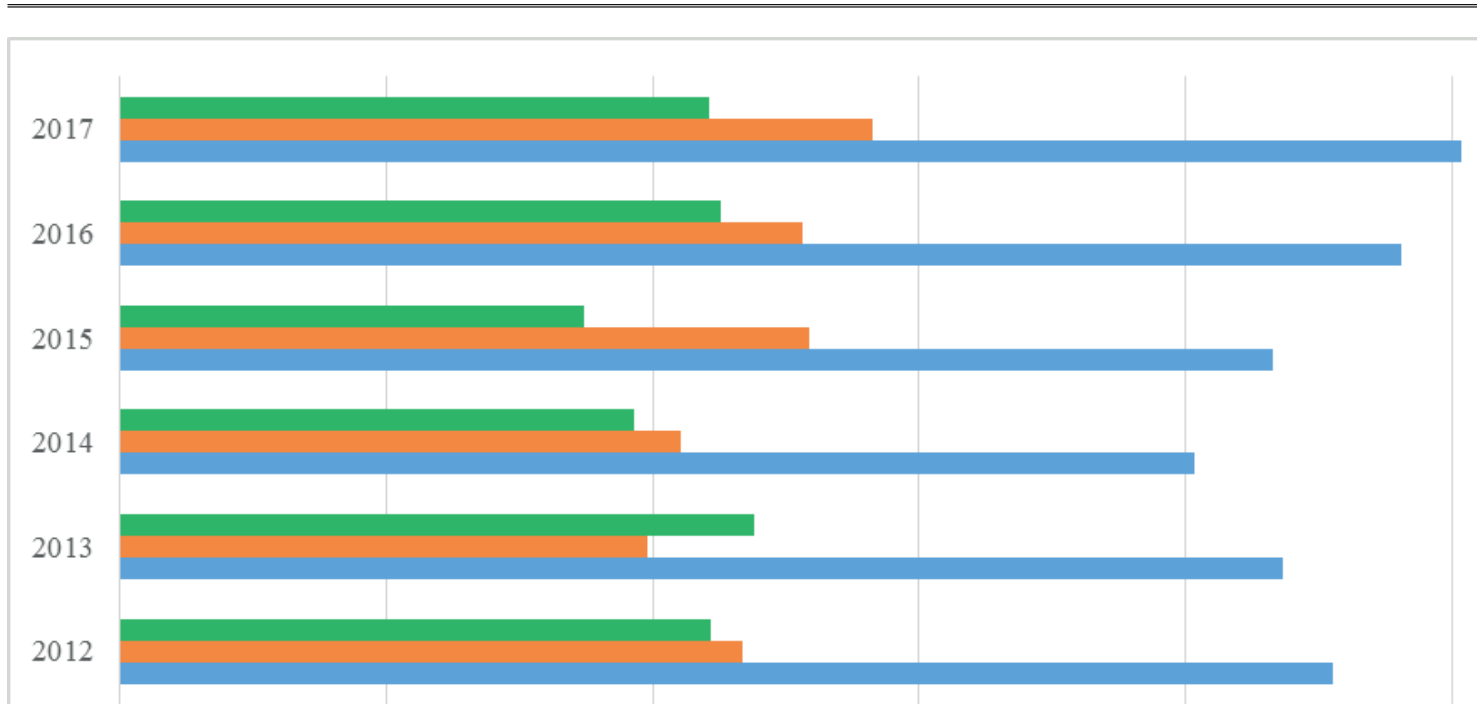

Gráfica NN.2. Elaboración propia. Fuente. Análisis de información reportada por las contralorías en el módulo SIA-SIREL de la AGR.

\subsubsection{Traslados a proceso sancionatorio, relacionados con rendición de cuenta.}

Como consecuencia del control fiscal que efectúan las contralorías se pueden generar hallazgos relacionadas con el deber de los sujetos vigilados de rendir cuentas como por ejemplo no comparecer a las citaciones; no rendir las cuentas o informes exigidos, o no lo hacerlo en la forma y oportunidad establecidas; incurrir reiteradamente en errores u omitir

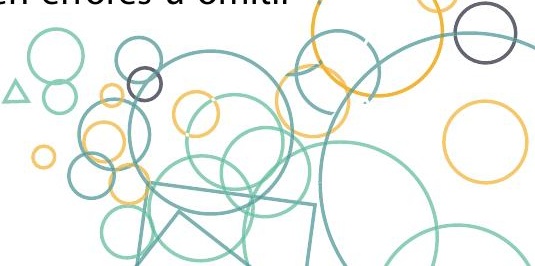


la presentación de cuentas e informes; que se les determinen glosas de forma en la revisión de sus cuentas; o de cualquier manera entorpezcan o impidan el cabal, cumplimiento de las funciones asignadas a las contralorías o no les suministren oportunamente las informaciones solicitadas (Ley 42, 1993, art. 101).

Del total de hallazgos administrativos identificados entre el $1^{\circ}$ de enero de 2012 y el 31 de diciembre de 2017, se reconocieron 19.358 procesos con incidencia sancionatoria. La mayoría de los hallazgos de esta naturaleza se encuentra relacionados con, i) la ausencia de rendición de cuenta en el periodo exigido por la contraloría correspondiente (rendición extemporánea) o la rendición de forma parcial; ii) la remisión incompleta o ausencia de remisión de la información solicitada por el equipo auditor; iii) el incumplimiento de las actividades dispuestas en los planes de mejoramiento de vigencias anteriores; iv) el incumplimiento de las responsabilidades legales y operativas en el desarrollo de la función pública.

Por ejemplo, durante la vigencia 2017 se identificaron 3.265 procesos con incidencia sancionatoria (fecha del auto de apertura del proceso) relacionados con cuentas, de los cuales, 987 se relacionaron con incumplimientos a la normatividad legal existente para el proceso de rendición o de entrega de información, 761 aluden al incumplimiento de puesta en marcha de los planes de mejoramiento de vigencias anteriores 689 se relacionaron con presentación extemporánea de cuentas o de información solicitada (se rindieron cuentas de vigencias anteriores), 269 por remisión incompleta de informes o información de cuenta, así:

\section{Gráfico No.3. Hallazgos sancionatorios relacionados con el deber de rendir cuenta a los órganos de control fiscal}

\section{Causas de hallazgos sancionatorios}

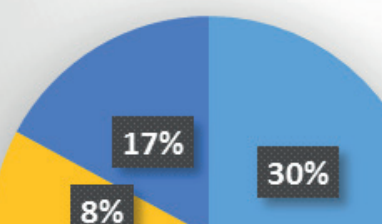

$8 \%$

$21 \%$
$24 \%$
- Incumplimiento

- No cumplimiento planes de mejoramiento

n Extemporáneo

Incompletitud

- Otros motivos

Gráfico No. 3. Elaboración propia. Fuente. Análisis de información reportada por las contralorías en el módulo SIA-SIREL de la AGR. 
En contraste con la totalidad de hallazgos administrativos, aquellos con incidencia sancionatoria representan el 6,9\%. No obstante, es importante resaltar que presentar cuentas de forma incompleta, extemporánea o no presentarlas, implica una afectación al proceso de vigilancia fiscal adelantado por las contralorías. Si bien pueden a primera vista pueden parecer aspectos meramente formales, hay debilidades de esa naturaleza que impiden u obstaculizan a los órganos de control hacer su trabajo, e incluso podrían eventualmente ser indicio de detrimento al erario, o de situaciones con presunta incidencia penal o disciplinaria.

Lo cierto es que la importancia del proceso auditor en la revisión de cuentas presentadas por los sujetos auditados es tal que, dentro del periodo examinado, se identificó una reducción de hallazgos administrativos, pasando de 59.565 en 2012 a 41.047 en 2017 y de hallazgos con incidencia sancionatoria pasando de 4.150 en 2012 a 3.265 en 2017. Esta disminución en el número de hallazgos obedece, en gran parte, a los planes de mejoramiento que se fijan una vez culminan los procesos de auditoría y a las recomendaciones que efectúa el grupo auditor durante la misma.

Por tanto, la revisión periódica de las rendiciones de cuenta de los sujetos vigilados permite que se intervenga positivamente en el ambiente institucional, logrando ajuste de los procedimientos mal efectuados, corrección de las actuaciones, mejora en las actividades propias de los sujetos vigilados y como consecuencia de ello, homogeneidad en la consolidación y presentación de la información legal, técnica, financiera y contable.

\subsection{PLANEACIÓN Y EJECUCIÓN DE AUDITORÍAS.}

\subsubsection{Lo planeado versus lo ejecutado.}

Siguiendo la cadena de valor del proceso auditor, la planeación de auditorías que hacen las contralorías del país reposa en el plan de auditorías, entendido como la programación anual de las auditorías que cada contraloría planea adelantar a la gestión de sus sujetos vigilados. El plan de auditorías lo elabora cada contraloría teniendo en consideración factores como la cantidad de sujetos vigilados a cargo, no es lo mismo un plan de auditorías para la Contraloría Departamental de Antioquia que para la Contraloría de Departamental del Vichada, o para la Contraloría General de la República que para la Contraloría Municipal de Itagüí; la cantidad de presupuesto asignado para el desarrollo de las actividades de vigilancia fiscal; la capacidad instalada en materia de recurso humano para hacer auditoría; el análisis de impacto y frecuencia de los riesgos que efectúe previamente la contraloría a sus vigilados; los informes de auditoría anteriores, las denuncias o quejas provenientes de la participación ciudadana, entre otros. 


\section{OPPCF}

Para el efecto de concluir en términos de cumplimiento de lo planeado, el análisis de la información reportada por las 66 contralorías durante el periodo en estudio (vigencias 20122017) permitió concluir lo siguiente.

\section{Gráfico No. 4. Número de auditorías programadas Vs número de auditorías ejecutadas por año vigencias 2012-2017.}

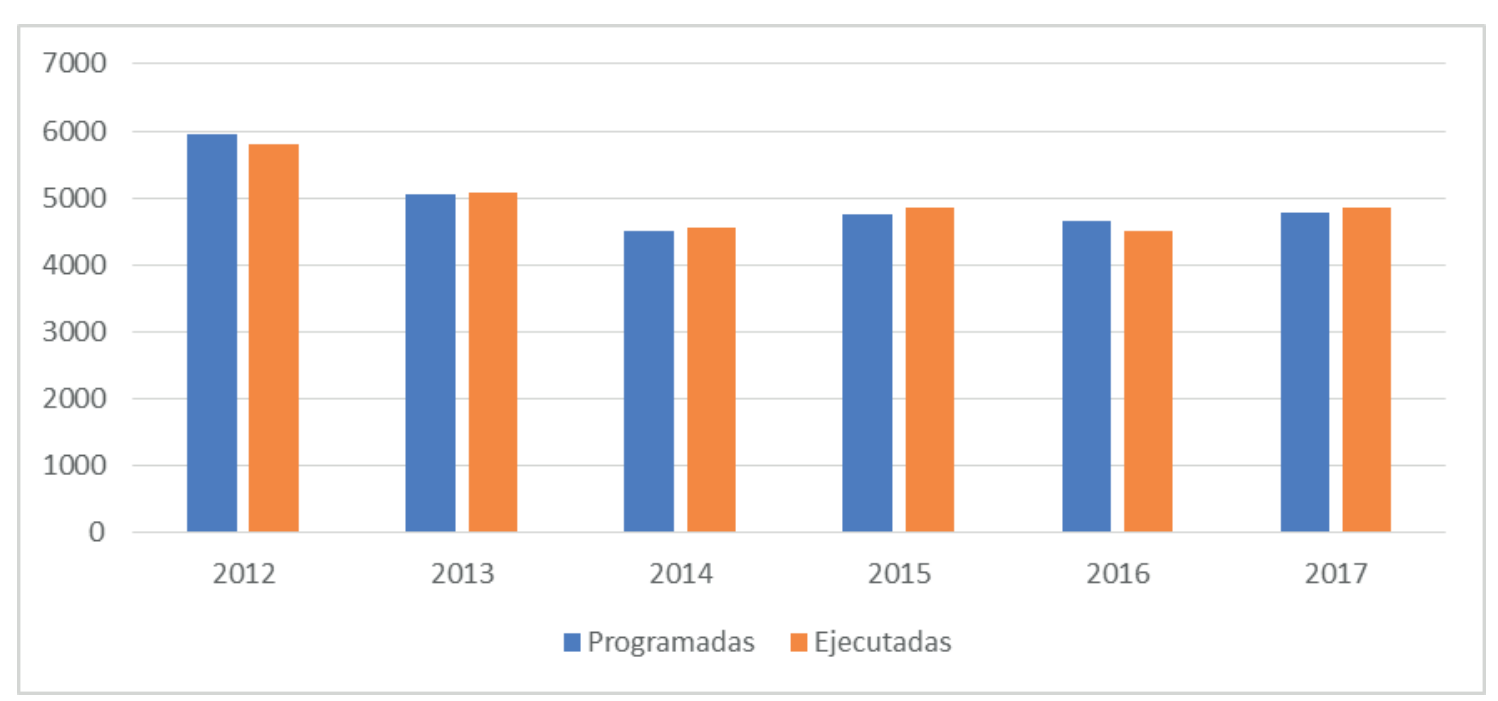

Gráfico No. 4. Elaboración propia. Fuente. Análisis de información reportada por las contralorías en el módulo SIA-SIREL de la AGR.

En términos generales, durante el periodo examinado, existe una relación directamente proporcional entre las auditorías que se programaron y las auditorías que se ejecutaron, por lo que podría inferirse que las contralorías cumplen con sus cronogramas de trabajo en lo relacionado con la vigilancia de la gestión fiscal; incluso, existen vigencias en las que el número de auditorías ejecutadas excede al número de auditorías programadas tal y como ocurre en los años 2013, 2014, 2015 y 2017.

Se evidencia una disminución en relación con el total de auditorías programadas y ejecutadas desde el 2012 al 2017. Ello puede ocurrir porque, por ejemplo, en el año 2012 existían 4546 sujetos vigilados mientras que en 2017 existían 3985, lo que significa que se redujo el número de sujetos vigilados en un $12.3 \%$ para el último año de análisis.

La reducción del número de sujetos vigilados corresponde a su vez, a que las contralorías han identificado mejor la diferencia entre estos y los puntos de control, adjudicando la categoría de punto a entidades que antes se inventariaban como sujetos. Esto ocurrió, por ejemplo, con las instituciones educativas. Algunas contralorías del país, dentro de su autonomía, dejaron de 
considerarlas sujetos, y pasaron a contarlas como puntos de control, variando así el número de sujetos vigilados.

Para el periodo 2012 se ejecutaron 5.803 auditorías. Las contralorías que evidencian mayores ejercicios de auditoría fueron, Antioquia con 859, General de la República con 739, Cundinamarca con 241 y Santander con 221. Por su parte, las Contralorías con menores registros de ejercicios de auditoría fueron Amazonas con 3, Guainía con 4, Soacha con 6 y Cúcuta con 7.

En la medida en que el cumplimiento de lo planeado también depende de la asignación presupuestal, desde esa óptica se analizó la información rendida y se encontró que las contralorías con mayores recursos asignados (54\% del total asignado al control fiscal territorial y que vigilan el $55 \%$ de los recursos), son aquellas que presentan la mayor cantidad de auditorías ejecutadas, en tanto que las de menor presupuesto ( $7 \%$ del total asignado que vigilan el $2 \%$ de los recursos a nivel nacional) son las de menores auditorías ejecutadas.

Llama la atención, que en el periodo analizado se presentan variaciones considerables en algunas contralorías. Variaciones por encima en el número de auditorías regulares ejecutadas por vigencia. Por ejemplo, la contraloría Distrital de Buenaventura, durante los años 2014 y 2015 se ejecutaron 129 y 147 auditorías respectivamente, pasando de ejecutar 11 (habiendo programado 11) en 2012 y a ejecutar 11 (habiendo programado 14) en 2017. Lo mismo ocurre con las Contralorías Departamentales de Guainía, y Guaviare en 2015 y Magdalena, Quindío y Risaralda en 2017.

También se presentan variaciones por debajo en el número de auditorías regulares ejecutadas por vigencia. Así se evidencia por ejemplo en la Contraloría Departamental de Caldas, en la que para el año 2012 se ejecutaron 113 auditorías (habiendo programado 113) mientras que en 2014 y 2015 se ejecutaron 48 y 41 auditorías, respectivamente, y en el año 2017 se ejecutaron 140 (habiendo programado 140). Igual situación se presenta con las Contralorías Departamentales del César y el Chocó entre el 2014 y el 2015, y la Contraloría Municipal de Popayán en las vigencias 2013 y 2014.

Por su parte, algunas Contralorías evidencian saltos de menos a más auditorías ejecutadas en periodos corto de tiempo (entre una o 2 vigencias). Es el caso de la Contraloría Departamental de Cundinamarca entre el 2014 y el 2016, pasando de 0 auditorías ejecutadas en el 2014 a 518 en el 2016. Lo mismo ocurre con la Contraloría Departamental de Huila y Municipal de Itagüí en las vigencias 2015 y 2016 y la Contraloría Departamental del Cauca entre 2014 y 2016. Contrario sensu, algunas contralorías evidencian saltos de más a menos auditorías en periodos

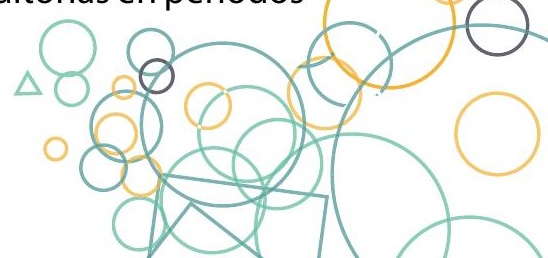


cortos de tiempo. Así lo evidencian los reportes del sistema para la Contraloría del Municipio de Floridablanca que pasó de ejecutar 483 auditorías en 2015 a ejecutar 11 en 2016.

El cotejo entre el primer año de análisis (2012) y el último (2017) nos permite identificar que, se ha presentado una disminución en la ejecución de auditorías por parte de algunas contralorías territoriales tales como, Santander, Medellín, Manizales, Magdalena y Antioquia; así mismo, un aumento en la ejecución de auditorías por parte de las contralorías ubicadas en los Departamentos de Boyacá, Cundinamarca y Valle del Cauca.

Esto podría ocurrir por la existencia de traslados misionales de unos a otros territorios dada la necesidad de contar con personal suficiente para el cabal cumplimiento de los planes de auditoría.

Las contralorías de Girón y Sincelejo no muestran datos ni de programación ni de ejecución de auditorías durante los años analizados porque fueron recientemente creadas; Bogotá no presenta información para los años 2016 y 2017. La Contraloría con mayor ejecución de auditorías corresponde a la del Departamento de Antioquia con un total de 7.040 en el periodo objeto de estudio. Un comparativo de las vigencias de estudio (2012-2017) en los extremos de auditorías programadas y ejecutadas es:

\section{Gráfico No. 5. Auditorias programadas y ejecutadas por contraloría a nivel} nacional 2012

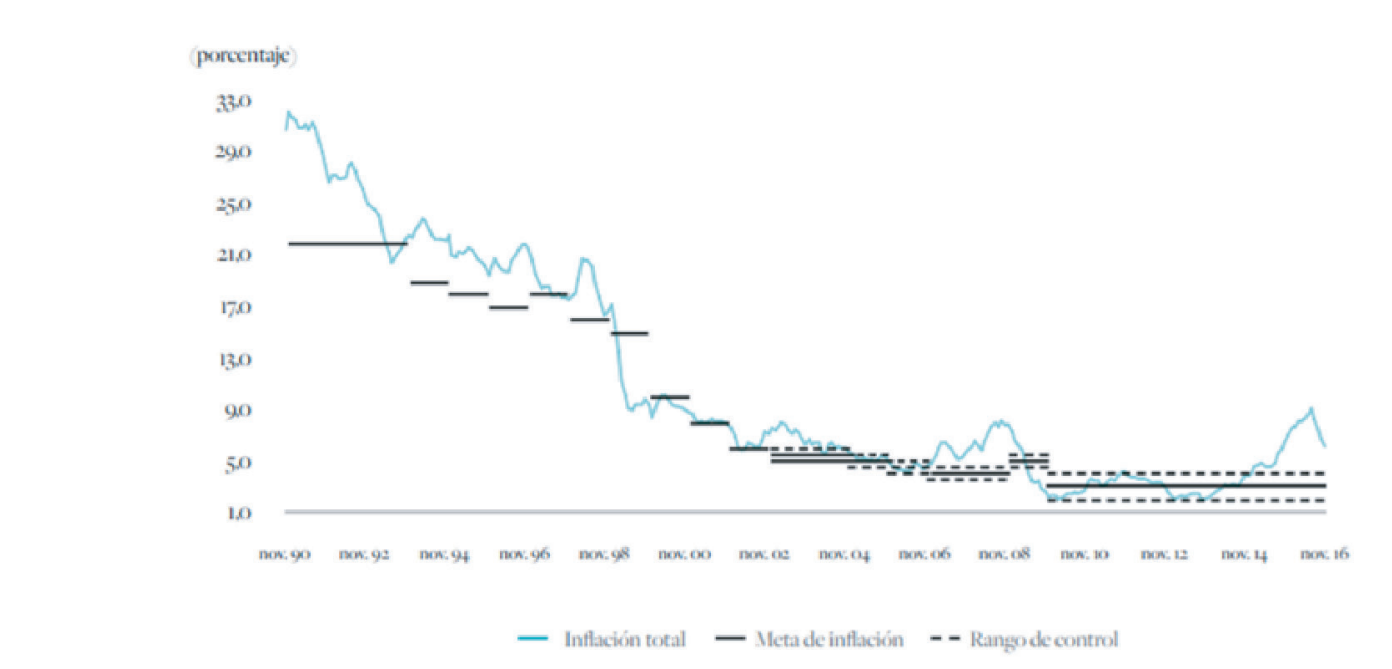

Gráfica No. 5. Elaboración propia. Fuente. Análisis de información reportada por las contralorías en el módulo SIA-SIREL de la AGR. 
Gráfico No. 6. Auditorias programadas y ejecutadas por contraloría a nivel nacional 2017

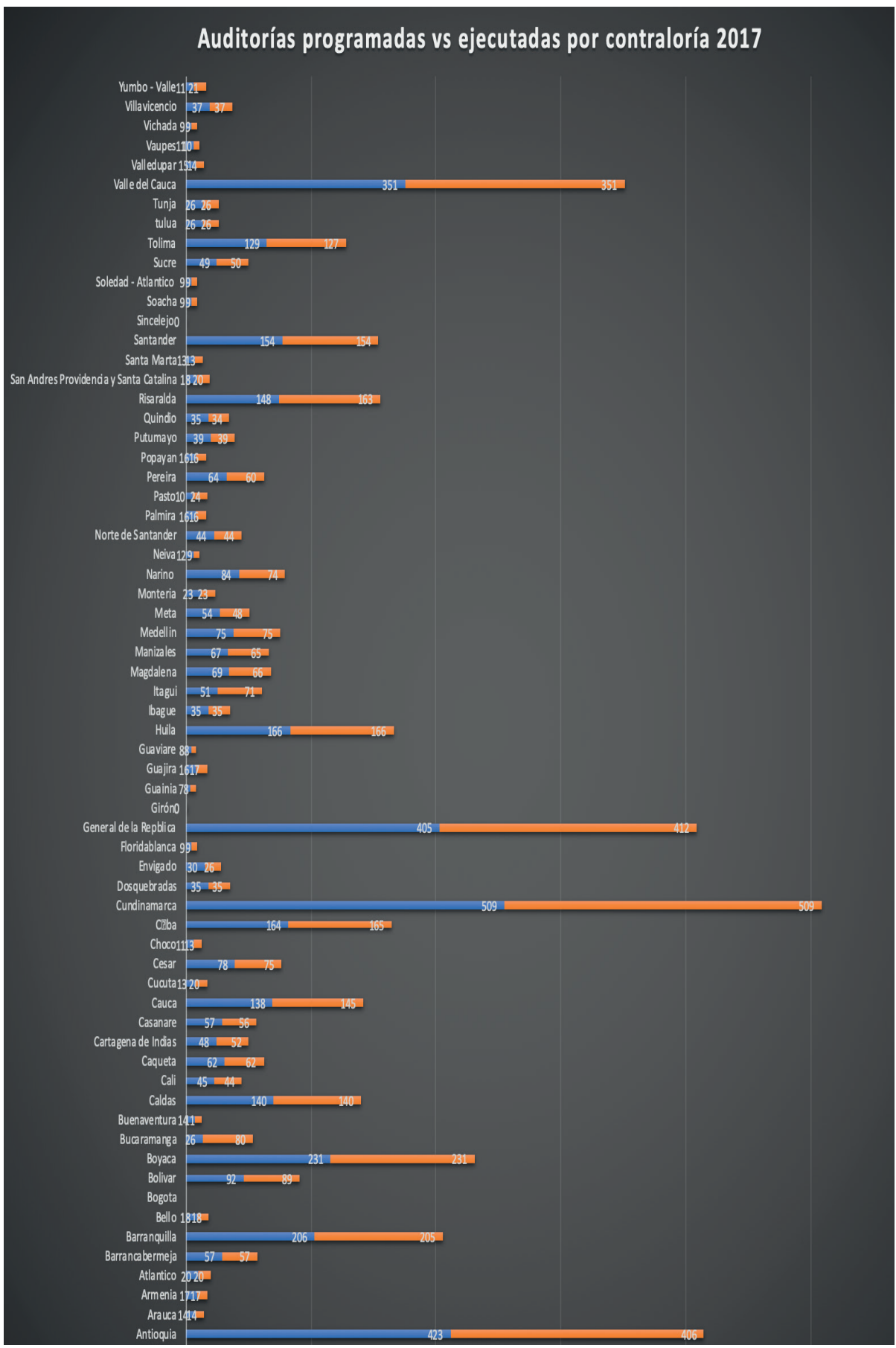

Gráfica No. 6. Fuente. Análisis de información reportada por las contralorías en el módulo SIA-SIREL de la AGR. Elaboración propia.
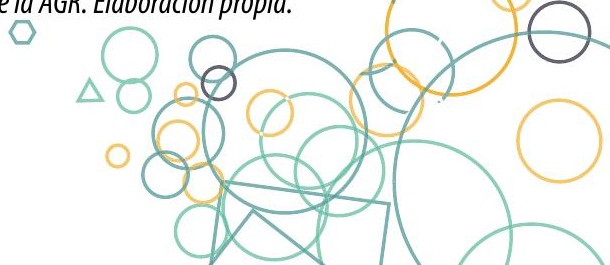


\subsubsection{Cobertura de los recursos auditados en desarrollo del criterio de selectividad}

En relación con el marco legal señalado por el artículo $9^{\circ}$ de la ley 42 de 1993, específicamente en la aplicación de los sistemas de control para el ejercicio del control fiscal, se esbozan algunos elementos de análisis sobre las herramientas disponibles en el ejercicio de la vigilancia de la gestión fiscal por parte la Contraloría General de la República y de las Contralorías Territoriales en Colombia.

En este sentido, si bien cualquiera de los sistemas de control referidos, puede dar cuenta de lo logrado por los sujetos de control fiscal, el análisis centrará la atención en gestión y de resultados.

Al respecto, es importante tener en cuenta tener en cuenta los conceptos desarrollados en el artículo 5 de la misma ley, que en alusión al artículo 267 Constitucional, estableció por control selectivo "la elección mediante un procedimiento técnico de una muestra representativa de recursos, cuentas, operaciones o actividades para obtener conclusiones sobre el universo respectivo en el desarrollo del control fiscal."

Dado que este criterio de selectividad se aplica al gestor fiscal para un período determinado sobre la administración y manejo de recursos públicos, los resultados de que trata este capítulo, y desde la planeación y ejecución del proceso auditor, intentaremos cualificar la cobertura de los recursos auditados frente a los recursos objeto de vigilancia en la Contraloría General de la República y las contralorías territoriales.

Este elemento objeto de análisis propone un tema de reflexión frente a la problemática del control fiscal micro en Colombia: ¿La cobertura de los recursos auditados en desarrollo del criterio de selectividad, incide en los resultados del control fiscal?

Para abordar este elemento de estudio, se tomaron dos casos objeto de análisis: uno para realizar un examen a los recursos auditados por la Contraloría General de la República (CGR) sobre el sistema general de regalías, período 2012-2017; y otro sobre la evaluación de los recursos auditados por las contralorías territoriales.

Para el primer caso la fuente de información fue el informe final de la auditoría regular realizada por la Dirección de Control Fiscal de la Auditoría General de la República, a la gestión adelantada por la Contraloría General de la República en la vigencia 2017.

Para el segundo, se tomó la información de la rendición de cuenta presentada por las contralorías territoriales en el período 2012-2017 en el módulo de rendición de cuenta SIASIREL de la Auditoría General de la República. De allí, se tomaron como datos de evaluación 
los formatos F20, sección 1: sujetos de control y presupuestos de gastos; y F21: sección 8: sujetos de control y presupuestos auditados. Del primer formato se tomó la información de los presupuestos de gastos de las entidades sujetas de control de las contralorías territoriales; y del segundo, la de los presupuestos auditados por parte de las contralorías territoriales respecto de sus sujetos de control.

\subsubsection{Estudio de caso: Porcentaje de recursos auditados por la Contraloría General de la República al Sistema General de Regalías.}

El primer caso el análisis se orientará a partir del diseño de un indicador de eficacia, centrado en el porcentaje de recursos auditados por la Contraloría General de la República al Sistema General de Regalías. De la normativa relacionada para esta fuente de recursos, señalada principalmente por el artículo 267 de la Constitución Política, los artículos 1, 2 y 4 de la ley 42 de 1993 sobre la competencia de la vigilancia; y la ley 1530 de 2012 sobre la regulación, organización y funcionamiento del sistema de regalías, se identifica el siguiente escenario.

La relación de los recursos auditados y el examen realizado se resume, según el informe de auditoría referido, de la siguiente manera:

Recursos auditados vigencia 2011 y anteriores (antiguo sistema, inflexibilidades, FONPET).

Recursos auditados vigencia 2012 (SGR).

Recursos auditados bienio 2013-2014 (SGR).

Recursos auditados bienio 2015-2016 (SGR)

Recursos auditados bienio 2017-2018 (SGR)

Se desprende del mismo informe, que se identificó un universo de recursos asignados por valor de $\$ 27.203 .307 .908$ de los cuales se auditó el 73,8\% por valor de $\$ 20.075 .586 .865 .584$. De este valor el $71 \%$ corresponde a una auditoría financiera; el 2,7\% a auditorias por asunto (procedimiento especializado para el SGR) y de cumplimiento, las cuales se orientaron a la evaluación de resultados de proyectos y contratos suscritos y ejecutados por las entidades territoriales. Respecto de la cobertura en sujetos de control el informe expresa que dicha cobertura en cabeza de la Contraloría Delegada Intersectorial para el Sistema General de Regalías, se auditaron 147 entidades territoriales de un total de 1.154 (32 departamentos y 1.122 municipios incluido el Distrito Capital), lo cual equivalente al $12.74 \%$.

En el siguiente cuadro se pueden observar los datos de cobertura para este sector. 
Tabla No. 7. Cobertura de auditoría sobre presupuesto entidades, año 2017

\begin{tabular}{|l|r|r|}
\hline \multicolumn{1}{|c|}{ Tipo de Auditoria } & Valor auditado(\$) & Porcentaje de cobertura \\
\hline Financiera & 19.349 .276 .079 .489 & $71,1 \%$ \\
\hline Por asunto & 649.124 .899 .897 & $2,4 \%$ \\
\hline Cumplimiento & 77.185 .886 .198 & $0,3 \%$ \\
\hline Desempeño & 0 & $0,0 \%$ \\
\hline Valor no auditado & 7.127 .721 .042 .429 & $26,2 \%$ \\
\hline Total, auditado Tabla No. 7. Elaboración Propia. Fuente: Papeles de trabajo Proceso Auditor CGR 2017.18 & $100 \%$ \\
\hline \multicolumn{2}{|c|}{}
\end{tabular}

De la información estadística citada, y frente a los elementos determinantes que sirven de soporte para evaluar el grado de representatividad de los resultados obtenidos por el control fiscal aplicado al Sistema General de Regalías, es necesario considerar entre otros escenarios los siguientes:

\section{- Las expectativas de la ciudadanía e interés de la población objetivo.}

En atención a lo consagrado en los artículos 23 y 58 de la ley 1530 de 2012 y sus modificaciones, en especial del decreto 1077 de 2012, la participación ciudadana y control social, de un lado, y las características de los proyectos de inversión, de otro, representa una condición garantista del Estado y sus Entidades frente a las necesidades de tipo social, económico o ambiental de la población. Sobre este aspecto, y aunque la auditoría ejecutada por la Auditoria General de la República no da cuenta en su evaluación del control aplicado por la Contraloría General a los procedimientos participativos de elaboración y presentación de los proyectos elegibles al sistema general de regalías, es claro que el instrumento de ejecución del sistema son los proyectos de inversión y de la ejecución de los recursos la celebración de contratos o convenios $^{19}$.

\section{- La competencia de vigilancia y control fiscal del sistema general de regalías.}

Desde el artículo 267 de la Constitución Política, la ley 42 de 1993, y el artículo 152 de la ley 1530 de 2012, es clara la competencia de la Contraloría General de la República para ejercer la vigilancia a la gestión de los recursos del sistema general de regalías. Uno de los temas que llama la atención en relación con esta competencia de vigilancia fiscal, frente a los resultados del control fiscal aplicado, reside en la asignación de recursos a la Contraloría General de la República por ésta última norma, la ley 150 de 2012, para financiar la labor de vigilancia fiscal a los recursos del sistema general de regalías, hecho que motivaría varios interrogantes: ¿Cuáles 18 Informe final, auditoría regular a la Contraloría General de la República - CGR, vigencia fiscal 2017. Dirección de Control Fiscal, PGA 2018, pág. 67, núm. 2.5.2.2.

19 Artículo 93 de la ley 1530 de 2012, Ejecución Presupuestal. 
eran los resultados de esta vigilancia de control antes de la entrada en vigencia de la ley? y ¿qué valor agregado se generó comparativamente desde el 2013 en los controles aplicados al sistema general de regalías con los nuevos recursos asignados a la Contraloría General? Aunque estos temas no son objeto de estudio en este documento sí podrían asociarse en otros análisis para evaluar los resultados del control fiscal.

\section{- Control de gestión y control de resultados.}

En atención a los preceptos definidos en el artículos 12 y 13 de la ley 42 de 1993, estos dos sistemas de control tienen una relación directa con la evaluación del impacto del control aplicado a un sujeto de control o, de la evaluación a la gestión desarrollada en la ejecución o manejo de un recurso público. Así:

Artículo 12. El control de gestión es el examen de la eficiencia y eficacia de las entidades en la administración de los recursos públicos, determinada mediante la evaluación de sus procesos administrativos, la utilización de indicadores de rentabilidad pública y desempeño y la identificación de la distribución del excedente que éstas producen, así como de los beneficiarios de su actividad.

Artículo 13. El control de resultados es el examen que se realiza para establecer en qué medida los sujetos de la vigilancia logran sus objetivos y cumplen los planes, programas y proyectos adoptados por la administración, en un período determinado.

Se desprende de lo anterior, que el resultado alcanzado por la Contraloría General de la República en el control fiscal aplicado a los recursos del sistema general de regalías en el período 2012-2017 es bajo, resultado señalado de esta forma en el informe de auditoría comunicado por la Dirección de Control Fiscal de la Auditoria General de la República, el cual cita que tal calificación se soporta en la orientación y propósitos de las nuevas guías de auditoría, en particular la de cumplimiento.

Esta cobertura o resultado de control, considerando las necesidades de la población en materia de salud, educación, agua potable, medio ambiente, entre otros, de 1.122 sujetos vigilados no es la más representativa. El $2.7 \%$ de vigilancia logrado con las auditorías ejecutadas por asunto y de cumplimiento, que en recursos representa $\$ 726$ mil millones de 27.2 billones, muestra un impacto bajo frente al volumen de los recursos objeto de vigilancia y frente a las expectativas de la población que técnicamente podrían compararse con el indicador de NBI.

Dado este resultado de control, se puede inferir que la selectividad o muestra planeada en cualquier proceso auditor, tratándose de variables cuantitativas, es determinante para impactar positivamente el objeto a auditar; y para el caso del control fiscal está claramente definida la correlación tanto conceptual como normativa, entre la técnica del muestreo y la evaluación de los recursos a través de los procedimientos y/o modalidades de contratación

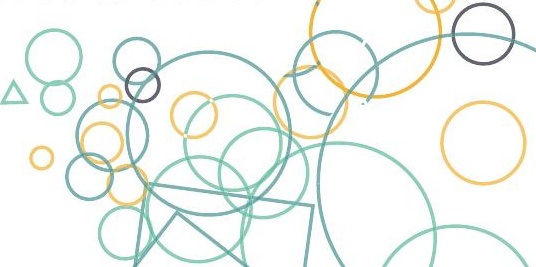


pública. Es decir, que no obstante la integralidad o especificidad de los procesos auditores, en los que se pueden evaluar procesos estratégicos, de apoyo o misionales, es en la contratación donde se materializa buena parte de la gestión fiscal. Este resultado de análisis se realiza en consideración al numeral 3.1.7 - Muestreo, de la "Guía de auditoria de cumplimiento de la Contraloría General de la República, marco de las normas de auditoria de las entidades fiscalizadoras ISSAI".

\subsubsection{Porcentaje de recursos auditados por las contralorías territoriales.}

Para el segundo caso de análisis, el de la evaluación de los recursos auditados por las contralorías territoriales, se tomó como indicador de referencia el porcentaje de recursos auditados por las contralorías territoriales a fin de identificar la medición de la cobertura de la vigilancia fiscal en términos de recursos públicos.

Como ya se enunció anteriormente, la información consultada corresponde a los datos de los formatos F20 y F21 del sistema de rendición electrónico de cuentas SIREL de la Auditoría General de la República, presentados por las contralorías territoriales en el período 2012-2017.

Para el análisis se tomaron tres tablas, la primera de comparación entre los presupuestos de gastos objeto de vigilancia y los presupuestos auditados; la segunda sobre la calidad de la información reportada; y la tercera sobre la comparación entre los presupuestos de gastos objeto de vigilancia y los presupuestos auditados con datos depurados.

De la primera tabla, de los presupuestos de gastos objeto de vigilancia y los presupuestos auditados, y por tratarse de a un indicador de eficacia, se procedió a la comparación entre los datos del presupuesto de gastos como universo o dato de referencia y el presupuesto auditado como dato de comparación. La tabla citada muestra la siguiente información:

Tabla No. 8. Porcentaje de recursos auditados por las contralorías territoriales

\begin{tabular}{|r|r|r|r|}
\hline Año & Presupuesto gastos (\$) & Presupuesto auditado (\$) & \multicolumn{1}{|c|}{ Porcentaje auditado } \\
\hline $\mathbf{2 0 1 2}$ & $109.634 .624 .689 .891,00$ & $54.103 .425 .017 .232,20$ & $49,35 \%$ \\
\hline $\mathbf{2 0 1 3}$ & $137.067 .509 .597 .717,00$ & $76.989 .491 .268 .926,30$ & $56,17 \%$ \\
\hline $\mathbf{2 0 1 4}$ & $107.283 .487 .061 .168,00$ & $94.966 .184 .255 .001,10$ & $88,52 \%$ \\
\hline $\mathbf{2 0 1 5}$ & $115.501 .571 .433 .991,00$ & $169.890 .292 .943 .780,00$ & $147,09 \%$ \\
\hline $\mathbf{2 0 1 6}$ & $137.225 .447 .503 .513,00$ & $163.283 .920 .561 .499,00$ & $118,99 \%$ \\
\hline $\mathbf{2 0 1 7}$ & $141.956 .176 .295 .575,00$ & $113.480 .833 .415 .813,00$ & $79,94 \%$ \\
\hline \multicolumn{2}{|c|}{ Tabla No. 8. Elaboración propia. Fuente. Análisis de información reportada porlas contralorías en el módulo SIA-SIREL dela AGR. } \\
\hline
\end{tabular}

Para cada vigencia se registra la información consolidada de todas las contralorías territoriales, 
entre departamentales, distritales y municipales. En las vigencias 2015 y 2016 se presenta una inconsistencia representada por una mayor cantidad de recursos auditados frente a los recursos objeto de vigilancia, caso en el cual, el escenario de mayor cobertura alcanzaría máximo el $100 \%$. Esta situación exige una revisión de las características de calidad de la información reportada, hecho que se desarrolla en la siguiente tabla.

\section{Datos validados, rendición de cuentas.}

Frente a la condición de la cuenta rendida, los casos representados por valores de presupuestos auditados superiores al valor de los presupuestos de gastos se consideran solamente para los propósitos de este estudio como datos inválidos. Tal situación obedece a un presunto error de rendición de la cuenta, bien sea por la falta de actualización de la información o por error al momento de realizar el registro de datos. Los casos corresponden a la cuenta rendida por 62 contralorías para el período 2012-2016, y de 63 contralorías para el año de 2017, con una afectación promedio del 30\%. De manera específica se presentaron 12 en el 2012; 12 en el 2013; 13 en el 2014; 17 en el 2015; 21 en el 2016 y 21 en el 2017. La afectación general se puede apreciar en la siguiente tabla:

Tabla No. 9. Datos validos tomados de le rendición de la cuenta.

\begin{tabular}{|c|c|c|}
\hline Año & \% de datos válidos & \% de datos no válidos \\
\hline $\mathbf{2 0 1 2}$ & $69,23 \%$ & $30,77 \%$ \\
\hline $\mathbf{2 0 1 3}$ & $74,47 \%$ & $25,53 \%$ \\
\hline $\mathbf{2 0 1 4}$ & $76,36 \%$ & $23,64 \%$ \\
\hline $\mathbf{2 0 1 5}$ & $69,09 \%$ & $30,91 \%$ \\
\hline $\mathbf{2 0 1 6}$ & $66,13 \%$ & $33,87 \%$ \\
\hline $\mathbf{2 0 1 7}$ & $64,41 \%$ & $35,59 \%$ \\
\hline Tabla No. 9. Elaboración propia. Fuente. Análisis de información reportada por las contralorias en el módulo SIA-SIREL de la AGR. \\
\hline
\end{tabular}

Porcentaje de recursos auditados, contralorías territoriales con datos validados. Tomando como información de análisis los datos de las cuentas rendidas de manera razonable, decir aquellas cuentas con datos de presupuestos auditados iguales o inferiores a los presupuestos de gastos, el porcentaje de contralorías ubicadas en los rangos de vigilancia desde 0 a $10 \%$, y desde 70.1 a $100 \%$ se pueden apreciar en la siguiente tabla. 
Tabla No. 10. Rango porcentual de recursos auditados / porcentaje de contralorías por cada rango.

\begin{tabular}{|c|c|c|c|c|c|c|c|c|c|c|}
\hline Año & \multicolumn{2}{|c|}{$\begin{array}{c}0-10 \% \\
(*)\end{array}$} & $\begin{array}{c}10,1- \\
20 \%\left(^{*}\right)\end{array}$ & $\begin{array}{c}20,1- \\
30 \%\left(^{*}\right)\end{array}$ & $\begin{array}{c}30,1- \\
50 \%(*)\end{array}$ & $\begin{array}{c}50,1- \\
70 \%\left(^{*}\right)\end{array}$ & $\begin{array}{c}70,1- \\
100 \%\left(^{*}\right)\end{array}$ & $\begin{array}{c}\text { Total } \\
\text { auditado }\end{array}$ & $\begin{array}{c}\text { Sin } \\
\text { datos }\end{array}$ & Total \\
\hline $\begin{array}{c}2012 \\
(* *)\end{array}$ & \multicolumn{2}{|c|}{$9,68 \%$} & $3,23 \%$ & $3,23 \%$ & $1,61 \%$ & $8,06 \%$ & $17,74 \%$ & $43,55 \%$ & $56,45 \%$ & $100,00 \%$ \\
\hline $\begin{array}{c}2013 \\
(* *)\end{array}$ & \multicolumn{2}{|c|}{$12,90 \%$} & $8,06 \%$ & $4,84 \%$ & $6,45 \%$ & $9,68 \%$ & $16,13 \%$ & $58,06 \%$ & $41,94 \%$ & $100,00 \%$ \\
\hline $\begin{array}{c}2014 \\
(* *)\end{array}$ & \multicolumn{2}{|c|}{$16,13 \%$} & $6,45 \%$ & $8,06 \%$ & $8,06 \%$ & $8,06 \%$ & $20,97 \%$ & $67,74 \%$ & $32,26 \%$ & $100,00 \%$ \\
\hline $\begin{array}{c}2015 \\
(* *)\end{array}$ & \multicolumn{2}{|c|}{$8,06 \%$} & $8,06 \%$ & $9,68 \%$ & $9,68 \%$ & $4,84 \%$ & $20,97 \%$ & $61,29 \%$ & $38,71 \%$ & $100,00 \%$ \\
\hline $\begin{array}{c}2016 \\
(* *)\end{array}$ & \multicolumn{2}{|c|}{$4,84 \%$} & $4,84 \%$ & $11,29 \%$ & $9,68 \%$ & $12,90 \%$ & $22,58 \%$ & $66,13 \%$ & $33,87 \%$ & $100,00 \%$ \\
\hline $\begin{array}{c}2017 \\
(* *)\end{array}$ & \multicolumn{2}{|c|}{$12,70 \%$} & $7,94 \%$ & $3,17 \%$ & $14,29 \%$ & $4,76 \%$ & $17,46 \%$ & $60,32 \%$ & $39,68 \%$ & $100,00 \%$ \\
\hline \multicolumn{2}{|c|}{ Nota1: $(*)$} & \multicolumn{9}{|c|}{ Rango porcentual de recursos auditados } \\
\hline \multicolumn{2}{|c|}{ Nota 2: $(* *)$} & \multicolumn{9}{|c|}{ Porcentaje de contralorías por vigencia anual } \\
\hline \multirow{2}{*}{\multicolumn{2}{|c|}{ Nota 3: }} & \multicolumn{9}{|c|}{ Universo de contralorías territoriales: 62 para 2012, 2013, 2014, 2015 y 2016.} \\
\hline & & \multicolumn{9}{|c|}{ Universo de contralorías territoriales: 63 para 2017} \\
\hline
\end{tabular}

Tabla No. 10. Elaboración propia. Fuente. Análisis de información reportada por las contralorías en el módulo SIA-SIREL de la AGR.

En una lectura horizontal por vigencia, entre otras que se pueden realizar, el promedio de recursos auditados para el período de análisis es del 59.52\%, mientras para las contralorías sin datos válidos el promedio alcanza un valor de $40.48 \%$. De esta manera la confiabilidad de los datos reportados presenta una alta tasa de incertidumbre, lo cual afecta notoriamente cualquier análisis que se pretenda realizar, más allá de la identificación de una nueva variable de evaluación, como podría ser la exactitud de la información reportada o confiabilidad de la información rendida, tema que no ha sido considerado en este estudio.

Ahora bien, considerando la alta limitación de los datos objeto de análisis y en una valoración subsidiaria del estudio, es decir, explorando las posibilidades de aprovechamiento de la información válida recaudada, se podrían acotar algunos aportes.

A manera de ejemplo, para las contralorías que mostraron una cobertura de control entre 0 y $50 \%$ el promedio de vigilancia fue del $32,16 \%$, como se pude apreciar en la siguiente tabla.

Tabla No. 11. Rango porcentual de recursos auditados / porcentaje de contralorías por rango

\begin{tabular}{|l|r|r|r|r|r|}
\hline Año & $\mathbf{0 - 1 0 \%} \mathbf{( *}^{*}$ & $\mathbf{1 0 , 1 - 2 0 \%} \mathbf{*}^{*}$ & $\mathbf{2 0 , 1 - 3 0 \%} \mathbf{( *}^{*}$ & $\left.\mathbf{3 0 , 1 - 5 0 \%} \mathbf{*}^{*}\right)$ & Subtotal \\
\hline $\left.\mathbf{2 0 1 2} \mathbf{( *}^{*}\right)$ & $9,68 \%$ & $3,23 \%$ & $3,23 \%$ & $1,61 \%$ & $17,74 \%$ \\
\hline $\left.\mathbf{2 0 1 3} \mathbf{( *}^{*}\right)$ & $12,90 \%$ & $8,06 \%$ & $4,84 \%$ & $6,45 \%$ & $32,26 \%$ \\
\hline $\left.\mathbf{2 0 1 4} \mathbf{( *}^{*}\right)$ & $16,13 \%$ & $6,45 \%$ & $8,06 \%$ & $8,06 \%$ & $38,71 \%$ \\
\hline
\end{tabular}




\begin{tabular}{|c|c|c|c|c|c|}
\hline $2015(* *)$ & $8,06 \%$ & $8,06 \%$ & $9,68 \%$ & $9,68 \%$ & $35,48 \%$ \\
\hline $2016(* *)$ & $4,84 \%$ & $4,84 \%$ & $11,29 \%$ & $9,68 \%$ & $30,65 \%$ \\
\hline $2017\left(^{(* *)}\right.$ & $12,70 \%$ & $7,94 \%$ & $3,17 \%$ & $14,29 \%$ & $38,10 \%$ \\
\hline & & & & Promedio & $32,16 \%$ \\
\hline Nota1: (*) & \multicolumn{5}{|c|}{ Rango porcentual de recursos auditados } \\
\hline Nota 2: (**) & \multicolumn{5}{|c|}{ Porcentaje de contralorías por vigencia anual } \\
\hline
\end{tabular}

En tanto, para las contralorías que mostraron una cobertura de control entre el 50,1 y 100\% el promedio de vigilancia fue del $27,36 \%$, como se puede apreciar en la tabla siguiente. Estos dos escenarios, que podrían evaluarse por cada contraloría y por cada vigencia, además de afectar la directamente la certificación de la gestión de estos órganos de control, debiera tener la publicidad suficiente y necesaria para que la ciudadanía y cuerpos colegiados, como las Asambleas y Concejos Municipales, conozcan la razones de tales resultados de vigilancia.

Tabla No.12. Rango porcentual de recursos auditados / porcentaje de contralorías por rango

\begin{tabular}{|c|c|c|c|}
\hline Año & $50,1-70 \%(*)$ & $70,1-100 \%(*)$ & Subtotal \\
\hline $2012(* *)$ & $8,06 \%$ & $17,74 \%$ & $25,81 \%$ \\
\hline $2013(* *)$ & $9,68 \%$ & $16,13 \%$ & $25,81 \%$ \\
\hline $2014(* *)$ & $8,06 \%$ & $20,97 \%$ & $29,03 \%$ \\
\hline $2015(* *)$ & $4,84 \%$ & $20,97 \%$ & $25,81 \%$ \\
\hline $2016(* *)$ & $12,90 \%$ & $22,58 \%$ & $35,48 \%$ \\
\hline $2017(* *)$ & $4,76 \%$ & $17,46 \%$ & $22,22 \%$ \\
\hline \multicolumn{3}{|r|}{ Promedio } & $27,36 \%$ \\
\hline Nota1: (*) & \multicolumn{3}{|c|}{ Rango porcentual de recursos auditados } \\
\hline Nota 2: $(* *)$ & \multicolumn{3}{|c|}{ Porcentaje de contralorías por vigencia anual } \\
\hline
\end{tabular}

Así las cosas, los resultados del control fiscal logrados por las contralorías territoriales en términos de recursos auditados son bajos, y muy cambiantes de una vigencia a otra. Entre las contralorías con menores tasas de cobertura en recursos auditados están las departamentales de Bolívar, Guajira, Meta, Vaupés y Arauca.

\subsubsection{Análisis cuantitativo del proceso auditor - Inversión y ahorro.}

La eficiencia de ningún órgano de control no puede medirse en términos de recaudo. Si bien es cierto que el artículo de 268 de la Constitución Política de Colombia dispone que el Contralor General deberá adelantar los procesos de responsabilidad fiscal y jurisdicción coactiva, de la

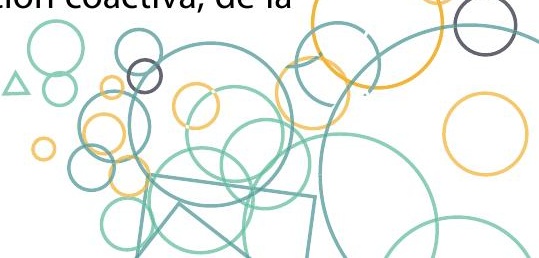




\section{OPPCF}

misma manera y por extensión las contralorías territoriales según el artículo 272 del estatuto superior, no es cierto que el ejercicio de vigilancia y control de los recursos públicos en cabeza del administración de las entidades y los particulares que los manejen pueda ser medido por lo que se recauda.

La cadena el proceso auditor atraviesa por una serie de fases encaminadas a identificar oportunidades de mejora de los vigilados y finaliza normalmente con hallazgos administrativos. Tales hallazgos pueden tener una o varias connotaciones: presunta incidencia penal, presunta incidencia disciplinaria, incidencia fiscal o sancionatoria, como se explica adelante.

Más que evidenciar irregularidades o inconsistencias, el proceso auditor busca contribuir al mejoramiento constante de la gestión de los vigilados, que redunda en un cada vez mejor y transparente manejo de los recursos públicos y en la recuperación del daño patrimonial que se hubiese causado en ejercicio de la gestión fiscal.

En ese orden de ideas, se puede afirmar que es incorrecto evaluar la labor desplegada por las contralorías única y exclusivamente por el recaudo en los procesos de responsabilidad fiscal y jurisdicción coactiva, último eslabón de la cadena que inicia con el proceso auditor.

En tal cadena, se presentan cuatro (4) eventos que se pueden cuantificar. Un primer evento relacionado con los gastos de sostenimiento y traducidos en pagos concernientes a gastos generales y de personal de cada una de las 66 contralorías del país. Un segundo evento relacionado con los hallazgos de auditoría que implican un posible daño patrimonial y que, por tanto, son cuantificables en valor. Un tercer evento, relacionado con los recaudos, es decir la recuperación del detrimento patrimonial en procesos de responsabilidad fiscal o de jurisdicción coactiva. Un último evento, relacionado con los beneficios de auditoría, entendidos como los aspectos positivos del ejercicio del proceso auditor, que pueden medirse en términos cuantificables y no cuantificables.

Según lo reportado a la AGR, en el periodo comprendido entre el 2012 y el 2017 la contraloría a nivel nacional destinó \$4.305.147.183.990 para el desarrollo de las actividades de vigilancia y control fiscal. Para el mismo periodo, en procesos de auditoría, se identificaron hallazgos administrativos por valor de $\$ 25.124 .874 .491 .493$. Las Contralorías del país reportaron \$2.543.374.636.493 como beneficios cuantificables de auditoría.

Sobre estas cifras es menester aclarar que los datos ofrecidos no pueden compararse a la misma escala dado que los pagos de auditoría tienden a mantenerse en el rango de $\$ 600.000 .000 .000$ y $\$ 900.000 .000 .000$, mientras que la cuantía de los hallazgos entre $\$ 500.000 .000 .000$ y 
$\$ 10.000 .000 .000 .000$ y los recaudos entre $\$ 10.000 .000 .000$ y $\$ 150.000 .000 .000$. Por tanto, se trata de cifras incomparables a escalas iguales. Sí llama la atención la variable relacionada con beneficios de auditoría en tanto que presenta datos bastante disímiles; En el 2012 se reportaron beneficios de auditoría por $\$ 2.423 .209 .163 .897$, en el año 2014 por valor de $\$ 58.056 .659$ y en el año 2017 ascienden a $\$ 80.256 .677 .682$. Es posible que la información reportada presente algún error.

Así mismo, es curioso que en el 2015 se haya presentado el menor número de hallazgos (\$518.531.807.435) sí en el análisis de auditorías programadas versus auditorías ejecutadas, algunas contralorías realizaron auditorías por encima de sus promedios habituales (ver auditorías programadas y auditorías ejecutadas). No obstante, salvo esa vigencia, para los años 2016 y 2017 se presentó un incremento de hallazgos 3 veces por encima de los reportados en el año 2012 (\$4.259.897.311.559).

En relación con los recaudos también se evidencia un crecimiento significativo para los años 2016 y 2017, pasando de recaudar $\$ 13.823 .012 .437$ en el 2012 a recaudar $\$ 148.506 .359 .428$ en la última vigencia de análisis.

\section{Gráfica No. 30. Comparativo entre cuantía hallazgos y cuantía recaudo 2012-}

\section{7.}

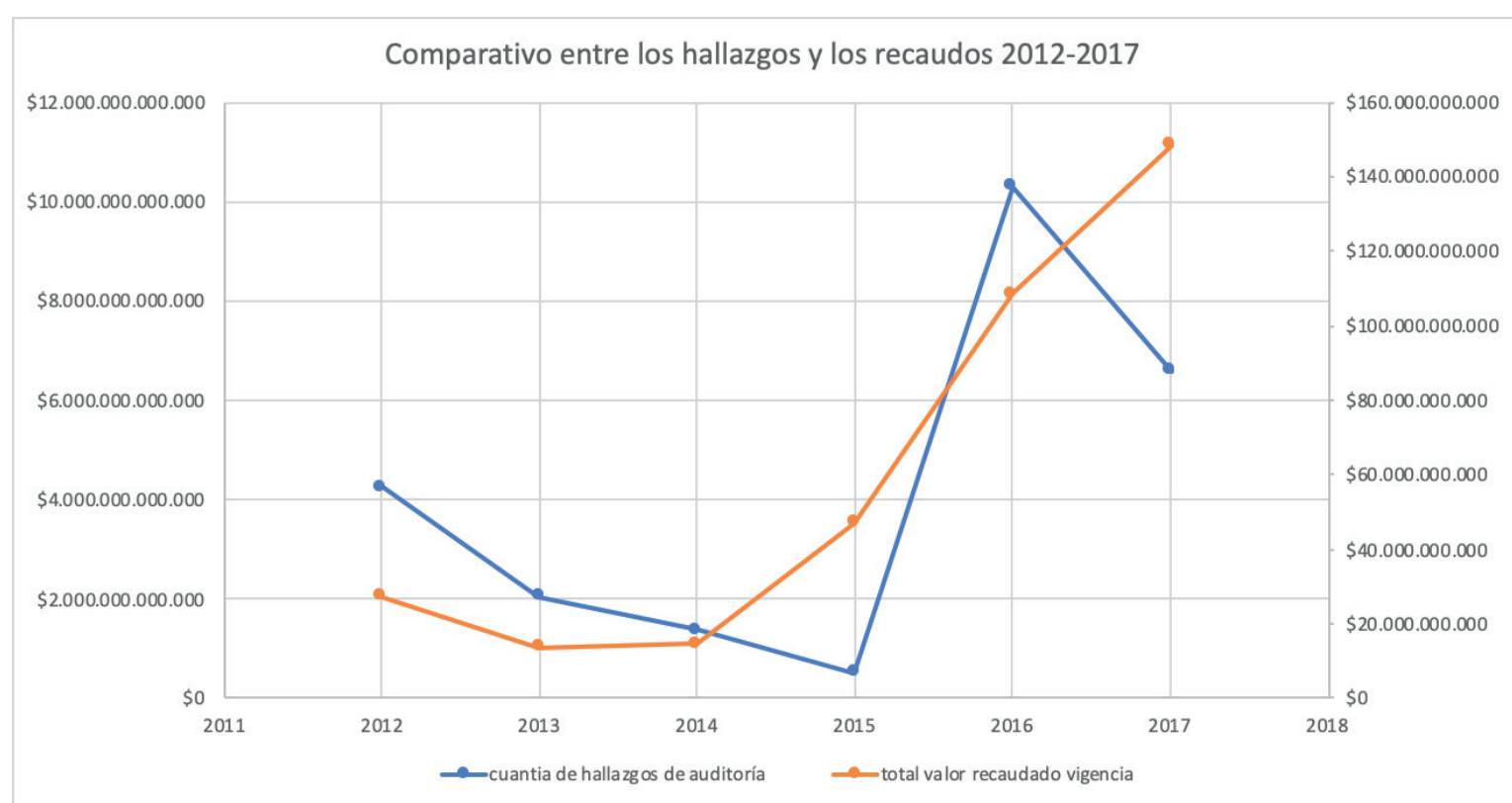

Gráfico \# 30. Elaboración propia. Fuente: Análisis de información reportada por las contralorías en el módulo SIA-SIREL de la AGR. 
Siempre los hallazgos de auditoría han de ser superiores a los valores generados en procesos de recaudo. Los primeros dependen del proceso de auditoría que se adelanta mediante la revisión de cuentas rendidas por sus sujetos vigilados y se consignan en los informes que auditoría que se entregan una vez culminada la revisión. Los segundos, dependen del desarrollo del proceso de responsabilidad fiscal y jurisdicción coactiva, que, como en la jurisdicción ordinaria, puede darse en el transcurso de varios años, una vez se haya iniciado el proceso. Para el análisis de los valores se tomaron dos escalas de comparación distinta según los valores promedio en uno u otro indicador.

La gráfica muestra que, a mayor existencia de hallazgos, mayores son los valores recaudados por vigencia. Ello podría indicar que el reporte de situaciones que pudieren implicar un detrimento patrimonial en el marco de ejercicios de auditoría permite adelantar procedimientos de recuperación de dineros en una mayor proporción. En síntesis, a mayor constitución de hallazgos de auditoría, mayor número de procesos de responsabilidad fiscal y mayor cantidad de recaudo de dineros producto de declaratoria de responsabilidad del funcionario implicado en el hallazgo identificado o reportado de pago voluntario del daño por parte de los investigados antes de tal declaratoria.

Recuérdese que los hallazgos de auditoría, que son en su totalidad de naturaleza administrativa, también pueden presentar presuntas implicaciones penales, disciplinarias y sancionatorias. Con el proceso auditor no sólo se evidencian, procesan y sancionan situaciones relacionadas con detrimento patrimonial, sino que, se identifican y trasladan a los órganos competentes, actuaciones con presuntas implicaciones en otros escenarios de la función pública.

De la misma manera, el comparativo entre los gastos de operación, hallazgos de auditoría y recaudos, evidencian que en la medida que existan procesos de auditoría, existirá la posibilidad de iniciar procesos de responsabilidad fiscal y en consecuencia de recuperar dineros que amortigüen de alguna manera el detrimento patrimonial ocasionado. Lo anterior sin perjuicio de los beneficios de auditoría que son de naturaleza cualitativa y cuantitativa. Los planes de mejoramiento y su gestión a lo largo de la historia de las contralorías y sus de sus vigilados, son una clara muestra de la mejora continua de los vigilados, con beneficios de avance y evolución que, aunque no se pueden cuantificar como logro económico, son sin duda resultados del trabajo de los órganos de control fiscal y de los recursos que se han invertido en su funcionamiento.

De ahí que se debe superar la idea retrógrada de medir la gestión de los órganos de control fiscal, comparando costos de presupuesto, con recaudo en procesos de responsabilidad fiscal o de cobro coactivo. La gestión de tales entidades es mucho más que eso. 


\subsection{CONCLUSIONES}

\section{- Generalidades de las contralorías territoriales - Contexto.}

Las contralorías territoriales de mayor presupuesto y capacidad concentran el $55 \%$ de la labor de vigilancia y control del recurso público territorial, indicando dispersión y fragilidad de los organismos de control que ejercen esta función en el territorio.

Las plantas de personal han mejorado en la estabilidad del personal, sin embargo, aún existe un alto porcentaje (39\%) en cargos a discrecionalidad del nominador generando riesgos en la permanencia del personal en el ejercicio del control fiscal.

En el estudio realizado se concluye que si bien se han realizado notorios esfuerzos en el mejoramiento de la ejecución presupuestal al realizar un análisis detallados sobre sus reservas presupuestales, se evidencias rezagos superiores a los dispuestos por la ley lo cual pone en riesgo la sostenibilidad financiera de las contralorías territoriales, si se atiende esta normativa.

\section{- Rendición y revisión de cuentas.}

El control fiscal es una función pública que vigila la gestión de fiscal de quienes, por ley, están obligados a rendir cuenta sobre el manejo de los recursos públicos a su cargo, a estos se les conoce como sujetos vigilados. Ese manejo se refleja en información de orden legal, técnico, financiero y contable que se traduce en procesos de "rendición de cuentas" respecto de los cuales, cada contraloría, ya sea del orden General, Distrital, Departamental o Municipal, define el procedimiento y la periodicidad. Las contralorías de todos los órdenes (66 a nivel nacional), se encargan de efectuar la revisión de las cuentas rendidas por los sujetos vigilados. Dicha revisión consiste en la verificación de los requisitos legales, técnicos y operativos con que debe cumplir cada una de las actividades desplegadas por estos que se reflejaron en la rendición efectuada.

En el periodo comprendido entre el 1 de enero de 2012 y el 31 de diciembre de 2017 se constató que, en términos generales, los sujetos vigilados cumplen con su obligación de rendir cuentas. Aunque no es posible discriminar de los datos analizados, cuántas de dichas cuentas corresponden a la vigencia (año para el cual debe rendirse la cuenta) en tanto que no todos los sujetos vigilados rinden cuentas en los misma periodicidad, el balance permite concluir que el número de cuentas rendidas supera para todas las vigencias al número de sujetos vigilados, incluyendo dentro de estas cifras, rendiciones de cuentas extemporáneas (de años anteriores), complementos (añadiduras a rendiciones de cuentas de año anteriores) y ajustes o arreglos (de cuentas pasadas). 
Las rendiciones de cuentas dependen a su vez, de la revisión efectuada por las contralorías. Dichas revisiones dependen de los planes de auditoría que se fijan anualmente por cada una de las Contralorías, según las variables que determinan una mayor o menor necesidad de realización; por ejemplo, el número de sujetos vigilados y el presupuesto asignado. Las conclusiones de la revisión de cuentas se encuentran en el numeral 3.9.3.

El proceso de revisión de cuentas desplegada por las contralorías culmina con lo que se denomina "hallazgos", entendidos estos como una contradicción entre lo que se analiza y lo que debería ser de conformidad con las leyes, los reglamentos y los principios que rigen la función pública (eficiencia, eficacia, equidad, economía y valoración de los costos ambientales). Todos los hallazgos son de naturaleza administrativa. Algunos de ellos pueden, adicionalmente, tener efectos desde el punto de vista fiscal, penal, disciplinario o sancionatorio. Estos últimos se constituyen en la medida que se ajusten a las causales contenidas en el artículo 101 de la ley 42 de 1993.

Entre el 1 de enero de 2012 y el 31 de diciembre de 2017 se identificaron 19.358 procesos con incidencia de tipo sancionatorio. Dentro de las causas más comunes se resaltan, i) Incumplimiento en el suministro de información o soportes por inobservancia de la normatividad legal existente para su presentación; ii) La falta de implementación de los planes de mejoramiento dispuestos por los ejercicios de auditoría de vigencias anteriores; iii) La presentación extemporánea y/o parcial de cuentas (se rinden cuentas de vigencias anteriores o complementos de cuentas presentadas de forma incompleta); iv) La remisión incompleta de información solicitada por el grupo auditor.

Aunque el porcentaje de hallazgos con incidencia sancionatoria sólo representa el 6,9\% de los hallazgos administrativos identificados, se concluye que, el hecho de presentar cuentas de forma incompleta, incorrecta, extemporánea o no presentarla dentro de los periodos fijados para ese efecto repercute considerablemente en que el proceso de vigilancia se efectué de manera adecuada. Lo ideal corresponde a la presentación completa, fidedigna y en término de la información que respalda el manejo de los recursos púbicos.

No obstante, se resalta que para el año 2017 el número de hallazgos con incidencia sancionatoria se redujo en 885 en contraste con el año 2012, lo que podría indicar que los planes de mejoramiento dispuestos en vigencias anteriores contribuyeron al ajuste o corrección de los fenómenos que generan esta clase de hallazgos.

\section{- Planeación y Ejecución de Auditorías}

De conformidad con la información suministrada por el sistema SIA-SIREL se concluye que las 
contralorías a nivel nacional cumplen con sus planes de auditoría. Así se demostró al cotejar el número de auditorías programadas contra el número de auditorías ejecutadas por cada una de las vigencias 2012-2017, encontrándose incluso en algunas vigencias que el número de auditorías ejecutadas era superior al número de auditorías programadas.

Se presenta un movimiento inusual sobre todo en los periodos 2014-2015, en los que algunas contralorías programaron y ejecutaron mayor número de auditorías en contraste con años anteriores o posteriores. De la misma forma, auditorías que programaron y ejecutaron mejor número de auditorías en contraste con años anteriores y posteriores. Una explicación posible podría ser que se produjo traslado de personal misional para atender auditorías en territorios donde el número de auditorías incrementó y el personal existente no era suficiente para atenderlas durante esas vigencias.

Tomado los datos de los casos analizados en el presente estudio, la cobertura de los recursos auditados como desarrollo del criterio de selectividad incide de manera notoria en los resultados del control fiscal aplicado. En la vigilancia de los recursos del sistema general de regalías, que tiene una expectativa muy alta en la población por su relación directa con las problemáticas y necesidades locales, la gestión de la Contraloría General no satisface la demanda en volumen de los recursos apropiados por el sistema, particularmente en el control a la contratación pública relacionada con los proyectos aprobados. Un caso muy similar se presenta con la gestión de las contralorías territoriales respecto de los recursos auditados, sobre los cuales, además de las deficiencias registradas presuntamente en materia de rendición de la cuenta, no registra unas tasas de cobertura representativas frente al total de los recursos objeto de vigilancia.

\subsection{BIBLIOGRAFIA}

Acto Legislativo 01 (Congreso de Colombia 18 de Junio de 1945).

Acto Legislativo 04 (Congeso de Colombia 18 de septiembre de 2019)

Auditoría General de la República, Criterios de auditoria que fundamentan la función que debe realizar la Auditoría General de la República a las contralorías en ejercicio del control fiscal ambiental (2015)

Auditoría General de la República, El Control Fiscal Ambiental en Colombia (2007). Revista Sindéresis Proyecciones del Control Fiscal. ISSN 0124-471. Bogotá.

Auditoría General de la República. (29 de enero de 2019). auditoria.gov.co. Recuperado el 02 
de noviembre de 2018, de http://www.auditoria.gov.co/

Bayona Aristizabal, D. M. (2018), Legislación internacional en materia de control interno y fiscal - INTOSAI.

Céspedes, F., \& Duque, L. J. (2018). El Control Fiscal y la Responsabilidad Fiscal. Bogotá: Grupo Editorial Ibañez.

Concepto Sala de Consulta y Servicio Civil, 11001-03-06-000-2013-00422-00 (Consejo de Estado 15 de Octubre de 2013).

Constitución Política de Colombia de 1991. Consultada en http:// http://www.secretariasenado. gov.co/senado/basedoc/constitucion_politica_1991.html

Contraloría General de la República. (2012). Guía de Auditoria para las Contralorías Territoriales. Bogotá.

Decreto 1539, Por el cual se establece una planta temporal de empleos en la Contraloría General de la República (2012 de Julio de 2012).

Decreto-Ley 267 (Por el cual se dictan normas sobre organización y funcionamiento de la Contraloría General de la República, se establece su estructura orgánica, se fijan las funciones de sus dependencias y se dictan otras disposiciones. 22 de Febrero de 2000).

Decreto-Ley 272 (Por el cual se determina la organización y funcionamiento de la Auditoría General de la República 22 de Febrero de 2000).

Fernández, J. A. \& Fernández, A. (1999). La economía de la corrupción y el control externo. Revista española de control externo, 1(3), 9-38.

Gómez Lee, Iván Darío (2006). Control Fiscal y Seguridad Jurídica Gubernamental. Bogotá: Universidad Externado de Colombia.

Ley 106, Por la cual se dictan normas sobre la organización y funcionamiento de la CGR, se establece su estructura orgánica, se determina la organización y funcionamiento de la Auditoría Exgterna, se organiza el Fondo de Bienestar Social, se determina el (...) (Congreso de la República 30 de Diciembre de 1993).

Ley 1416 , Por medio de la cual se fortalece al ejercicio del control fiscal. (Congreso de la República 24 de Noviembre de 2010).

Ley 1474, Por la cual se dictan normas orientadas a fortalecer los mecanismos de prevención, investigación y sanción de actos de corrupción y la efectividad del control de la gestión 
pública. (Congreso de la República 12 de Julio de 2011).

Ley 1523 , Por la cual se adopta la política nacional de gestión del riesgo de desastres y se establece el Sistema Nacional de Gestión del Riesgo de Desastres y se dictan otras disposiciones. (Congreso de la República 24 de Abril de 2012).

Ley 1530 , Por la cual se regula la organización y el funcionamiento del Sistema General de Regalías. (Congreso de Colombia 17 de Mayo de 2012).

Ley 1712 , Por medio de la cual se crea la Ley de Transparencia y del Derecho de Acceso a la Información Pública Nacional y se dictan otras disposicione (Congreso de la República 14 de Marzo de 2014).

Ley 1807 (Congreso de la República 1 de Septiembre de 2016).

Ley 1904, Por la cual se establecen las reglas de la convocatoria pública previa a la elección de Contralor General de la República por el Congreso de la República. (Congreso de Colombia 27 de Junio de 2018).

Ley 1955, por el cual se expide el Plan Nacional de Desarrollo 2018-2022. “Pacto por Colombia, Pacto por la Equidad". (Congreso de Colombia 25 de Mayo de 2019).

Ley 20, Por la cual se modifican y adicionan las normas orgánicas de la Contraloría General de la República, se fijan sistemas y directrices para el ejercicio del control fiscal y se dictan otras disposiciones (Congreso de la República 28 de Abril de 1975).

Ley 330, Por la cual se desarrolla parcialmente el artículo 308 de la Constitución Política y se dictan otras disposiciones relativas a las Contralorías Departamentales. (Congreso de Colombia 11 de Diciembre de 1996).

Ley 42 , Sobre reorganización de la contabilidad oficial y creación del Departamento de Contraloría (Congreso de Colombia 19 de Julio de 1923).

Ley 610 , Por la cual se establece el trámite de los procesos de responsabilidad fiscal de competencia de las contralorías. (Congreso de Colombia 15 de Agosto de 2000).

Ley 617, Por la cual se reforma parcialmente la Ley 136 de 1994, el Decreto Ext. 1222 de 1986, se adiciona la Ley Orgánica de Presupuesto, el Decreto 1421 de 1993, se dictan otras normas tendientes a fortalecer la descentralización, y se dictan normas par (Congreso de la República 6 de Octubre de 2000).

Ley 734 , Por la cual se expide el Código Disciplinario Unico. (Congreso de la República 5 de 


\section{OPPCF}

Febrero de 2002).

Linz, J., \& Stepan, A. (1978). The Breakdown of Democratic Regimes: Europe (Vol. 2). JHU Press.

Ministerio de Hacienda y Crédito Público (2011). Conceptos jurídicos Presupuestales. Bogotá: Minhacienda, P. 65-68

Naranjo Gálves, Rodrigo (2007). Eficacia del Control Fiscal en Colombia. Derecho comparado, historia, macroorganizaciones e instituciones. Colección de libros de Jurisprudencia. Editorial Universidad del Rosario. Primera Edición. Bogotá

Olken, B. (2007). Monitoring Corruption: Evidence from a Field Experiment in Indonesia. Boston, USA: Harvard University and National Bureau of Economic Research.

Ordóñez Vásquez, Tatiana. (2005). Colombia impunidad en Materia Fiscal. Bogotá: Revista Sindéresis. Auditoría General de la República.

Ortiz Ospino, Liliana. (2017). Eficiencia y eficacia en la asignación y ejecución del presupuesto cultural: un desafío para las entidades territoriales en Colombia. Bogotá: AGR.

Resolución Reglamentaria Orgánica REF-ORG-0029-2019, Por la cual se establecen las reglas para el ejercicio de la potestad sancionatoria fiscal al interior de la Contraloría General de la República (Contraloría General de la República 19 de Junio de 2019).

Resolución Reglamentaria Orgánica REG - ORG- 0012-2017, “Por la cual se adoptan principios, fundamentos y aspectos generales para las auditorías en la Contraloría General de la República y la Guía de Auditoría Financiera como instrumentos de control fiscal posterior y selectivo, dentro de los parámetros de las (Contraloría General de la República 24 de Marzo de 2017).

Resolución Reglamentaria Orgánica REG-ORG-0014-2017, Por la cual se adopta la Guía de Auditoría de Cumplimiento como instrumento de control fiscal posterior y selectivo, en el marco de las Normas Internacionales de Auditoría para las Entidades (Contraloría General de la República 14 de Junio de 2017).

Resolución Reglamentaria Orgánica REG-ORG-022-2018, Por la cual se adopta la nueva Guía de Auditoría de Cumplimiento, en concordancia con las Normas Internacionales de Auditoria para las Entidades Fiscalizadoras Superiores — ISSAls, y se deroga la Resolución Reglamentaria Orgánica 0014 de 2017 (Contraloría General de la República 31 de Agosto de 2018).

Resolución Reglamentaria Orgánica REG-ORG-030-2019, Por la cual se reglamentan los 
requerimientos de la Contraloría General de la República para el acceso a los sistemas de información o bases de datos (Contraloría General de la República 5 de Julio de 2019).

Resolución Reglamentaria Orgánica RES-ORG-023-2018, "Por la cual se adopta la nueva Guía de Auditoría de Desempeño, en concordancia con las Normas Internacionales de Auditoria para las Entidades Fiscalizadoras Superiores - ISSAIs, y se deroga la Resolución Reglamentaria Orgánica 0015 de 2017 (Contraloría General de la República 31 de Agosto de 2018).

Restrepo Acevedo, Edgar Alfredo. (2017). La fragilidad en el diseño institucional de los organismos de control fiscal del Departamento de Antioquia (Tesis de grado). Universidad Nacional de Colombia. Medellín.

Senado de la República de Colombia, Decreto 1957 de 2007

Senado de la República de Colombia, Ley 42 de 1993.

Senado de la República de Colombia, Ley 819 de 2003.

Senado de la República, Gaceta del Congreso No. 607 de 7 de septiembre de 2010

Sentencia C-1339 (Corte Constitucional 4 de Octubre de 2000).

Sentencia C-499 (Corte Constitucional 15 de Septiembre de 1998).

Shleifer, A. \& Vishny, R. (1993). Corruption. In: The Quarterly Journal of Economics, Vol. 108, No. 3. Boston: MIT Press. pp. 599-617. Disponible en: Tanarro (2003). Evolución y práctica del control interno contable en Técnica Contable. Vol (58)

Tullock, G (1989). "The welfare cost of tariffs, monopoly and theft" in: Economic United Nations, Corruption in government. New York: United Nations.

Villardefrancos, M. y Rivera, Z. (2006). La auditoría como proceso de control: concepto y tipología en: Ciencias de la Información Vol. 37, No. 2-3. Agosto-septiembre, 2006. P. 53-58

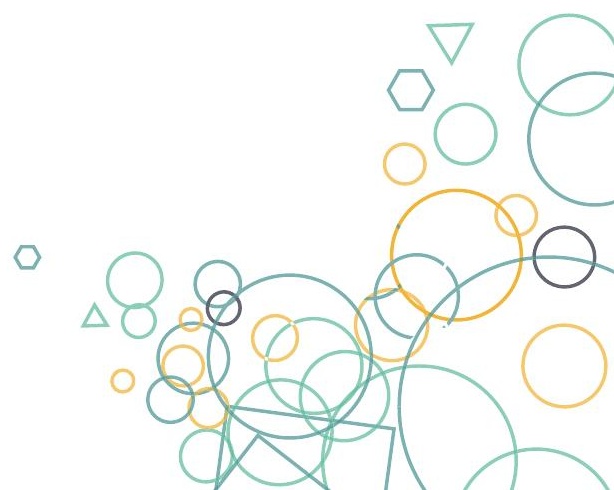




\section{CAPÍTULO III}

\section{RESULTADOS DEL PROCESO AUDITOR:}

\section{HALLAZGOS Y PROCESOS FISCALES}

\section{RESULTS OF THE AUDITING PROCESS: FINDINGS AND FISCAL PROCESSES}

Tatiana Ordóñez Vásquez ${ }^{20}$

\section{Resumen}

El proceso auditor adelantado por los órganos de control fiscal entre el $1^{\circ}$ de enero de 2012 y el 31 de diciembre de 2017 generó, según la evidencia empírica 23.178 hallazgos fiscales.

El proceso auditor adelantado por los órganos de control fiscal entre el $1^{\circ}$ de enero de 2012 y el 31 de diciembre de 2017 fue eficaz por varias razones. La primera, porque 22.165 hallazgos fiscales identificados en auditoría, por cuantía de $\$ 24.094 .891 .899 .653$, generaron la apertura de 16.999 procesos de responsabilidad fiscal en ese mismo periodo, y un recaudo persuasivo en etapa de hallazgo de $\$ 31.092 .950 .769$. La segunda, porque el $67,36 \%$ de los procesos de responsabilidad fiscal abiertos en el periodo fue originado por hallazgos de auditoría, Otra, porque calculada la relación matemática entre el número de hallazgos fiscales identificados en auditoria entre 2012 y 2017 y los procesos de responsabilidad fiscal abiertos en el mismo periodo, se encontró una razón matemática positiva, tanto en número como en cuantía.

Se comprobó con un caso de estudio, que el procedimiento verbal es una medida adecuada para la eficiencia y eficacia del control fiscal colombiano, en la lucha contra la corrupción; y

20 Tatiana Ordóñez Vásquez. Abogada de la Universidad del Rosario. Magister en Derecho Administrativo de la Universidad Militar, Especialista en Instituciones Jurídico-Procesales de la Universidad Nacional de Colombia y Especialista en Derecho Administrativo de la Universidad Santo Tomás. Profesional Especializado Auditoría Auxiliar AGR. Docente de posgrado, e investigadora del “Observatorio de Política Pública del Control Fiscal" adscrito -según convenio- a la Auditoría General de la República y la Universidad Santo Tomás de Bogotá. 
que en términos de resultados fue más eficiente el procedimiento verbal que el ordinario.

Finalmente, en procesos de jurisdicción coactiva, el análisis empírico permitió concluir que entre 2012 y 2017 las contralorías del país notificaron el mandamiento de pago en 5.013 procesos de jurisdicción coactiva, con base en títulos ejecutivos por cuantía total de \$434.103.987.751 y que a diciembre de 2017 se había obtenido un recaudo de $\$ 51.952 .155 .179$.

En materia de control fiscal ambiental, entre 2012 y 2017, las contralorías del país reportaron 310 hallazgos fiscales por cuantía de $\$ 61.217 .900 .608$, y abrieron 55 procesos de responsabilidad fiscal y 43 indagaciones preliminares. Tramitaron 365 procesos de responsabilidad fiscal por una cuantía de daño según auto de apertura de $\$ 373.131 .511 .650$, de los cuales se reportó un recaudo total inicial a diciembre de 2017 , de $\$ 1.445 .867 .777$.

\section{Abstract}

The audit process advanced by the fiscal control bodies between January 1, 2012 and December 31, 2017 generated, according to empirical evidence 23,178 fiscal findings.

Such audit process was effective for several reasons: First, because 22,165 fiscal findings identified in audit, amounting to $\$ 24,094,891,899,653$, generated the opening of 16,999 fiscal liability processes in the same period, and a persuasive collection in the discovery stage of $\$$ $31,092,950,769$. Second, because $67.36 \%$ of the fiscal responsibility processes opened during the period were originated by audit findings, and third, because the mathematical relationship between number of fiscal findings identified and the processes of fiscal responsibility is $s$ a positive mathematical reason, both in number and amount.

It was proved with a case study that the verbal procedure is an adequate measure for the efficiency and effectiveness of the Colombian fiscal control, in the fight against corruption; and that in terms of results the verbal procedure was more efficient than the ordinary one. Finally, in processes of coercive jurisdiction, the empirical analysis allowed us to conclude that between 2012 and 2017 the country's comptrollers notified the payment order in 5,013 processes of coercive jurisdiction, based on executive titles for a total amount of $\$ 43,103,987,751$ and that at December 2017, a collection of $\$ 51,952,155,179$ had been obtained.

In terms of environmental fiscal control, between 2012 and 2017, the country's comptrollers reported 310 fiscal findings amounting to $\$ 61,217,900,608$, and opened 55 fiscal liability processes and 43 preliminary inquiries. They processed 365 fiscal liability processes for an amount of damage according to the opening order of $\$ 373,131,511,650$, of which an initial total collection was reported at December 31,2017 , of $\$ 1,445,867,777$.

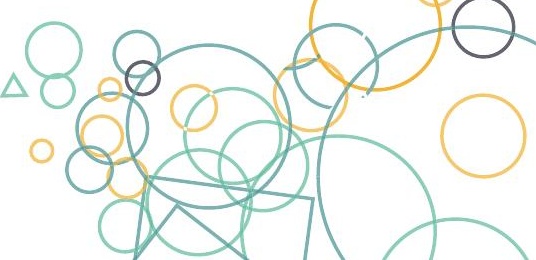




\section{Palabras clave}

Resultados del proceso auditor, hallazgos fiscales, procesos fiscales, resarcimiento, daño de recursos públicos

\section{Key words}

Results of the auditing process, fiscal findings, fiscal processes, compensation, damage of public resources

Temario: 3.1. Hallazgos fiscales como resultado del proceso auditor 2012-2017. 3.2. Resultado de los procesos de responsabilidad fiscal 2012-2017. 3.3. Eficacia de la oralidad en los procesos de responsabilidad fiscal. 3.4. Resultado de los procesos de jurisdicción coactiva 2012-2017. 3.5. Hallazgos y procesos de responsabilidad fiscal derivados del control fiscal a la gestión ambiental 2012-2017. 3.6. Conclusiones. 3.7. Bibliografía.

\section{Introducción}

Dentro de los productos de auditoría de control fiscal están, quizá los más importantes después del mejoramiento de los sujetos vigilados orientado a la correcta gestión de recursos públicos, los denominados hallazgos fiscales, o hallazgos con connotación fiscal que es lo mismo. Son las conclusiones contundentes a las que se llega al final del proceso auditor, una vez garantizado el derecho de contradicción que le asiste al auditado, que permiten identificar y cuantificar un daño patrimonial a los recursos públicos causado en ejercicio de gestión fiscal.

Con base en ellos se abren los procesos de responsabilidad fiscal, que tienen por objeto buscar el resarcimiento "(...) de los daños ocasionados al patrimonio público como consecuencia de la conducta dolosa o culposa de quienes realizan gestión fiscal mediante el pago de una indemnización pecuniaria que compense el perjuicio sufrido por la respectiva entidad estatal", a la luz del artículo $4^{\circ}$ de la Ley 610 de 2000.

En ese contexto, y entendiendo que el proceso de responsabilidad fiscal es el conjunto de actuaciones administrativas adelantadas por las contralorías con el fin de determinar y establecer la responsabilidad de los servidores públicos y de los particulares, cuando en el ejercicio de la gestión fiscal o con ocasión de ésta, causen por acción u omisión y en forma dolosa o culposa un daño al patrimonio del Estado, se buscó con este estudio, primero establecer los resultados concretos de los hallazgos fiscales, segundo, qué tantos generaron procesos de responsabilidad fiscal, tercero, cómo fue la gestión y los resultados de tales procesos según fueran tramitados por procedimiento verbal u ordinario, y cuarto, analizar contra información depurada si, según los resultados, la oralidad como herramienta cumple o 
no la motivación expuesta en el proyecto de Ley 1484 de 2011, ley fundamento del Estatuto Anticorrupción vigente.

Lo anterior, como corolario empírico que aporta de manera autorizada elementos sobre los hallazgos fiscales, los procesos fiscales y la oralidad, rompiendo paradigmas, para tener en consideración al momento de construir políticas públicas de control fiscal; haciendo eco a las palabras del maestro Rodrigo Naranjo Galves:

No está mal que se busque el consejo de expertos, pues el tema del control fiscal tiene más de un arista técnica; pero estos aspectos técnicos no son más numerosas ni más difíciles que los presentes en otras ramas del Derecho Público. Cabe afirmar -parodiando a Clemenceauque el control fiscal es asunto tan importante que sería absurdo dejarlo sólo en manos de quienes se consideran o aspiran a ser especialistas en la materia; especialistas cuya labor debe ser más bien la de ilustrar el criterio de la academia y de la sociedad a la hora de plantear reformas. Debe recordarse, que las reformas substanciales en este campo, suelen romper con los paradigmas establecidos, labor que casi nunca han efectuado los especialistas ${ }^{21}$ y que este tema, por su carácter esencialmente político, interesa al conjunto de la sociedad.

\subsection{HALLAZGOS FISCALES COMO RESULTADO DEL PROCESO AUDITOR 2012- 2017.}

"El hallazgo de auditoría es un hecho relevante que se constituye en un resultado determinante en la evaluación de un asunto en particular, al comparar la condición [situación detectada] con el criterio [deber ser] y concluir que distan uno del otro. Igualmente, es una situación determinada al aplicar pruebas de auditoría que se complementará estableciendo sus causas y efectos.

Todos los hallazgos determinados (...) son administrativos, sin perjuicio de sus efectos fiscales y posibles penales, disciplinarios o de otra índole y corresponden a todas aquellas situaciones que hagan ineficaz, ineficiente, inequitativa, antieconómica o insostenible ambientalmente, la actuación del auditado, o que viole la normatividad legal y reglamentaria o impacte la gestión y el resultado del auditado (efecto).

Se refiere a las deficiencias de control y/o observaciones de auditoría encontradas que inicialmente se presentan como tal y se configuran como hallazgo una vez evaluado, valorado y validado en mesa de trabajo, con base en la respuesta del sujeto de vigilancia y control fiscal, cuando esta se da." (CGR, 2017. p.41)

En ese contexto, los hallazgos pueden tener connotación fiscal, penal o disciplinaria. Para el efecto, y previo a otra cosa, como se reseña:

Hallazgo con presunta incidencia penal, es la conclusión a la que llega el equipo auditor, tras identificar hechos que presuntamente revisten características de delito. Al respecto, la parte especial del Código Penal - Ley 599 de 2000- Libro II, describe los delitos en particular, y entre ellos, el Título XV que refiere a los delitos contra la Administración Pública. De conformidad con el deber de denuncia de que trata el artículo 67 del Código de Procedimiento Penal -Ley 906 de 2004, al evidenciarse la posible comisión de un delito, se debe poner inmediatamente el

21 KHUN Thomas S, La Estructura de las Revoluciones científicas, Fondo de Cultura Económica, México D.F., 1992, pág. 125 
hecho en conocimiento ante la autoridad competente; en el entendido además, que es deber de todos los funcionarios públicos denunciar los delitos, contravenciones y faltas disciplinarias de los que tuviere conocimiento, según el numeral 24 del artículo 34 del Código Disciplinario Único - Ley 734 de $2002^{22}$.

En el mismo sentido, los hallazgos con presunta connotación o incidencia disciplinaria son las conclusiones contundentes a las que llega el equipo auditor, que permiten identificar hechos que presuntamente revisten características de falta disciplinaria.

De conformidad con el numeral 24 del artículo 34 de del Código Disciplinario Único - Ley 734 de $2002^{23}$, al evidenciarse la posible comisión de una falta disciplinaria, se debe poner el hecho en conocimiento ante la autoridad disciplinaria competente. Falta disciplinaria es la incursión en cualquiera de las conductas o comportamientos previstos en el Código Disciplinario Único $(\mathrm{CDU})^{24}$, que conlleve incumplimiento de deberes, extralimitación en el ejercicio de derechos y funciones, prohibiciones y violación del régimen de inhabilidades, incompatibilidades, impedimentos y conflicto de intereses, sin estar amparado por cualquiera de las causales de exclusión de responsabilidad contempladas en el artículo 28 de ese mismo ordenamiento.

De la misma manera, los hallazgos fiscales, o hallazgos con connotación fiscal que es lo mismo, son las conclusiones contundentes a las que se llega al final del proceso auditor, una vez garantizado el derecho de contradicción que le asiste al auditado, que permiten identificar y cuantificar un daño patrimonial a los recursos públicos. Estos hallazgos y su gestión son objeto del análisis empírico que se expone adelante.

Finalmente, es de tener en cuenta que todos los hallazgos negativos de auditoria son clasificados como hallazgos administrativos, sin perjuicio de los efectos fiscales, posibles penales, y posibles disciplinarios; en la medida en que implican al auditado adoptar acciones de mejora, preventivas, correctivas o correcciones, y por tal motivo van a hacer parte de los planes de mejoramiento, y de seguimiento de las oficinas de control interno.

En ese contexto, el proceso auditor adelantado por las contralorías del país ${ }^{25}$ entre el $1^{\circ}$ de enero de 2012 y el 31 de diciembre de 2017 generó, según la evidencia empírica de lo reportado en las cuentas anuales a la AGR a través del módulo SIA-SIREL, un total de 279.572 hallazgos administrativos, 67.199 hallazgos con presunta incidencia disciplinaria, 5.559 con

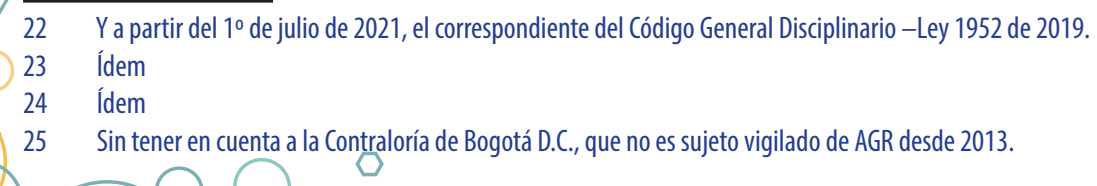


presunta incidencia penal, y 23.178 hallazgos fiscales ${ }^{26}$.

Gráfico No. 7. Hallazgos producto del proceso auditor vigencias 2012-2017

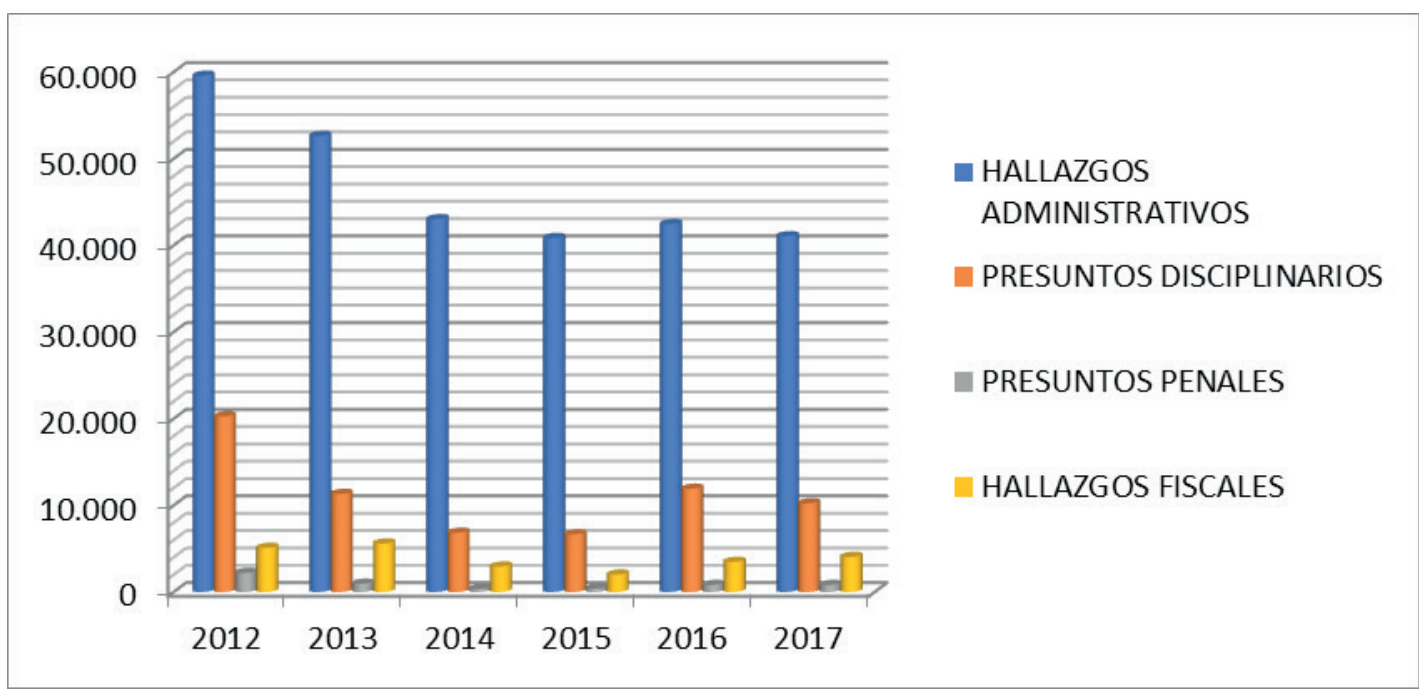

Gráfica No. 7. Fuente: Fuente. Elaboración propia. Fuente. Análisis de información reportada por las contralorías en el módulo SIA-SIREL de la $A G R$.

Además de las connotaciones referidas, los hallazgos pueden tener incidencia sancionatoria, a la luz de las causales del artículo 101 de la Ley 42 de 1993, en los casos en que los vigilados no comparezcan a las citaciones que en forma escrita les hagan las contralorías; no rindan las cuentas e informes exigidos o no lo hagan en la forma y oportunidad establecidos por ellas; incurrirán reiteradamente en errores u omitan la presentación de cuentas e informes; se les determinen glosas de forma en la revisión de sus cuentas; de cualquier manera entorpezcan o impidan el cabal, cumplimiento de las funciones asignadas a las contralorías o no les suministren oportunamente las informaciones solicitadas; teniendo bajo su responsabilidad asegurar fondos, valores o bienes no lo hicieren oportunamente o en la cuantía requerida; no adelanten las acciones tendientes a subsanar las deficiencias señaladas por las contralorías. Al respecto, en el numeral 3.2.2 de este mismo capítulo se efectuó un análisis empírico sobre la frecuencia de esas causales en los hallazgos sancionatorios identificados entre el $1^{\circ}$ de enero de 2012 y el 31 de diciembre de 2017 por las contralorías del país.

A lo largo de todo el proceso auditor de control fiscal, como se explicó antes, los auditores pueden identificar situaciones que implican un posible daño patrimonial ${ }^{27}$ a los recursos

26 La gestión y resultados de estos hallazgos fiscales y los de la AGR, son analizados en subcapítulo especial más adelante en esta misma publicación.

27 Según el artículo $6^{\circ}$ de la Ley 610 de 2000, daño patrimonial al Estado es la lesión del patrimonio público, representada en el menoscabo, disminución, perjuicio, detrimento, pérdida, o deterioro de los bienes o recursos públicos, 0 a los intereses patrimoniales del Estado, producida por

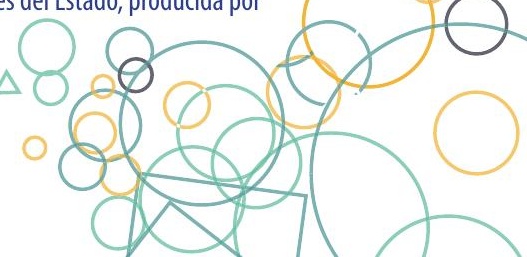




\section{OPPCF}

públicos. Las conclusiones soportadas de la existencia del daño son calificadas al final del proceso auditor como hallazgos fiscales que pasan a ser objeto de proceso de responsabilidad con el fin de determinar responsabilidades fiscales, y obtener el resarcimiento de los daños ocasionados al patrimonio público.

Tales hallazgos fiscales, independientemente de las otras incidencias que puedan tener las situaciones irregulares identificadas, como una presunta falta disciplinaria o penal, exigen un adecuado y suficiente estudio del equipo auditor para establecer además de la existencia del daño patrimonial, indicios serios sobre sus posibles autores y su responsabilidad.

El riguroso ejercicio de configuración y soporte de todos los elementos del hallazgo fiscal que hace el equipo auditor es el que permite que, al llegar a manos del abogado sustanciador de procesos fiscales, éste puede contar con todos los elementos necesarios para abrir rápidamente un proceso de responsabilidad fiscal verbal, o en su defecto un ordinario, o excepcionalmente una indagación preliminar cuando el equipo auditor no consiguió en la auditoria certeza sobre el hecho, el daño patrimonial, la entidad afectada y la determinación de los presuntos responsables.

Con el objetivo de tratar de determinar la eficacia del proceso auditor en términos del número de procesos de responsabilidad abiertos con fundamento en hallazgos fiscales identificados en auditoría, se tomó como punto de partida el total de hallazgos fiscales producto de auditoría de los órganos de control fiscal del país ${ }^{28}$ entre el $1^{\circ}$ de enero de 2012 y el 31 de diciembre de 2017, para después establecer su relación, con los procesos de responsabilidad fiscal abiertos en ese mismo periodo.

Los órganos de control fiscal, del nivel territorial ${ }^{29}$ y del nacional, identificaron como producto de la vigilancia y del control fiscal en ese periodo un total de 23.355 hallazgos fiscales, por cuantía de $\$ 24.764 .627 .160 .614$.

De ese total, 146 hallazgos en cuantía de $\$ 31.092 .950 .769$ fueron objeto de resarcimiento del daño en etapa de hallazgo y 1.044 hallazgos, por cuantía de $\$ 638.642 .310 .192$ fueron devueltos a proceso auditor por no contar con los elementos suficientes del hallazgo fiscal, cifras ambas que quedaron excluidas del total de potenciales procesos de responsabilidad fiscal.

Precisado lo anterior, el conocimiento empírico de lo reportado en el módulo SIA-SIREL ${ }^{30}$

una gestión fiscal antieconómica, ineficaz, ineficiente, e inoportuna que, en términos generales, no se aplique al cumplimiento de los cometidos y de los fines esenciales del Estado.

28 Según lo reportado por las contralorías en el módulo SIA-SIREL de la AGR, sin contar a la Contraloría de Bogotá D.C., que no rinde cuentas a la AGR porque no es su sujeto vigilado.

29 Sin tener en cuenta a la Contraloría de Bogotá D.C., que no es sujeto vigilado de AGR desde 2013.

30 Formato 21 Resultados del Ejercicio de Control Fiscal, sub-formato Hallazgos Fiscales 
permitió concluir que entre el $1^{\circ}$ de enero de 2012 y el 31 de diciembre de 2017 se identificaron 22.165 hallazgos fiscales (potenciales procesos de responsabilidad fiscal), por cuantía de $\$ 24.094 .891 .899 .653$.

También, según lo reportado y depurado para ese mismo periodo, se identificó que fueron abiertos por los órganos de control fiscal del país ${ }^{31}$, un total de $25.236^{32}$ procesos de responsabilidad fiscal, en cuantía de $\$ 42.998 .670 .292 .022$. Revisado el origen de tales procesos de responsabilidad fiscal, se identificó que el 67,36\% fue originado por hallazgos de auditoría; el $18,75 \%$ por otras formas de control fiscal y el $13,89 \%$ fue abierto con base en denuncias de participación ciudadana.

Calculada la razón matemática entre el número de hallazgos fiscales identificados en auditoria entre 2012 y 2017 y el número de procesos de responsabilidad fiscal abiertos en el mismo periodo, fue de 1:1,30; es decir que por cada hallazgo fiscal que se identificó en auditoría, se dio apertura a más de un proceso de responsabilidad fiscal. De la misma manera, en términos de cuantías, se estableció que, por cada peso identificado en hallazgo fiscal de auditoria, se dio apertura a dos pesos en proceso de responsabilidad fiscal, siendo la razón matemática 1:2,07.

Se desprende de lo anterior, que durante las 6 vigencias del periodo de estudio (2012-2017) el proceso auditor adelantado por los órganos de control fiscal del país ${ }^{33}$ fue eficaz, toda vez que se concluyó, desde la generalidad de su gestión, que tanto el número de hallazgos fiscales producto del proceso auditor, como su cuantía, tienen una relación matemática positiva con relación al número y cuantía de los procesos de responsabilidad fiscal abiertos en el mismo periodo.

\subsection{RESULTADO DE LOS PROCESOS DE RESPONSABILIDAD FISCAL 2012-2017.}

Aspecto importante para describir el comportamiento del control fiscal en Colombia, son sus resultados en términos de eficiencia y eficacia. Es de precisar que, tanto los procesos de responsabilidad fiscal, como los procesos de cobro coactivo, son eslabones finales de la cadena de valor del proceso de auditoría de control fiscal, y son medios sine qua non, para identificar responsabilidades fiscales y el grado de culpa de los gestores fiscales ${ }^{34}$; y para

31 Sin tener en cuenta a la Contraloría de Bogotá D.C., que no es sujeto vigilado de AGR desde 2013.

32 Tomando como fuente la información consolidada y depurada de procesos de responsabilidad fiscal verbales y ordinarios que sirvió de base para el estudio de oralidad (Ordóñez, 2019).

33 Sin tener en cuenta a la Contraloría de Bogotá D.C., que no es sujeto vigilado de AGR desde 2013.

34 Son gestores fiscales los servidores públicos y las personas de derecho privado que manejen 0 administren recursos o fondos públicos, que realizan actividades económicas, jurídicas y tecnológicas, tendientes a la adecuada y correcta adquisición, planeación, conservación, administración, custodia, explotación, enajenación, consumo, adjudicación, gasto, inversión y disposición de los bienes públicos, la recaudación, manejo e inversión de sus rentas en orden a cumplir los fines esenciales del Estado y con sujeción a los principios de legalidad, eficiencia, economía, eficacia, equidad, imparcialidad, moralidad, transparencia, publicidad y valoración de los costos ambientales (Artículo 30 Ley 610 de 2000)

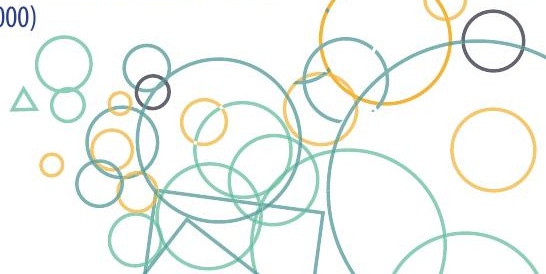




\section{OPPCF}

obtener el resarcimiento de los daños ocasionados al patrimonio público en los casos en que corresponda.

Definido el proceso de responsabilidad fiscal como el conjunto de actuaciones administrativas adelantadas por los órganos de control fiscal con el fin de determinar y establecer la responsabilidad de los gestores fiscales que causan por acción u omisión, y en forma dolosa o culposa un daño al patrimonio del Estado ${ }^{35}$; es importante tener en cuenta la premisa de que no siempre que hay un probado daño patrimonial al Estado, es posible resarcirlo. Premisa que cobra especial importancia al momento de evaluar o calificar la gestión en procesos de responsabilidad fiscal. Por ejemplo, si a lo largo del proceso de responsabilidad fiscal el investigado demuestra que el daño se causó por culpa leve o descuido, no hay lugar a fallarle con responsabilidad fiscal porque la Corte Constitucional, en sentencia C-619 de 2000, dejó sin dientes el proceso, al exigir a los órganos de control fiscal del país la obligatoriedad de probar culpa grave, asimilable a dolo, como requisito para fallar con responsabilidad fiscal y obtener el resarcimiento del daño. (T. Ordóñez, 2007)

En ese contexto, para concluir sobre el resultado de los procesos de responsabilidad fiscal adelantados por los distintos órganos de control fiscal del país, se tomó como punto de partida la información recopilada y depurada que sirvió de fuente para el estudio denominado Eficacia de la Oralidad en los Procesos de Responsabilidad Fiscal (Ordóñez, 2019) ${ }^{36}$, además de la información reportada por los órganos de control fiscal del país ${ }^{37}$ entre el $1^{\circ}$ de enero de 2012 y el 31 de diciembre de 2017 en el módulo SIA-SIREL de la AGR.

Se entran a describir, partiendo del recurso humano destinado al trámite de procesos fiscales, los resultados obtenidos del análisis de la gestión de los procesos de responsabilidad fiscal tanto ordinarios como verbales, la oralidad que introdujo el Estatuto Anticorrupción, y lo resultados de los procesos de jurisdicción coactiva, en términos de eficiencia.

\subsubsection{Recurso humano que adelanta procesos fiscales 2012-2017}

La cantidad de recurso humano que los órganos de control fiscal ${ }^{38}$ destinaron al trámite de los procesos fiscales entre 2012 y 2017, fue un factor sustancial para la gestión y los resultados del control fiscal, la determinación de los elementos de la responsabilidad fiscal, la identificación del daño patrimonial al Estado y su consecuente resarcimiento.

Partiendo de la información reportada en el módulo SIA-SIREL de la AGR durante el periodo

35 Según el texto del artículo $1^{\circ}$ de la Ley 610 de 2000. Documento de trabajo AGR en proceso de publicación.

Sin tener en cuenta a la Contraloría de Bogotá D.C., que no es sujeto vigilado de AGR desde 2013 ídem. 
en estudio, se encontró que solo el 13,31\% de los funcionarios de las plantas de cargos de los órganos de control fiscal ${ }^{39}$ se dedicó a adelantar procesos fiscales; no obstante ser la función misional orientada a la determinación de responsabilidades fiscales y el recaudo efectivo del daño patrimonial causado al patrimonio público.

Por otro lado, calculando el porcentaje de los cargos de planta de los órganos de control fiscal que se dedican al trámite de procesos fiscales, el análisis empírico permitió comparar la mediana estadística por año, del porcentaje referido, valor que se toma como parámetro de comparación sólido entre las vigencias de estudio, en la medida en que su cálculo no admite afectación por datos extremos.

En consecuencia, se determinó empíricamente que dicha mediana de cargos dedicados a adelantar procesos fiscales tuvo un comportamiento directamente proporcional con el porcentaje de procesos de responsabilidad fiscal abiertos en las distintas vigencias de estudio. Por ejemplo en los años en que la mediana fue más alta (casi llegó al 16\% de personal de planta dedicado a adelantar procesos de responsabilidad fiscal), fue en 2013 y 2014, y en esas dos vigencias se dio apertura al $42,13 \%$ de los procesos abiertos a lo largo de los seis años de estudio; y quedaron ejecutoriados con decisión definitiva el 30\% del total de los terminados en ese periodo.

Ahora bien, con el fin de determinar qué tantos procesos de responsabilidad fiscal tuvo que tramitar entre 2012 y 2017 cada funcionario que adelantó procesos, el análisis empírico permitió concluir que los 25.236 procesos de responsabilidad fiscal que fueron abiertos y tramitados durante ese periodo por los órganos de control fiscal del país ${ }^{40}$, fue gestionado por los funcionarios que detentaban 5.913 cargos misionales en total. En consecuencia, a cada funcionario que adelantó procesos fiscales le correspondió tramitar, entre 2012 y 2017, un promedio aritmético de 4,26 procesos de responsabilidad fiscal, sin contar los procesos de responsabilidad fiscal que venían en trámite a $1^{\circ}$ de enero de 2017 , los de cobro coactivo y los sancionatorios que le pudieran haber correspondido.

En el mismo sentido, el cálculo de la mediana estadística de los valores discriminados por órgano de control fiscal es de 30,72 procesos por funcionario, siendo el dato más bajo observado el de 2 procesos de responsabilidad fiscal por funcionario, y el dato más alto reportado, de 153 procesos de responsabilidad fiscal por funcionario en una contraloría.

\subsubsection{Procesos de responsabilidad fiscal tramitados por procedimiento ordinario 2012-} 2017.

El análisis empírico permitió concluir que entre el $1^{\circ}$ de enero de 2012 y el 31 de diciembre 39 ídem

40 ídem

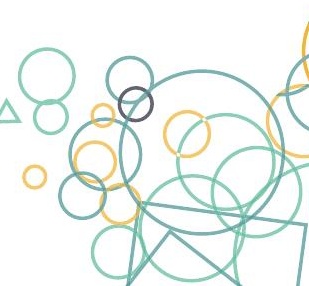




\section{OPPCF}

de 2017 los órganos de control fiscal ${ }^{41}$ dieron apertura a un total a 21.623 procesos de responsabilidad fiscal por procedimiento ordinario, en cuantía de \$39.944.252.871.509.

De ese total, y durante ese mismo periodo según lo reportado, fueron terminados con decisión de fondo ejecutoriada 9.155 procesos de responsabilidad fiscal tramitados por procedimiento ordinario, y cuya cuantía de apertura había sido de $\$ 6.854 .487 .884 .182$, lo que corresponde al $42,34 \%$, de los procesos de responsabilidad fiscal abiertos por procedimiento ordinario en dicho periodo, y al $17,16 \%$ de su cuantía de apertura.

El $24,23 \%$ de los procesos terminados, lo fue por fallo con responsabilidad fiscal o archivo por pago ejecutoriados, decisiones de fondo con las que se obtuvo un recaudo efectivo inicial en el periodo investigado, de un total de \$223.543.554.681. Se afirma como recaudo inicial, en la medida en que no se puede conjeturar a cuánto pueda ascender el recaudo posterior por indexación, acuerdos de pago, cobro persuasivo, o los procesos de jurisdicción coactiva, correspondientes.

El restante $75,77 \%$ de los procesos terminados, acabó y fue archivado por razones diferentes. La de mayor frecuencia, (72,67\%), en total de 6.653 decisiones de fondo y cuantía de apertura total de \$5.774.365.726.881, fue por fallos sin responsabilidad fiscal y archivos por no mérito ejecutoriados, es decir por no haberse configurado los elementos de la responsabilidad fiscal: daño, culpa grave y nexo causal.

\subsubsection{Procesos de responsabilidad tramitados por procedimiento verbal 2012-2017.}

El análisis permitió determinar que, entre el $1^{\circ}$ de enero de 2017 y el 31 de diciembre de 2017, los órganos de control fiscal ${ }^{42}$ dieron apertura a un total a 3.613 procesos de responsabilidad fiscal por procedimiento verbal, en cuantía de $\$ 3.054 .417 .420 .513$.

De ese total, y durante el mismo periodo según lo reportado fueron terminados, con decisión de fondo ejecutoriada, 1.800 procesos de responsabilidad fiscal tramitados por procedimiento verbal, y cuya cuantía de apertura había sido de $\$ 891.108 .949 .481$, lo que corresponde al $49,82 \%$, de los procesos de responsabilidad fiscal abiertos por procedimiento verbal en dicho periodo, y al $29,17 \%$ de su cuantía de apertura.

El 44,89\% de los procesos terminados, lo fue por fallo con responsabilidad fiscal o archivo por pago ejecutoriados, decisiones de fondo que permitieron un recaudo efectivo inicial en el periodo investigado, de un total de $\$ 30.973 .354 .274$. Inicial, en la medida en que no se puede conjeturar a cuánto pueda ascender el recaudo posterior por indexación, acuerdos de pago, 41 Ídem.

42 ídem. 
cobro persuasivo, o los procesos de jurisdicción coactiva, correspondientes.

El restante $55,11 \%$ de los procesos terminados, acabó y fue archivado por otras razones. La de mayor frecuencia, (53,50\%), en total de 963 decisiones de fondo, y cuantía de apertura total de $\$ 528.174 .071 .121$, fue por fallos sin responsabilidad fiscal y archivos por no mérito ejecutoriados, es decir por no haberse configurado los elementos de la responsabilidad fiscal: daño, culpa grave y nexo causal.

\subsubsection{Recaudo en procesos de responsabilidad fiscal tramitados por procedimiento ordinario 2012-2017.}

Según el análisis empírico, fueron suscritos y quedaron ejecutoriadas 2.218 decisiones entre fallos con responsabilidad fiscal y autos de archivo por pago entre 2012 y 2017 , y con base en ellas se recaudó un total de $\$ 223.543 .554 .681$.

Adicional a lo anterior, se concluye que, de los 12.468 procesos de responsabilidad fiscal abiertos por procedimiento ordinario que a 31 de diciembre de 2017 continuaban en trámite, los órganos de control fiscal ${ }^{43}$ había recaudado a esa fecha la suma de $\$ 103.795 .434 .667$. Lo descrito permite determinar el total del recaudo por procesos de responsabilidad fiscal tramitados por procedimiento ordinario, de $\$ 327.338 .989 .348$, exclusivamente durante el periodo en estudio, valor que tiende a aumentar después con lo que se recaude en cumplimiento de acuerdos de pago, el pago voluntario de los investigados y los procesos de jurisdicción coactiva.

Por otro lado, es de precisar que la cuantía de apertura de un proceso de responsabilidad fiscal es una tasación preliminar del daño patrimonial investigado; y que no es igual a la cuantía de los fallos con responsabilidad fiscal que los procesos puedan generar, porque la inicial se somete a valoraciones probatorias y decisiones de fondo a lo largo del proceso, que además incluyen el cálculo de la indexación (valor presente).

La claridad de lo afirmado permite concluir que no es práctico, ni técnico comparar, en términos de gestión, ese valor inicial de apertura, con el valor recaudado a lo largo del proceso o al final de él. No obstante, teóricamente se puede establecer, solo para efectos hipotéticos que la relación matemática entre el valor total de los autos de apertura de los procesos abiertos por procedimiento ordinario en el periodo de estudio, y el valor de lo recaudado en tales procesos en ese mismo lapso es de 122:1.

\subsubsection{Recaudo en procesos de responsabilidad fiscal tramitados por procedimiento} verbal 2012-2017.

$43 \quad$ ídem

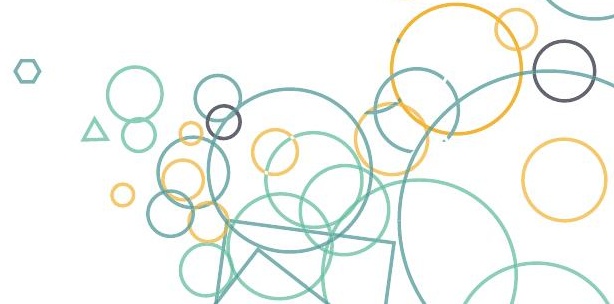


Según el análisis empírico, fueron suscritos y quedaron ejecutoriadas 808 decisiones entre fallos con responsabilidad fiscal y autos de archivo por pago entre 2012 y 2017, y con base en ellas se recaudó un total de \$30.973.354.274.

Adicional a lo anterior, de los 1.813 procesos de responsabilidad fiscal abiertos por procedimiento verbal que a 31 de diciembre de 2017 continuaban en trámite, los órganos de control fiscal ${ }^{44}$ habían recaudado a esa fecha la suma de $\$ 7.018 .908 .170$. Lo descrito permite determinar el total del recaudo por procesos de responsabilidad fiscal tramitados por procedimiento verbal, de \$37.992.262.444, exclusivamente durante el periodo en estudio, suma que tiende a aumentar después con lo que se recaude en cumplimiento de acuerdos de pago, el pago voluntario de los investigados y los procesos de jurisdicción coactiva.

Por otro lado, precisado el hecho que no es no es técnicamente válido comparar los dos valores, igual que se hizo en lo que respecta a procesos ordinarios, se establece de manera puramente académica una relación matemática de 80:1, entre el valor total de los autos de apertura de los procesos abiertos por procedimiento verbal en el periodo de estudio, y el valor de lo recaudado en tales procesos en ese mismo lapso.

\subsubsection{Ocurrencia de los fenómenos de prescripción y caducidad en los procesos de responsabilidad fiscal 2012-2017.}

Tanto la caducidad como la prescripción son dos fenómenos jurídicos que ocurren por el paso del tiempo. En virtud de la primera, la acción fiscal caduca a los cinco años, contados a partir de la ocurrencia del hecho sin que se hubiera abierto proceso de responsabilidad fiscal. En virtud de la segunda la responsabilidad fiscal prescribe, cinco años contados a partir de la notificación del auto de apertura proceso sin que se hubiera suscrito decisión de fondo que pusiera fin al mismo.

El análisis empírico permitió concluir que el 3,10\% de los procesos de responsabilidad fiscal abiertos por procedimiento ordinario entre el $1^{\circ}$ de enero de 2012 y el 31 de diciembre de 2017, y culminados en ese mismo periodo, fue terminado anormalmente por ocurrencia de los fenómenos de caducidad de la acción fiscal o de prescripción de la responsabilidad fiscal, en cuantía total de \$189.013.207.820. De ese porcentaje, 1,75\% correspondió a archivados por caducidad de la acción fiscal y el restante 1,35\% a prescripción de la responsabilidad fiscal.

Ahora bien, en lo que respecta a la ocurrencia de tales fenómenos en los procesos de responsabilidad fiscal tramitados por procedimiento verbal, con base en lo reportado a la AGR en las cuentas del periodo estudiado, el análisis empírico permitió concluir que de todos

$44 \quad$ ídem 
los abiertos y culminados en ese término, el 1,5\% fue terminado anormalmente por ocurrencia de los fenómenos de caducidad de la acción fiscal o de prescripción de la responsabilidad fiscal, en cuantía total de $\$ 22.028 .110 .898$. De ese porcentaje, $0,83 \%$ correspondió a archivados por caducidad de la acción fiscal y el restante $0,67 \%$ a prescripción de la responsabilidad fiscal.

\subsubsection{Otros resultados de gestión de los procesos de responsabilidad fiscal tramitados por procedimiento ordinario 2012-2017.}

En la medida en que la evaluación de la gestión procesos de responsabilidad fiscal involucra mucho más que el recaudo efectivo, y que la finalidad del proceso -según explica el artículo $1^{\circ}$ de la Ley 610 de 2000- es determinar y establecer responsabilidad frente a situaciones identificadas de daño patrimonial al Estado, y no es, como se suele confundir, simplemente recaudar dinero, es probo referir en este estudio a otros resultados de gestión de procesos de responsabilidad fiscal, distintos al recaudo.

Del amplio espectro de actuaciones administrativas que se debieron adelantar durante el trámite de los 25.236 procesos de responsabilidad fiscal, abiertos por procedimiento ordinario entre 2012 y 2017 por los órganos de control fiscal del país ${ }^{45}$, el análisis de la información reportada permitió concluir que se debieron tramitar primero 3.772 indagaciones preliminares; que se vinculó a las compañías aseguradoras en calidad de terceros civilmente responsables en 14.187 procesos; que se decretaron y registraron medidas cautelares en más de 2.536 procesos; y que se reportaron resueltos más de 9.716 recursos de reposición, apelación contra autos de imputación o fallos con responsabilidad fiscal y grados de consulta.

Es de advertir que en cuando se mide la gestión de procesos de responsabilidad fiscal, hay una serie de figuras procesales que no se reflejan en las rendiciones de cuenta de las contralorías, como por ejemplo nulidades, revocatorias, impedimentos, recusaciones, aplazamientos y reprogramación de diligencias, cambio de abogados, notificaciones, consecución y nombramiento de apoderados de oficio, etc. que deben ser tramitadas con sujeción al debido proceso y en estricta protección del derecho de defensa de los presuntos responsables fiscales; no obstante implicar reprocesos, dilatan el trámite y pueden incluso incidir en la ocurrencia de terminaciones anormales por prescripción o caducidad atrás referidos.

\subsubsection{Otros resultados de gestión de los procesos de responsabilidad fiscal tramitados por procedimiento verbal 2012-2017.}

En el mismo sentido, más allá del recaudo de recursos públicos generado por los procesos de responsabilidad fiscal abiertos y tramitados por procedimiento verbal, la gestión que involucró el poder determinar y establecer responsabilidades frente a situaciones de daño patrimonial al 45 ídem.

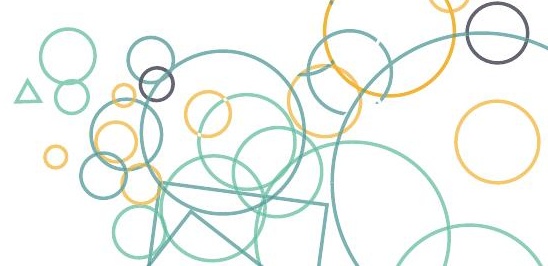


Estado, se describe lo que se observó en el análisis empírico del trámite de los 3.595 procesos de responsabilidad fiscal abiertos por procedimiento verbal entre el $1^{\circ}$ de enero de 2012 y el 31 de diciembre de 2017 por las contralorías del país ${ }^{46}$, así: se debieron tramitar primero 838 indagaciones preliminares; se vinculó a las compañías aseguradoras en calidad de terceros civilmente responsables en 2.653 procesos; se decretaron y registraron medidas cautelares en más de 541; se dio apertura a más de 2.940 audiencias de descargos y a más de 1.647 audiencias de decisión; se suscribieron más de 2.050 decreto de pruebas, y se reportaron resueltos más de 2.079 recursos de reposición, apelación contra autos de imputación o fallos con responsabilidad fiscal y grados de consulta. Es de reiterar que, en términos de medición de la gestión de los procesos verbales también se debe considerar el trámite de las figuras procesales a que se hizo referencia en el punto inmediatamente anterior, y que necesariamente causan dilación procesal.

\subsection{EFICACIA DE LA ORALIDAD EN LOS PROCESOS DE RESPONSABILIDAD FISCAL TRAMITADOS ENTRE 2012 Y 2017.}

La Ley 1474 de 2011 -Estatuto Anticorrupción- introdujo la oralidad en el trámite de los procesos de responsabilidad fiscal como una de las medidas para la eficiencia y eficacia del control fiscal colombiano, en la lucha contra la corrupción.

Según la exposición de motivos de dicha ley ${ }^{47}$, las razones para incluir un procedimiento verbal en el trámite de procesos de responsabilidad fiscal, se concretaron a mejorar los resultados del control fiscal a nivel nacional, que se habían evidenciado bajos por la frecuente ocurrencia de los fenómenos de caducidad de la acción fiscal y prescripción de la responsabilidad fiscal; los términos poco expeditos del procedimiento ordinario, los trámites innecesarios y las debilidades en los mecanismos de notificación procesal. Se buscó, con la introducción de la oralidad en el proceso de responsabilidad fiscal, mejorar la eficiencia y la eficacia del control fiscal en la lucha contra la corrupción y lograr legitimidad del control fiscal frente a la ciudadanía. (Ordóñez, 2019).

Tomando como referente un estudio reciente elaborado en la Auditoría Auxiliar de la Auditoria General de la República con base en la información depurada de lo que reportaron anualmente las contralorías del país en el aplicativo SIA- SIREL de la entidad, y que concluyó de manera soportada sobre resultados concretos de la aplicación del procedimiento verbal (oralidad) por los órganos de control fiscal del país, que:

"Lo anterior permite concluir, en términos de eficacia como principio de desempeño y en el contexto ampliamente descrito que, la oralidad en materia de oportunidad, objetivos y resultados

46 ídem.

47 Gaceta del Congreso №. 607 de 7 de septiembre de 2010 -Senado de la República. 
es ciertamente una herramienta eficaz para adelantar procesos de responsabilidad fiscal.

En conclusión, guardadas las proporciones entre el número de procesos de responsabilidad fiscal tramitados por procedimiento verbal y el número de los tramitados por procedimiento ordinario; y conociendo las dificultades que han tenido los órganos de control fiscal en la puesta en marcha del sistema oral, se demuestra claramente que el procedimiento verbal sí ofrece los resultados y cumple los objetivos y finalidad esperados; pues confirmó haber sido mucho más eficiente que el procedimiento ordinario en procesos de responsabilidad fiscal, resultado atribuible a factores determinantes, como la exigencia de configurar hallazgos sólidos y completos, la inmediación, la celeridad, la concentración, la oportunidad de las decisiones, las medidas cautelares; el temor de las vertiginosas consecuencias de un fallo con responsabilidad fiscal, entre otros.

Los resultados expresan que la oralidad como herramienta si cumple y atiende la motivación expuesta en el proyecto de Ley 1474 de $2011^{48}$, en la medida en que evidentemente mejora los resultados del control fiscal, se contrarresta la ocurrencia de los fenómenos de caducidad de la acción fiscal y de prescripción de la responsabilidad fiscal; se decide con una más alta celeridad y oportunidad, se agilizan las notificaciones, se recauda más y en menor tiempo, y en términos generales se mejora la efectividad del control fiscal en la lucha contra la corrupción y se logra legitimidad del control fiscal frente a la ciudadanía." (T. Ordóñez, 2019).

En ese escenario, para efectos de este capítulo, se buscó analizar empíricamente el grado de eficiencia del procedimiento verbal introducido por el Estatuto Anticorrupción, respecto del procedimiento ordinario reglamentado en la Ley 610 de 2000, se tomó como caso de estudio una situación generadora de daño patrimonial sencilla y concreta: el indebido uso o pago de cheques con recursos públicos.

De la información depurada reportada por las contralorías territoriales ${ }^{49}$ sobre el caso de estudio, se identificó que entre el $1^{\circ}$ de enero de 2012 y el 31 de diciembre de 2017, se dio apertura a 183 procesos de responsabilidad fiscal con el fin de determinar y establecer la responsabilidad de los gestores fiscales que pudieron haber causado daño patrimonial por el indebido uso o pago de cheques con recursos públicos.

En consecuencia, para comparar los resultados entre el procedimiento verbal y el ordinario, se partió de los resultados de los procesos abiertos entre 2012 y 2017 por procedimiento verbal relacionados con el indebido uso o pago de cheques; y de los resultados de los procesos en los que se optó por procedimiento ordinario.

En términos porcentuales, el $22 \%$ del total de los procesos de responsabilidad fiscal abiertos entre 2012 y 2017 orientados a determinar y establecer la responsabilidad de los gestores fiscales que pudieron haber causado el daño patrimonial al usar o pagar indebidamente cheques con recursos públicos, se tramitó por procedimiento verbal, y el $88 \%$ restante, se tramitó por procedimiento ordinario. Se obtuvieron los siguientes resultados:

$48 \quad$ Gaceta del Congreso №. 607 de 7 de septiembre de 2010 -Senado de la República.

49 Sin tener en cuenta a la Contraloría de Bogotá D.C., que no es sujeto vigilado de AGR desde 2013. 
Tabla No. 13. Comparativo de resultados de procesos tramitados por procedimiento verbal y tramitado por procedimiento ordinario, con base en caso de estudio concreto.

\begin{tabular}{|c|c|c|c|c|}
\hline & \multicolumn{2}{|c|}{$\begin{array}{c}\text { Procesos tramitados por } \\
\text { procedimiento VERBAL } \\
\text { (cheques) }\end{array}$} & \multicolumn{2}{|c|}{$\begin{array}{l}\text { Procesos tramitados por } \\
\text { procedimiento ORDINARIO } \\
\text { (cheques) }\end{array}$} \\
\hline $\begin{array}{l}\text { Total de procesos abiertos } \\
\text { 2012- } 2017 \text { (cheques) }\end{array}$ & \multicolumn{2}{|c|}{33} & \multicolumn{2}{|c|}{ (2) } \\
\hline $\begin{array}{l}\text { Cuantía total procesos } \\
\text { abiertos 2012-2017 (cheques) }\end{array}$ & \multicolumn{2}{|c|}{$\$ 2.349 .739 .809$} & \multicolumn{2}{|c|}{$\$ 15.646 .618 .781$} \\
\hline $\begin{array}{l}\text { Total de procesos terminados } \\
\text { en ese mismo periodo } \\
\text { (cheques) }\end{array}$ & 21 & $\begin{array}{l}\text { 63,64 \% de } \\
\text { los verbales } \\
\text { abiertos }\end{array}$ & 61 & $\begin{array}{l}40,67 \% \text { de } \\
\text { los ordinarios } \\
\text { abiertos }\end{array}$ \\
\hline $\begin{array}{l}\text { Total de fallos con } \\
\text { responsabilidad fiscal } \\
\text { y archivos por pago } \\
\text { ejecutoriados en ese mismo } \\
\text { periodo (cheques) }\end{array}$ & 15 & $\begin{array}{l}\mathbf{7 1 , 4 3} \% \text { de } \\
\text { los verbales } \\
\text { terminados }\end{array}$ & 27 & $\begin{array}{l}44,26 \% \text { de } \\
\text { los ordinarios } \\
\text { terminados }\end{array}$ \\
\hline $\begin{array}{l}\text { Cuantía total del recaudo } \\
\text { obtenido por fallos con } \\
\text { responsabilidad fiscal, en } \\
\text { trámite y archivos por pago } \\
\text { ejecutoriados. (cheques) }\end{array}$ & $\$ 134.510 .509$ & $\begin{array}{l}\mathbf{5 , 7 2} \% \text { de la } \\
\text { cuantía total } \\
\text { de los verbales } \\
\text { abiertos }\end{array}$ & & $\begin{array}{l}2,06 \% \text { de la } \\
\text { cuantía total de } \\
\text { los ordinarios } \\
\text { abiertos }\end{array}$ \\
\hline $\begin{array}{l}\text { Total de prescripciones y } \\
\text { caducidades reportadas } \\
\text { (cheques) }\end{array}$ & 0 & - & 0 & - \\
\hline $\begin{array}{l}\text { Promedio de duración de } \\
\text { los procesos desde que } \\
\text { se abrieron hasta que se } \\
\text { terminaron }\end{array}$ & 366 días & 1 año & 846 & 2,32 años \\
\hline
\end{tabular}

Se concluyó, con base en lo observado, que: 1) El procedimiento verbal superó en un 22,97\% al porcentaje de los procesos terminados en ese mismo periodo por procedimiento ordinario. 2) El procedimiento verbal superó en un $27,17 \%$ el porcentaje de los fallos con responsabilidad fiscal y archivos por pago derivados de procesos tramitados por procedimiento ordinario, en ese mismo periodo, 3) superó en un 3,66\% la cuantía total del recaudo obtenido por fallos con responsabilidad fiscal y archivos por pago y 4) permitió decidir los procesos en promedio de 1,32 años antes que si se hubieran tramitado por ordinarios.

Además, se identificó que, de los 101 procesos relacionados con cheques, abiertos en el periodo estudiado y que continuaban a 31 de diciembre de 2017 abiertos, su estado a esa fecha era más avanzado en los verbales. De los 89 procesos tramitados por procedimiento ordinario: 73 estaban con auto de apertura y antes de imputación; 12 con auto de imputación 
y antes de fallo; 3 decidiendo recursos contra fallo de primera instancia y 1 decidiendo grado de consulta. En el mismo sentido, de los 12 procesos tramitados por procedimiento ordinario: 4 se encontraban en etapa previa a la audiencia de descargos; 5 en etapa de audiencia de descargos; 1 decidiendo recursos contra el fallo y 2 decidiendo el grado de consulta.

Por otro lado, con la misma finalidad académica, entre los referidos 183 procesos de responsabilidad fiscal se buscaron dos procesos con características lo más similar posible, el primero tramitado por procedimiento verbal y el segundo por ordinario:

\section{Tabla No. 14. Comparativo de resultados entre dos procesos de responsabilidad fiscal con características muy similares, tramitado uno por procedimiento verbal y otro por procedimiento ordinario.}

\begin{tabular}{|c|c|c|}
\hline & $\begin{array}{l}\text { Proceso tramitado por } \\
\text { procedimiento verbal }\end{array}$ & $\begin{array}{l}\text { Proceso tramitado por } \\
\text { procedimiento ordinario }\end{array}$ \\
\hline Contraloría & Departamental X & Departamental Y \\
\hline Auto de apertura & 29 de agosto de -2012 & 18 de abril de 2012 \\
\hline Presunto detrimento & $\$ 225.303 .000$ & $\$ 217.260 .000$ \\
\hline $\begin{array}{l}\text { Fecha fallo con responsabilidad } \\
\text { fiscal }\end{array}$ & 3 de abril de-2014 & - \\
\hline $\begin{array}{l}\text { Fecha decide recurso apelación } \\
\text { contra fallo }\end{array}$ & 4 de julio abril de 2014 & - \\
\hline Fecha resuelve grado de consulta & 9 de julio de 2014 & - \\
\hline $\begin{array}{l}\text { Estado reportado a } 31 \text { de } \\
\text { diciembre de } 2017\end{array}$ & $\begin{array}{c}\text { Fallo con responsabilidad } \\
\text { fiscal ejecutoriado, y en cobro } \\
\text { coactivo por } \$ 239.977 .704\end{array}$ & $\begin{array}{c}\text { En trámite con auto } \\
\text { de apertura y antes de } \\
\text { imputación (alto riesgo de } \\
\text { prescripción) }\end{array}$ \\
\hline
\end{tabular}

Como se describe claramente en la tabla anterior, el análisis empírico del caso de estudio confirmó, lo concluido en el documento de trabajo referido, que efectivamente es más eficiente el proceso tramitado por procedimiento verbal, que el tramitado por procedimiento ordinario, desde todos los puntos de comparación.

\subsection{RESULTADO DEL PROCESO DE JURISDICCIÓN COACTIVA.}

Entendido el proceso de jurisdicción coactiva ${ }^{50}$, o cobro coactivo ${ }^{51}$, como la facultad de los órganos de control para cobrar los créditos fiscales contenidos en los fallos con responsabilidad fiscal plasmados en providencias debidamente ejecutoriadas, las pólizas de seguros a favor de las entidades públicas que se integren a ellos, y las sanciones y otros títulos ejecutivos, en ese contexto, con el objetivo de describir algo del comportamiento de tales procesos fiscales, se tomó como punto de partida la información reportada por los órganos de control fiscal del

50 De acuerdo con los artículos 90 y 92 de la Ley 42 de 1993

51 Como refiere a dicha facultad el artículo $5^{\circ}$ de la Ley 1066 de 2006.

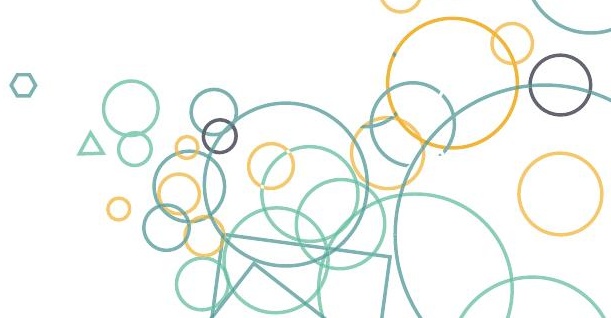




\section{OPPCF}

país ${ }^{52}$ entre el $1^{\circ}$ de enero de 2012 y el 31 de diciembre de 2017 en el módulo SIA-SIREL de la AGR en lo concerniente procesos de jurisdicción coactiva.

El análisis empírico permitió concluir que entre el $1^{\circ}$ de enero de 2012 y el 31 de diciembre de 2017 las contralorías del país notificaron el mandamiento de pago en 5.013 procesos de jurisdicción coactiva, con base en títulos ejecutivos por cuantía total de \$434.103.987.751.

De esos, el 83,56\%, (4.189) seguían en trámite al final del periodo en estudio -31 de diciembre de 2017- y, según lo reportado se había obtenido a esa fecha un recaudo de \$51.952.155.179.

El restante $16,44 \%$ de los procesos de cobro coactivo abiertos en el periodo estudiado, fue finalizado y generó un recaudo de $\$ 7.019 .860 .779$ con base en 824 títulos ejecutivos.

En consecuencia, el análisis empírico de lo reportado permite concluir que entre $1^{\circ}$ de enero de 2012 y el 31 de diciembre de 2017 las contralorías del país recaudaron en desarrollo del proceso de jurisdicción coactiva abiertos en ese periodo, cerca de \$58.972.015.958, que representa el $14 \%$ de la cuantía total de los títulos ejecutivos de tales procesos.

En la medida en que la evaluación de la gestión de cobro involucra mucho más que recaudo efectivo, y que las dificultades para recaudar las deudas fiscales son una constante para las entidades públicas, es preciso referir que en el trámite de los 5.013 procesos de jurisdicción coactiva abiertos y tramitados entre el $1^{\circ}$ de enero de 2012 y el 31 de diciembre de 2017 por las contralorías del país, 1.233 fueron objeto de práctica de medidas cautelares y 889 de inscripción de estas. Se determinó de lo reportado, que 443 medidas cautelares recayeron sobre inmuebles, 660 sobre muebles, 335 afectaron las cuentas bancarias; 278 los salarios y 133 recayeron sobre otros bienes de los ejecutados. Adicionalmente, se observó que la tarea de cobro persuasivo fue efectiva en 1.100 de esos procesos abiertos en el periodo en estudio, por pago voluntario o a través de acuerdo de pago.

\subsection{HALLAZGOS Y PROCESOS DE RESPONSABILIDAD FISCAL DERIVADOS DE CONTROL FISCAL A LA GESTIÓN AMBIENTAL 2012-2017}

La valoración de los costos ambientales a cargo de las contralorías del país es una de las piedras angulares de la vigilancia de la gestión fiscal. Es un principio constitucional del control fiscal.

El artículo 267 de la Constitución Política de Colombia establece que "la vigilancia de la gestión fiscal del Estado incluye el ejercicio de un control financiero, de gestión y de resultados, fundado en la eficiencia, la economía, la equidad y la valoración de los costos ambientales".

52 Sin contar a la Contraloría de Bogotá D.C., que no rinde cuentas a la AGR porque no es su sujeto vigilado. 
(Resaltado fuera del texto)

Adicionalmente, el ordenamiento constitucional en su artículo 46 establece a las entidades vigiladas por la Contraloría General de la República, la obligatoriedad de "incluir en todo proyecto de inversión pública, convenio, contrato o autorización de explotación de recursos, la valoración en términos cuantitativos del costo beneficio sobre conservación, restauración, sustitución, manejo en general de los recursos naturales y degradación del medio ambiente, así como su contabilización y el reporte oportuno a la Contraloría."

Al respecto, el artículo 8º de la Ley 42 de 1993 establece:

"La vigilancia de la gestión fiscal del Estado se fundamenta en la eficiencia, la economía, la eficacia, la equidad y la valoración de los costos ambientales, de tal manera que permita determinar en la administración, en un período determinado, que la asignación de recursos sea la más conveniente para maximizar sus resultados; que en igualdad de condiciones de calidad los bienes y servicios se obtengan al menor costo; que sus resultados se logren de manera oportuna y guarden relación con sus objetivos y metas. Así mismo, que permita identificar los receptores de la acción económica y analizar la distribución de costos y beneficios entre sectores económicos y sociales y entre entidades territoriales y cuantificar el impacto por el uso o deterioro de los recursos naturales y el medio ambiente y evaluar la gestión de protección, conservación, uso y explotación de estos.

La vigilancia de la gestión fiscal de los particulares se adelanta sobre el manejo de los recursos del Estado para verificar que estos cumplan con los objetivos previstos por la administración". (Resaltado fuera del texto)

En desarrollo de lo anterior, la Contraloría General de la República define el principio de valoración de costos ambientales como"la obligación del Estado (actores públicos y privados) de identificar, evaluar (medir cuantitativa y/o cualitativamente) e incorporar en la toma de decisiones los costos y beneficios ambientales que se generan por las actividades humanas y que afectan positiva o negativamente a la naturaleza" (CGR, 2018. Procedimiento Especializado de Auditoría a la aplicación del Principio de Valoración de Costos Ambientales. p.3)

Por otra parte, el control fiscal ambiental se define como:

“Una herramienta de evaluación de la gestión de las entidades públicas, con el fin de proteger las inversiones en materia ambiental y evaluar las acciones encaminadas al mejoramiento del ambiente, y a su vez, que se dé un uso racional a los recursos naturales y al ambiente. Es una función de naturaleza pública, que se desarrolla a través de un conjunto de técnicas y procedimientos que tienen por objetivo vigilar y controlar las entidades de carácter público, privadas y mixtas que intervienen en el uso, conservación, protección y explotación de los recursos naturales y el ambiente." (Escudero, 2015)

"En este marco, los objetivos que se persiguen a través del control fiscal ambiental se circunscriben a valorar que i) se dé la destinación y aplicación correcta a los recursos presupuestales asignados para el manejo, protección, conservación y recuperación ambiental; ii) las entidades realicen las inversiones requeridas para cumplir con las funciones asignadas por la ley en materia ambiental; iii) las entidades vigiladas cumplan con los deberes

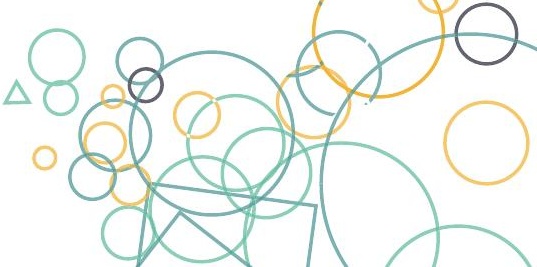




\section{OPPCF}

constitucionales y legales de garantizar el derecho de las personas a gozar de un ambiente sano y de proteger la diversidad e integridad del ambiente; y iv), que las entidades y particulares den cumplimiento a los requerimientos exigidos por la autoridad y la legislación ambiental en el desarrollo de la gestión ambiental o de las actividades relacionadas con el uso, disfrute o explotación del ambiente." (Molina, 2017)

La Auditoría General de la República ha aportado en desarrollo de la función legal de coadyuvancia, a lo largo de los años, referentes teórico prácticos sobre control fiscal ambiental y responsabilidad fiscal en la materia, como "El Control Fiscal Ambiental en Colombia (2007)" y con el apoyo del Departamento de Investigaciones Ambientales de la Universidad Externado de Colombia elaboró un instrumento denominado "Criterios de auditoria que fundamentan la función que debe realizar la Auditoría General de la República a las contralorías en ejercicio del control fiscal ambiental (2015)", con la ruta crítica para determinar el alcance y procedimientos de evaluación de las contralorías hacia sus entidades vigiladas.

Por su parte, la Contraloría General de la República, de la mano con el Instituto de Estudios Ambientales -IDEA- de la Universidad Nacional, y gracias a un proyecto de cooperación con Canadá, cuenta desde finales de 2018 con el Procedimiento Especializado de Auditoria a la aplicación del Principio de Valoración de Costos Ambientales, como un instrumento teórico práctico actualizado en el marco de las normas ISSAI, para aplicar según el caso, en desarrollo de auditorías de cumplimiento, de desempeño o financieras.

\subsubsection{Hallazgos fiscales identificados en auditorías al Proceso de Gestión Ambiental 2012-2017.}

En ese contexto general, se propuso para esta investigación partir de los hallazgos fiscales de auditoria, identificados y trasladados por las contralorías del país entre el $1^{\circ}$ de enero de 2012 y el 31 de diciembre de 2017, concretamente los obtenidos como resultado de auditorías al proceso de gestión ambiental.

No se incluyen en el estudio los hallazgos que no obstante relacionarse con temas ambientales, se hubieran generado por auditorías a otros distintos, como por ejemplo a procesos de contratación pública, a programas y proyectos, a obras de infraestructura, proyectos de inversión, entre otras, toda vez que en las rendiciones de cuenta de las contralorías no hay manera de identificarlos.

Entre 2012 y 2017, las contralorías del país reportaron haber identificado en auditorías al proceso de gestión ambiental concretamente, 310 hallazgos fiscales por cuantía de \$61.217.900.608, así: la Contraloría General de la República reportó 103 hallazgos fiscales, y las contralorías territoriales reportaron 207 hallazgos fiscales (Cundinamarca 30, Huila 25, Valle 
del Cauca 23, Cesar 22, Tolima y Córdoba 11 cada una; Bolívar 9, Cali 8, Meta 6, Santander, Ibagué y Caquetá 5 cada una; Tunja, Norte de Santander, Medellín, Caldas y Arauca 4 cada una; Bello y Guajira 3 cada una; Villavicencio, Sucre y envigado, 2 cada una; y Antioquia, Armenia, Barrancabermeja, Buenaventura, Cartagena, Cauca, Floridablanca, Magdalena, Palmira, Pasto, Popayán, Putumayo, Soledad, Tuluá y Yumbo, 1 cada una.)

El análisis empírico de esos 310 hallazgos fiscales identificados como resultado de auditorías efectuadas al proceso de gestión ambiental permitió concluir que, 55 hallazgos generaron apertura de proceso de responsabilidad fiscal, 43 hallazgos dieron lugar a la apertura de indagación preliminar, uno fue archivado en etapa de hallazgo por resarcimiento del daño (CGR $\$ 1.365 .892)$, tres fueron devueltos al proceso auditor y los restantes 208 fueron reportados en etapa de estudio.

Revisados los temas de los hallazgos se encontró que, entre muchos y variados asuntos, los de mayor frecuencia, fueron:

Contratación pública. El 40,65\% hallazgos, es decir (126) se relacionaron con contratación pública, entre otros en temas como: planes de manejo ambiental (PMA); planes de saneamiento y manejo de vertimientos; estudios de impacto ambiental; programas de ahorro y uso eficiente del agua; saneamiento básico ambiental, rellenos sanitarios; planes municipales de gestión de riesgo de desastres, caracterización de aguas residuales y compra de predios.

Sanciones. El 11,61\% de los hallazgos (36) se causaron por el pago de sanciones, ambientales y no ambientales, con recursos públicos, el 2,6\% interpuestas por las corporaciones autónomas regionales, y las demás por la Superintendencia de Servicios Públicos Domiciliarios, el Departamento Administrativo del Medio Ambiente (DAMA) y el INVIMA. En materia de tema, las sanciones de mayor frecuencia fueron las relacionadas con el suministro de agua no apta para consumo humano según IRCA; permisos de vertimientos, plantas de beneficio animal, manejo de residuos hospitalarios, y manejo de residuos sólidos.

El 31,29\% de los hallazgos (97) se relacionaron con temas como: canon superficiario en áreas de concesión (9,7\%); tasa retributiva e intereses de mora (6,1\%); Plantas de tratamiento de Aguas Residuales -PTAR (5,2\%); afectación de recurso arbóreo (3,2\%); compensación forestal $(1,6 \%)$; tasa de uso por concesión de aguas subterráneas $(0,6 \%)$; convenios de asociación, Plan de Gestión Integral de Residuos Hospitalarios-PGIRH; Plan de Manejo Ambiental; plantas de beneficio animal, vertimientos, plantas de transferencia de residuos

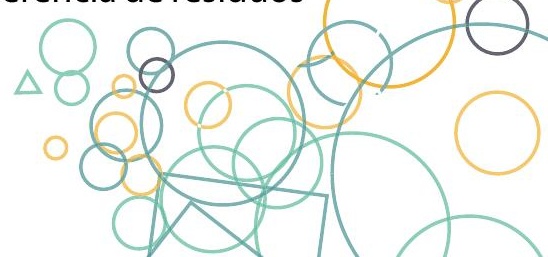


sólidos, plan de adaptación a guía ambiental -PAGA, deterioro superficial, tasa por uso del agua, plan institucional de gestión ambiental -PIGA-.

\subsubsection{Procesos de responsabilidad fiscal en materia ambiental 2012-2017.}

Sin entrar a conceptos de daño ambiental, daño ecológico, las diferencias doctrinarias entre ambos tipos de daño; o las dificultades que durante el periodo investigado pudieron existir por falta de experiencia o conocimiento de las contralorías territoriales en materia de valoración de daño ambiental; o entrar en la discusión de si las multas impuestas en derecho sancionatorio ambiental son o no daño patrimonial en desarrollo de gestión fiscal ambiental; o las dificultades y el alcance del control fiscal ambiental; o las problemáticas de tipo técnico y económico que pueden tener las contralorías; o las diferentes deficiencias legales, teóricoconceptuales e institucionales en el ejercicio del control fiscal ambiental (Molina, 2017 p.42); se propuso a título académico en esta investigación, tratar de identificar los procesos de responsabilidad fiscal abiertos por las contralorías del país ${ }^{53}$ entre el $1^{\circ}$ de enero de 2012 y el 31 de diciembre de 2017, relacionados con recursos públicos de gestión fiscal ambiental, en la medida en que la información de cuenta que reposa en el módulo SIA-SIEL no permite hacerlo.

Así pues, en los 25.236 procesos de responsabilidad fiscal abiertos en ese periodo por las contralorías del país (Ordóñez, 2019), se buscó identificar los que incluyeran en su descripción palabras como: ambiental, saneamiento básico, vertimientos, aire, flora, suelo, paisaje, relleno sanitario, sanción ambiental, beneficio animal, planta de tratamiento de aguas residuales, residuos sólidos, residuos hospitalarios, PTAR, recurso arbóreo, compensación forestal, deterioro superficial, daño ambiental, daño ecológico, derrame de crudo, petróleo, material vegetal, riesgo ambiental, contaminación, lixiviados, lodos, ecosistema, recursos naturales, plantaciones forestales, reforestación, biodiversidad, incentivo forestal, plan de manejo ambiental.

Una vez reconocidos, se excluyeron los procesos que se concretaban específicamente a temas como, alcantarillado, acueducto, redes de agua doméstica, redes de agua lluvia, salud ambiental, transferencia ambiental, urbanismo, ornamentación, planta de tratamiento de agua potable, tasa de aprovechamiento forestal, tasa de uso de agua, tasa de uso de suelo, tasa retributiva por vertimientos, sobretasa ambiental, canon superficiario.

Como resultado de ese ejercicio académico, se identificaron 300 procesos de responsabilidad fiscal $^{54}$ relacionados con recursos públicos de gestión fiscal ambiental, tramitados por

Sin tener en cuenta a la Contraloría de Bogotá D.C., que no es sujeto vigilado de AGR desde 2013.

Procesos incluidos en los resultados del análisis empírico de procesos de responsabilidad fiscal que se presentan en el subcapítulo correspondiente de este mismo capítulo. 
procedimiento ordinario abiertos durante el periodo de estudio, por una cuantía de daño según auto de apertura de \$270.312.830.488; y 65 abiertos por procedimiento verbal, por cuantía de daño en el auto de apertura e imputación, de \$102.818.681.162.

De tales procesos de responsabilidad fiscal, según lo reportado, que a 31 de diciembre de 2017 continuaban en trámite 186 procesos tramitados por procedimiento ordinario y 39 por procedimiento verbal.

Los 140 procesos de responsabilidad fiscal restantes fueron terminados en el periodo investigado, así:

\section{Tabla No. 15 Resultados de los procesos de responsabilidad fiscal terminados entre 2012 y 2017, relacionados con recursos públicos de gestión fiscal ambiental.}

\begin{tabular}{|l|c|c|}
\hline Razón de la terminación & Procesos & Cuantía (\$) \\
\hline Fallo con responsabilidad fiscal ejecutoriado durante la vigencia & 16 & $\$ 6.466 .890 .604$ \\
\hline Fallo sin responsabilidad fiscal ejecutoriado durante la vigencia & 21 & $\$ 5.772 .206 .352$ \\
\hline Archivo ejecutoriado por pago durante la vigencia & 26 & 164.544 .968 \\
\hline Archivo ejecutoriado por no mérito durantela vigencia & 74 & $\$ 17.800 .347 .968$ \\
\hline Archivo ejecutoriado por prescripción durante la vigencia & 1 & $\$ 11.046 .240$ \\
\hline Archivo ejecutoriado por caducidad durante la vigencia & 2 & $\$$ \\
\hline \multicolumn{2}{|c|}{ Tabla No. 15. Elaboración propia. Fuente: Anälisis de información reportada por las contralorías en el módulo SIA-SIREL de la AGR. }
\end{tabular}

En términos de recaudo total efectivo de la gestión de los procesos de responsabilidad fiscal identificados para el ejercicio académico, según lo reportado a 31 de diciembre de 2017 , fue de $\$ 1.445 .867 .777$ ( $\$ 444.017 .028$ por procedimiento ordinario y $\$ 1.001 .850 .749$ por procedimiento verbal). Valores todos que no incluyen lo que después se recupere en los consecuentes procesos de jurisdicción coactiva, ni lo que se pueda recaudar en los que no habían terminado a 31 de diciembre de 2017. Es de precisar que, según esos resultados de recaudo, el procedimiento verbal es más efectivo que el ordinario, para tramitar procesos de responsabilidad fiscal (T. Ordóñez, 2019), conclusión explicada en extenso en el aparte correspondiente de este mismo capítulo.

Para finalizar, es de referir que por mandato constitucional, numeral $7{ }^{\circ}$. Artículo 268 , la Contraloría General de la República presenta al Congreso de la República un informe anual sobre el estado de los recursos naturales y del ambiente, y las contralorías territoriales hacen lo propio a las Asambleas Departamentales, Concejos Municipales y Distritales, en virtud del inciso sexto del artículo 272 del mismo texto constitucional, y el numeral $77^{\circ}$ del artículo $9^{\circ}$ de la Ley 330 de 1996. En desarrollo de la función de coadyuvancia, la Auditoría General puso a disposición de las contralorías territoriales una guía metodológica para la elaboración del informe sobre la situación de los recursos naturales y el medio ambiente.

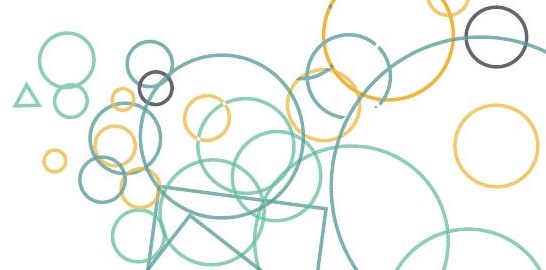




\subsection{CONCLUSIONES}

El proceso auditor adelantado por los órganos de control fiscal entre el $1^{\circ}$ de enero de 2012 y el 31 de diciembre de 2017 generó, según la evidencia empírica, 279.572 hallazgos administrativos, 67.199 hallazgos con presunta incidencia disciplinaria, 5.559 con presunta incidencia penal, y 23.178 hallazgos fiscales.

El proceso auditor adelantado por los órganos de control fiscal entre el $1^{\circ}$ de enero de 2012 y el 31 de diciembre de 2017 fue eficaz por varias razones. La primera, porque 22.165 hallazgos fiscales identificados en auditoría, por cuantía de $\$ 24.094 .891 .899 .653$, generaron la apertura de 16.999 procesos de responsabilidad fiscal en ese mismo periodo, y un recaudo persuasivo en etapa de hallazgo de $\$ 31.092 .950 .769$. La segunda, porque el $67,36 \%$ de los procesos de responsabilidad fiscal abiertos en el periodo fue originado por hallazgos de auditoría, Otra, porque calculada la relación matemática entre el número de hallazgos fiscales identificados en auditoria entre 2012 y 2017 y los procesos de responsabilidad fiscal abiertos en el mismo periodo, se encontró una razón matemática positiva, tanto en número como en cuantía.

Antes de estudiar la gestión de los órganos de control fiscal, en materia de procesos de responsabilidad fiscal, hay que conocer y tener en consideración los principales obstáculos a los que se enfrentan los abogados al momento de sustanciar y adelantar los referidos procesos. Se destacan entre ellos, las siguientes limitaciones y tropiezos procesales: 1) La obligatoriedad de probar culpa grave que impuso la Corte Constitucional en el año 2000; 2) La insuficiencia de recursos humanos, tecnológicos y/o financieros para adelantar los procesos de responsabilidad fiscal y aún más para tramitarlos por el procedimiento verbal creado por el Estatuto Anticorrupción y 3) La existencia de figuras procesales que demoran o retroceden el proceso, como por ejemplo las nulidades, las revocatorias, los impedimentos, las recusaciones, los aplazamientos y reprogramaciones de diligencias, el cambio de abogados, la consecución y el nombramiento de apoderados de oficio, etc. que deben ser tramitadas con sujeción al debido proceso y en estricta protección del derecho de defensa de los presuntos responsables fiscales, no obstante atrasar el trámite, implicar reprocesos y poder incluso hasta incidir en la ocurrencia de terminaciones anormales, por el paso del tiempo, como la prescripción o la caducidad atrás referidos. 4) Las grandes dificultades para recaudar las deudas fiscales que son comunes a las entidades públicas cuando de cobrar deudas se trata.

En ese contexto, se concluyó en este estudio sobre la eficacia de los resultados del proceso auditor en términos de resultados de los procesos de responsabilidad fiscal y jurisdicción coactiva, como eslabones finales de la cadena de valor del proceso de auditoría de control 
fiscal, de manera resumida así:

Entre el $1^{\circ}$ de enero de 2012 y el 31 de diciembre de 2017 en el módulo SIA-SIREL de la AGR solo el 13,31\% de los funcionarios de las plantas de cargos de los órganos de control fiscal ${ }^{55}$ se dedicó a adelantar procesos fiscales; no obstante ser la función misional orientada a la determinación de responsabilidades fiscales y el recaudo efectivo del daño patrimonial causado al patrimonio público. De hecho, a cada funcionario que adelantó procesos fiscales en los órganos de control fiscal del país ${ }^{56}$, entre 2012 y 2017, un promedio aritmético de 4,27 procesos de responsabilidad, fuera de los procesos de responsabilidad fiscal que venían en trámite a $1^{\circ}$ de enero de 2017 , los de cobro coactivo y los sancionatorios que le pudieran haber correspondido. La mediana estadística entre los óranos de control fiscal fue de 30,72 procesos por funcionario, siendo 2 el dato más bajo observado y 153 el más alto reportado por funcionario.

Por otro lado, en materia de procesos de responsabilidad fiscal y términos de eficacia como principio de desempeño, se comprobó empíricamente y con un caso de estudio, que el procedimiento verbal (oralidad introducida por la Ley 1474 de 2011) ciertamente es una medida adecuada para la eficiencia y eficacia del control fiscal colombiano, en la lucha contra la corrupción; y se demostró que en materia de oportunidad, objetivos y resultados fue más eficiente el trámite de procesos por el procedimiento verbal, que por el ordinario de la Ley 610 de 2000.

Dentro de los resultados obtenidos, y que soportan las conclusiones, se resaltan:

\begin{tabular}{|c|c|}
\hline $\begin{array}{l}\text { Tramitados por procedimiento ordinario entre el } 1^{\circ} \text { de enero de } \\
\qquad 2012 \text { y el } 31 \text { de diciembre de } 2017\end{array}$ & $\begin{array}{l}\text { Tramitados por procedimiento verbal entre el } 1^{\circ} \text { de enero de } \\
2012 \text { y el } 31 \text { de diciembre de } 2017\end{array}$ \\
\hline $\begin{array}{l}\text { Haber dado apertura a } 21.623 \text { procesos de responsabilidad fiscal por } \\
\text { procedimiento ordinario, en cuantía de } \$ 39.944 .252 .871 .509 \text {. }\end{array}$ & $\begin{array}{l}\text { Haber dado apertura a } 3.613 \text { procesos de responsabilidad fiscal } \\
\text { por procedimiento verbal, en cuantía de } \$ 3.054 .417 .420 .513 \text {. }\end{array}$ \\
\hline $\begin{array}{l}\text { Haber terminado, con decisión de fondo ejecutoriada el } 42,34 \% \text {, de } \\
\text { los procesos de responsabilidad fiscal abiertos por procedimiento } \\
\text { ordinario en dicho periodo, y al } 17,16 \% \text { de su cuantía de apertura. }\end{array}$ & $\begin{array}{l}\text { Haber terminado, con decisión de fondo ejecutoriada el } \\
49,82 \% \text {, de los procesos de responsabilidad fiscal abiertos por } \\
\text { procedimiento verbal en dicho periodo, y al } 29,17 \% \text { de su cuantía } \\
\text { de apertura. }\end{array}$ \\
\hline $\begin{array}{l}\text { De los terminados, el } 24,23 \% \text { fue con fallo con responsabilidad fiscal } \\
0 \text { archivo por pago ejecutoriados, decisiones de fondo con las que se } \\
\text { obtuvo un recaudo efectivo inicial en el periodo investigado, de un } \\
\text { total de } \$ 223.543 .554 .681 \text {. }\end{array}$ & $\begin{array}{l}\text { De los procesos terminados, el } 44,89 \% \text { fue por fallo con } \\
\text { responsabilidad fiscal o archivo por pago ejecutoriados, } \\
\text { decisiones de fondo que permitieron un recaudo efectivo inicial } \\
\text { en el periodo investigado, de un total de } \$ 30.973 .354 .274 \text {. }\end{array}$ \\
\hline
\end{tabular}


Tramitados por procedimiento ordinario entre el $1^{\circ}$ de enero de 2012 y el 31 de diciembre de 2017

De los terminados, el 75,77\% fue archivado por razones diferentes, dentro de las cuales la de mayor frecuencia, $(72,67 \%)$, en total de 6.653 decisiones de fondo y cuantía de apertura total de $\$ 5.774 .365 .726 .881$, fue por no haberse configurado los elementos de la responsabilidad fiscal: daño, culpa grave y nexo causal.

El total del recaudo por procesos de responsabilidad fiscal tramitados durante el periodo de estudio, por procedimiento ordinario (archivados y en trámite) fue de $\$ 327.338 .989 .348$, valor que tiende a aumentar después con lo que se recaude en cumplimiento de acuerdos de pago, el pago voluntario de los investigados y los procesos de jurisdicción coactiva.

Como quedó explicado, no obstante no ser práctico, ni técnico comparar en términos de gestión, los dos valores, se estableció, solo para efectos hipotéticos que la relación matemática entre el valor total de los autos de apertura de los procesos abiertos por procedimiento ordinario en el periodo de estudio, y el valor de lo recaudado en tales procesos en ese mismo lapso, fue de 122:1.

El análisis empírico permitió concluir que el 3,10\% de los procesos de responsabilidad fiscal abiertos por procedimiento ordinario entre el $1^{0}$ de enero de 2012 y el 31 de diciembre de 2017, y culminados en ese mismo periodo, fue terminado anormalmente por ocurrencia de los fenómenos de caducidad de la acción fiscal o de prescripción de la responsabilidad fiscal, en cuantía total de \$189.013.207.820. De ese porcentaje, 1,75\% correspondió a archivados por caducidad de la acción fiscal y el restante 1,35\% a prescripción de la responsabilidad fiscal.

Del amplio espectro de actuaciones administrativas que se debieron adelantar durante el trámite de los 25.236 procesos de responsabilidad fiscal abiertos por procedimiento ordinario entre 2012 y 2017, el análisis de la información reportada permitió concluir que se debieron tramitar primero 3.772 indagaciones preliminares; que se vinculó a las compañías aseguradoras en calidad de terceros civilmente responsables en 14.187 procesos; que se decretaron y registraron medidas cautelares en más de 2.536 procesos; y que se reportaron resueltos más de 9.716 recursos de reposición, apelación contra autos de imputación o fallos con responsabilidad fiscal y grados de consulta.
Tramitados por procedimiento verbal entre el $1^{\circ}$ de enero de 2012 y el 31 de diciembre de 2017

De los terminados, el 55,11\% acabó por otras razones. La de mayor frecuencia, (53,50\%), en total de 963 decisiones de fondo, y cuantía de apertura total de $\$ 528.174 .071 .121$, fue por fallos sin responsabilidad fiscal y archivos por no mérito ejecutoriados, es decir por no haberse configurado los elementos de la responsabilidad fiscal: daño, culpa grave y nexo causal.

El total del recaudo por procesos de responsabilidad fiscal tramitados durante el mismo periodo, por procedimiento verbal (archivados y en trámite) fue de $\$ 37.992 .262 .444$, suma que también tiende a aumentar después, con lo que se recaude en cumplimiento de acuerdos de pago, el pago voluntario de los investigados y los procesos de jurisdicción coactiva.

De la misma manera que se hizo con los tramitados por procedimiento ordinario, y solo para efectos hipotéticos se calculó la relación matemática entre el valor total de los autos de apertura de los procesos abiertos por procedimiento verbal en el periodo de estudio, y el valor de lo recaudado en tales procesos en ese mismo lapso, que resultó ser de 80:1.

El análisis empírico permitió concluir que el 1,5\% de los procesos abiertos por procedimiento verbal fue terminado anormalmente durante el mismo periodo, por ocurrencia de los fenómenos de caducidad de la acción fiscal 0 de prescripción de la responsabilidad fiscal, en cuantía total de $\$ 22.028 .110 .898$. De ese porcentaje, el $0,83 \%$ correspondió a archivados por caducidad de la acción fiscal y el restante $0,67 \%$ a prescripción de la responsabilidad fiscal.

En el mismo sentido, el análisis empírico del trámite de los 3.595 procesos de responsabilidad fiscal abiertos por procedimiento verbal entre 2012 y 2017 permitió determinar que se debieron tramitar primero 838 indagaciones preliminares; se vinculó a las compañías aseguradoras en calidad de terceros civilmente responsables en 2.653 procesos; se decretaron y registraron medidas cautelares en más de 541 procesos; se dio apertura a más de 2.940 audiencias de descargos y a más de 1.647 audiencias de decisión; se suscribieron más de 2.050 decreto de pruebas, y se reportaron resueltos más de 2.079 recursos de reposición, apelación contra autos de imputación o fallos con responsabilidad fiscal y grados de consulta.

Finalmente, en desarrollo de la facultad de los órganos de control para cobrar los créditos fiscales contenidos en los fallos con responsabilidad fiscal plasmados en providencias debidamente ejecutoriadas, las pólizas de seguros a favor de las entidades públicas que se integren a ellos, y las sanciones y otros títulos ejecutivos, es decir en materia de procesos de jurisdicción coactiva, el análisis empírico permitió concluir que entre el $1^{\circ}$ de enero de 2012 y el 31 de diciembre de 2017 las contralorías del país notificaron el mandamiento de pago 
en 5.013 procesos de jurisdicción coactiva, con base en títulos ejecutivos por cuantía total de \$434.103.987.751. De esos, el 83,56\%, seguían en trámite al final del periodo en estudio -31 de diciembre de 2017- y, según lo reportado de ellos se había obtenido un recaudo de $\$ 51.952 .155 .179$. El restante $16,44 \%$ fue finalizado y generó un recaudo de $\$ 7.019 .860 .779$ con base en 824 títulos ejecutivos. En el trámite de los procesos de jurisdicción coactiva abiertos y tramitados en el periodo, hubo una importante gestión adicional al recaudo, descrita de manera muy general así: 1.233 procesos fueron objeto de práctica de medidas cautelares y 889 de inscripción de estas. Se determinó de lo reportado, que 443 medidas cautelares recayeron sobre inmuebles, 660 sobre muebles, 335 afectaron las cuentas bancarias; 278 los salarios y 133 recayeron sobre otros bienes de los ejecutados. Adicionalmente, se observó que la tarea de cobro persuasivo fue efectiva en 1.100 de esos procesos abiertos en el periodo en estudio, por pago voluntario o a través de acuerdo de pago.

La valoración de los costos ambientales a cargo de las contralorías del país es una de las piedras angulares de la vigilancia de la gestión fiscal. Es un principio constitucional del control fiscal.

Entre 2012 y 2017, las contralorías del país reportaron haber identificado en auditorías al proceso de gestión ambiental concretamente, 310 hallazgos fiscales por cuantía de $\$ 61.217 .900 .608$, cuyo resultado fue 55 procesos de responsabilidad fiscal, 43 indagaciones preliminares, 1 archivado en etapa de hallazgo por resarcimiento del daño, 3 fueron devueltos al proceso auditor y 208 fueron en etapa de estudio.

Los temas de mayor frecuencia en los hallazgos estudiados fueron contratación pública y sanciones.

De los procesos de responsabilidad fiscal abiertos por las contralorías del país ${ }^{57}$ entre el $1^{\circ}$ de enero de 2012 y el 31 de diciembre de 2017, relacionados con recursos públicos de gestión fiscal ambiental, se identificaron 365 procesos de responsabilidad fiscal por una cuantía de daño según auto de apertura de $\$ 373.131 .511 .650$. Dentro de los resultados se pudo concluir que 225 continuaban en trámite a 31 de diciembre de 2017 continuaban en trámite 186 y los demás terminaron, entre otras razones, por fallo con responsabilidad fiscal, 16 procesos, en cuantía de $\$ 6.466 .890 .604$; y por archivo por pago ejecutoriado durante la vigencia, 26 procesos, en cuantía de $\$ 164.544 .968$. Se reportó un recaudo total por la gestión de los 365 procesos, y sin contar lo que después se recupere después por cobro coactivo, ni lo que se pueda recaudar en los que no habían terminado a 31 de diciembre de 2017, fue de $\$ 1.445 .867 .777$.

\subsection{BIBLIOGRAFÍA}

57 Sin tener en cuenta a la Contraloría de Bogotá D.C., que no es sujeto vigilado de AGR desde 2013. 
Auditoría General de la República, Criterios de auditoria que fundamentan la función que debe realizar la Auditoría General de la República a las contralorías en ejercicio del control fiscal ambiental (2015)

Auditoría General de la República, El Control Fiscal Ambiental en Colombia (2007). Revista Sindéresis Proyecciones del Control Fiscal. ISSN 0124-471. Bogotá.

Contraloría General de la República, 2018. Procedimiento Especializado de Auditoría a la aplicación del Principio de Valoración de Costos Ambientales. Consultado en https:// www.contraloria.gov.co/web/guest/guia-de-auditoria-en-el-marco-de-normas-issai/ procedimiento-especializado-valoracion-de-costos-ambientales

Escudero Aranda, Gustavo (2005). De la teoría a la práctica en la vigilancia de la gestión fiscal a la valoración de los costos ambientales. Revista sindéresis 8 - Diciembre. Auditoría General de la República. Bogotá.

Molina Ríos, Janis. (2017). Control fiscal ambiental: Elementos para una valoración de la justicia ambiental. (Tesis de maestría). Universidad Nacional de Colombia. Bogotá.

Ordóñez Vásquez, Tatiana. (2005). Colombia impunidad en Materia Fiscal. Bogotá: Revista Sindéresis. Auditoría General de la República.

Ordóñez Vásquez, Tatiana. (2007). La responsabilidad fiscal en Colombia y la imposibilidad de resarcimiento patrimonial. Bogotá: Revista IUSTA. Facultad de Derecho Universidad Santo Tomás.

Ordóñez Vásquez, Tatiana. (2019). Eficacia de la Oralidad en los Procesos de Responsabilidad Fiscal. Documento de trabajo en proceso de publicación. Auditoría general de la República. Bogotá.

Restrepo Acevedo, Edgar Alfredo. (2017). La fragilidad en el diseño institucional de los organismos de control fiscal del Departamento de Antioquia (Tesis de grado). Universidad Nacional de Colombia. Medellín. 


\section{CAPÍTULOIV}

\section{EFECTOS DEL CONTROL FISCAL EN EL APRENDIZAJE ORGANIZACIONAL DE LAS CONTRALORÍAS}

\section{Effects of fiscal control on the organizational learning of comptrollers}

Jhonny Marlon Cárdenas Arévalo58.

\section{Resumen:}

El impacto del control fiscal se debe ver reflejado en la gestión de los sujetos de control, específicamente en la operación de sus procesos. Esta investigación tiene como propósito validar tal hipótesis y para ello se ha valido de una herramienta que condensa los resultados de las auditorías, anualmente practicadas a las contralorías de Colombia, por la Auditoría General de la República, el plan de mejoramiento. Se analizaron los últimos siete planes de mejoramiento de tres contralorías, entre ellas la Contraloría General de la República y se compararon sus hallazgos con el ánimo de verificar si estos se repetían año a año. De esta manera se estableció la curva de aprendizaje de cada sujeto de control respecto de sus procesos operativos.

\section{Abstract:}

The impact of fiscal control must be reflected in the management of control subjects, specifically in the operation of their processes. The purpose of this investigation is to validate

58 Ingeniero Industrial de la Universidad Distrital Francisco José de Caldas. Psicólogo de la Universidad Nacional de Colombia. Especialista en Ingeniería de Calidad y el Comportamiento de la Universidad Católica de Colombia. Magíster en Estudios y Gestión del Desarrollo de la Universidad de la Salle. Asesor de Gestión del Auditor General de la República. Investigador "Observatorio de Política Pública del Control Fiscal" adscrito -según convenio- a la Auditoría General de la República y la Universidad Santo Tomás de Bogotá.

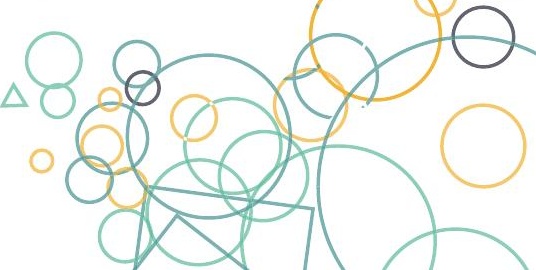


this hypothesis and for this purpose it has used a tool that condenses the results of the audits, annually carried out to the comptrollers of Colombia, by the General Audit of the Republic, the improvement plan. The last seven improvement plans of three comptrollerships were analyzed, among them the Comptroller General of the Republic and their findings were compared in order to verify whether they were repeated year after year. In this way, the learning curve of each control subject with respect to its operational processes was established.

\section{Palabras clave:}

Aprendizaje organizacional; plan de mejoramiento; proceso auditor; control fiscal; curva de aprendizaje.

\section{Key words:}

Organizational learning; Improvement plan; audit process; fiscal control; learning curve.

Temario: 4.1. Marco conceptual. 4.2. Pretensión. 4.3. Procedimiento Empleado. 4.4. Resultados. 4.5. Conclusiones. 4.6. Bibliografía.

\section{Introducción}

El control fiscal es una función pública orientada a verificar la correcta destinación y uso de los recursos públicos de un país. Tal función es desarrollada por entidades del Estado, cuya estructura, organización y funcionamiento son similares a las de las empresas del sector privado. En ese sentido, el comportamiento de las organizaciones del sector privado y del sector público puede ser analizado utilizando las mismas herramientas. Dentro del amplio panorama de fenómenos que comprende el comportamiento organizacional, está el aprendizaje. Esta capacidad institucional se puede reflejar en diferentes escenarios, de acuerdo con la naturaleza de cada organización. Tal es el caso de aquellas entidades dedicadas a ejercer la vigilancia del erario. Estas, al igual que sus sujetos vigilados deben ser eficaces, eficientes y efectivas en su actuar y para ello deben tener en cuenta sus yerros y a partir de los mismos aplicar correctivos adecuados, de tal suerte que no se vuelvan a repetir, es decir, las entidades deben aprender de sus errores. Este documento, a partir del análisis del plan de mejoramiento de las contralorías territoriales, interpreta la manera en que se desarrolla el aprendizaje organizacional.

\subsection{MARCO CONCEPTUAL}

\subsubsection{Objeto del control}

De acuerdo con el artículo 1 de la Ley 87 de 1993 por la cual se establecen normas para el ejercicio del control interno en las entidades y organismos del Estado, el control interno 
se define como: “(...) sistema integrado por el esquema de organización y el conjunto de los planes, métodos, principios, normas, procedimientos y mecanismos de verificación y evaluación adoptados por una entidad. (...)"y su propósito es:

(...) procurar que todas las actividades, operaciones y actuaciones, así como la administración de la información y los recursos, se realicen de acuerdo con las normas constitucionales y legales vigentes dentro de las políticas trazadas por la dirección y en atención a las metas u objetivos previstos. (p.1).

Desde una perspectiva administrativa, Ayala (2007) citando a Berry (2005) señala que el control se identifica como el:

(...) proceso de conducir a las organizaciones hacia patrones de actividad viables en un entorno cambiante", lo cual implica que el control se refiere a la acción de influir "sobre el comportamiento de (...) los miembros de la organización de forma que se consigan al menos, algunos de los objetivos organizacionales.

Atendiendo las diferentes dimensiones en las que se presenta el control, bien sea como un conjunto de mecanismos, como un proceso, como una capacidad o como un medio, Ayala (2007) propone la siguiente definición integrada:

El control organizacional es aquel proceso que, basándose en la capacidad de influencia sobre las personas, trata de asegurar que el desempeño de los individuos se oriente a los objetivos fijados por la organización, aplicando las medidas correctoras necesarias en cada caso.

En síntesis, el control es una función inherente a la administración de una organización, que se realiza como un proceso, se soporta en instrumentos metodológicos y busca el cumplimiento de los planes institucionales que lo enmarcan.

\subsubsection{Aprendizaje organizacional}

Si el control es una función organizacional para asegurar el cumplimiento de los planes institucionales, entonces, es pertinente plantear las definiciones que existen de aprendizaje organizacional.

En palabras de Castañeda, para Fasterby-Smith y Lyles (2003), “(...) el elemento característico del aprendizaje organizacional es el proceso mediante el cual las entidades, a partir de individuos, adquieren, construyen y transfieren conocimiento."

El aprender se puede entender como una capacidad y en el caso de las organizaciones, Garzón (2012) afirma que esta capacidad se define como:

(...) el potencial dinámico de creación, asimilación, difusión y utilización del conocimiento por medio de numerosos flujos de conocimiento que hacen posible la formación y evolución de las memorias organizacionales de conocimiento que capacitan a las organizaciones y sus agentes de conocimiento para actuar intencionalmente en entornos cambiantes (Prieto, 2004).

En conclusión, el aprendizaje organizacional se ve favorecido por la información que genera el 


\section{OPPCF}

proceso auditor, es decir por la aplicación del control. Uno de los productos facticos del control realizado a través del proceso auditor, es el plan de mejoramiento, el cual contiene aquellas actividades que presentan errores o fallas en su ejecución y que como tal, deben ser tratadas para asegurar que dicha situación no vuelva a presentarse.

\subsubsection{El plan de mejoramiento, instrumento para el aprendizaje}

Conforme el Manual del Proceso Auditor, versión 9.1 publicado por la Auditoría General de la República en 2018:

"El plan de mejoramiento es el documento que contiene el conjunto de acciones que ha decidido adelantar un sujeto de control fiscal, tendientes a subsanar o corregir los hallazgos identificados en ejercicio de la auditoría (...), (...) con el fin de adecuar la gestión fiscal a los principios de economía, eficiencia, eficacia, equidad o a mitigar el impacto ambiental. Sobre dicho plan, la AGR no emitirá pronunciamiento sobre las acciones propuestas; dentro del siguiente proceso auditor, se evaluará la efectividad de las mismas para eliminar las causas que originaron los hallazgos." (p. 32)

Como se aprecia el plan de mejoramiento permite ver la falla (hallazgo) y sus causas, y con base en las mismas, el sujeto de control formular acciones para superar esta situación (acciones de mejora). Se espera que, de ser efectivo el diseño de las acciones de mejora, las causas de eliminen y el hallazgo no se vuelva a presentar.

\subsubsection{La curva de aprendizaje}

Este concepto fue desarrollado por Theodore P. Wright en 1936 en el marco de la industria aeronáutica y lo empleo para explicar la relación entre la cantidad de producción alcanzada y el tiempo necesario para ello. Al repetir el ejercicio, la producción debe aumentar en el mismo periodo de tiempo o menos.

Para el propósito de este estudio, el concepto de curva de aprendizaje permite ver la relación entre los hallazgos o presencia de errores en la gestión de una contraloría a lo largo del tiempo. Cada vez que se realiza una auditoría a una contraloría, los hallazgos o errores en un proceso específico, deben disminuir. Esta es la curva de aprendizaje de la contraloría a partir del control fiscal.

\subsection{PRETENSIÓN}

El objetivo de esta investigación se fundamenta en los beneficios organizacionales que trae el ejercicio del proceso auditor para los sujetos de control. En el entendido de que este último es el medio a través del cual una organización, en este caso una contraloría, identifica los aspectos 
operativos en los que está fallando y sobre ellos implementa acciones de mejora.

En definitiva la pretensión es demostrar que: "el proceso auditor, a través del plan de mejoramiento, genera aprendizaje organizacional en las contralorías".

Desde un punto de vista contrario, es decir, utilizando una premisa que permita falsear la pretensión, es posible afirmar que "la recurrencia de un mismo hallazgo en dos o más planes de mejoramiento de un mismo sujeto de control, demuestra la inefectividad del proceso auditor."

De lo anterior se desprende que es una situación indeseable que un hallazgo se repita en dos o más planes de mejoramiento. De allí que una organización que efectivamente aprende no repite hallazgos en sus planes de mejoramiento, toda vez que ha transformado aquellas actividades identificadas en el mencionado plan, producto del proceso auditor.

\subsection{PROCEDIMIENTO EMPLEADO}

\subsubsection{Muestra - Criterios}

Para el desarrollo de esta investigación se utilizaron, como fuente de información, los planes de mejoramiento de las contralorías.

En términos de tiempo, fueron analizados los planes de mejoramiento de las vigencias 2012 a 2018.

Para un total de 455 planes de mejoramiento presentados en el periodo de tiempo señalado, se diseñó una muestra que permitiera la factibilidad del análisis. El criterio para seleccionar los planes de mejoramiento fue: Por cada vigencia se seleccionaron las contralorías con mayor y menor presupuesto de funcionamiento. Esto como una manera de desvirtuar la posible asociación entre capacidad presupuestal y aprendizaje.

\subsubsection{Categorías descriptivas}

Para el procesamiento de la información se diseñó una matriz que permitió comparar los planes de mejoramiento de los siete años de análisis. De cada plan de mejoramiento se extrajeron las columnas "causa", "efecto" y "condición", las cuales constituyen elementos que caracterizan el hallazgo.

Para facilitar la identificación de patrones, tendencias o similitudes entre hallazgos, estos se asociaron a categorías genéricas de información como los procesos a través de los cuales opera un sujeto de control. En suma, cada hallazgo fue asociado a un proceso, que en la matriz hizo posible identificar el proceso sobre el que debía aprender el sujeto de control.

Debe interpretarse entonces que, cada categoría encontrada es un proceso de gestión sobre

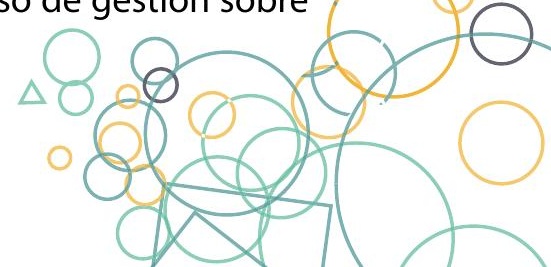


el cual debe mejorar su aprendizaje la contraloría.

\subsection{RESULTADOS}

Dado que el presupuesto asignado al funcionamiento de las contralorías, varía cada año, las parejas establecidas no fueron las mismas para cada vigencia. Por lo tanto, se realizó un análisis efectivo a los siete planes de mejoramiento de tres contralorías: Contraloría General de la República, Contraloría de Medellín y Contraloría del Vaupés.

La cantidad esperada de hallazgos por proceso, anualmente es cero. Si un hallazgo no se repite en el siguiente año, demuestra que la organización aprendió sobre dicho proceso y que el control le permitió identificar aquellos procesos en los que debía aprender.

Entonces, si al graficar el número de hallazgos sobre un mismo proceso a lo largo de ocho años, la curva de aprendizaje tiende a cero, se entiende que hay un desarrollo progresivo de la entidad hacia el aprendizaje en esa materia.

\subsubsection{Análisis por categoría descriptiva}

A continuación se presenta la frecuencia con la que se identificaron hallazgos en los planes de mejoramiento. 
Tabla 1. Frecuencia de los hallazgos, distribuida por proceso y contraloría en el periodo $2012-2018$

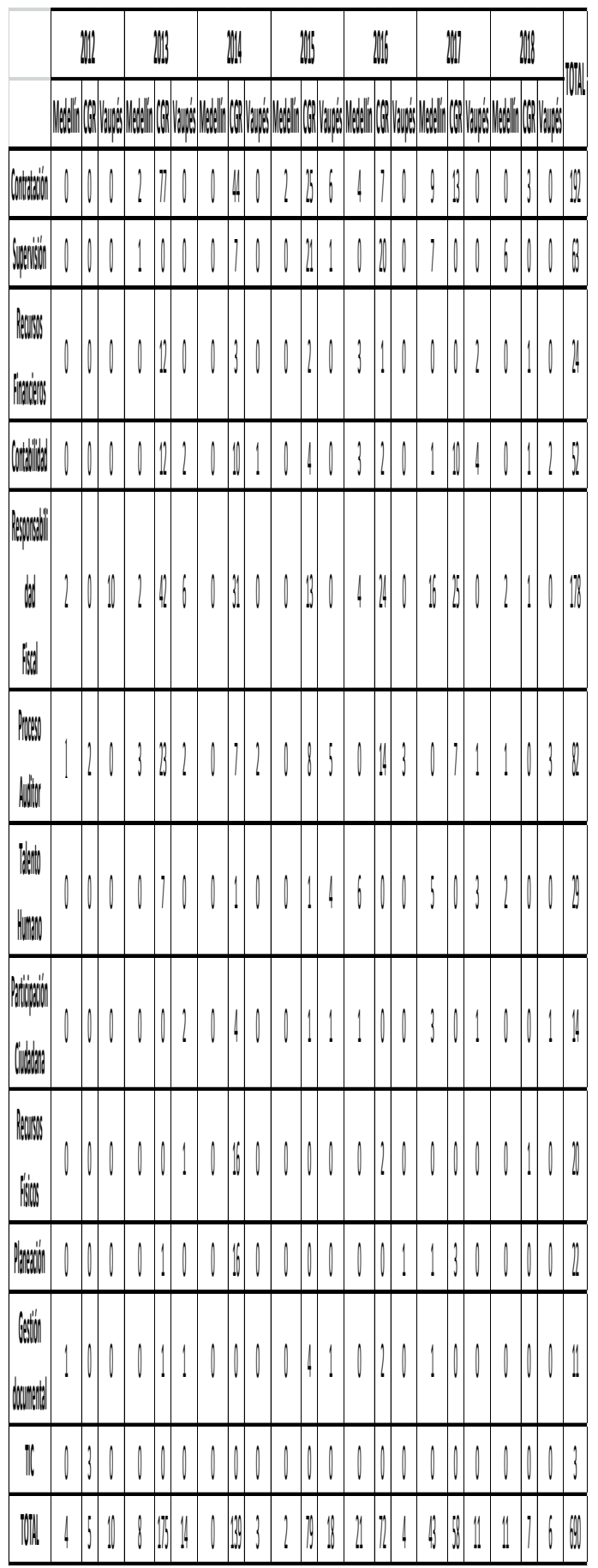




\subsubsection{Categorías - Procesos:}

Las categorías identificadas en las bases de datos analizadas fueron: Contratación; Supervisión; Financiera; Contabilidad; Responsabilidad Fiscal; Proceso Auditor; Talento Humano; Participación Ciudadana; Recursos Físicos; Planeación; Gestión documental y TIC.

\subsubsection{Curvas de aprendizaje}

A continuación se presentan los resultados obtenidos frente al aprendizaje por proceso. Estos valores son acumulados entre los tres sujetos de control.

\section{Gráfico 1. Curva de aprendizaje de Contratación}

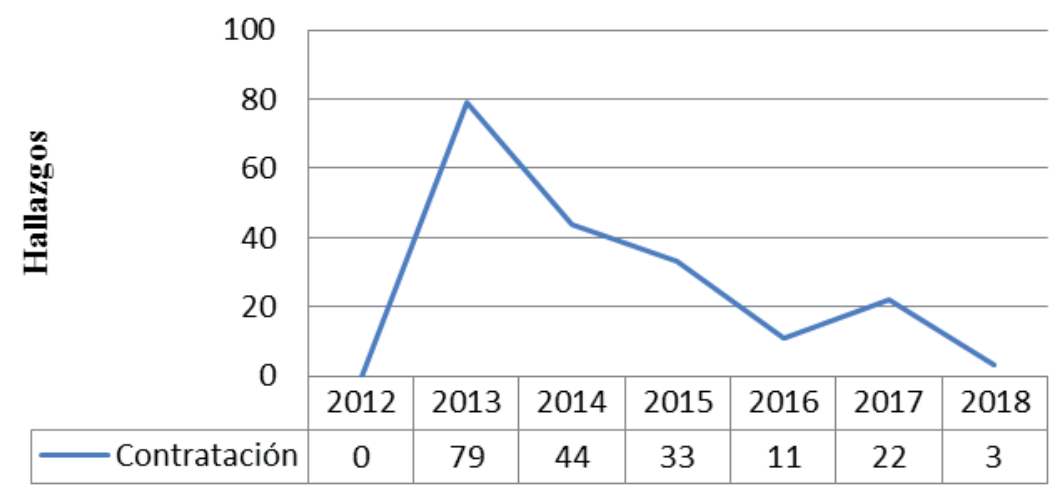

Fuente: Elaboración propia

Gráfico 2. Curva de aprendizaje de Supervisión

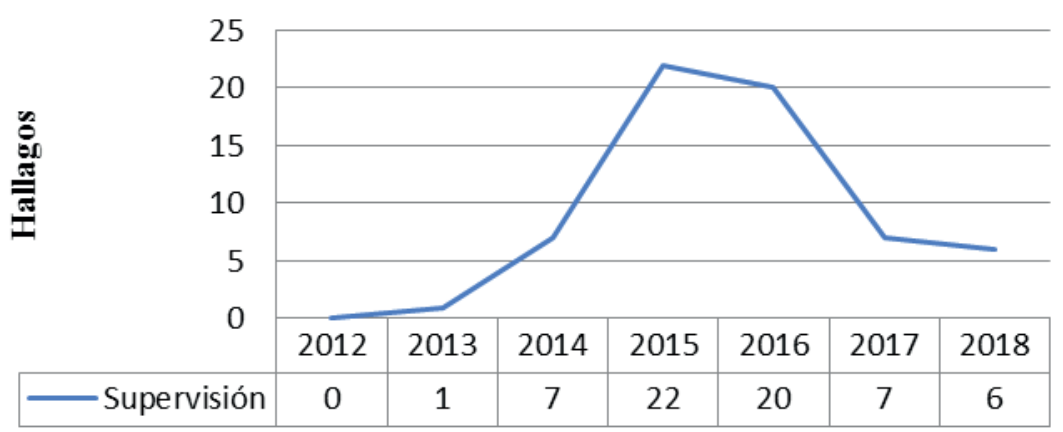

Fuente: Elaboración propia 
Gráfico 3. Curva de aprendizaje de Recursos Financieros

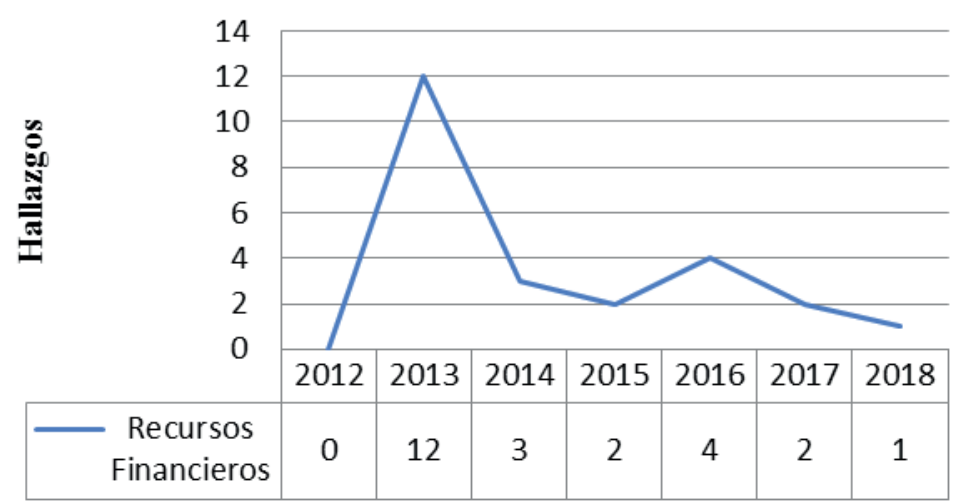

Fuente: Elaboración propia

\section{Gráfico 4. Curva de aprendizaje de} Contabilidad

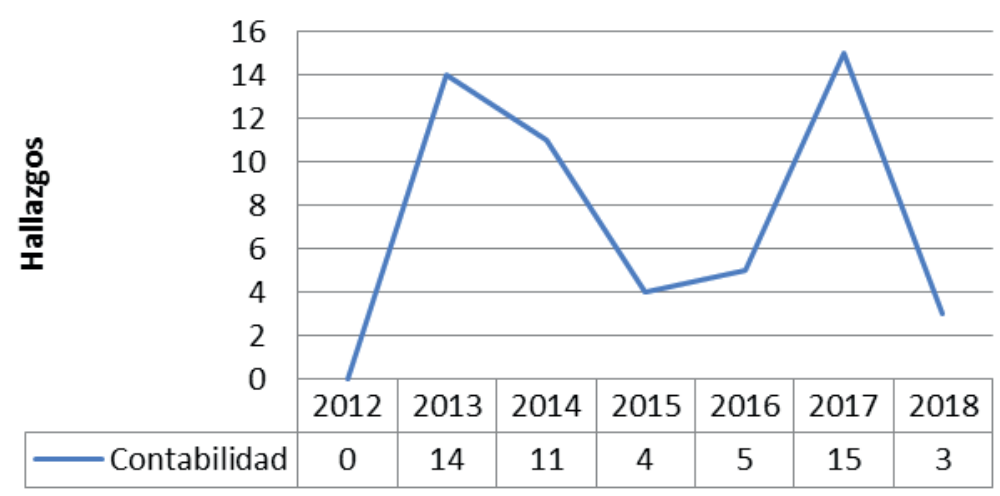

Fuente: Elaboración propia 
Gráfico 5. Curva de aprendizaje de Responsabilidad

Fiscal

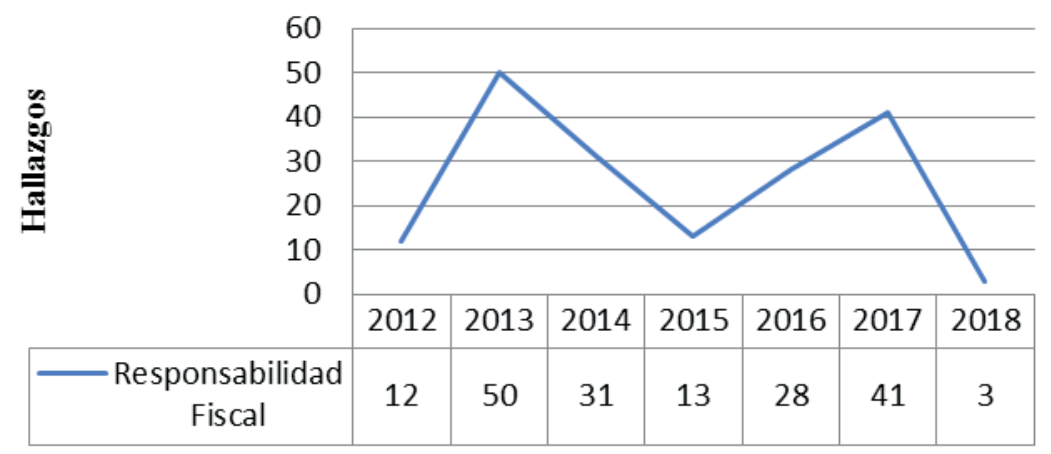

Fuente: Elaboración propia

Gráfico 6. Curva de aprendizaje de Proceso Auditor

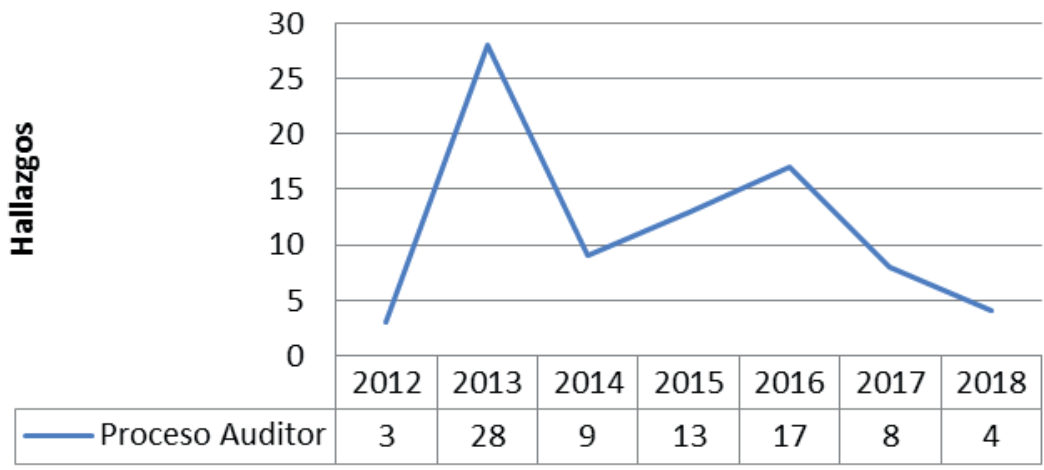

Fuente: Elaboración propia

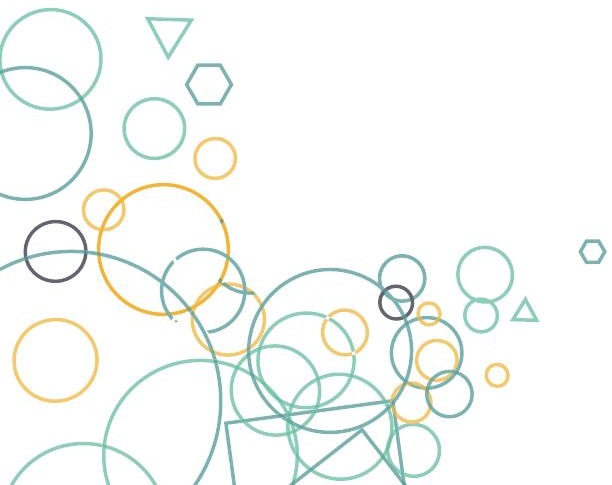


Gráfico 7. Curva de aprendizaje de Talento

\section{Humano}

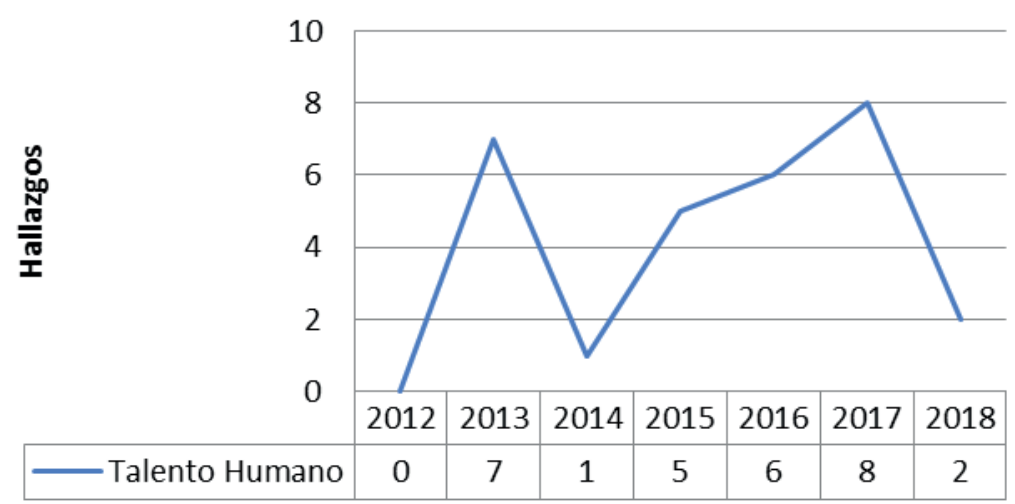

Fuente: Elaboración propia

\section{Gráfico 8. Curva de aprendizaje de}

\section{Participación Ciudadana}

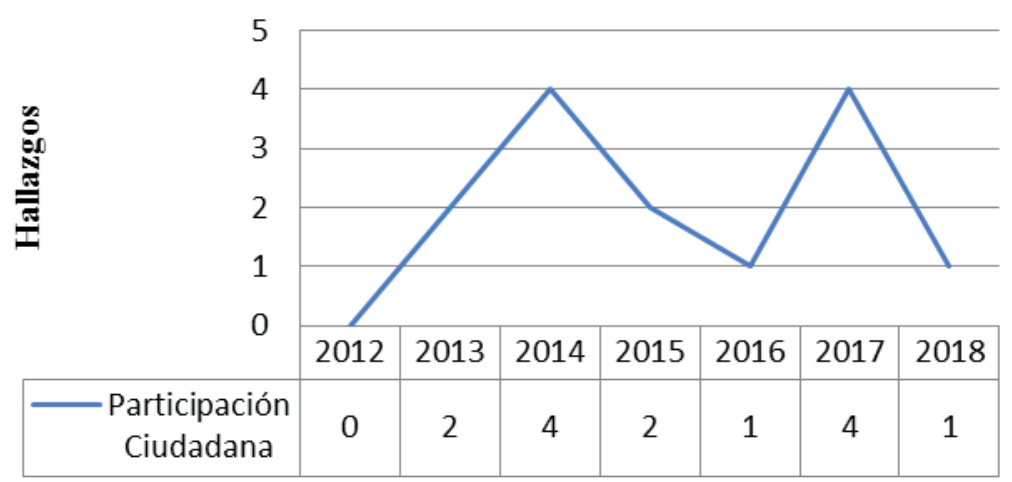

Fuente: Elaboración propia 
Gráfico 9. Curva de aprendizaje de Recursos Físicos

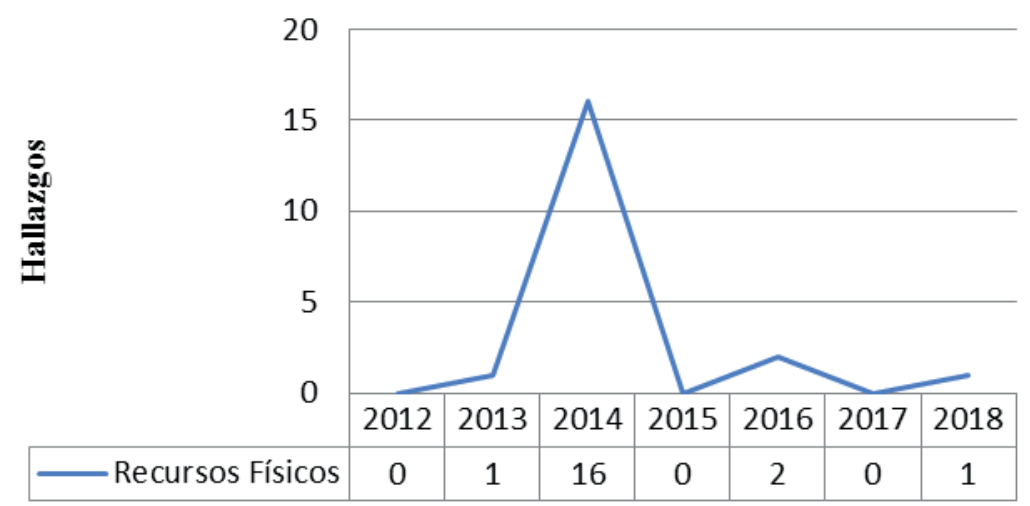

Fuente: Elaboración propia

Gráfico 10. Curva de aprendizaje de Planeación

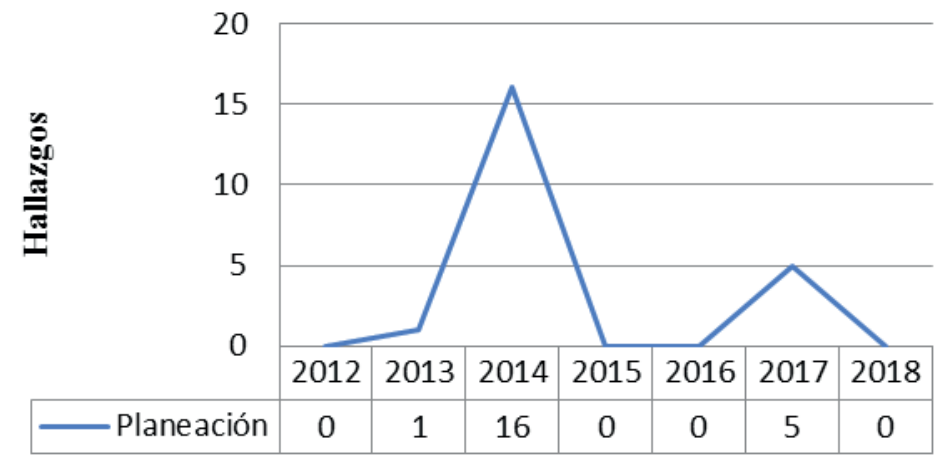

Fuente: Elaboración propia

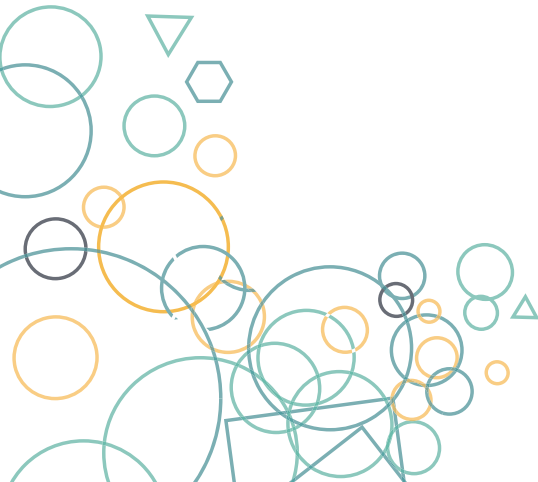


Gráfico 11. Curva de aprendizaje de Gestión documental

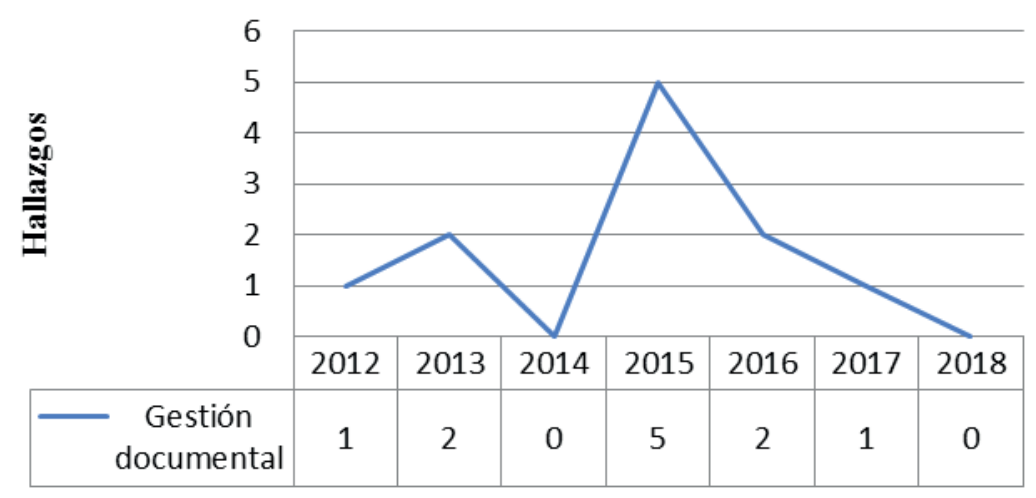

Fuente: Elaboración propia

\subsubsection{Análisis por contraloría}

A continuación se presentan, por contraloría, solo aquellos procesos que evidencian aprendizaje en los últimos siete años.

Gráfico 12. Curva de aprendizaje en Contratación CGR

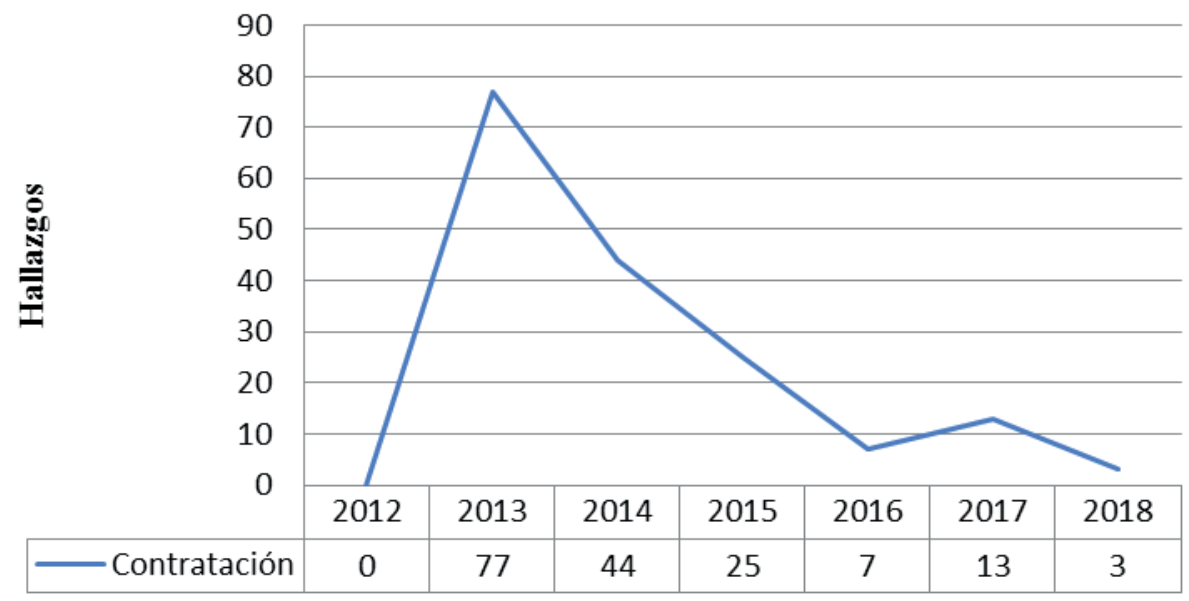

Fuente: Elaboración propia 
Gráfico 13. Curva de aprendizaje en Supervisión CGR

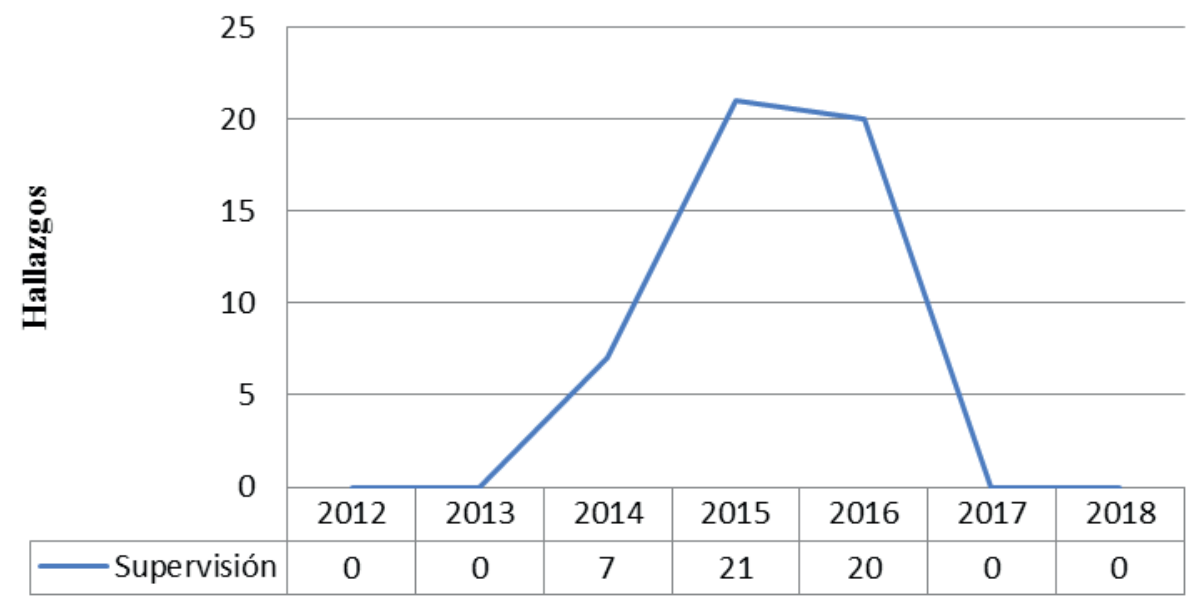

Fuente: Elaboración propia

En supervisión de contratos la contraloría mejoró su desempeño en los últimos tres años.

Gráfico 14. Curva de aprendizaje en Recursos

Financieros

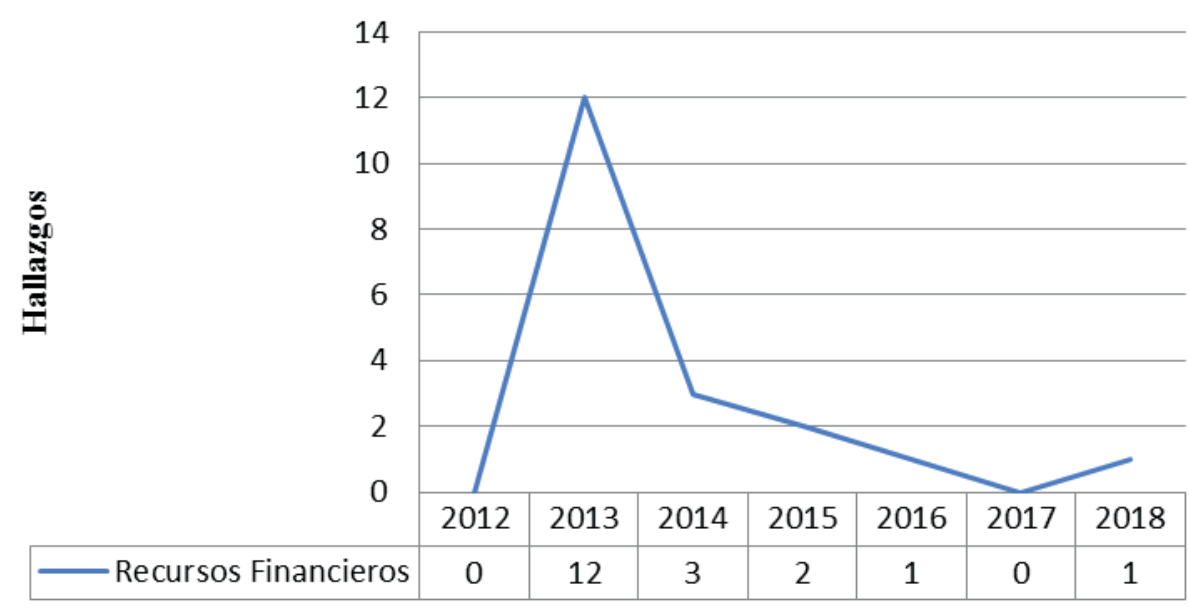

Fuente: Elaboración propia 


\section{Gráfico 15. Curva de aprendizaje en Contabilidad -}

Contraloría de Medellín

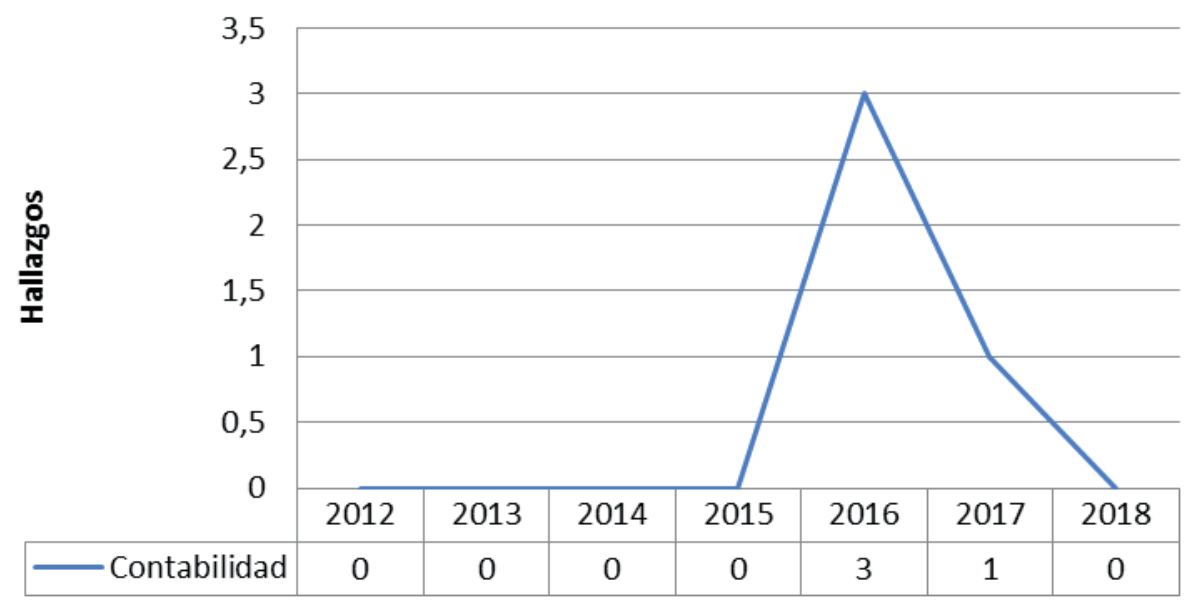

Fuente: Elaboración propia

A partir de las fallas detectadas en 2016, la contraloría desarrolló el aprendizaje suficiente para disminuir y eliminar las causas de los hallazgos.

Gráfico 16. Curva de aprendizaje en Responsabilidad Fiscal - Contraloría del Vaupés

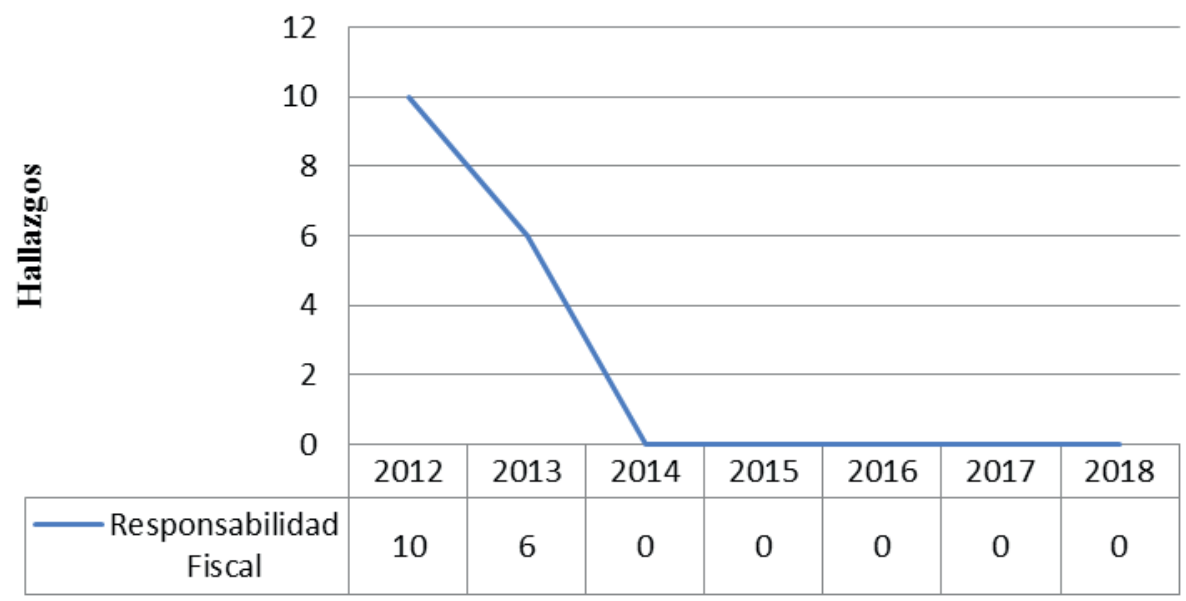

Fuente: Elaboración propia 
La Contraloría de Vaupés, en materia del proceso de responsabilidad fiscal, demuestra la sostenibilidad de su aprendizaje, al no presentar hallazgos en esta materia durante los últimos cinco años.

Gráfico 17. Curva de aprendizaje en Proceso Auditor CGR

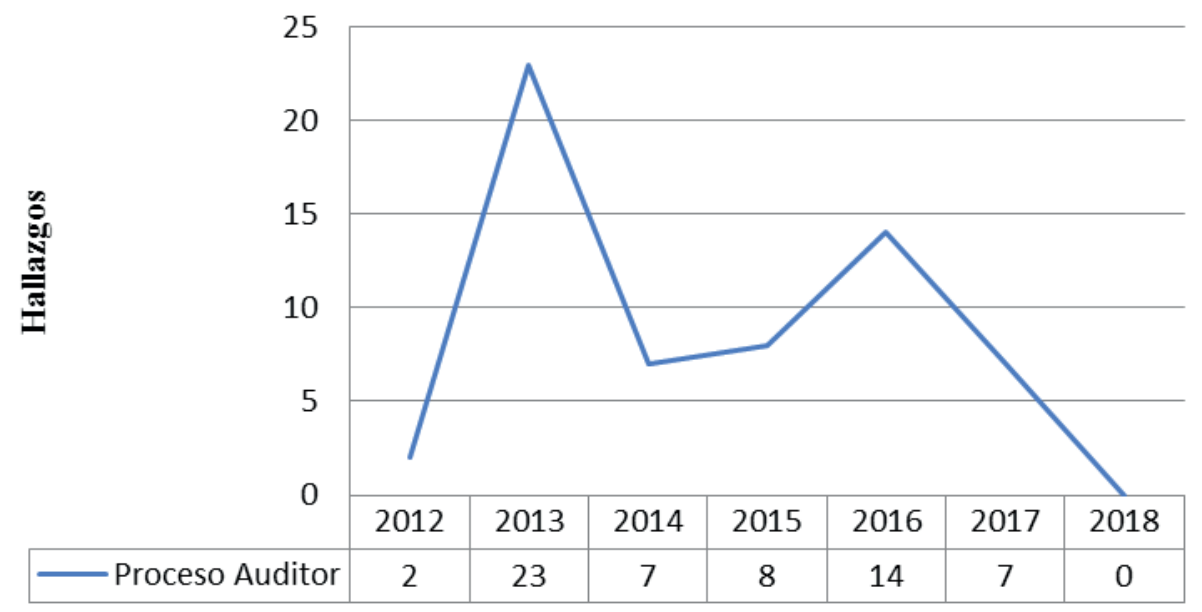

Fuente: Elaboración propia

Gráfico 18. Curva de aprendizaje en Talento Humano CGR

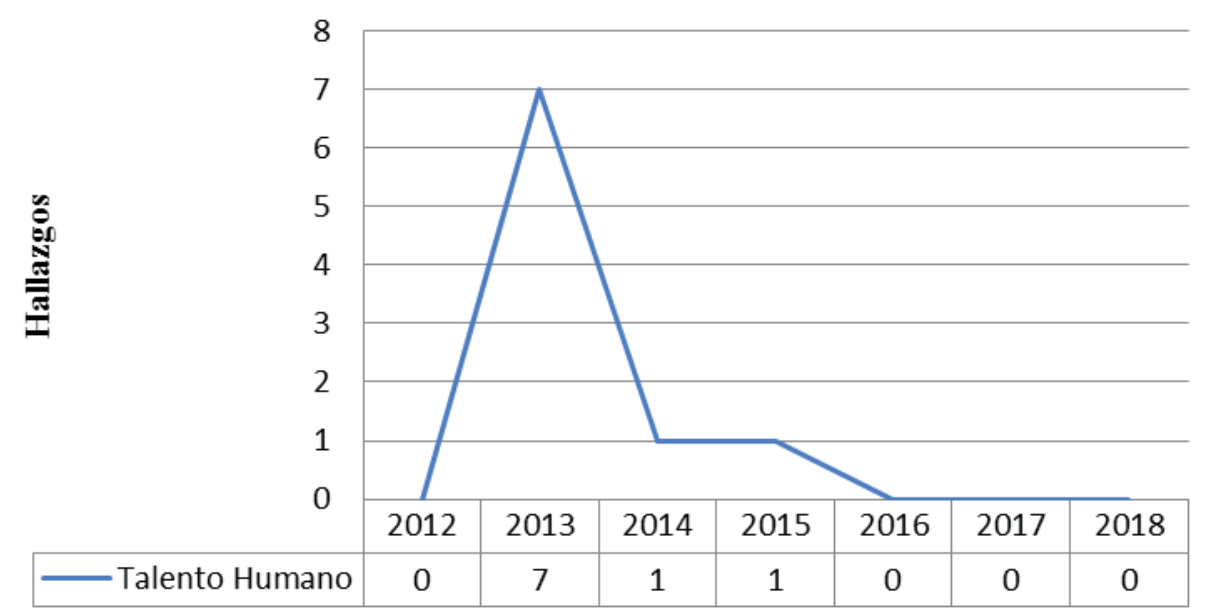

Fuente: Elaboración propia 


\section{Gráfico 19. Curva de aprendizaje en Talento Humano} Contraloría del Vaupés

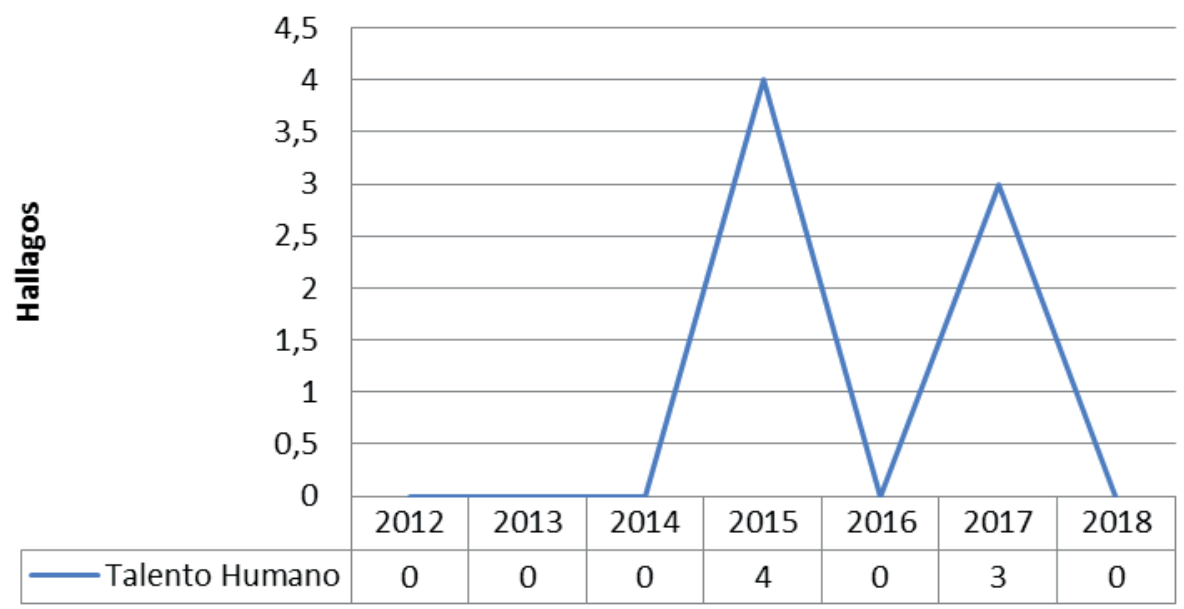

Fuente: Elaboración propia

En el caso del proceso de gestión del talento humano que administra la Contraloría del Vaupés, es evidente que su aprendizaje no se ha dado en la medida en que a pesar de haber reducido a cero los hallazgos de un año a otro, en el siguiente estas situaciones volvieron a presentarse.

Gráfico 20. Curva de aprendizaje en Participación Ciudadana - CGR

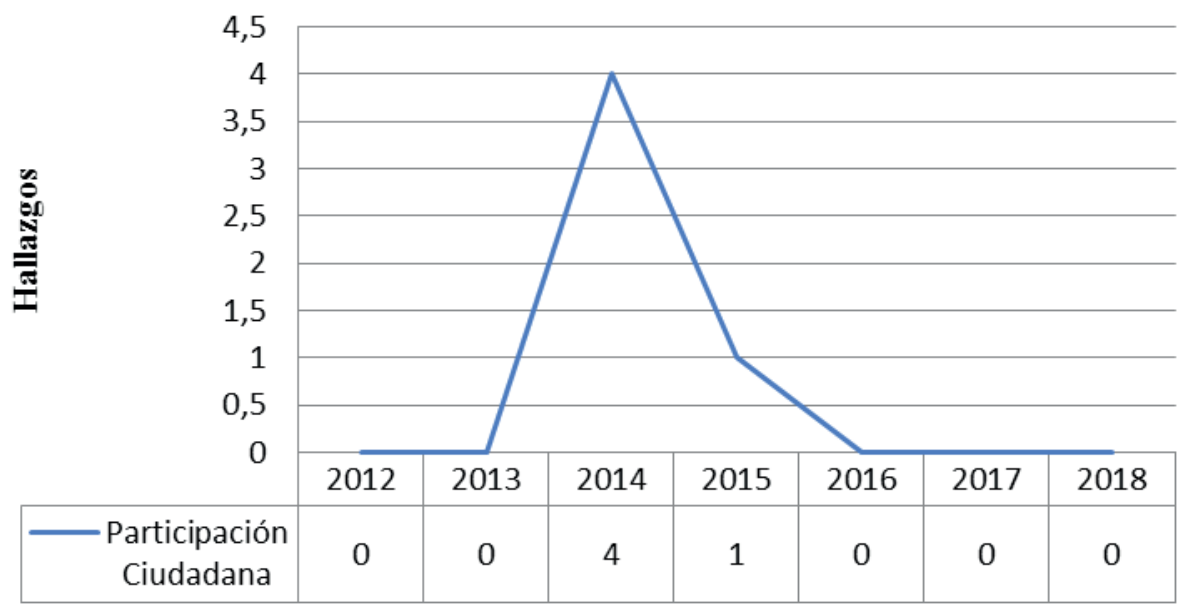

Fuente: Elaboración propia

En la Contraloría General de la República se evidencia que en materia del proceso de participación ciudadana, las acciones de mejora implementadas desde 2014 han generado el 


\section{OPPCF}

aprendizaje necesario para realizar el proceso cumpliendo los parámetros previstos, y por ello no se presentan hallazgos desde hace tres años.

\subsection{CONCLUSIONES}

Los resultados agrupados por proceso demuestran que gracias a los hallazgos encontrados, en el marco del control fiscal, los sujetos vigilados desarrollan acciones de mejora (aprenden), que les permite superar la situaciones encontradas. En este sentido, se cumple la hipótesis: el proceso auditor genera aprendizaje organizacional en los sujetos de control.

Por contraloría, los resultados demuestran que no en todos los procesos el aprendizaje es sostenible. Es decir, una contraloría puede volver a repetir hallazgos sobre un mismo proceso después de dos años.

En materia de contratación y supervisión de contratos es en donde más, las instituciones han aprendido. Esto obedece a que es el proceso que más hallazgos presentó hacia el año 2012 y los cuales se han visto disminuidos paulatinamente.

El proceso auditor, eje de la misión de las contralorías, demuestra un aprendizaje que se ha sostenido con el tiempo, pues los hallazgos se han disminuido en cada vigencia.

El proceso misional que no demuestra aprendizaje es el de responsabilidad fiscal. Lo anterior se sustenta que en entre 2012 y 2018 se siguen presentando el mismo número de hallazgos y las acciones de mejora aplicadas no se han mantenido en el tiempo.

Es necesario hacer este análisis comparativo para cada una de las contralorías pues estos resultados sirven de insumo para retroalimentar el proceso auditor que realiza la Auditoría General de la República. Al elaborar el plan general de auditorías, saber el estado del aprendizaje por procesos, ayuda a focalizar la muestra de auditoría, es decir, a priorizar la vigilancia de aquello que no ha mejorado en el sujeto de control.

Es pertinente profundizar este tipo de análisis para identificar los factores que impiden la sostenibilidad del aprendizaje organizacional.

\subsection{BIBLIOGRAFÍA}

Auditoría General de la República. (29 de Enero de 2019). auditoria.gov.co. Recuperado el 02 de noviembre de 2018, de http://www.auditoria.gov.co/

Ayala Calvo, J. C. (2007). Dialnet. Recuperado el 16 de julio de 2019, de https://dialnet.unirioja. es 
Castañeda, D. \&. (2007). Dialnet. Recuperado el 15 de junio de 2019, de https://dialnet.unirioja. es

Congreso de la República de Colombia. . (1993). funcionpublica.gov.co. Recuperado el 17 de julio de 2019, de https://www.funcionpublica.gov.co/eva/gestornormativo/norma. php?i=300

Garzón Castrillón, M. A. (2008). Dialnet. Recuperado el 15 de octubre de 2018, de https:// dialnet.unirioja.es

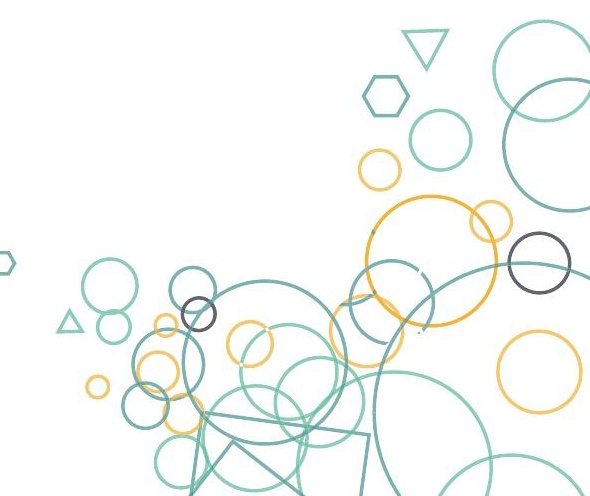




\section{CAPITULO V}

\section{CONTROL SOCIAL, RENDICIONES DE CUENTA A LA CIUDADANÍA Y NIVEL DE SATISFACCIÓN DE LOS USUARIOS: FACTORES DETERMINANTES EN LA VIGILANCIA FISCAL DE LAS CONTRALORÍAS TERRITORIALES EN COLOMBIA. \\ SOCIAL CONTROL, CITIZENSHIP ACCOUNTABILITY AND USERS SATISFACTION LEVEL: DETERMINING FACTORS IN THE FISCAL SURVEILLANCE OF THE TERRITORIAL COMPTROLLERS IN COLOMBIA.}

\section{Coautoras:}

Liliana Patricia Ortiz Ospino, Ingeniera Industrial de la Universidad del Norte, Magíster en Políticas Públicas de la Universidad de los Andes y especialista en Gerencia y Gestión Cultural de la Universidad del Rosario. Docente investigador de pregrado y posgrado, Profesional Especializado Oficina de Estudios Especiales y Apoyo Técnico de la AGR e investigadora del "Observatorio de Política Pública del Control Fiscal" adscrito -según convenio- a la Auditoría General de la República y la Universidad Santo Tomás de Bogotá. De otra parte los incisos

Diana Maite Bayona Aristizábal, Abogada de la Universidad Santo Tomás - Bogotá y actual Coordinadora de la Maestría en Derecho Penal de dicha institución; Especialista en Ciencias Penales y Criminológicas de la Universidad Externado de Colombia. Candidata a Magíster en Derecho Penal de la Universidad Santo Tomás. Docente universitaria de pregrado y posgrado, e investigadora del "Observatorio de Política Pública del Control Fiscal" adscrito -según convenioa la Auditoría General de la República y la Universidad Santo Tomás de Bogotá.

\section{Resumen}

Este capítulo analiza las características y condiciones de control que inciden significativamente en los resultados de la vigilancia fiscal realizada a las contralorías departamentales del país por 
parte de la Auditoría General de la República. En relación con estos órganos de control, el estudio evidencia que un aumento en la capacidad de promover el control social y de realizar esfuerzos en rendiciones de cuentas, tiene incidencia significativa en sus hallazgos fiscales. En general los resultados sugieren que un monitoreo que combine estrategias tradicionales 'bottom-up' y 'top-down', puede jugar un papel importante en la vigilancia fiscal de las contralorías territoriales. De otro lado, la investigación sugiere que las políticas institucionales y pedagógicas del estatuto anticorrupción no producen aún, impacto significativo en los hallazgos de las contralorías, por esa razón se requiere una investigación más profunda sobre la implementación de la Ley 1474 de 2011 (Estatuto Anticorrupción) en estos organismos de control.

Asimismo conocer la percepción de las contralorías territoriales sobre el proceso de auditoría que adelanta la Auditoría General de la República (AGR) es importante para identificar los aspectos del proceso auditor que ameritan una revisión. Los contextos locales, la realidad en materia de presupuesto, personal y los factores sociales, económicos, políticos y culturales que inciden en el desempeño de las actividades de vigilancia y control fiscal en las regiones, son variables que deben considerarse. Por ello, los comentarios de los sujetos auditados en el periodo 2012-2017 suministran evidencias concretas que podrían coadyuvar a la flexibilización del proceso auditor, entendiendo esta, como la posibilidad de ampliar las formas y actuaciones que existen para la cadena del proceso auditor en el país. Aunado a ello, es importante identificar el grado de satisfacción en relación con el personal, el servicio y la calidad de los procesos de auditoría adelantados por la AGR, con la intención última de hacer del proceso auditor una herramienta indispensable y valorada en el ejercicio de la gestión fiscal en Colombia.

\section{Abstract}

This research analyzes characteristics and conditions of control that affect results of fiscal surveillance on local fiscal control entities by the General Audit of the Colombian Republic. Empirical evidence of this study suggests that increasing in capacity to produce population monitoring and accountability, has a significant impact on their fiscal findings. In general, results show traditional bottom-up and top-down monitoring can play an important role in reducing corruption in local fiscal surveillance organisms. On the other hand, research presents that anticorruption policies and pedagogies mechanism there is not have significant impact on findings of the local comptroller's offices, which requires a more in-depth investigation into the control bodies' implementation of Law 1474 of 2011, Anticorruption Statute. 
Knowing the perception of the territorial comptrollers about the audit process that the General Audit of the Colombian Republic (AGR) advances, is important to identify aspects of the audit process that merit a review. The local contexts, the reality in term of budget, personnel and the social, economic, political and cultural factors that affect the performance of fiscal surveillance and control activities in the regions, are variables that should be considered. Therefore, the comments of the audited subjects in the 2012-2017 period provide concrete evidence that could contribute to the flexibility of the audit process, understanding this, as the possibility of expanding the forms and actions that exist for the audit process chain in the country. In addition, it is important to identify the degree of satisfaction in relation to the personnel, service and quality of the audit processes carried out by the AGR, with the ultimate intention of making the audit process an indispensable and valued tool in the exercise of tax management in Colombia.

\section{Palabras clave}

Control social, rendiciones de cuenta a la ciudadanía, control interno, políticas anticorrupción

\section{Key words}

Social control, accountability to citizenship, internal control, fight against corruption policies.

Temario: 5.1. Relación entre número de hallazgos fiscales identificados frente a la calidad de realizar rendiciones de cuenta. 5.2. Capacidad de realizar ejercicios de rendiciones de cuenta a la ciudadanía por parte de las contralorías territoriales. 5.3. El control social, el rol del control interno, y sus efectos en la eficacia del control fiscal. 5.4. Nivel de satisfacción de las contralorías respecto del proceso auditor de la Auditoría General de la República - AGR. 5.5. Conclusiones. 5.6. Bibliografía

\section{Introducción}

Los trabajos de Tullock (1989), Klitgaard (1991), Schleifer \& Vishny (1993), Mauro (1993) y Olken (2007), demuestran cómo estrategias top-down (de arriba hacia abajo) o bottom-up (de la base de la organización hacia arriba) como las auditorías, el control interno, las actividades de visibilidad y transparencia, la satisfacción de los usuarios, las rendiciones de cuenta y la promoción del control social producen impacto en la lucha contra la corrupción. Estos autores afirman que en entornos altamente corruptos este tipo de medidas y mecanismos aumentan la capacidad de vigilancia de los recursos públicos.

En relación con este tipo de dispositivos de control diversos investigadores han encontrado que la auditoría como estrategia de arriba hacia abajo o conocida como 'top-down' es una 
"herramienta de control y supervisión que contribuye a la creación de una cultura de la disciplina de la organización y permites cubrir fallas en las estructuras o vulnerabilidades existentes en la organización" (Villardefrancos y Rivera, 2006). Dichas autoras la clasifican en auditoría independiente, interna y gubernamental.

Particularmente la auditoría interna o de control interno, según Villardefrancos y Rivera (2006) es:

Una herramienta de apoyo a la dirección de las organizaciones, las que, generalmente, poseen un departamento especial dedicado a estos menesteres. Este tipo de auditoría, denominado también auditoría de gestión u operativa, pone el énfasis en la evaluación de políticas, procedimientos, métodos, así como en el análisis de tareas. (Villardefrancos y Rivera, 2006, p. 54-55)

Deotrolado,"la auditoría gubernamental es ejercida por numerosas agencias gubernamentales, cuyas investigaciones, por lo general, quedan limitadas al nivel del departamento, localidad o región en cuestión" (Villardefrancos y Rivera, 2006, p. 54-55).

Ahora bien, las Normas de Auditoría Gubernamental (NAGU), definen la auditoría gubernamental como "el examen objetivo, sistemático y profesional de las operaciones financieras y/o administrativas, efectuado con posterioridad a su ejecución, en las entidades sujetas al Sistema Nacional de Control, elaborando el correspondiente informe" (Delgado, 2012)

Dentro de sus principales objetivos se encuentran:

a. Evaluar la correcta utilización de los recursos públicos, verificando el cumplimiento de las disposiciones legales y reglamentarias.

b. Determinar la razonabilidad de la información financiera.

c. Determinar el grado en que se han alcanzado los objetivos previstos y los resultados obtenidos en relación a los recursos asignados y al cumplimiento delos planes y programas aprobados de la entidad examinada.

d. Recomendar medidas para promover mejoras en la gestión pública.

e. Fortalecer el sistema de control interno de la entidad auditada.

De otra parte, las aportaciones a la literatura teórica sobre la corrupción destaca el enfoque basado en la teoría de la agencia, según el cual se plantea como un problema de asimetría de información. Al respecto se plantea a las entidades como agente principal con gran cantidad de información sobre las transacciones y acciones fraudulentas, frente al desconocimiento de la ciudadanía y sus insuficientes herramientas para intervenir (Fernandez y Fernandez, 1999). 
Es por esta razón que, retomando a Olken (2007), se plantea como acciones efectivas para corregir esta falla del estado la generación de masa crítica ciudadana mediante ejercicios de visibilidad, transparencia y empoderamiento del control social.

En contraposición con ello, los detractores de los dispositivos de control señalan la inminencia del acto fraudulento a pesar de los todos los controles que se impongan al proceso. Según eso en las organizaciones o entidades donde se den las condiciones propicias para burlar los controles establecidos, tarde o temprano, el funcionario desleal que haya constatado la oportunidad de perpetrar una apropiación o irregularidad indebida con un riesgo remoto de ser detectado, acabará cometiéndola (Tanarro, 2003).

En ese mismo sentido, y en materia de control fiscal concretamente, en un hipotético caso:

Volviendo entonces a que si "Fortunato Corrupto" calcula la probabilidad de impunidad que traduce en la relación costo-beneficio para decidir si comete la conducta dañina, y encuentra que la probabilidad de ser efectivamente obligado a resarcir el daño es del 6,35\%, tiene un incentivo enorme para embolsillarse el dinero que se le ha entregado en confianza para su manejo, guarda o administración.

Así las cosas, se puede reafirmar, haciendo un analogía con lo que dice Becker sobre las conductas criminales que, dañar el patrimonio público se ha convertido tristemente en una industria rentable en términos económicos, pues ofrece buenos dividendos al infractor y un bajo riesgo de ser descubierto, investigado, responsabilizado fiscalmente y obligado a restablecer el daño. Es de advertir que tal circunstancia no solo no se compadece con las enormes posibilidades que tiene un gestor fiscal de causar despilfarro y malversación del erario, sino que está en clara contravía con el interés general e implica una medida de la perdida social demasiado elevado, lo que permite reprochar con más ahínco, la conducta de "Fortunatos Corruptos" que a conciencia de su impunidad causan de alguna manera daño al patrimonio estatal. (Ordóñez, 2005. p.63)

Para establecer sus supuestos esta investigación se inclina por los aportes científicos de la corrupción vista desde los problemas de la asimetría de información que proponen Fernandez y Fernández (1999).

Ahora bien, sobre el contexto colombiano se puede señalar que no obstante cada entidad gubernamental procura la existencia de oficinas de control interno y de sistemas de gestión de calidad, existen organismos nacionales y locales (o territoriales) que de manera externa ejercen control sobre sus finanzas y resultados.

De esta manera en el Artículo 267 de la Constitución de Colombia se establece que:

El control fiscal es una función pública que ejercerá la Contraloría General de la República, la cual vigila la gestión fiscal de la administración y de los particulares o entidades que manejen fondos o bienes de la Nación. Dicho control se ejercerá en forma posterior y selectiva conforme a los procedimientos, sistemas y principios que establezca la ley. (...). La vigilancia de la gestión fiscal del Estado incluye el ejercicio de un control financiero, de gestión y de resultados, fundado en la eficiencia, la economía, la equidad y la valoración de los costos 
ambientales. En los casos excepcionales, previstos por la ley, la Contraloría podrá ejercer control posterior sobre cuentas de cualquier entidad territorial.

De otra parte, la Ley 42 de 1993, en su Artículo 4 instituyó:

El control fiscal es una función pública, la cual vigila la gestión fiscal de la administración y de los particulares o entidades que manejen fondos o bienes del Estado en todos sus órdenes y niveles.

Este será ejercido en forma posterior y selectiva por la Contraloría General de la República, las contralorías departamentales y municipales, conforme a los procedimientos, sistemas y principios que se establecen en la presente Ley.

Estas dos premisas normativas que le confieren competencia a la Contraloría General de la República, y a las Contralorías Departamentales y Municipales, para ejercer la vigilancia fiscal de las entidades de los ámbitos nacional y territorial, son el principal sustento para preguntarse cuáles factores de la estructura de estas organizaciones tienen incidencia significativa en la vigilancia de la gestión fiscal.

Este análisis es pertinente porque sabida cuenta de las restricciones presupuestales por las que atraviesan la mayoría de los órganos de control fiscal, especialmente las contralorías territoriales, puede brindar luces importantes sobre la manera en que se deben enfocar los recursos disponibles concentrándose en los esfuerzos que resulten significativamente efectivos para la vigilancia fiscal.

Dicho cuestionamiento se hace bajo los supuestos de que actualmente existe restricción en la asignación de recursos a las contralorías territoriales y de que promover la generación de una masa crítica en control social y aumentar la transparencia de las instituciones mitiga las asimetrías de información que tienen las entidades frente a la ciudadanía y amplía la capacidad de vigilancia fiscal. También se parte, de que a mayor gestión del control interno es posible lograr mejoras sustanciales en las entidades de tal suerte que disminuyan los hallazgos totales de las mismas.

En el marco de los procesos de control de calidad en las actividades adelantadas por la Auditoría General de la República - AGR, dentro del proceso de Orientación Institucional se definió el procedimiento Ol.200.P03 "medición de la satisfacción de los usuarios". Tiene como finalidad analizar la percepción de la población que tiene relación directa o indirecta con las actividades de la entidad, tales como las contralorías como sujetos vigilados, la ciudadanía, los sujetos procesales dentro de los procesos fiscales que adelanta la Dirección de Responsabilidad Fiscal y Jurisdicción Coactiva, y la de los participantes a los distintos eventos llevados a cabo a través de la Oficina de Estudios Especiales de la entidad principalmente. Dicha percepción 
tiene como finalidad redundar en el mejoramiento constante de los distintos productos de la entidad a la ciudadanía. En el presente capítulo (subcapítulo 5.4) se analizará la percepción de las contralorías territoriales en relación con los procesos de auditoría en cabeza de la AGR durante los periodos 2012-2017.

Los subcapítulos 5.1, 5.2 y 5.3 se ocupan del análisis de factores de control social y rendición de cuentas a la ciudadanía y su incidencia en los hallazgos fiscales. Ahora bien, los datos recolectados para el análisis corresponden a la información de los años 2013-2016 reportada por las contralorías territoriales en el módulo SIREL del Sistema de Información de Auditoríade la Auditoría General de la República, en contraste con indicadores recolectados por la Corporación Transparencia por Colombia en el marco del cálculo del Índice de Transparencia de dichos organismos. Sin embargo teniendo en cuenta que el año común en la producción de datos es el 2016, el análisis de regresiones y correlaciones elaboradas en este capítulo se redujo a las variables correspondientes a esa vigencia.

Esta información fue procesada a través de un análisis cuantitativo utilizando como variables explicativas los indicadores de control territoriales más destacados de las fuentes descritas y como variables dependientes, los hallazgos fiscales de las contralorías territoriales, con el propósito de establecer cuáles son las intervenciones de control que afectan de manera significativa el aumento o disminución de los mismos.

Por la desagregación de la información territorial disponible el análisis de estos apartados, tiene alcance en el ámbito departamental, es decir que las unidades estadísticas de observación son las contralorías departamentales.

La metodología utilizada consistió en la construcción de regresiones lineales por Mínimos Cuadrados Ordinarios (MCO). Las iteraciones se realizaron por características similares de intervención en las políticas, de acuerdo con las fichas metodológicas de las operaciones estadísticas de la Auditoría General de la República (AGR) y de la Corporación Transparencia por Colombia (CTC). Se utilizó como variable dependiente los hallazgos fiscales, como explicativas las capacidades de visibilización de las rendiciones de cuenta, controlando con niveles de riesgos de estos factores.

Las variables asociadas a diferentes intervenciones realizadas por la Auditoría General de la República y otras entidades estatales, aparecen nombradas en los cuadros de resultados de la modelación realizada como se detalla en la siguiente tabla:

Tabla No. 5.1 Factores, características y condiciones de transparencia, 
divulgación y visibilidad de las Contralorías Territoriales

\begin{tabular}{|l|c|c|}
\hline \multicolumn{1}{|c|}{ Indicador } & & Fuente \\
\hline Número de hallazgos fiscales identificados & HALLAZGOS & SIA-SIREL-AGR \\
\hline Medida de transparencia de la región & TRANSPIGA & IGA- PGN \\
\hline $\begin{array}{l}\text { Capacidad de divulgación de información pública } \\
\text { Capacidad de divulgación de la atención a los } \\
\text { ciudadanos }\end{array}$ & DIVULGAINFPUB100 & ITC CTC \\
\hline $\begin{array}{l}\text { Capacidad de realizar procesos de rendición de cuentas } \\
\text { Nivel de riesgo de divulgación de la gestión } \\
\text { administrativa }\end{array}$ & RENDICUENTAS100 & ITC CTC \\
\hline $\begin{array}{l}\text { Nivel de riesgo de divulgación del presupuesto de la } \\
\text { entidad }\end{array}$ & DIVULGAPRESPON \\
\hline $\begin{array}{l}\text { Nivel de riesgo de realizar procesos de rendición de } \\
\text { cuentas }\end{array}$ & AUDIENCIA & ITC CTC \\
\hline $\begin{array}{l}\text { Capacidad de divulgación de su compromiso ético } \\
\text { Fuente:laboración propia }\end{array}$ & ITC CTC \\
\hline
\end{tabular}

Como primer acercamiento a los datos analizados en la tabla a continuación se muestra el índice de transparencia por contralorías en el período 2013-2017:

Tabla No. 5.2 Índice de Transparencia de las Contralorías Territoriales

\begin{tabular}{|l|l|l|}
\hline Nombre de la Entidad & $\mathbf{2 0 1 3 - 2 0 1 4}$ & $\mathbf{2 0 1 5 - 2 0 1 6}$ \\
\hline Contraloría de Amazonas & 22.0 & 34.6 \\
\hline Contraloría de Antioquia & 71.6 & 72.4 \\
\hline Contraloría de Arauca & 46.1 & 58.2 \\
\hline Contraloría de Atlántico & 59.6 & 57.1 \\
\hline Contraloría de Barrancabermeja & 72.9 & s.i.* \\
\hline Contraloría de Bolívar & 52.1 & 56.9 \\
\hline Contraloría de Boyacá & 58.5 & 67.7 \\
\hline Contraloría de Bucaramanga & 74.9 & $5 . i^{*}$ \\
\hline Contraloría de Caldas & 71.6 & 71.4 \\
\hline Contraloría de Caquetá & 57.9 & 50.4 \\
\hline Contraloría de Casanare & 58.6 & 49.4 \\
\hline Contraloría de Córdoba & 63.8 & 64.0 \\
\hline Contraloría de Cundinamarca & 57.2 & 87.0 \\
\hline Contraloría de Floridablanca & 56.7 & $5 . i^{*}$ \\
\hline Contraloría de Guainía & 31.4 & 40.6 \\
\hline Contraloría de La Guajira & 52.2 & 64.2 \\
\hline Contraloría de Nariño & 62.0 & 66.2 \\
\hline
\end{tabular}




\begin{tabular}{|l|l|l|}
\hline Contraloría de Norte de Santander & 64.6 & 68.3 \\
\hline Contraloría de Putumayo & 53.6 & 52.7 \\
\hline Contraloría de Risaralda & 62.2 & 80.1 \\
\hline Contraloría de San Andres, Providencia y Santa Catalina & 61.2 & 62.1 \\
\hline Contraloría de Santander & 59.8 & 52.1 \\
\hline Contraloría de Sucre & 43.0 & 53.5 \\
\hline Contraloría de Vichada & 36.2 & 43.4 \\
\hline Contraloría del Cauca & 71.0 & 75.8 \\
\hline Contraloría del Cesar & 43.5 & 45.3 \\
\hline Contraloría del Chocó & 29.5 & 48.6 \\
\hline Contraloría del Guaviare & 71.9 & 71.0 \\
\hline Contraloría del Huila & 78.7 & 87.1 \\
\hline Contraloría del Magdalena & 41.8 & 59.4 \\
\hline Contraloría del Meta & 75.3 & 73.8 \\
\hline Contraloría del Quindío & 61.8 & 78.9 \\
\hline Contraloría del Tolima & 62.8 & 55.0 \\
\hline Contraloría del Valle del Cauca & 65.2 & 71.6 \\
\hline Contraloría del Vaupés & 28.4 & 46.5 \\
\hline
\end{tabular}

*s.i.: Sin Información, información no reportada en el bienio.

Fuente: ITC, Transparencia por Colombia

Como se observa en estos datos, en el bienio 2013-2014 ninguna contraloría territorial supera el $80 \%$ de la calificación realizada por Transparencia por Colombia (TC), y en el siguiente bienio solo tres de ellas lo logra: Cundinamarca, Risaralda y Huila. De otra parte, se observa una alta dispersión de los datos en el 2015-2016, la cual supera la del bienio anterior. Un sencillo análisis sobre los datos da cuenta del deterioro que están sufriendo estas entidades en sus indicadores de transparencia y visibilidad, características deseables en los organismos de control que en principio deberían dar ejemplo e imponer mejoras en ese sentido.

\subsection{RELACIÓN ENTRE NÚMERO DE HALLAZGOS FISCALES IDENTIFICADOS FRENTE A LA CAPACIDAD DE REALIZAR RENDICIONES DE CUENTA.}

Respecto del número de hallazgos fiscales frente a la actividad de control social de realizar rendiciones de cuenta el análisis evidencia algunos resultados esperados, confirmando lo que se ha mencionado en distintos escenarios del control que la correlación entre los hallazgos de tipo fiscal y la utilización de estrategias como rendición de cuenta, audiencias públicas, actividades de divulgación resultan significativas. 
Según los resultados del modelo empleado, al analizar los factores, características y condiciones de transparencia, divulgación y visibilidad de las contralorías territoriales es posible inferir con confianza que los hallazgos fiscales tienen relación significativamente estadística con la capacidad de realizar rendiciones de cuenta, lo cual alcanza un coeficiente de correlación del 0,92 , muy cercano a uno (1), el cual es la relación más alta entre dos variables.

Según la tabla 5.3 las rendiciones de cuenta ponderadas o en puntos porcentuales resultan significativas frente a los hallazgos de responsabilidad fiscal.

\section{Cuadro No. 5.1 Salida modelos MCO y ANOVA, variable dependiente: Hallazgos Fiscales.}

\begin{tabular}{|c|c|c|c|c|c|c|}
\hline \multirow{2}{*}{\multicolumn{2}{|c|}{ Modelo }} & \multicolumn{2}{|c|}{$\begin{array}{l}\text { Coeficientes no } \\
\text { estandarizados }\end{array}$} & \multirow{2}{*}{$\begin{array}{c}\begin{array}{c}\text { Coeficientes } \\
\text { estandarizados }\end{array} \\
\text { Beta }\end{array}$} & \multirow[t]{2}{*}{$\mathrm{t}$} & \multirow[t]{2}{*}{ Sig. } \\
\hline & & B & Desv. Error & & & \\
\hline \multirow[t]{10}{*}{1} & (Constante) & $-79,622$ & 140,758 & &,- 566 & ,577 \\
\hline & TRANSPIGA & 1,766 & 1,676 & , 175 & 1,053 & 304 \\
\hline & DIVULGAINFPUB100 & 1,406 & 1,246 & ,281 & 1,129 & ,271 \\
\hline & DIVULGAATC100 & ,117 & ,787 & ,028 & , 149 & ,883 \\
\hline & RENDICUENTAS100 & 42,249 & 12,882 & 8,720 & 3,280 & ,003 \\
\hline & DIVULGAGESADMPON & 5,228 & 17,239 & ,084 & ,303 & ,765 \\
\hline & DIVULGAPRESPON & $-9,615$ & 9,483 &,- 271 & $-1,014$ & ,322 \\
\hline & RENDICUENTASPON & $-408,655$ & 132,546 & $-8,397$ & $-3,083$ & ,005 \\
\hline & AUDIENCIA & $-33,385$ & 35,646 &,- 242 &,- 937 & 359 \\
\hline & DIVULGETICA & $-52,924$ & 35,045 &,- 249 & $-1,510$ & , 145 \\
\hline
\end{tabular}

Esta evidencia lleva a reflexión sobre la focalización de esfuerzos en mecanismos de control social y rendiciones de cuenta que permitan el aumento de la visibilidad y la transparencia de las instituciones, y en consecuencia la credibilidad de las instituciones por parte de la sociedad civil.

\subsection{CAPACIDAD DE REALIZAR EJERCICIOS DE RENDICIONES DE CUENTA A LA CIUDADANÍA POR PARTE DE LAS CONTRALORÍAS TERRITORIALES}

Pese al impacto significativo que tienen las rendiciones de cuenta en los hallazgos fiscales la evidencia empírica reportada por la Corporación Transparencia por Colombia demuestra que las Contralorías han bajado en su capacidad de realizar rendiciones de cuenta. 
En el período 2013-2014 nueve (9) de las 35 contralorías analizadas tenían calificación superior a 80 en la capacidad de realizar rendiciones de cuentas sobre 100 , calificación que solo alcanzaron tres contralorías en el siguiente período. Esto se ve claramente reflejado en las variaciones bianuales que en el $57 \%$ de las contralorías fue negativa y la comparación de las medianas de los datos que en el primer período es de 48 y en el segundo desciende a 43, como se muestra en la tabla a continuación:

\section{Tabla 5.3. Capacidad de realizar rendiciones de cuenta a la ciudadanía y variaciones bianuales de los períodos 2013-2014 y 2015-2016.}

\begin{tabular}{|c|c|c|c|}
\hline Nombre de la Entidad & $\begin{array}{c}\text { Rendición de cuentas } \\
\text { a la ciudadanía/100 } \\
2013-2014\end{array}$ & $\begin{array}{c}\text { Rendición de cuentas } \\
\text { a la ciudadanía/100 } \\
2015-2016\end{array}$ & $\begin{array}{c}\text { Variación } \\
\text { Anual }\end{array}$ \\
\hline Contraloría de Amazonas & 0 & & \\
\hline Contraloría de Antioquia & 94 & 58 & -39 \\
\hline Contraloría de Arauca & 15 & 21 & 35 \\
\hline Contraloría de Atlántico & 37 & 19 & -49 \\
\hline Contraloría de Barrancabermeja & 45 & s.i. & \\
\hline Contraloría de Bolívar & 47 & 42 & -10 \\
\hline Contraloría de Boyacá & 86 & 45 & -47 \\
\hline Contraloría de Bucaramanga & 82 & $\mathrm{nr}$ & \\
\hline Contraloría de Caldas & 87 & 56 & -36 \\
\hline Contraloría de Caquetá & 27 & 24 & -12 \\
\hline Contraloría de Casanare & 80 & 15 & -82 \\
\hline Contraloría de Córdoba & 70 & 44 & -37 \\
\hline Contraloría de Cundinamarca & 54 & 94 & 74 \\
\hline Contraloría de Floridablanca & 71 & $\mathrm{nr}$ & \\
\hline Contraloría de Guainía & 29 & 38 & 34 \\
\hline Contraloría de La Guaiira & 26 & 70 & 174 \\
\hline Contraloría de Nariño & 90 & 62 & -30 \\
\hline Contraloría de Norte de Santander & 59 & 58 & -3 \\
\hline Contraloría de Putumayo & 15 & 28 & 87 \\
\hline Contraloría de Risaralda & 66 & 83 & 26 \\
\hline $\begin{array}{l}\text { Contraloría de San Andrés, } \\
\text { Providencia y Santa Catalina }\end{array}$ & 21 & 32 & 56 \\
\hline Contraloría de Santander & 48 & 15 & -70 \\
\hline Contraloría de Sucre & 45 & 21 & -53 \\
\hline Contraloría de Vichada & 27 & 25 & -6 \\
\hline Contraloría del Cauca & 43 & 65 & 51 \\
\hline Contraloría del Cesar & 21 & 36 & 68 \\
\hline Contraloría del Chocó & 57 & 28 & -50 \\
\hline Contraloría del Guaviare & 80 & 56 & -29 \\
\hline Contraloría del Huila & 93 & 92 & -1 \\
\hline Contraloría del Magdalena & 7 & 50 & 594 \\
\hline Contraloría del Meta & 86 & 53 & -38 \\
\hline Contraloría del Quindío & 50 & 64 & 28 \\
\hline Contraloría del Tolima & 25 & 22 & -11 \\
\hline Contraloría del Valle del Cauca & 74 & 73 & -1 \\
\hline Contraloría del Vaupés & 29 & 21 & -27 \\
\hline
\end{tabular}

El valor máximo reportado en el período 2013-2014 es de 94 (Contraloría de Antioquia) y el mínimo de 0 (Contraloría de Amazonas), esta distancia es una medida de variabilidad que 
demuestran los datos.

De otra parte, en el período 2015-2016 la variabilidad de los datos es de 85, es decir la dispersión de los datos es menor en relación con el período anterior, pero los resultados de la capacidad disminuyen.

En resumen, lo que se puede concluir es que pese a la incidencia significativa que tienen las rendiciones de cuenta en el desempeño de las contralorías en el período 2013-2016, estas han disminuido en su capacidad de realizar rendiciones de cuenta, lo que sugiere que se requieren realizar procesos de divulgación de los resultados y de tratar de influir en los tomadores de decisión para incrementar su calidad.

\subsection{EL CONTROL SOCIAL, EL ROL DEL CONTROL INTERNO, Y SUS EFECTOS EN LA EFICACIA DEL CONTROL FISCAL.}

Frente a los indicadores de control social y control interno se encontró que un aspecto significativo del impacto en la mejoría de las contralorías a partir del proceso auditor está asociado a las acciones de control interno y de sensibilización. La evidencia muestra que en presencia de acciones de control que imponen las oficinas que realizan control interno en las entidades hay mejores desempeños en relación con los hallazgos.

Los datos recolectados corresponden a las variables de la tabla siguiente, las cuales contienen información sobre el Índice de Gobierno Abierto de la Procuraduría General de la Nación y el Sistema de Información de Auditorías de la AGR.

Tabla No. 5.4. Factores, características y condiciones de los controles internos y externos realizados por las contralorías territoriales

\begin{tabular}{|l|l|l|}
\hline \multicolumn{1}{|c|}{ Indicador } & Nombre en la base & Fuente \\
\hline Capacidad de Control Interno & CONTROLINTERIGA & IGA PGN \\
\hline Capacidad de Control Simple & CONTROLSIMPIGA & IGAPGN \\
\hline Implementación de MECI & MECIGA & IGA PGN \\
\hline Capacidad de Control total & CONTROL100 & ITC CTC \\
\hline Capacidad de promover el Control Social & CONTROSOCIAL100 & ITC CTC \\
\hline Capacidad de Control Interno & CONTROLINTER100 & ITC CTC \\
\hline Riesgo de Control total & CONTROLPON & ITC CTC \\
\hline Riesgo de Control social & CONTROLSOCIALPON & ITC CTC \\
\hline Riesgo de Control Interno & CONTROLINTERPON & ITC CTC \\
\hline Capacidad de Control lnterno y Control Disciplinario & CONTROLINTYSISC & ITC CTC \\
\hline Capacidad de Gestión del Control Interno & GESTCONTINTERNO & ITC CTC \\
\hline Capacidad de Gestión del Control Fiscal & GESTCF100 & ITC CTC \\
\hline Riesgo en la Gestión del Control Fiscal & GESTCFPON & ITC CTC \\
\hline Pertinencia del Control Social desarrollado & PERTINCONTSOC \\
\hline Pertinencia del Control Fiscal desarrollado & ITC CTC \\
\hline
\end{tabular}

En el modelo se indaga sobre los factores, características y condiciones de los controles 
internos y externos realizados por las contralorías territoriales. En ese sentido la evidencia empírica muestra que los hallazgos fiscales guardan relación significativa con la capacidad de promover el control social de las contralorías, los riesgos del control social y la gestión del control interno.

\section{Cuadro 5.2. Salida modelos MCO y ANOVA, variable dependiente: Hallazgos} Fiscales.

\begin{tabular}{|c|c|c|c|c|c|}
\hline \multirow{2}{*}{ Modelo } & \multicolumn{2}{|c|}{ Coeficientes no estandarizados } & \multirow{2}{*}{$\begin{array}{c}\begin{array}{c}\text { Coeficientes } \\
\text { estandarizados }\end{array} \\
\text { Beta }\end{array}$} & \multirow{2}{*}{$\mathrm{t}$} & \multirow{2}{*}{ Sig. } \\
\hline & $B$ & Desv. Error & & & \\
\hline (Constante) & 169,127 & 213,780 & & 791 & ,438 \\
\hline CONTROLINTERIGA &,- 951 & 2,684 &,- 061 &,- 354 & ,727 \\
\hline MECIIGA & 2,121 & 1,408 & 277 & 1,506 & , 148 \\
\hline CONTROLSOCIAL100 & 24,309 & 7,531 & 2,854 & 3,228 & ,004 \\
\hline CONTROLPON & 8,986 & 8,093 & ,334 & 1,110 & , 280 \\
\hline CONTROLSOCIALPON & $-499,400$ & 157,825 & $-2,783$ & $-3,164$ & ,005 \\
\hline CONTROLINTYDISC & $-1,556$ & 16,308 &,- 026 &,- 095 & 925 \\
\hline GESTCONTINTERNO & $-3,757$ & 1,620 &,- 658 & $-2,319$ & 031 \\
\hline GESTCF100 & $-29,776$ & 18,331 & $-4,538$ & $-1,624$ & 120 \\
\hline GESTCFPON & 594,362 & 368,756 & 4,512 & 1,612 & 123 \\
\hline PERTINCONTSOC & 62,214 & 49,433 & 255 & 1,259 & ,223 \\
\hline PERTINCONTFISC & 703 & 54,020 & ,002 & ,013 & ,990 \\
\hline
\end{tabular}

Tabla No. 18. Fuente: elaboración propia

Así, a un aumento en una unidad porcentual en la capacidad de promover el control social, los hallazgos fiscales se incrementan en 24 unidades. Asimismo, a un aumento de una unidad porcentual en los riesgos identificados en el control social, los hallazgos fiscales disminuyen. De otra parte, un incremento en una unidad porcentual de la gestión del control interno, los hallazgos fiscales disminuyen en 3,7 unidades.

Estas relaciones significativas demuestran que en presencia de varios tipos de control aquellos que muestran mayor efectividad están asociados a la capacidad de control social y el control interno que posean las contralorías territoriales.

En otras palabras, los controles que demuestran mayor efectividad son los asociados a los mecanismos de autocontrol y de prevención en el ámbito interno y de involucramiento de la sociedad civil en el ámbito externo. 


\title{
5.4. NIVEL DE SATISFACCIÓN DE LAS CONTRALORİAS RESPECTO DEL PROCESO AUDITOR DE LA AGR.
}

El punto de referencia internacional con el que la AGR compara su calidad del servicio es el QUALITY SERVICE INDEX, en el cual se establece que las organizaciones que obtengan calificaciones sobre el $78,0 \%$ de satisfacción y que se sostengan como mínimo cinco (5) años, pueden considerarse como Entidad Oficial con experiencia en el servicio al usuario (Medición Satisfacción del Cliente Semestre I_2016.pdf, s. f.).

En el caso concreto de las encuestas de percepción de las contralorías como sujetos vigilados, el instrumento para la verificación y consolidación de la información es un cuestionario de cinco (5) preguntas, en la que la calificación más baja es uno (1) y la más alta es cinco (5), siendo la primera insuficiente y la última excelente. En esas preguntas se aprecian las siguientes variables, i) Posibilidad de controversia de los hallazgos en su totalidad (proceso), ii) Atención de requerimientos de forma oportuna (proceso), iii) Aporte de los procesos de auditoría al mejoramiento de la entidad, iv) Evidencia de apoyo de la AGR, v) Competencia del grupo auditor (personal en contacto, servicio, soporte físico, tiempo). Al final del formato se encuentra un espacio de justificación abierta para la explicación de las respuestas emitidas.

Para este análisis se tomaron como insumo los reportes de encuestas de satisfacción diligenciadas por las contralorías al terminar las auditorías adelantadas por la AGR en el período comprendido entre 2012 y 2017, para el efecto no se tuvo en cuenta la contraloría de Bogotá, D:C:, que no es sujeto vigilado de la AGR desde el 2012.

Define el referido procedimiento:

\begin{abstract}
Las encuestas de Medición de Satisfacción de Usuarios (Contralorías) se aplicarán dos veces al año por parte de la Auditoría Delegada, y se consolidarán al inicio de los meses de julio y enero, de forma tal que sus resultados estén disponibles y analizados a la fecha que sean solicitados por la Auditoria Auxiliar. Solamente se aplicará la encuesta a aquellas Contralorías que durante el semestre evaluado hayan recibido informes finales de auditoría por parte de la AGR. La encuesta debe aplicarse preferiblemente al momento de comunicar el informe definitivo. También serán objeto de aplicación de encuestas las Gerencias Departamentales de la Contraloría General de la República, cuando hayan sido auditadas en el semestre objeto de evaluación.
\end{abstract}

Las preguntas definidas para la encuesta de satisfacción de usuarios son las siguientes,

1. ¿Los hallazgos detectados en los procesos de auditoría han tenido la posibilidad de ser controvertidos en su totalidad?

2. ¿Dentro de los procesos de auditoría, sus requerimientos han sido atendidos oportunamente? 
3. ¿Los Planes de Mejoramiento suscritos con la Auditoría General de la República han coadyuvado al mejoramiento de su entidad?

4. ¿Cómo ha sido el apoyo que ha recibido de la Auditoría General de la República?

5. ¿Cómo califica la competencia (habilidad, destreza y conocimiento) del grupo auditor de la Auditoría General de la República?

Con fines prácticos, se analizaron los resultados anuales (promedio de la información obtenida por cada año analizado en tanto que, los reportes de las encuestas se emiten de manera semestral), de conformidad con la evaluación otorgada para cada una de las cinco (5) preguntas para generar un balance general por pregunta y, en consecuencia, por variable.

Como criterio orientador, entre el periodo 2012 y 2017, la Auditoría General de la República realizó actividades de auditoría sobre 330 sujetos vigilados por ese órgano de control, esto es, sobre contralorías territoriales. De esas contralorías auditadas, 299 diligenciaron la encuesta de satisfacción de usuarios. En dicha muestra, hubo 1 contraloría que dejó en blanco la pregunta número 2 en el año 2013 y 1 contraloría que en el año 2015 que dejó en blanco la pregunta número 1. Lo anterior afecta el promedio general de esas preguntas para cada una de esas vigencias.

\section{Gráfica 28. Promedio de calificación - encuestas de satisfacción contralorías} territoriales respecto del proceso auditor de la AGR 2012-2017.

\section{Promedio de Calificación 2012 - 2017}

— Promedio de Califícación 2012 - 2017

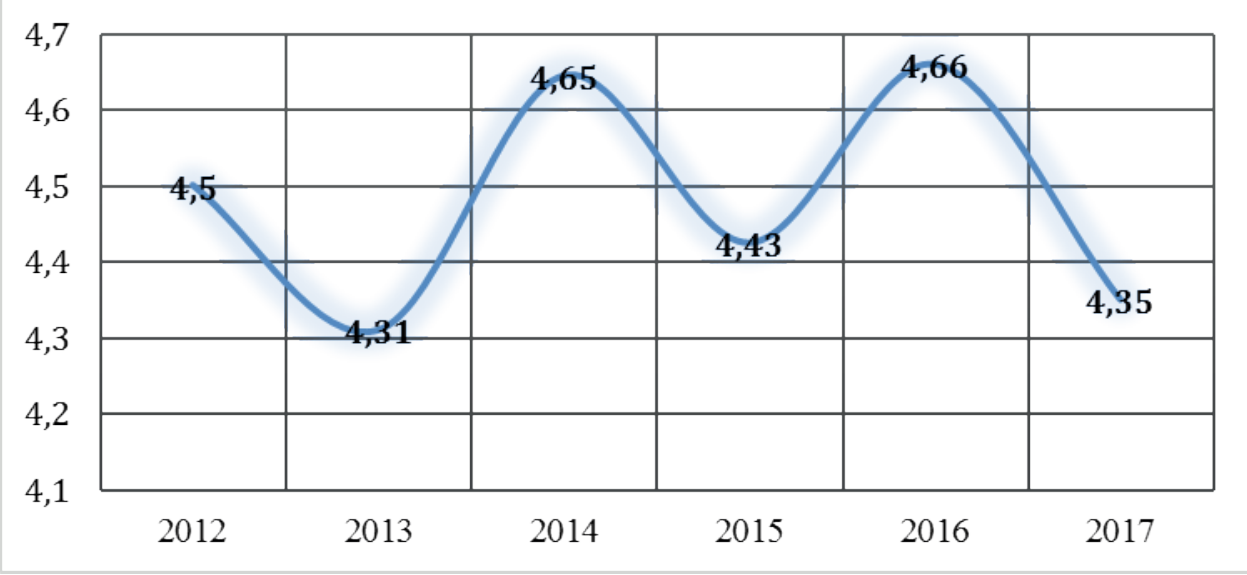

Gráfica No. 28. Elaboración propia. Fuente: Análisis de información reportada por las contralorías en el módulo SIA-SIREL de la AGR. 
En términos generales las encuestas de satisfacción evidencian una percepción positiva de los procesos de auditoría que emanan de la Auditoría General de la República. Ello se deriva de la calificación general de las encuestas, compuestas por el promedio de las respuestas otorgadas a las cinco (5) preguntas en conjunto. Durante la vigencia 2013 se presentó la menor calificación promedio con un $86 \%$ sobre la calificación máxima (5.0). En contraste, la mayor calificación promedio se obtuvo en el año 2016 con un 93\% sobre el límite favorable de calificación. La calificación general se ubica en un promedio de evaluación de BUENO.

Hay que tener en cuenta que, por lo general, cuando un sujeto vigilado considera que el ejercicio del proceso de auditoría no fue llevado a cabo correctamente, bien sea porque el equipo de auditoría no estuvo presto a escuchar sus apreciaciones sobre los hallazgos, o porque el órgano de control no atendió los requerimientos necesarios para atender la auditoría o porque los recursos humanos, físicos y financieros a su cargo no le permiten atender las solicitudes del equipo auditor o incluso porque los resultados que se traducen en hallazgos de auditoria no le favorecen, la calificación a la encuesta de satisfacción atenderá a esas circunstancias, con independencia de que en el desarrollo de la auditoría se hayan presentado de forma negativa todos, varios o sólo 1 de los criterios a evaluar. De igual manera sucede cuando las circunstancias son positivas.

Sobre el aspecto relacionado con la posibilidad de controvertir los hallazgos de auditoría (variable 1 pregunta 1), durante las vigencias 2013 y 2017 se identificaron un mayor número de evaluaciones en el rango de deficiente y aceptable (9\%). En el apartado de justificación de la encuesta, las contralorías manifestaron que el equipo auditor no atendió a los soportes, informaciones y justificaciones dadas por ellos a los hallazgos identificados. En ocasiones reiteraron la particularidad de sus procesos, tomando en consideración el personal asignado, los cambios de funcionarios en cortos periodos de tiempo y la incapacidad presupuestal para adelantar las actividades de mejora solicitadas. En algunas ocasiones se refieren a la subjetividad en la evaluación de las justificaciones por parte del equipo auditor. Por el contrario, para los años 2014 y 2016 los sujetos evaluados calificaron la posibilidad de controvertir hallazgos de auditoría con porcentajes superiores al $65 \%$.

En el mismo sentido se encuentra el promedio de respuestas a la segunda pregunta (variable 2) relacionada con los requerimientos efectuados por parte del sujeto vigilado a equipo auditor durante los procesos de auditoría. La posibilidad de convocar a mesas de trabajo o los comentarios y solicitudes expresados durante las mesas de trabajo son algunos de ellos. Durante las vigencias 2013 y 2017 se identificaron un mayor número de evaluaciones en el rango de deficiente y aceptable en relación con esta variable (6\%). Contrario sensu, para el 
2014 sólo un 1\% de los sujetos encuestados manifestó una evaluación aceptable en relación con este aspecto.

Para las contralorías territoriales los planes de mejoramiento contribuyen positivamente al mejoramiento constante y continuo de las actividades desplegadas por ellos. Así lo evidencia la calificación otorgada a la pregunta 3 (variable 3) en la que el 95\% de los encuestados catalogó dicho efecto en los rangos de bueno y excelente. En el apartado de justificación las contralorías reconocen que la posibilidad de contar con un equipo externo que identifique acciones de mejora técnica, operativa y de desarrollo de las actividades que desempeñan en sus respectivos territorios contribuye a fortalecer su capacidad de autocrítica y a implementar actuaciones que dinamicen y hagan más sencillo el trabajo.

La variable relacionada con el apoyo de la Auditoría General de la República recibido por los sujetos vigilados guarda especial coherencia con las respuestas emitidas a las preguntas 1 y 2 de la encuesta. Así, para quienes no tuvieron oportunidad de controvertir los hallazgos, o habiéndolo hecho no se sintieron conformes con las apreciaciones del equipo auditor, o para quienes no recibieron respuesta a los requerimientos solicitados durante la auditoría, la percepción sobre el apoyo del ente auditor fue igualmente negativa. En ese orden de ideas, en los años 2013, 2015 y 2017 se evaluó por algunas contralorías, el apoyo de la auditoría en los rangos de insuficiente, deficiente y aceptable, consolidando un $11 \%$ percepción negativa, a diferencia de los años 2014 y 2016 en los que la percepción general se mantuvo en el rango de bueno y excelente.

Finalmente, la pregunta relacionada con las competencias del equipo auditor, los datos evidenciaron que, entre los años 2012 y 2017, los sujetos encuestados calificaron negativamente al equipo auditor en un $9 \%$ dentro de los rangos insuficiente, deficiente y aceptable. A diferencia de las variables anteriores, para esta pregunta en particular (pregunta 5) la calificación de aceptable estuvo presente en cada una de las vigencias con promedios que se encuentran entre el $2 \%$ y el $8 \%$ de evaluación negativa por cada año. Dejando de lado las evaluaciones de 2013 y 2017, en tanto que estas presentan una percepción negativa del proceso auditor en general (respecto de las 5 preguntas formuladas), valdría la pena preguntarse ¿Cuál es la razón por la cual las competencias del equipo de auditoría, en algunos casos, son percibidas negativamente?

Al margen de lo anterior, se mantiene como regla general la evaluación positiva y la percepción favorable de los sujetos vigilados sobre las actividades de auditoría desplegadas por la Auditoría General de la República. A excepción de los porcentajes negativos, la cadena del proceso 
auditor en general, es bien recibido por las contralorías territoriales, valoran positivamente los hallazgos y reconocen la existencia de circunstancias que ameritan mejoría, reconocen los conocimientos técnicos y las recomendaciones efectuadas en los planes de mejoramiento, catalogan a la Auditoría General de la República como un entidad que apoya los procesos de vigilancia del control fiscal y consideran a los funcionarios que participan de los equipos auditores como personas profesionales y capacitadas para el desarrollo de la gestión. Los porcentajes de satisfacción durante el periodo analizado se muestran a continuación,

\section{Gráfica No. 29. Porcentaje de satisfacción contralorías territoriales respecto del proceso auditor de la AGR 2012-2017.}

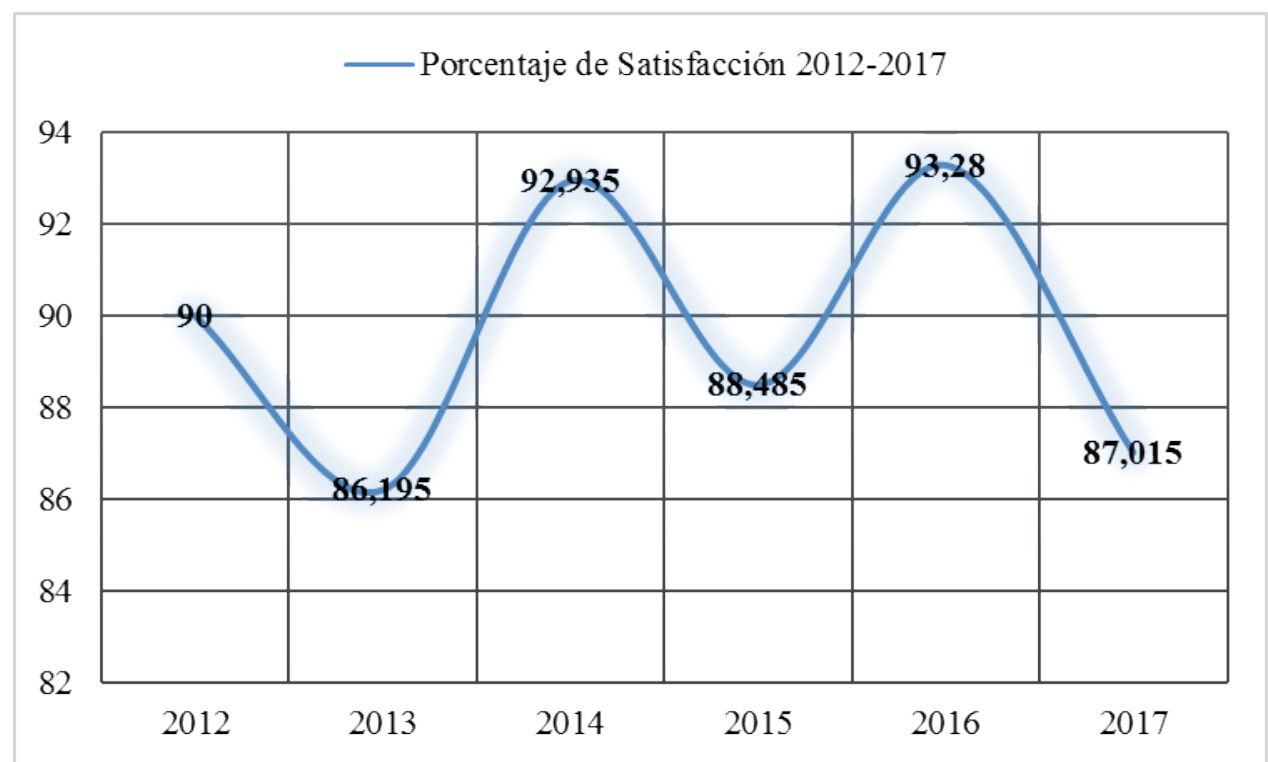

Gráfica No. 29. Elaboración propia. Fuente: Análisis de información reportada por las contralorías en el módulo SIA-SIREL de la AGR.

\subsection{CONCLUSIONES}

En el estudio se encontró que, los factores con correlación más significativa hacia los hallazgos administrativos son los asociados al control social, a la gestión del control interno y a las rendiciones de cuenta. Esto es, al contrastar los hallazgos administrativos con las condiciones de control, capacidades y riesgos de estas entidades se evidenció con alta confianza una relación directa con sus capacidades y una relación inversa con los riesgos en las mismas condiciones.

En ese sentido y dada la misión de la Auditoría General de la República de coadyuvar a la transformación, depuración y modernización de los órganos instituidos para el control de la 
gestión fiscal, reducir los hallazgos administrativos en las contralorías territoriales implicaría, entre otros factores técnicos, concentrar mayores esfuerzos en aumentar la efectividad del control social, y asimismo, en procesos de divulgación y transparencia más específicamente en las rendiciones de cuenta a la ciudadanía, pues son estos factores los que gozan de correlación significativa respecto de los hallazgos fiscales.

Otro de los descubrimientos destacados del análisis se presentó al establecer como variable explicativa del modelo los hallazgos administrativos y ciertas medidas anticorrupción de la Ley 1474 de 2011. De esta manera se pudo establecer que las políticas institucionales y pedagógicas del estatuto anticorrupción no producen aún impacto significativo en los hallazgos administrativos, y sus distintas connotaciones fiscales, disciplinarios y penales; esto sugiere una investigación más profunda sobre el asunto con la determinación de otra metodología de medición del impacto; o una revisión y evaluación de estas medidas, a fin de lograr una reorientación de estrategias, que conduzcan a una relación significativa con los hallazgos y en consecuencia, a una mayor efectividad de esta política.

En general los resultados sugieren que un monitoreo que combine estrategias tradicionales 'bottom-up' y 'top-down', puede jugar un papel importante en la vigilancia fiscal de las contralorías territoriales, incluso en un entorno altamente corrupto.

Otro de los mecanismos existentes para el ejercicio de la vigilancia al control fiscal es el proceso de auditoría que emana de la Auditoría General de la República. Este organismo de control efectúa ejercicios de auditoría sobre las contralorías, a excepción de la Contraloría General de la República que dejó de ser sujeto vigilado por la AGR en 2012.

Dentro de los procesos de calidad dispuestos en la OI.200.P3, se contempla una encuesta de satisfacción de usuarios. En general esta herramienta está dispuesta para la población que tiene relación directa o indirecta con las actividades de la institución, a saber, las contralorías, la ciudadanía, los sujetos procesales y participantes en eventos adelantados por dicho organismo.

En relación con las contralorías, para el periodo comprendido entre 2012 y 2017 se contó con la percepción de 330 contralorías territoriales. La sumatoria de las cinco (5) preguntas contentivas de la encuesta ubicó el promedio de calificación entre 4,3 y 4,7, siendo el proceso de auditoría adelantado por la AGR evaluado como BUENO.

A excepción de algunas evaluaciones negativas relacionadas con vigencias 2013-2017, sobre todo en los aspectos relacionados con la posibilidad de controvertir hallazgos y la eficacia en 
la atención a los requerimientos invocados por las contralorías, la percepción general valora positivamente la labor desplegada por la Auditoría General de la República, resaltándose, las recomendaciones consignadas en los planes de mejoramiento y las competencias del equipo auditor.

\subsection{BIBLIOGRAFÍA}

- Bayona Aristizábal, D. M. (2018), Legislación internacional en materia de control interno y fiscal - INTOSAI.

- blogspot.com. (2013). http://estudiodeltrabajoindustrial.blogspot.com/2013/06/ curva-de-aprendizaje_5.html. Recuperado el 15 de julio de 2019, de http:// estudiodeltrabajoindustrial.blogspot.com/2013/06/curva-de-aprendizaje_5.html

- Congreso de la República de Colombia.. (1993). funcionpublica.gov.co. Recuperado el 17 de julio de 2019, de https://www.funcionpublica.gov.co/eva/gestornormativo/ norma. php?i=300

- Constitución Política de Colombia de 1991. Consultada en http:// http://www. secretariasenado.gov.co/senado/basedoc/constitucion_politica_1991.html

- Contraloría General de la República, 2017. Principios Fundamentales y Aspectos Generales para las Auditorías en la CGR, en el marco de las normas de auditoría de entidades fiscalizadoras superiores-ISSAI.

- Fernández, J. A. \& Fernández, A. (1999). La economía de la corrupción y el control externo. Revista española de control externo, 1(3), 9-38.

- Garzón Castrillón, M. A. (2008). Dialnet. Recuperado el 15 de octubre de 2018, de https://dialnet.unirioja.es $\quad \underline{\text { http://links.jstor.org/sici?sici }=0033-5533 \% 28199308 \% 29108}$ \%3А3\%3С599\% 3АC\%3E2.0.CO\%3B2-8

- $\quad$ Linz, J., \& Stepan, A. (1978). The Breakdown of Democratic Regimes: Europe (Vol. 2). JHU Press.

- Ministerio de Hacienda y Crédito Público (2011). Conceptos jurídicos Presupuestales. Bogotá: Minhacienda, P. 65-68

- Olken, B. (2007). Monitoring Corruption: Evidence from a Field Experiment in Indonesia. Boston, USA: Harvard University and National Bureau of Economic Research.

- Ordóñez Vásquez, Tatiana. (2005). Colombia impunidad en Materia Fiscal. Bogotá: Revista 


\section{OPPCF}

Sindéresis. Auditoría General de la República.

- Ordóñez Vásquez, Tatiana. (2007). La responsabilidad fiscal en Colombia y la imposibilidad de resarcimiento patrimonial. Bogotá: Revista IUSTA. Facultad de Derecho Universidad Santo Tomás.

- Ortiz, L. (2017). Eficiencia y eficacia en la asignación y ejecución del presupuesto cultural: un desafío para las entidades territoriales en Colombia. Bogotá: AGR.

- Restrepo Acevedo, Edgar Alfredo. (2017). La fragilidad en el diseño institucional de los organismos de control fiscal del Departamento de Antioquia (Tesis de grado). Universidad Nacional de Colombia. Medellín.

- $\quad$ Senado de la República de Colombia, Decreto 1957 de 2007

- $\quad$ Senado de la República de Colombia, Ley 42 de 1993.

- $\quad$ Senado de la República de Colombia, Ley 819 de 2003.

- Senado de la República, Gaceta del Congreso No. 607 de 7 de septiembre de 2010

- Shleifer, A. \& Vishny, R. (1993). Corruption. In: The Quarterly Journal of Economics, Vol. 108, No. 3. Boston: MIT Press. pp. 599-617. Disponible en:

- Tanarro (2003). Evolución y práctica del control interno contable en Técnica Contable. Vol (58)

- Tullock, G (1989). "The welfare cost of tariffs, monopoly and theft" in: Economic United Nations, Corruption in government. New York: United Nations.

- Villardefrancos, M. y Rivera, Z. (2006). La auditoría como proceso de control: concepto y tipología en: Ciencias de la Información Vol. 37, No. 2-3. Agosto-septiembre, 2006. P. 53-58 


\section{CAPÍTULO V}

\section{ANÁLISIS SEMIÓTICO DE LA JUSTICIA FISCAL \\ Fundamentos teórico-prácticos de la culpabilidad fiscal como condición de la responsabilidad derivada del ejercicio del control y vigilancia fiscal \\ Manuel Fernando Moya Vargas ${ }^{59}$}

\section{Resumen}

La justicia fiscal en Colombia hace parte del derecho sancionatorio. Por ello mismo, se basa en la responsabilidad subjetiva. Es decir, la responsabilidad fiscal es el fruto de demostrar que la persona en particular actuó con dolo o culpa. Esta condición es necesaria para remover la presunción de inocencia, y proceder a las sanciones correspondientes. La historia de la culpabilidad particularmente manifiesta en derecho penal, indica que el contenido de la culpabilidad, es decir, del dolo y de la culpa, no son construcciones técnicas, provenientes de expertos en culpabilidad, sino que son fruto de las representaciones sociales.

\section{Abstract}

Tax justice in Colombia is part of the sanctioning right. It is therefore based on subjective responsibility. That is, fiscal responsibility is the result of showing that the particular person acted with will or guilt. This condition is necessary to remove the presumption of innocence, and to proceed with the corresponding sanctions. The history of guilt particularly manifested in criminal law indicates that the content of guilt, that is, of wrongtelling and guilt, are not technical constructions, coming from experts in guilt, but are the result of representations Social.

59 Abogado de la Universidad Externado de Colombia, Doctor en Sociología Jurídica e Instituciones Políticas de la misma Casa de Estudios, Posdoctorante en Derecho Universidad de Buenos Aires. Docente Investigador en semiótica penal, Investigador Senior ante Colciencias.

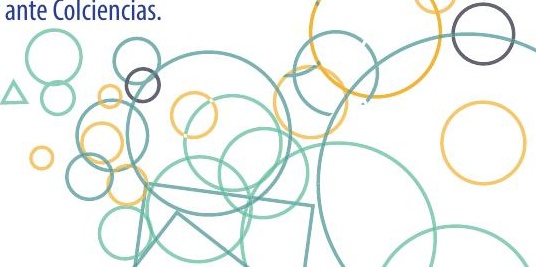




\section{OPPCF}

Palabras clave

Control y vigilancia fiscal, culpabilidad fiscal, justicia fiscal

\section{Key words}

Fiscal control and surveillance, tax culpability, tax justice

Temario: Introducción. 1. Naturaleza de la justicia fiscal.2. Orígenes históricos de la culpabilidad.

3. La puja dogmática y el origen de la versión estandarizada de la responsabilidad subjetiva como fundamento de la sanción. 3.1. La fórmula kantiana. 3.2. La disidencia hegeliana. 4. Consolidación de la responsabilidad sancionatoria basada en la culpabilidad. 5. Efectos de la hegemonía kantiana. 6. Concreción de un abordaje semiótico y su influencia sobre la justicia fiscal. 7. Conclusiones. 8. Referencias bibliográficas.

\section{Introducción}

La justicia fiscal proviene de las entrañas sociales, y de ello se deben servir los expertos en vigilancia y control fiscal para poder declarar la responsabilidad. La justicia fiscal implica el control de las autoridades respectivas sobre la ejecución del gasto público. Entendiendo que los recursos están orientados a la realización material de los principios en que se basa el Estado democrático, social y de derecho.

Visto así, la relación entre control fiscal y realización de los Derechos Humanos y, más específicamente, de los Derechos Fundamentales, es interdependiente. Esto por cuanto el cometido de esta concepción constitucional del Estado implica principalmente, que las personas individualmente consideradas y colectivamente entendidas, puedan realizarse bajo presupuestos de convivencia pacífica, lo cual se condiciona precisamente a la realización de las condiciones que lo hace posible. Y esto de forma inevitable implica que sus derechos sean realizables.

En últimas la realización de los derechos fundamentales constituye la razón de ser del control fiscal. Así como los recursos existen para que se materialicen las condiciones identificadas como de mínimo vital, el control fiscal se orienta a que la destinación de los recursos corresponda con los presupuestos constitucionales y legales. Todo lo cual debe responder con el marco de una política pública preexistente.

En esta perspectiva, los principios del control fiscal se encuentran expresados en términos de eficiencia, economía, eficacia, equidad y valoración de costos ambientales.

Su dinámica, según la fuente constitucional, implica que este se ejerce principalmente a través 
de la Contraloría General de la República y de las Contralorías regionales.

Pese a ello, es decir, a que es ejercida por una entidad pública, las implicancias de su proyección involucran a toda la sociedad y, otras entidades públicas, como la Auditoría General de la República. De tal suerte, configura un encuentro entre el sector público y el privado. Pese a que de una u otra forma hay un especial acento en la intervención del sector público, lo cual se explica por la naturaleza misma de la responsabilidad fiscal.

Ahora bien, desde el mismo rótulo "control...", se anuncia un cierto tipo de intervención que implica, etimológicamente, un contraste. Por un lado, lo que se hace con los recursos públicos, y por otro, lo que debía hacerse legamente con ellos.

Si no hay convergencia, emerge el control fiscal, cuya justicia implica sancionar a los responsables, sean ellos, las personas encargadas de la ejecución de los recursos públicos. Como también, las personas que nivel local, regional o nacional, debieron evitar el desvío o malversación de los mismos.

La justicia fiscal implica en sí misma una corrección. De tal suerte, su ejercicio apareja sanciones en contra de personas naturales e, incluso, de personas jurídicas. Lo cual es completamente paralelo a las consecuencias de orden penal y disciplinario.

De hecho, hay una inevitable familiaridad con estos otros tipos de intervención que fuerzan considerar la naturaleza del proceso de control fiscal en relación con aquellos. Pero dicha familiaridad es mucho más estrecha con la justicia penal, entre otros porque la responsabilidad fiscal, de una u otra forma implica la responsabilidad penal. Así como la responsabilidad penal asociada a afectaciones respecto de la ejecución presupuesto público, necesariamente implica la responsabilidad fiscal.

Para mayor claridad, podríamos decir que todo el derecho sancionatorio atiende a los mismos presupuestos. Pero, sin embargo, el penal es a no dudarlo, el más agresivo.

Por ello es que hemos hallado el control fiscal se fundamenta en los mismos criterios axiomáticos del derecho sancionatorio, muchos de los cuales son compartidos con el derecho penal.

Así, el modelo de responsabilidad fiscal inevitablemente se basa en los mismos presupuestos axiológicos que se encuentran en el artículo 29 de la Constitución Política, al menos en cuanto se comparten desde la raíz común sancionatoria.

Y de la misma forma, emerge la inquietud acerca de la intervención social. Pues bien, claramente 
se reconoce la importancia protagónica de las comunidades para hacer real el control fiscal, la verdad es que sería muy improbable el control penal y el control disciplinario, si la sociedad no pudiera intervenir, cuando menos respetando a las autoridades a realizar la justicia en los términos que les corresponde.

Con base en el método semiótico se asume el estudio de los fundamentos de la justicia fiscal, de cara a establecer su proximidad con la justicia penal y, su consideración social, entendiendo que el sentido de justicia sea penal, fiscal o de otra naturaleza, fluye de lo social, antes que de lo estrictamente técnico.

Anticipando, advertimos que la semiótica ha sido entendida como la ciencia que estudia los signos. No obstante, en la actualidad, no sólo se trata de signos, sino de sistemas sígnicos, en tanto sirven como precursores de procesos comunicativos. Y dichos procesos comunicativos, zona su vez, los precursores del proceso de producción y circulación del sentido.

Por suerte que el método semiótico se caracteriza por aproximarse a los fenómenos en su expresión sígnica, en los procesos comunicativos a los cuales sirve $y$, al sentido que se crea mediante ellos.

\subsection{NATURALEZA DE LA JUSTICIA FISCAL}

Al considerar en términos generales los aspectos más importantes de la justicia, se advierten dos, a partir de los cuales se puede realizar el abordaje semiótico que interesa. Por un lado, el tipo de intervención que se permite a partir de sus presupuestos legales y constitucionales.

Y, por otro lado, la identidad o tipología de responsabilidad en que se basa, entendiendo que su configuración es lo que permite declarar a alguien como responsable y con ello, derivar las sanciones pertinentes.

Ambos son aspectos de naturaleza legal, entendiendo que sólo a partir de disposiciones positivas, el Estado puede intervenir la vida de las personas y, consecuencia de ello, declararlas responsables.

Lo cual implica el elemento que a su turno activa la producción y circulación de sentido social que, al cabo, como lo hemos venido sosteniendo en distintas investigaciones, involucra el juicio de los jueces, dando por resultado la justicia como efecto social.

Al respecto, lo primero que encontramos es que el artículo primero de la Ley 610 de 2000 en cuanto tiene que ver con el proceso de responsabilidad fiscal derogó lo pertinente de la Ley 42 de1993, define dicho proceso, como (...) el conjunto de actuaciones administrativas 
adelantadas por las Contralorías con el fin de determinar y establecer la responsabilidad de los servidores públicos y de los particulares, cuando en el ejercicio de la gestión fiscal o con ocasión de ésta, causen por acción u omisión y en forma dolosa o culposa un daño al patrimonio del Estado. (...), disposición declarada exequible mediante sentencia C-840 de 2001.

La disposición implica necesariamente, una intervención especializada por parte del Estado que, como se verá, concluye en la declaración de la justicia fiscal, implicando sanciones de esa misma naturaleza.

El artículo segundo, a su turno, indica puntualmente que el proceso de responsabilidad fiscal se sujeta a los principios consagrados en el artículo 29 de la Constitución Política, (...) En el ejercicio de la acción de responsabilidad fiscal se garantizará el debido proceso y su trámite se adelantará con sujeción a los principios establecidos en los artículos $\underline{29}$ y $\underline{209}$ de la Constitución Política y a los contenidos en el Código Contencioso Administrativo. (...).

Es preciso señalar en este momento que el artículo 29 de la Constitución consagró el principio de culpabilidad, para todo el ámbito general del derecho sancionatorio, en el cual se inscribe el proceso de responsabilidad fiscal. En sus términos predica la disposición, (...) Toda persona se presume inocente mientras no se la haya declarado judicialmente culpable. (...) (subraya fuera de texto).

Y este presupuesto con carácter de principalidad, lo desarrolla actualmente el artículo quinto de la Ley 610 de 2000, al especificar los elementos. Pues conforme con la norma el primer elemento de la responsabilidad fiscal es la demostración de (...) Una conducta dolosa o culposa atribuible a una persona que realiza gestión fiscal. (...)

Con base en lo anterior, no es discutible que la responsabilidad fiscal hace parte del sistema de derecho sancionatorio y que, en tanto tal, se rige por el principio de culpabilidad.

Lo primero porque la justicia fiscal implica una competencia por parte del Estado con base en la cual puede proceder a sancionar a las personas implicadas, conforme a un modelo procesal de intervención específica, reglada conforme al principio de legalidad estricta.

Lo segundo, es decir, el modelo de responsabilidad subjetiva, o lo que es igual, basado en el principio de culpabilidad, implicando que la justicia fiscal implica que, si bien las personas se amparan en su presunción constitucional de inocencia, esta se desvirtúa cuando es demostrado que actuaron con dolo o culpa.

Lo cual significa que sólo puede ser declarado responsable fiscalmente a quien le es demostrada su culpabilidad, que es lo único que permite la intervención sancionatoria del Estado. Luego,

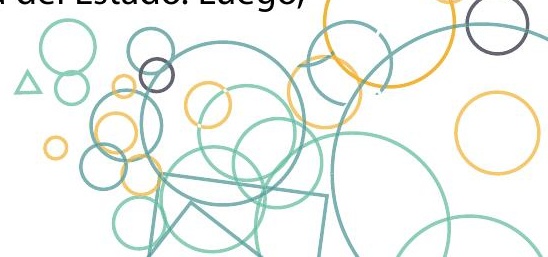


la justicia fiscal se encuentra determinada por el principio de culpabilidad, en la medida que sólo al culpable le puede ser impuesta la sanción correspondiente a la demostración de su responsabilidad.

Es a partir de este presupuesto que debe leerse en clave semiótica, lo que es la justicia fiscal. Y es precisamente lo que permite establecer el punto esencial de contacto entre la concepción de las autoridades públicas, con la percepción social, o sentido de justicia social.

Lo que se encontró en desarrollo de la investigación, es que no hay un desarrollo propio de la culpabilidad a instancia de la justicia fiscal. Es decir, la doctrina no arroja un contenido a la culpa fiscal. De donde sirva este desarrollo que se formula semióticamente, a partir de la historia de la culpabilidad, con su proximidad específica a la culpabilidad penal, para la construcción de una teoría de la justicia fiscal, basada en un modelo de culpabilidad fiscal.

Por tal motivo, la investigación tiene el objetivo de desentrañar lo que es la culpabilidad en general, en cuanto a sus orígenes, para establecer su especificidad en relación con la justicia fiscal, y buscar la sinapsis que inevitablemente entraña con la intervención social, en su concepción de justicia.

\subsection{ORÍGENES HISTÓRICOS DE LA CULPABILIDAD}

La culpabilidad fue considerada originalmente con base en presupuestos hermenéuticos, lo cual dificultó la asunción de la culpa, como una de sus variables, pues a falta de expresión normativa, pretendieron tratarla como trataron el dolo, su otra variable, que, en cambio, sí la tenía.

Resultado de lo cual terminó siendo identificado con la responsabilidad, sobre la base de la mora debitoris. La culpa, en cambio no registró sino confusión.

De esta forma, la culpabilidad así mismo, prácticamente quedó identificada con el dolo que, conforme a la lógica intrínseca del derecho de las obligaciones, alcanza su sentido en las interioridades de esa institución. La certeza en relación con el dolo no fue suficiente para fraguar la ambigüedad en cuanto a la culpa, impidiendo un tratamiento integral y homogéneo, lo cual se tradujo en contradicciones manifiestas en los distintos casos de los cuales las fuentes dan cuenta. Unas veces se tendió a la responsabilidad objetiva y, otras a la subjetiva.

Muchos siglos después, precisamente, cuando la dogmática se ocupó de ella, la integró sistémicamente a la imputabilidad y, con ello, se completó la que podríamos designar, una teoría general de la responsabilidad. 
Por ello, al referirse la culpa, no debe perderse de vista su colocación dentro de una teoría de la responsabilidad, ni mucho menos pretender que resulte ser sinónimo absoluto de culpabilidad, tampoco de imputabilidad, a no ser el propósito de una reducción como ha sucedido en ocasiones, lo cual impide evidenciar las cualidades originales con que fue concebida.

De la imputabilidad se empezó a hablar de forma clara, cuando se pensó dogmáticamente, y de ello daría cuenta inicialmente Kant. Con posterioridad, la teoría del delito prácticamente terminó por monopolizarla, al punto que cuando se la considera, con frecuencia se identifica como imputabilidad penal, prefiriendo asignar el mismo significado al concepto de responsabilidad en derecho privado.

Pero la tesis que nos asiste es fundamentalmente que, si bien ha habido toda una construcción sígnica de la justicia en general, entendido en su más técnico significado, ello corresponde realmente a la imputabilidad. Mientras que la culpabilidad corresponde con un cierto sentido social de justicia, del cual el derecho se apropia, sin haber logrado desprenderse.

Y ello es tan válido para la justicia penal, como para la fiscal. En cuanto a aquélla, sin mayor novedad, pero en cambio, respecto de esta, tan novedosa que implica prácticamente un redescubrimiento.

En uno y otro caso, y como consecuencia, no existe forma de comprender la culpabilidad, más que a partir del sentido social de justicia que circula en el tratamiento jurídico de la responsabilidad, sea o no jurisdiccional.

Es decir, si bien la culpabilidad es lo que explica técnicamente la responsabilidad subjetiva que caracteriza a la justicia penal y a la justicia fiscal en Colombia, su contenido no es ajeno al sentido social de justicia que lo define.

La semiótica de la justicia confluye en ello precisamente. La culpabilidad es una construcción social que, a partir de la negativización de unas personas, tiende a su positivización.

Este reconocimiento implica que los jueces no sean los comprometidos en darle contenido a la culpabilidad en los procesos, sino que dispongan de mecanismos de reconocimiento de un situado histórico que en manera alguna puede depender de ellos.

El aporte de esta investigación metodológicamente semiótica es que la hermenéutica y la dogmática han venido negando una realidad que, en la práctica se traduce en forzar a los jueces a dar cuenta de algo que escapa de sus posibilidades.

De cualquier forma, se halló que la perspectiva hermenéutica y dogmática en materia de 
derecho sancionatorio, siempre ha estado rodeada de la realidad inconcusa de la culpabilidad como fenómeno social, pero lo ha venido ignorando, valiéndose de una compleja trama teórica, propia de las ciencias humanas y sociales que, han sustituido en su estatuto científico a las personas y a las comunidades por teorías sobre las personas y las comunidades.

Ningún de esos estudios han logrado prescindir del elemento semiótico, aun cuando han preferido minimizarlo y, al cabo, la semiótica revela lo que los otros métodos han procedido a superar mediante la negación.

Todo apunta a una raíz griega, no muy documentada, por cierto, que confluye en un gran desarrollo a manos de los juristas clásicos. Lo que frecuentemente les ha granjeado el honor de haberla establecido.

Pues bien, no podemos desconocer una conexión entre algunas expresiones griegas y la culpa, tal y como la habría concebido el derecho romano (AEDO BARRENA, 2013). Del empleo dado

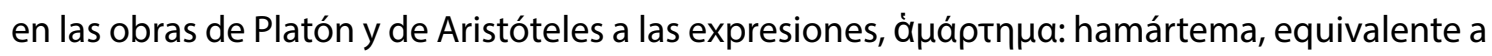

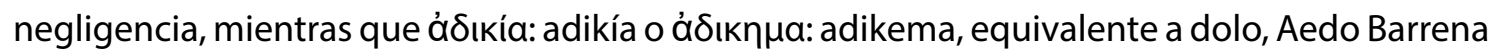
dedujo el elemento de la culpa, identitario de la institución propia del derecho romano.

Este investigador admitió la conocida progresión formulada por Ricoeur, discriminada en tres dimensiones históricas. La primera correspondería a la mancilla; la segunda, al pecado; y la última, a la culpabilidad, propiamente dicha. Las dos primeras serían algo así como sus precursores.

Se trata de una exhibición en correspondencia con una especie de evolución -tal vez preferiríamos decir transformación, que alcanza su último estadio en el desarrollo técnico de la responsabilidad.

Pero hay algo que se destaca sin que no obstante haya sido considerado con suficiencia por Ricoeur ni por Aedo Barrena. Y es que aceptando la idea de una transformación iniciada con lo que llamaron mancilla, desde ésta hasta la versión acabada de la responsabilidad, particularmente la llamada responsabilidad subjetiva, la culpa -si se prefiere la culpabilidad, ha servido de vehículo para circular la oposición evidenciada entre la conducta que justifica la imputación, y una cierta representación social.

Representación que no proviene del derecho, ni es obra de los juristas, sino que expresa cierto alto concepto social, acerca de lo que está bien y de lo que no lo está y, por identidad, de lo que es justo y de lo que es, por el contrario, injusto.

El rol del experto con respecto a esa representación ha sido más bien de un traslado, que 
va desde de las exterioridades hacia las interioridades del derecho. Dándole quizás un matiz lingüístico propio de las ciencias jurídicas, pero manteniendo el contenido social original.

En efecto, lo más probable es que los clásicos se hayan servido no sólo de la filosofía estoica, sino de toda la cultura helénica, para la concreción de su jurisprudencia. La cual, más que romana, es el fruto del denuedo por alcanzar un estándar jurídico que sirviera para compatibilizar el derecho de origen extra-romano, con el derecho proveniente de Roma.

Tal al fin y al cabo la labor del pretor peregrino, que dio sentido clásico al derecho de los grandes juristas, es decir, un estándar jurídico meta-fronterizo. El derecho clásico es un derecho sin identidad nacionalista, se trata precisamente de un derecho con aptitud para ser practicado sin identidad jurídica civil, entendida como derecho particular legislado en una ciudad.

Visto así, la busca del lugar de la culpabilidad se orientó hacia la dinámica de la responsabilidad civil. Para su comprensión, en primer lugar, debe considerarse que el deudor debía haber entrado en mora, pese a la posibilidad de la mora creditoris.

En segundo lugar, se consideraba que, habiendo entrado en mora y, si ello se debía a su dolo, tendría que responder al acreedor. Pero, en cuanto si la mora se debía a culpa, las cosas ya no resultaban tan claras.

En tercer lugar, el casus, al parecer únicamente en eventos de culpa, liberaba al deudor. Es decir, lo que posteriormente sería denominado como, caso fortuito y fuerza mayor (ÁLVAREZ CORREA, 1979).

Es importante considerar que las cosas no estaban reducidas a una oposición entre dolo y culpa, contrariamente a lo afirmado por Mommsen. Romanistas como Arangio Ruiz convergen en que se trató de un entramado mucho más complejo, en donde la condición subjetiva de incumplimiento no liberaba al deudor, como en cambio sí la objetiva.

Para entender la dinámica debe partirse, mantienen, de la verdadera oposición, no entre dolo y culpa, sino entre la fides bona y, el dolus malus. Entendido éste como condición para el surgimiento de la responsabilidad, y aquélla, como todo lo contrario.

Sin que pueda deducirse que fue un error en la tentativa de alcanzar un nivel de abstracción que garantizara la universalidad de la culpabilidad, o tal vez una excepción, es lo cierto que los juristas tendieron a considerar caso a caso, si había o no lugar a responsabilidad. Y los criterios siguieron siendo de la misma naturaleza que en la mancilla, en el pecado y en la culpabilidad de Ricoeur. Es decir, la conciencia social cuando no, la concentración del beneficio y, con ello razones de justicia que, característicamente, no provenían del derecho.

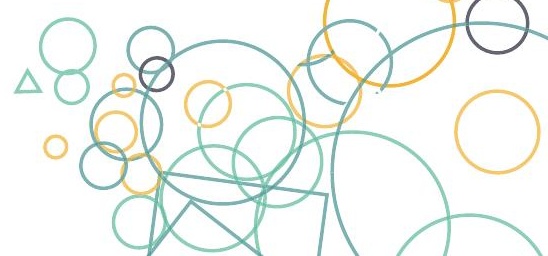


En unos casos se respondía con criterios propios de responsabilidad objetiva, mientras que otros reclaman la condición dolosa del responsable. Todo indica que las consideraciones acerca de la responsabilidad surgieron en relación con el hurto, sin perder de vista que se trataba de un ilícito civil -que no penal, conforme a la acepción vigente.

Como conclusión, la estandarización de la culpa en tanto presupuesto de la responsabilidad, es "tardía", es decir, de estirpe cristiana, dando como resultado que la culpa leve sería, por oposición a la culpa lata -que se equipara al dolo, la verdadera culpa; de otro lado, se consideró la culpa en abstracto, es decir, la diligentia diligentis patris familias y, la culpa en concreto, quam suis (ARANGIO-RUÍZ, 1952).

De más está aquí observar el elemento social o, si se prefiere extrajurídico de origen social, que no por cristiano es novedoso, y menos griego (ESPITIA GARZÓN, 2004).

El delictum o maleficium era ilícito civil, si se quiere, de derecho privado, mientras que el crimen, correspondía a ilícitos públicos o, el objeto de conocimiento de lo que posteriormente llamaríamos derecho penal.

El delito de furtum, como también la iniuria, implicaban actuar con dolus malus. Mientras que el damnum iniuria datum habría admitido la responsabilidad objetiva, tal y como surge la decisión de Labeón -que recibiera aval de Ulpiano, en que se declaró la responsabilidad de una comadrona por proporcionar de su propia mano, una medicina a una esclava, produciéndole la muerte (SHULZ, 1951).

Como puede apreciarse, la incorporación de la culpa como integradora de la responsabilidad civil, contractual o extracontractual, es muy confusa. Existió la tentativa de incorporarla, quizás de explicar la responsabilidad por la vía de la culpa o su ausencia, pero no hay nada claro al respecto.

Pese a que importantes estudiosos pretendieron lo contrario. Para Mommsen, por ejemplo, (...) El concepto de culpa, lo mismo que el de dolus, no pertenecía a la legislación, sino a la interpretación científica de las leyes. Es de presumir que el Código de Las Doce Tablas no llegara en materia de derecho privado más que a establecer la responsabilidad humana en general, en oposición al hecho que no estuviera ligado por ninguna relación de causalidad con la acción u omisión humana; es decir, empleando la terminología actual, que no hará otra cosa sino establecer la antítesis entre los hechos procedentes de dolus o de culpa, y los procedentes del casus. (...) (MOMMSEN, 1999, pp. 62).

Como puede apreciarse, inició desvirtuando que la responsabilidad subjetiva pueda tener 
asidero en la ley, en cambio sí en la jurisprudencia. Pero terminó afirmando todo lo contrario, es decir, que la LDT opuso el dolo y la culpa. Y en todo caso, se empeñó en que la responsabilidad basada en la culpabilidad procede de la época republicana. Lo cual se considera actualmente desmentido.

De cualquier forma, a Mommsen no le quedó más remedio que reconocer la proximidad entre lo que llamó ley moral y la justicia penal, aun cuando se esforzó en demarcar sus diferencias (63-65).

Si las cosas fueron confusas en el arte más desarrollado, que fue el derecho de las obligaciones, es previsible que, respecto de lo que había de derecho penal y su posterior especificación en cuanto a la justicia fiscal, más que confusión lo que había era un todo por hacerse, puesto que para le época Republicana estaba muy por debajo del desarrollo del derecho civil (SHULZ, 1951, pp. 548).

Y la verdad sea dicha, no es mucho lo que se avanzó posteriormente, ni aun en época clásica, pues al fin y al cabo los grandes juristas no alcanzaron la claridad que en cambio sí nos legaron en otros temas.

En efecto, en materia de derecho privado, incluso respecto de los delicta, es mucho más verídico Juan Iglesias, al señalar la más completa incertidumbre acerca de la operatividad de la culpa. Al parecer, hay certeza en cuanto a que el deudor respondía por dolo, pero se liberaba por casus, entendiendo por dolo, (...) la intención o propósito deliberado de observar una conducta que acarrea la imposibilidad de cumplir la prestación (...) (IGLESIAS, 1993, pp. 435).

La culpabilidad, entendida como responsabilidad subjetiva, se habría sobrepuesto a la objetiva, por obra de los compiladores, en manera alguna de los juristas clásicos. Sugiere el romanista que el recurso a la culpa provendría del tratamiento dado en la Lex Aquilia, lo cual tiene soporte en Gaius 202 y 211 principalmente (GAYO, 2000).

(...) La jurisprudencia de los últimos tiempos republicanos y, sobre todo, de la época clásica, aprecia en las relaciones contractuales una noción de imputabilidad distinta de la que sirve de sustento al dolo. Mientras el dolo implica una infracción intencionada de la obligación contractual, la culpa entraña una conducta deshonesta, una inobservancia de un deber de prudencia que pesa sobre cada miembro de la comunidad ciudadana en la vida de relación. La culpa es concebida como desviación de un modelo ideal de conducta: el modelo viene representado, unas veces, por la fides o bona fides, y otras, por la diligentia de un pater familias cuidadoso-diligens pater familias. Dentro de los iudicia bonae fidei, la conducta contraria a la fides es asimilada, en su efecto, al dolus. (...) (GAYO, 2000, pp. 435-436).

Lo cierto es que, al parecer, la incomodidad de los juristas clásicos provendría de tener que integrar dentro de lo más depurado del arte jurídico, algo que no sólo no era jurídico, sino 
que seguramente lo desafiaba. Es decir, dentro de la teoría de las obligaciones, la culpa resultaba acentuadamente incompatible, frente a la prestación, al objeto de la prestación y a sus extremos subjetivos. Muy posiblemente el rigor estoico los inclinaba a filtrar todo aquello que escapara a los dominios de la razón.

Más adelante, la cristianización insinuada en el Código de Theodosius y, ya decididamente tramitada en la obra ordenada por Justiniano, todo empezarían a cambiar, como que se reconoció una especie de legislador superior, y con ello un derecho supra-humano. El derecho civil habría cedido al derecho natural, según la conocida triangulación de Cicerón.

Pero esto implicó una cierta violencia simbólica, pues por fuerza legislativa se quiso hacer norma jurídica, lo que no podía ser sino conocimiento social, de estirpe abductiva. ${ }^{60}$

60 En el texto en que fue presentado el Observatorio de Política Pública del Control Fiscal, se destacó que, (...) En cuanto pensamiento esa otra opción ha sido comúnmente designada como abducción. Y de ella proviene el pensamiento abductivo.

Para comprenderlo es preciso volver sobre las características generales de la inferencia. Simplemente para reconocer que la deducción revela una dinámica conforme con la cual, dada una premisa general, respecto de un caso particular conocido, se puede obtener una conclusión originalmente desconocida, -su equivalente semiótico sería la connotación, que relaciona dentro de una generalidad sintagmática, las posibilidades semánticas de un signo intencionalmente considerado.

Mientras que la inducción procede a la inversa, esto es, dado un caso conocido frente a una premisa específica, puede derivarse una premisa general desconocida, -su equivalente semiótico corresponde a la denotación, que asocia un signo con un significado intencionalmente previsto.

En ambos, la experiencia empírica se basa en el conocimiento del caso, el cual se confronta a una premisa general 0 a una premisa especial, dependiendo de la situación, para derivar una conclusión, que en el primer evento es la premisa especial y, en el segundo la general.

En cambio, para una mejor comprensión del pensamiento abductivo -muy afín al método semiótico, es preciso considerar que relaciona la que puede ser una premisa general con otra especial, para intuir el caso -en semiótica un signo suscita una experiencia "no experimentada" mediante un juego de sustitución. Es decir, lo que se "infiere" es la realidad, o experiencia cognoscible, lo cual resulta aparentemente inexpugnable desde el punto de vista del pensamiento lógico formal. Pues pareciera que su premisa fundamental consiste en la porción de verdad o realidad dada, que requiere ser escrutada mediante la razón.

Hasta cierto punto el pensamiento abductivo pareciera un juego de abalorios, en que el pensador asume que esto o aquello fue o será de cierto modo, nada más que a partir del conocimiento con que cuenta. Formalmente, se describe como a partir de la consideración de una premisa general, a la que es contrapuesta otra especial, para intuir un caso desconocido.

Por ejemplo, si tenemos por premisa general, "el consumo excesivo de dulce durante la infancia crea riesgo de obesidad". Y otra específica, "Ios niños no deben consumir dulce hasta después de los cinco años para evitar riesgo de obesidad". Podríamos abductivamente derivar el caso, "mi hija de tres años puede comer dulce moderadamente".

Sometiéndolo al escrutinio ortodoxo de la lógica, el resultado puede resultar no sólo inexacto sino hasta caprichoso o, cuando menos, carente de la pretendida exactitud que caracteriza a la inducción y a la deducción.

Más aún, puede haber quien lo señale de absurdo y hasta de encubrir falacias argumentativas, porque desafía el presupuesto empirico, y al conocimiento exacto o inexacto, le sucede un complemento de irracionalidad, entendiendo por ello lo que no procede de la razón sino de la intuición.

No obstante, la recurrencia con que nos relacionamos en la vida mediante abducción conlleva considerar que puede ser una forma de pensar más importante en la cotidianidad de las comunidades. De ello da sobrada cuenta la semiótica. Es decir, hay más realidad construida mediante abducción que mediante deducción o inducción. Al cabo, más que certeza en términos de exactitud de tipo matemático, se trata de una forma de ser, y a diferencia de la lógica formal, tienen cabida una serie de elementos como los 
La explicación semiótica nos ha conducido a anticipar que existe un cierto sentido de juridicidad, que es lo que hace posible que las sociedades piensen en derecho, proveniente de un conocimiento característicamente abductivo. Es lo que explica la existencia de lo que llamamos en su momento alterius, que no es derecho divino, ni mucho menos natural, sino simplemente el saber jurídico social. Más precisamente un cierto sentido social de justicia, que inclina incluso al jurista hacia cierto tipo de consideración (MOYA VARGAS, Los Fallos Penales por Inasisteniaa Alimentaria. Un desfase entre la realidad y la práctica judicial, 2007).

La idea del alterius provino del reconocimiento de las aequitas en el derecho arcaico. Y la investigación arrojó que correspondía con ideas ya formuladas, puesto que se halló que Kaufmann (1999), en línea con Radbruch y Hassimer, hizo referencia a un, "sentimiento del derecho" que específicamente Radbruch lo asoció como una especie de "precomprensión" del derecho técnicamente comprendido (RADBRUCH, Filosofía del Derecho, 1952).

De la misma forma como Dworkin terminó por admitir la existencia de un sentido de la justicia o, equilibrio reflexivo, que al cabo conviene a una cierta condición inmanente de las personas, favorable para el desarrollo de procesos de conocimiento jurídico, no obstante ser, para nada deductivos ni inductivos, sino predominantemente abductivos (DWORKIN, 1995). Aun cuando lo tramita como intuicionismo moral, en tanto presupuesto del modelo constructivo y, la convicción, como su prerrequisito. Lo cual sigue de cerca a Rawls (2002, pp. 55), pese no coincidir del todo con Bobbio (1993).

sentimientos, las sensaciones, los gustos, los disgustos, las intuiciones, las indiferencias, etc., todo aquello que quiérase o no, hace parte de los seres humanos.

Por supuesto, esto es algo que desafía la lógica de origen aristotélico, normalmente hegemónica, aun así, fuertemente golpeada en su monarquía a propósito de las investigaciones de Charles Sanders Peirce.

No es que haya descubierto ese alter, más bien le confirió la importancia que hasta ahora le había sido ocultada. Al fin y al cabo, hasta el mismo Aristóteles tuvo ocasión de advertir de su existencia, pero pareciera el límite de la racionalidad, su negación o el punto que no debía franquearse.

La propuesta de Peirce es simplemente reconocerlo como algo que quiérase o no, ocurre y que considerarlo como la némesis de la razón, es simplemente negar el noema del fenómeno del conocimiento. Incluso, podrían el pensamiento lógico formal y el abductivo llegar a prestarse algún tipo de servicio orientado a la consolidación de los dos.

Peirce llamó la atención respecto de la particular importancia social del pensamiento abductivo, pues es más recurrido en la vida cotidiana, así como en la intimidad del ser, y por ello mismo tiene una relación mucho más estrecha con la realidad social, que la registrada por el pensamiento racional en su proporción lógico formal.

Es así precisamente porque su práctica entraña en las creencias sociales, de hecho, son su fundamento, pues si bien es pensamiento inferencial, invierte la estructura lógica que caracteriza a la inducción y a la deducción.

Para asumir sus cualidades es preciso advertir que la vinculación del pensamiento con la creación social de la realidad no demanda mayores inferencias de estirpe sicológica. Sino que a partir de la fenomenología misma del pensamiento se enciende la conciencia de su dinámica.

Así, se aprecia que mediante el pensamiento se activan las creencias. Las creencias son propicias a que su portador experimente el ímpetu comprometido en sus sentimientos y sensaciones. Y con ello vienen las acciones sociales. (...) 


\section{OPPCF}

De tal suerte, del conocimiento atribuido a Jesús de Nazareth, puede sin mayor dificultad extraerse una cierta condición inmanente de la personas -hijos de Dios, al fin y al cabo, que desata un cierto sentido de justicia, metajurídico sin duda, pero asociado a los más significativos valores predicados. De donde no haya sido demasiado difícil a los compiladores ingresar a la culpa en su especificidad y probabilidad, y en definitiva a la culpabilidad en su generalidad, como condiciones de la responsabilidad en derecho privado.

Y ello también explica el por qué, para el derecho medieval resultó aún menos desafiante. Es así, como signo del continuum del derecho medieval, Grossi refirió con particular énfasis las aequitas, en cuya tentativa de definición acudió a la convenientia, para decir, (...) armonía, orden recíproco, semejanza, igualdad sustancial; todo esto individualizado en las cosas, dimensión y evolución de las cosas. Por consiguiente, esta aequitas es fuente y comienzo de la justicia; $y$, por consiguiente, también del Derecho; que es la manifestación de la justicia en las normas de los hombres; esta aequitas tiene una primera faceta fundamental: no es un producto de la mente humana; está en las cosas y desde las cosas se proyecta entre los hombres. (...) (GROSSI, 1996, pp. 181).

\subsection{LA PUJA DOGMÁTICA Y EL ORIGEN DE LA VERSIÓN ESTANDARIZADA DE LA RESPONSABILIDAD SUBJETIVA COMO FUNDAMENTO DE LA SANCIÓN}

Los orígenes revelaron una cierta opacidad asociada particularmente con la culpa. La explicación hallada por la semiótica indicó que ello se explica en que a los hermeneutas les resulta muy incómodo hallar el sentido de algo, cando ese algo carece de expresión institucional clara.

Lo que intentaron fue homogenizar la expresión normativa del dolo con la culpa, y no sólo no lograron, sino que confundieron pues, al fin y al cabo, se trata de una polaridad. La culpa es en cierto modo la némesis del dolo.

Pero la piedra donde se tuerce la pala del hermeneuta, al igual que del dogmatista, se encuentra en la culpa y, en general, la culpabilidad, no dependen de sus expresiones jurídicas que, de una u otra forma, no son sino una forma, como en cambio sí del sentido social de justicia. Es decir, particularmente la culpa proviene de las entrañas sociales.

Los dogmatistas fueron de alguna forma audaces, pues renuncian a buscar el sentido de la culpabilidad en las interioridades de las normas, para abrirse paso más allá, es decir, en los límites de saturación del sistema normativo. Por decirlo más claramente, entre los principios de dicho sistema. Por ello, como corresponde a su identidad epistemológica, se dieron inicialmente a establecer los principios, para ubicar la culpabilidad en general, pero 
lo que terminaron formulando fue que la culpabilidad era en sí misma un principio, lo cual corresponde a la llamada responsabilidad subjetiva, o sin serlo, no superaría una condición normativa de carácter contingente.

Como resultado, en el primer caso, la culpabilidad sigue siendo una forma jurídica a la cual el juez le da contenido. En el segundo, hay una negación sustitutiva sobre la base de una especie de presunción, pues quien está dentro del sistema debe conocer las reglas del sistema e, incumplirlas lo hace per sé responsable.

La fórmula kantiana, como se deduce con cierta facilidad, conviene a un juez que iura novit curia puede y debe producir la justicia a través de sus decisiones. Luego, el juicio de culpabilidad corresponde naturalmente con su condición. Hay un orden meta-jurídico que hay que restablecer, y ello sólo debe ser realizado por un experto, el mismo que protagoniza los procesos de tendencia inquisitorial.

En este punto debemos observar que el proceso fiscal, conforme lo tiene desarrollado la normativa interna colombiana, tiene más a esta concepción procesal.

En cambio, los procesos de estirpe acusatorio-adversativa se acomodan espontáneamente a la fórmula hegeliana, al fin y al cabo, no es al juez a quien corresponde el juicio de culpabilidad, cuya esencia es meta-jurídica. El juez recibe algo construido en punto a la culpabilidad, que debe completar mediante la construcción judicial de la responsabilidad. Estos procesos son bastante apropiados a contribuir al reforzamiento de las representaciones sociales que, por cierto, no dependen de él. Muy bien les viene el jurado de conciencia.

\subsubsection{La fórmula kantiana}

Quien convirtió la culpabilidad en fundamento de la responsabilidad sancionatoria, dándole un cierto lugar funcional y sistémico a la culpa y otro al dolo, fue Kant.

No pretenderíamos que haya sido el más grande filósofo alemán, quien primeramente formuló la culpabilidad como fundamento de la responsabilidad. Como vimos, los juristas clásicos lo intentaron y, los compiladores de Justiniano lo formularon en el Corpus luris Civilis. Pero quien por primera vez construyó todo un entramado dogmático, epistemológicamente objetivo, y de tal solidez que aún ahora se sigue y con mucha resistencia a un giro hacia lo hegeliano, fue definitivamente Kant.

Su empeño estaba orientado a consolidar un modelo teórico de la responsabilidad, con aptitud para servir de soporte al derecho público tanto como al derecho privado. Para ello la categorización que formuló, implícitamente compromete una sistematización de naturaleza

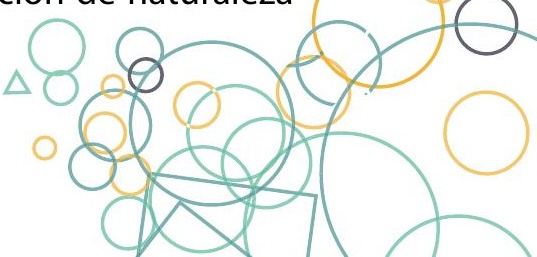


dogmática, no obstante haberse servido de los resultados hermenéuticos alcanzados por los juristas clásicos, en materia de derecho de las obligaciones (KANT, 1995). ${ }^{61}$

Si bien opuso el ius frente a la ética, las englobó en una misma metafísica de las costumbres, de la cual se sirvió Kant para precisar su entidad apriorística. De donde sus conclusiones resulten tan válidas al derecho penal, como a la justicia fiscal.

Al derecho lo identifica su exterioridad, en cambio a la ética todo lo contrario, (...) La legislación ética es la que no puede ser exterior -aunque los deberes pueden también ser exteriores-; la jurídica es la que también puede ser exterior (...) (1995, pp. 25).

De la metafísica de las costumbres hace parte el acto, al cual define como acción que corresponde, por un lado, con el concepto de obligación, en tanto tal, necesaria a partir de un imperativo categórico de la razón. Y por otro, del libre albedrío, implicando la contingencia derivada de la libertad del sujeto.

En sus términos, (...) A través de un acto semejante se considera al agente como autor del efecto, y éste, junto con la acción misma, pueden imputársele, cuando se conoce previamente la ley en virtud de la cual pesa sobre ellos una obligación. (...) (1995, pp. 30).

De su filosofía se extrae que el sujeto y su acción, para efectos de la imputación, constituyen una unidad inescindible. Sólo quienes tienen libre albedrío realizan acciones que completan la condición de imputabilidad. A la cual hay lugar, cuando alguien que conoce previamente la ley y es simultáneamente libre, elige realizar u omitir una acción, que legalmente debe ser obligatorio el realizarla o el evitarla. De donde, resulte imposible predicar la condición de imputable a todo aquello que carezca de libre albedrío, como las cosas precisamente.

Por otra parte, los actos son correctos o incorrectos, según que el sujeto al realizarlos u omitirlos, haya atendido o no al deber correspondiente. Si no existe tal correspondencia, es decir, si se aparta del deber, acontece la transgresión.

(...) Una transgresión no intencionada que, sin embargo, puede imputarse, se llama culpa. Una intencionada (es decir, la que está ligada a la conciencia de ser una transgresión) se llama delito (dolus) (...) (1995, pp. 30).

Al denuedo kantiano por mantenerse -como buen dogmatista- dentro del sistema jurídico, cuyo entorno se integra por el complejo sistema de principios en que se soporta y le da sentido, no le resultó suficiente el derecho para explicar la culpabilidad. Al igual que los 61 Por dogmática se entiende la metodología que integra sistémicamente unos elementos, con fundamento en principios. Así lo entiende el filósofo al referirse a la división de los derechos personales y, la opone a la concepción empírica, es decir, a la que busca el sentido en las unidades, en los textos 0 instituciones, lo cual es típicamente hermenéutico. 
juristas $y$, al igual que a Ricoeur, no quedó otra alternativa que ingresarlo al derecho como signo conceptual, pero a la hora de aplicarlo debió considerarlo en su entidad comunicativa, asociándolo como un juicio que nadie más que el juez puede realizar, en su unidad sintáctica de imputación.

Precisamente, cuando Kant especificó los sentidos que puede adquirir la imputación, señaló que sería moral, cuando se considera un (...) juicio por medio del cual alguien es considerado como autor (causa libera) de una acción, que entonces se llama acto (factum), y está sometida a leyes; si el juicio lleva consigo a la vez las consecuencias jurídicas del acto, es una imputación judicial (imputatio iudiciaria s. valida), en caso contrario, sólo una imputación dictaminatoria (...) $(1995$, pp. 35).

La única persona competente para hacer una imputación judicial es el juez o el tribunal, es decir, en el acto comunicacional que implica el proceso. Aquí ya no depende de la ley, sino de la sabiduría del juez, y esa sabiduría desborda con mucho lo estrictamente jurídico.

Más aún, lo que inquietó particularmente a Kant fue la relación dinámica entre culpa y consecuencia, es decir la sanción. El grado de imputabilidad (imputabilitas) de las acciones ha de valorarse subjetivamente, según la magnitud de los obstáculos que han tenido que superarse (...) cuanto menor es el obstáculo natural, y cuanto mayor es el obstáculo fundado en el deber, tanto más es imputable la infracción (como delito). (...) (1995, pp. 36).

Al fin y al cabo, una metafísica de las costumbres, por algún lado, sea a través de la moral o a través de la ética, tenía que permearse de un juicio que la ley no puede anticipar, porque depende de condiciones típicamente extra-normativas. Lo metajurídico implicado en la culpabilidad, es proveído por el juez, por ello la imputación es un juicio necesariamente jurisdiccional, pues si el grado de imputabilidad debe valorarse subjetivamente, nadie sino el juez es el encargado de otorgarle contenido al dolo y a la culpa para determinar las consecuencias.

Sobre esta base, Kant formuló la responsabilidad subjetiva y, con ello, introdujo sistémica y funcionalmente la culpabilidad al derecho penal en particular $y$, al derecho sancionatorio en general.

Partió del presupuesto según el cual el derecho auténtico proviene de la razón pura, como tal se ordena sistemáticamente por leyes universales, en las que se formulan los principios apriorísticos. El derecho en general, pero muy particularmente el penal sancionatorio, y más precisamente la responsabilidad aparejada como la penal, se basa en el libre albedrío, (...) Por tanto, el derecho es el conjunto de condiciones bajo las cuales el arbitrio de uno puede 


\section{OPPCF}

conciliarse con el arbitrio de otro según una ley universal de la libertad (...) Una acción es conforme a derecho cuando permite, o cuya máxima permite a la libertad del arbitrio de cada uno coexistir con la libertad de todos según una ley universal (...) (1995, pp. 39).

La responsabilidad subjetiva no es si quiera pensable sin admitir preliminarmente el libre albedrío. En efecto, la naturaleza del castigo se condiciona a la posibilidad de elegir, en el caso de la responsabilidad penal, entre lo que es lícito y lo que no es tal, lo cual es igualmente válido respecto del derecho sancionatorio en general.

De donde le haya resultado confuso, como en efecto lo es, la posición de los juristas clásicos respecto del estado de necesidad, pues para Kant no genera otra cosa que impunidad, mientras que los juristas eliminaron la reprochabilidad de la conducta (1995, pp. 46). La ausencia de culpabilidad en Kant tiene implicancias sobre la sanción, pero no elimina la acción y, por ello mismo, debe haber algún tipo de consecuencia. ${ }^{62}$

Su medición fue lo que más inquietó a Kant y, en últimas a ello se debe la introducción de la culpabilidad como fundamento de la punibilidad. De esta forma, si el llamado principio de legalidad modulaba el poder del Estado, en Kant la completitud del control sobre ese poder estaría dado por la culpabilidad (1995, pp. 166).

Lo cual no contradice, por el contrario, resulta contributivo a conservar la división entre crímenes públicos y privados, pudiendo aquéllos ser abyectos o violentos. Entre los crímenes se hayan los atentados contra la ejecución legal del presupuesto público, lo que hoy llamaríamos justicia fiscal.

Por su parte, las sanciones podían ser naturales o judiciales, según fueran implicadas por la naturaleza de la acción o no, es decir, por ejemplo, al homicida le es natural la pena de muerte, aun cuando judicialmente pueda recibir una diferente.

Kant no admitió la instrumentalización del ser humano, así que realzó la incorporación de la culpabilidad en la responsabilidad penal nada más que para determinar la pena, pero no para ejemplarizar. El grado de maldad interna determina la intensidad del castigo (1995, pp. 169), (...) Toda legislación (prescriba acciones internas o externas, y éstas, bien a priori mediante la mera razón, bien mediante el arbitrio ajeno) comprende dos elementos: primero, una ley que representa objetivamente como necesaria la acción que debe suceder, es decir, que convierte la acción en deber; segundo, un móvil que liga subjetivamente con la representación de la ley el fundamento de determinación del arbitrio para la realización de esa acción; por tanto el segundo elemento consiste en que la ley hace del deber un móvil. Por medio del primer 62 Es poco más o menos lo que se conocería posteriormente como efectos de la cosa juzgada penal absolutoria. 
elemento la acción se representa como deber, lo cual es un conocimiento meramente teórico de la posible determinación del arbitrio, es decir, de la regla práctica; por medio del segundo, la obligación de obrar de este modo se une en el sujeto con un fundamento de determinación del arbitrio en general (...) (1995, pp. 23).

No obstante, encontró excepciones, como cuando una ley civil resulta ser benigna respecto de la penal, dándole un contenido acentuadamente kantiano al principio de favorabilidad (1995, pp. 173-174).

Pero el castigo es en sí mismo inevitable como inevitable entiende la justicia, la cual estableció como imperativo categórico (1995, pp. 167). Su entidad, intensidad o grado fue definido inicialmente por la reciprocidad derivada de la acción, mientras que la sustituibilidad podía operarse como, por ejemplo, la agresión física por la vergüenza pública, pedir perdón, incluso besando la mano de la víctima, o acaso reducir al agresor a un deshonroso y público arresto, cuando no a trabajos forzados.

Hay un punto de contacto entre la culpabilidad jurídica y la culpabilidad social. Según Kant, el que mata invariablemente debe morir, y cualquier transigencia a instancia de la comunidad implicaría, (...) considerársele como cómplice de esta violación pública de la justicia (...) (1995, pp. 16), pese admitir la posibilidad extrema del indulto, nada más que como medida completamente necesaria para salvaguardar la unidad social (1995, pp. 170-171).

\subsubsection{La disidencia hegeliana}

La solidez con que el más grande filósofo alemán formuló la responsabilidad subjetiva ha implicado prácticamente su inamovilidad, tanto en lo civil como en lo penal, con algunas salvedades en derecho administrativo que, aún hoy siguen generando inquietud.

Si ha habido morigeración, ha sido más bien una especie de coqueteo respecto del modelo de responsabilidad, más que objetiva, de base no subjetiva. A ello se ha osado llamar neokantismo. Lo cual, muy seguramente, indignaría profundamente a Kant, el verdadero.

Y dicho modelo, caracterizado por desembarazarse de todo aquello que carezca de contenido jurídico, fue formulado por Hegel.

Al igual que Kant, Hegel acudió a los orígenes romanos, de tal suerte se identificó el derecho con su objeto, seguramente en consideración óntica. Específicamente en el derecho de propiedad, y en virtud de esa identidad, en la cosa objeto del derecho quedaba evidenciada la voluntad del titular. En consecuencia, conforme a su concepción, violentar la cosa implicaría inevitablemente violencia contra la voluntad del titular, (...) La auténtica injusticia es el delito, 
en el cual no se respeta el derecho ni en sí como se me aparece a mí, con lo que se lesionan ambos lados, el objetivo y el subjetivo (...) (HEGEL, 1999, pp. 179).

De esta forma abrió camino al "derecho cuya lesión es el delito", es decir, al derecho penal, manifiesto mediante figuras típicas específicas (1999, pp. 182).

La verdadera violencia no consiste en la agresión, tanto como en el no retorno a su ser en sí, subjetivo, (...) En cuanto viviente, el hombre puede por cierto ser sojuzgado, es decir, puestos sus aspectos físicos y exteriores bajo la fuerza de otro. La voluntad libre, en cambio, no puede ser en sí y por sí violentada, sino sólo en cuanto ella misma no retorna a sí de la exterioridad en que se la mantiene o de su representación. Sólo se puede violentar a algo a quien quiere dejarse violentar (...) (1999, pp. 179).

De tal suerte, el punto esencial del delito, si bien es la violencia, no lo es en tanto considerada como proveniente del agresor, como en cuanto sufrida por el titular del derecho. Fuerza y violencia experimentada por él, es injusticia. Y la única forma de retornar a situación inicial, subjetiva, es ejerciendo una nueva violencia que, contrario a la primera, es legítima.

La segunda violencia es exclusiva del Estado, por lo que advierte, (...) En el Estado ya no puede haber héroes: éstos aparecen sólo en una situación de falta de cultura (...) (1999, pp. 180).

Para Hegel, a diferencia de Kant, hay un paralelismo objetivo entre moral y derecho, insuperable aún por la vía de una metafísica de las costumbres, pues (...) Las leyes del Estado no pueden, pues, pretender, extenderse al carácter de cada uno, pues en lo moral soy para mí mismo y la fuerza no tiene ningún sentido (...) (1999, pp. 181), de tal suerte únicamente la primera violencia, que es el delito, puede ocupar al derecho penal.

La voluntad puede lesionarse en su extensión cuantitativa o, en sus determinaciones cualitativas, muchas de las cuales, por ejemplo, el riesgo para la seguridad pública es inferencial, de donde no necesariamente aparezca de un daño comprobable, (...) el delito más peligroso por su característica inmediata es precisamente la lesión más peligrosa según su extensión cualitativa (...) (1999, pp. 183).

Esta consideración es la llamada a determinar la consecuencia, y esa relación es histórica, tanto así que para Hegel no son los delitos ni las penas lo que cambia, sino la relación entre unos y otros.

Ahora bien, la consecuencia es en sí misma una violencia, pero es una violencia sobre algo nulo, el derecho efectivo sucede cuando se niega esa nulidad. Solamente puede violentarse la voluntad individual subjetivada en la cosa, pues el derecho o la ley en sí no son susceptibles de lesión. 
La eliminación de la negación mediante otra negación es una cuestión de justicia, irreductible a lo que han hecho los tratadistas de la sanción, como Feuerbach y acaso el mismo Kant, de sustituir un perjuicio por otro, pues no se trata de realzar el aspecto subjetivo del delincuente, sino de suprimir una injusticia, de otro modo (...) se convierte en esencial el punto de vista moral, el lado subjetivo del delito, mezclado con triviales representaciones psicológicas sobre la fuerza y atracción de los estímulos sensibles en contra de la razón, sobre la violencia psicológica y su influencia en la representación (como si ésta no fuera rebajada por la libertad a algo meramente contingente) (...) En esta discusión lo único que importa es que el delito debe ser eliminado no como la producción de un perjuicio, sino como lesión del derecho en cuanto derecho. Esta existencia es el verdadero perjuicio que hay que hacer desaparecer, y determinar dónde se encuentra es el punto esencial (...) (1999, pp. 186).

La explicación de Hegel se operó por sobre la justicia de lesionar al infractor, en el reconocimiento de su propia voluntad, ya que hace parte de su derecho el exponerse a la consecuencia, así ésta sea su propia muerte. Lo que al cabo importa es la sostenibilidad de un orden sistémicamente diseñado, (...) el Estado no es un contrato, ni su esencia sustancial es de un modo condicional la protección y la seguridad de la vida y la propiedad de los individuos singulares. Él mismo es por el contrario lo más elevado, que reivindica para sí aquella vida y propiedad y exige su sacrificio (...) (1999, pp. 187-188).

Negar la negación que es el ilícito mediante la sanción, es el único fin racional de la sanción, y si bien debe existir una relación proporcional, dicha proporcionalidad depende de su cualidad representativa, de su valor intrínseco, tal y como ocurre en los delitos que implican peligro a la seguridad pública.

De tal suerte la sanción honra al infractor como ser racional, (...) no se le concedería este honor si el concepto y la medida de la pena no se tomaran del hecho mismo, si se lo considerara como un animal dañino que hay que hacer inofensivo, o si se toma como finalidad de la pena la intimidación o la corrección (...) (1999, pp. 188).

Tal predicamento confluyó en la objetivación proporcionada por la universalidad del derecho, en tanto tal, la responsabilidad no podría depender del arbitrio, no por sabio menos subjetivo, del juez, pues no habría mayor distancia con la venganza arcaica, manifiesta en el tratamiento de los delitos privados, de los cuales se ocupaba la LDT, que implicaban, por ejemplo, pagar el valor del bien según lo declarara el agraviado, el duplo el cuádruplo.

Lo que diferencia a la justicia vindicativa de la justicia punitiva, es el posicionamiento de la voluntad subjetiva que caracteriza a aquélla, en cuanto en ésta ese lugar lo ocupa la voluntad

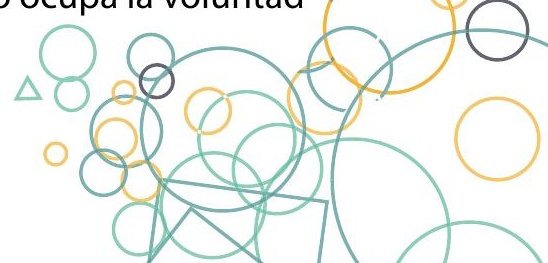


que busca hacerse universal y, por tanto, objetiva, lo cual convienen a un nuevo concepto de moralidad.

Como puede apreciarse, en Hegel la culpabilidad no cuenta sino como exigibilidad, lo que de forma inconcusa declaró al afirmar, (...) El derecho de la intención es que la cualidad universal de la acción no es sólo en sí, sino además sabida por el agente, y por lo tanto puesta en su voluntad subjetiva. Inversamente, el derecho de la objetividad de la acción, como puede ser llamado, es que se la afirme como sabida y querida por el sujeto en cuanto éste es un ser pensante. (...) (1999, pp. 51).

\subsection{CONSOLIDACIÓN DE LA RESPONSABILIDAD SANCIONATORIA BASADA EN LA CULPABILIDAD}

Desde que el derecho penal se consolidó como saber científico, monopolizó el derecho sancionatorio, hasta hace relativamente poco tiempo y, sin que haya concluido completamente el proceso. Por esta razón, desde el planteamiento de la culpabilidad como base de la responsabilidad, el derecho penal fue el que se ocupó de los desarrollos importantes. Posteriormente de ello se han venido sirviendo las otras manifestaciones sancionatorias, como a disciplinaria, y lo que postulamos ahora es que la justicia fiscal no sólo puede, sino que constitucionalmente tiene que servirse de dicho desarrollo, toda vez que existen bases de esa misma naturaleza para predicar que en Colombia nadie puede ser sancionado en desarrollo del proceso de control y vigilancia fiscal, sin habérsele demostrado su culpabilidad.

En efecto, la relación ilícito-sanción, explicada, comunicada o vinculada mediante la culpabilidad, trajo como consecuencia que lo más característico del derecho kantiano, resulte ser el haber acogido la función retributiva de la sanción, hasta identificarse con ella.

Lo cual de una u otra forma resulta ser la contracara del humanismo del derecho. Se trata de un diseño sancionatorio pensado muy efectivamente para la negación de derechos del declarado como responsable. Se trata de la racionalización de la venganza, la institucionalización de la aflicción como método de intervención de las personas, entendiendo el sufrimiento como contraprestación por la que fue la negación de los derechos de quien sufrió las consecuencias del ilícito.

Pese a que Hegel se opuso como ninguno, a cualquier forma de encubrimiento de la venganza en términos de derecho, su fórmula paradójicamente la expresa mejor que su némesis: si a una negación agregamos otra producimos algo positivo, así se quiera justificar en que se recobra la representación social del orden alterado. 
Lo que no consideraron con demasiado detenimiento Kant ni Hegel, es que la relación predominante implica que la declaración de la responsabilidad autoriza al Estado a intervenir sobre los derechos del responsable para afectarlos -se insiste negativamente, es decir minarlos, suspenderlos y hasta suprimirlos, entendiendo que las sociedades interpretan que castigar a los responsables siempre es bueno, deseable $y$, en fin, positivo.

No obstante, las sanciones cumplen otras funciones, pero la que resulta eidética al tipo de derecho sancionatorio acogido es la retributiva. Lo cual no es aventurado, sino que se respalda en un complejo de representaciones sociales animadas por el Estado en favor de la retribución.

Consecuencia de lo cual, sólo pueden ser culpables las personas jurídicamente capaces. Es decir, quienes pueden comprender la licitud o ilicitud de sus actos. Y, así mismo, pueden orientar su comportamiento de conformidad con su comprensión.

Acerca de la forma como se construyó este complejo sígnico en el cual descansa la negación de las personas asimiladas al concepto de incapaces, entre los cuales se hallan la sanción y el responsable -como persona susceptible de ser negada, encontramos que inicialmente Feuerbach fue quien se propuso sistematizar los modelos punitivos, acentuando la prevención general como efecto proveniente del castigo, cuya intensidad consideraba al sujeto como parte del hecho castigable (von FEUERBACH P. , 1989).

Poco después Kant erigió la culpabilidad en el fundamento de la punibilidad, y desde entonces el denuedo de los teóricos está orientado en favor de una correlación científica entre los dos extremos, es decir, estimada la intensidad del daño debe corresponder una sanción equivalente.

La concepción psicológica de la culpabilidad se manifestó poco después en las obras de von Liszt, quien identificó la culpabilidad con la imputabilidad del autor precisamente (1929). En la misma tónica Radbruch entendió el dolo y la culpa como condiciones psicológicas del sujeto agente (1955). Y también participó de esta línea Beling para quien la culpabilidad es una relación psicológica del sujeto con el hecho (2011).

Sin lugar a dudas quien mejor y más claramente lo ha expresado fue Kant, es decir, la intensidad de la sanción conviene a la maldad interior, al sujeto condenado se lo castiga presuntamente por lo que sabía y por haberlo querido. De tal suerte, a mayor maldad interior, mayor sanción, y esto se identifica o explica como dolo. Mientras que, a menor maldad interior, menor sanción, y esto se identifica o explica como culpa.

No obstante, lo cuestionable es que eso difícilmente logra demostrarse, a un nivel estrictamente

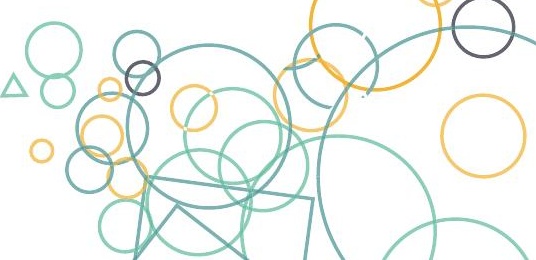


probatorio, y siendo así lo que permite construir la sentencia en términos de retribución, es simplemente, al no haber razón que demuestre la inimputabilidad: no hay más remedio que deducir por cognición que sabía todo lo que tenía que saber y quería todo lo que tenía que querer para merecer ser castigado.

Se han intentado otras explicaciones -que no son por cierto soluciones, fue así como Goldschmidt intentó superar las manifiestas deficiencias del vínculo psicológico, pero prefirió no invocarlo al señalar que el fundamento de la sanción se halla en la infracción normativa, esto es, en el desconocimiento o, la no atención a la norma. Por lo que para los ilícitos dolosos sería derivado directamente del desacatar la norma positiva. Mientras para los culposos, en la infracción al deber objetivo de cuidado, significando la violación al acatamiento de normas no penales, incluso tipificaciones sociales (1943).

Mezger en cambio, planteó la culpabilidad como una desaprobación social de la personalidad adquirida, sobre presupuestos normativos facultativos (1957). Implicando el sentido social negativo sobre la persona del responsable. $Y$ por ello mismo la imputabilidad y la inimputabilidad, no podían ser son significaciones de estricto contenido institucional (2006, pp. 7-17). Es decir, se trata de signos socialmente construidos para producir una cierta semiosis, esto es la experiencia social de personas capaces e incapaces.

Welzel completó la visión normativa de la culpabilidad, por cuanto la conciencia de antijuridicidad y la conducta exigible, esto es, la adecuada a la norma, pasaron a ser elementos del tipo objetivo, y en la culpabilidad no quedó sino la responsabilidad por la comisión del delito. ${ }^{63}$ Por suerte que la culpabilidad permaneció en el terreno psicológico de la decisión por autocontrol de no atender al mandato de prohibición implicado en la norma -por consiguiente para ser culpable, es decir para ser responsable se precisa que la persona pueda autocontrolarse (WELZEL, La Culpabilidad, 2000).

Sean las unas o sean las otras las tendencias teóricas acogidas, de la obra de Kaufmann se desprende que todas estas concepciones se basan en el modelo kantiano de libertad y de maldad interior (KAUFMANN, Derecho, Moral e Historicidad, 2000). Y fue Wolff quien lo restauró en el Siglo XX como imperativo categórico (ZACZYK, 2010).

El dilema se encuentra en que científicamente no ha sido posible demostrar que cerebralmente exista la función de decidir libremente.

63 Así, en Colombia las modalidades de la conducta punible por lo que antes eran formas de culpabilidad (art. 21 L 599/00), implica que la pena se vincula a la forma normativa, hay una pena para el dolo, otra para la culpa y otra para la preterintención. La culpabilidad se integra al principio nulla poena sine legem. 
Con todo sigue siendo la experiencia -falsa o real- de libertad, lo que justifica ideológicamente la función preventiva de la sanción, tal y como lo reconocen entre otros Hirsch (1996).

La tendencia cobró caudal hegeliano con la obra de Jakobs, para quien el fundamento del castigo penal no proviene del autor, sino de la norma de la prevención general, por suerte que se justifica en la reafirmación de la vigencia de la norma (JAKOBS, 2003).

Entre tanto el planteamiento de Roxin estaba orientado a identificar la culpabilidad como un máximum o límite superior que sirve a fijar el máximo de determinación de la pena con fines preventivos, en función compensatoria de la consciencia del autor en cuanto a la ilicitud de su conducta (ROXIN, 1981).

Según Jescheck, hay una tendencia hegeliana extrema hacia la negación total de la culpabilidad, lo cual informa una reconcepción misma de la teoría del delito (JESCHECK, 2003).

Lo cierto es que en la actualidad se sigue al Tribunal Constitucional Federal (Alemania) el cual dedujo que la relación culpa con intensidad de la pena es un principio constitucional derivado del modelo Estado Social Democrático y de Derecho. ${ }^{64}{ }^{1}$

La experiencia del derecho penal da cuenta que la intensidad de la pena en la mayor parte de Estados no se mide sino por extensión temporal de la prisión. Pues se trata de la pena predominante $y$, pese a que las normas de Naciones Unidas implican los niveles propios del sistema progresivo, en países como Colombia está muy lejos de atenderse (MOYA VARGAS, Análisis jurídico del tratamiento penitenciario, 2009).

Lo cierto es que en la prisión se experimentan las mismas consecuencias sea largo o corto el tiempo de duración, y se sabe que el momento más crítico de ese daño sucede cuando comienza la ejecución de la pena, que es el inicio de la negación del sujeto confinado. Es decir, en días, semanas o años en la prisión se sufren los mismos efectos, pues suprimir los primeros días es un imposible, con el paso del tiempo la persona tiende a acomodarse a las nuevas condiciones, por lo que siempre se experimenta el rigor del castigo.

\subsection{EFECTOS DE LA HEGEMONÍA KANTIANA}

Hemos hallamos que de la magnífica obra jurídica de Kant surgió para la concepción sistémica más completa del derecho hasta ahora conocida, la base dogmática de la responsabilidad subjetiva (KANT, 1995). ${ }^{65}$

64 Bundesverfassungsgericht. (2006). 20, 323, 331. Meinz.

65 No desconocemos que a nivel del derecho civil el modelo de imputación subjetiva tendría raíz clásica, pero a este mismo nivel histório no creemos que pueda hablarse del derecho como sistema que integrase todas las expresiones, muy particualrmente deficiente fue la csontrucción del derecho penal. Atribuimos a Kant haber formulado todo un modelo de responsabilidad satisfactorio

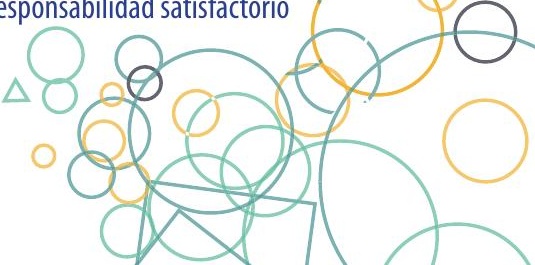


Desde sus fundamentos se presentó como imperativo categórico. Se trató de la existencia de una condición antepredicativa, a partir de la cual se erigía toda opción de derivación de la responsabilidad, consistente en lo que el filósofo denominó como libertad. ${ }^{66}$

Postuló al respecto que para poder ser declarado responsable una persona precisa ser previamente libre, entendida la libertad como una condición ex ante, constituida por el poder entender y, la voluntad de optar con base en dicho entendimiento (SELMINI, 1998).

Los presupuestos en que descansa la libertad, así entendida, surgen de la posibilidad real de comprender lo perverso o bondadoso del actuar, lo cual se proyecta en un trasfondo que revela lo jurídico por oposición a lo antijurídico.

El segundo presupuesto es la condición de tener dominio de sí, entendiendo por ello que las acciones $u$ omisiones correspondan a la voluntad de obrar mal o bien, jurídica o antijurídicamente (SCALISI, 1998).

Por consiguiente, la libertad es el efecto del encuentro entre la conciencia y la voluntad, de modo que sólo pueden ser responsables las personas libres. De aquí surgió la compleja episteme en materia de responsabilidad que enfocó la necesidad de vincular la sique de las personas a sus actos, de tal suerte que sólo cuando ese vínculo surgiera dispondría el juez del baremo para establecer no sólo la responsabilidad sino también su intensidad; y con ello la consecuencia o sanción.

De ahí proviene la estandarización del dolo en los ilícitos penales, y el excepcional vínculo en términos de culpabilidad culposa y, en su momento, preterintencional. Lo que en todo caso apareja problemas seguramente no pensados por Kant ni por los grandes teóricos, que de hecho hace muy difícil la funcionalidad de una demostración (RAGUÉS I VALLES, 2002).

Sin duda es el modelo que más ha predominado, al menos en el mundo informado por el derecho romano clásico y su sucedáneo procedente del llamado usus modernus pandectarum, conforme es revelado a través de la obra de Emilio Betti (BETTI, La estructura de la obligación romana y el problema de su génesis, 2015), (BETTI, Teoría general del negocio jurídico. 4

a cualquier expresión jurídica, osntruido a partir del principio de culpabilidad.

66 No se trata de una construcción sencilla y resulta mucho más aprehensible entenderla por oposición al idea que con la misma nominación poco después Hegel construyera los cimientos de lo que terminaría siendo la responsabilidad por imputación objetiva. Así, mientras Kant estimaba el derecho como una obra suprahumana, señalaba sus fundamentos como algo dado, preestablecido por un orden supremo frente al cual el hombre podría subvertirlo pero no replantearlo. Por suerte que mientras para Kant la libertad es ex ante el derecho, para Hegel es ex post, entendiendo que la libertad es el efecto der social e integrarse a una estructura que para ser en sí demanda adecuar la conducta de sus integrantes a un sistema de reglas lógicamente explicables. La libertad vista así es construida, es constituyente. Mientras que vista de la otra forma, es más bien una condición constitutiva a partir de la cual y para sí, explica la existencia de un ordo jurídico. Lo cierto es que en la iusphera la libertad siempre ha ocupado un sitial importante, aun cuando hy día sigue siendo conceptualmente aceptada, pero ónticamente cuestionada. 
estudios fundamentales, 2001), (BETTI, Teoría general del negocio jurídico, 2000), (BETTI, Le categorie civilistiche dell' interpretazione. Edizione ad uso degli studenti, 1999), (BETTI, Teoría general de las obligaciones, 1970), (BETTI, Análisis del sistema jurídico alemán; principales ideas directrices, 1967), (BETTI, Cours di droit civil comparé II : etude d'un sistème juridique, système du code civil Allemand, 1965).

En materia penal, lo que más inquietaba a Kant era precisamente la diversificación de las sanciones, particularmente ahí donde la equivalencia asociada por una especie de ley del talión, poco o nada contribuyera a asociar racionalmente del delito y la sanción. Cuanta más conciencia y voluntad, lo que Kant llamó maldad interior, mayor debía ser la sanción, pues no resultaba jurídico desproporcionar los dos extremos de la ecuación de la responsabilidad (LUZÓN DOMINGO, 2004).

Heredera de la filosofía kantiana la llamada Escuela clásica edificó una concepción que asociaba la idea del dolo con la perversidad en términos morales y políticos. Así, según Carrara para que una acción pueda ser objeto de reproche (...) no basta que lo sea desde el punto de vista moral, ni que sea en sí malvado, según el precepto moral. Es menester, además, que el acto moralmente imputable a alguno como malo, sea políticamente dañoso. Esto se sigue del principio según el cual el derecho de prohibir ciertas acciones y declararlas delito, se atribuye a la autoridad social como medio de mera defensa del orden externo, y no para conseguir el perfeccionamiento interno (...) Además, el daño acarrea la acción perversa del hombre debe ser un daño social, es decir, de tal naturaleza que no se pueda con otros medios, salvo sometiéndolo a la represión de la ley, proveer la defensa del orden externo. Si el daño se limita al individuo, o si es reparable mediante una acción directa, el legislador excederá sus facultades si declara delito el acto que fue su causa (...) (1971, pp. 38-39).

A la discapacidad mental la designó "locura" distinguiéndola como una condición patológica que resta a la persona comprender la relación de su comportamiento con lo mandado por la norma, por lo que pueden violarla incluso sin habérselo propuesto (1971, pp. 179).

Como ya lo hemos sostenido quizás el diseño del modelo de responsabilidad subjetiva no haya sido ingeniado por el filósofo alemán (STOLFI, 1959), -al menos las referencias de los juristas clásicos vinculadas al derecho privado así lo sugieren (BONFANTE, 1929), pero sí le debemos haberle otorgado entidad dogmática y con ello, estructural al sistema normativo (LEÓN HURTADO, 1952).

Cuanto hace al derecho sancionatorio en general y, penal en particular, fue Kant quien puso las cosas en el orden y claridad que antes no había sido alcanzado. 
No obstante, en derecho privado no es habitual que se refiera a Kant (LOHMANN LUCA DE TENA, 1994), pues como dijimos si bien no lo formuló, se le debe la versión dogmática, sistémica e integral, antes nada clara (GROSSO, 2011).

Sin lugar a dudas a partir de la Metafísica de las Costumbres se consolidó el modelo de responsabilidad subjetiva, con base en el cual las personas con cierto tipo de deficiencia en su capacidad de entender y de querer o bien quedan negadas en tanto tales o, al menos radicaban la responsabilidad en otros (GORDILLO CAÑAS, 1986).

Este es el fondo teórico en que se sustenta y justifica la representación técnica del "culpable", por ello el incapaz o inimputable no es culpable, y de ahí la incomodidad que constituye para la teoría kantiana, resuelta finalmente de forma tan adversa que la reducción que sufren de su condición de persona surge de hecho por la selectiva indiferencia del derecho.

En efecto, sobre la base de poder negar la condición de persona o radicar en otros la responsabilidad, ${ }^{67}$ es de donde proviene el discernimiento entre personas capaces e incapaces o, imputables e inimputables (WOLFGANG, 2004).

Precisamente, dijo Reyes que la responsabilidad consiste en, la (...) sujeción del agente a las consecuencias jurídicas del hecho punible cometido; una persona es penalmente responsable cuando ha realizado (un) hecho delictivo o contravencional; ahora bien, si tal sujeto es imputable se le impondrá pena y si es inimputable, se le aplicará la medida de seguridad. Dedúcese de este planteamiento que en nuestro derecho positivo imputables e inimputables son penalmente responsables, puesto que ambos están sujetos a las consecuencias legales del hecho punible cometido, no importa que el primer caso se les aplique pena y en el segundo medida asegurativa. Resulta así evidente que responsabilidad e imputabilidad son fenómenos diversos que no se excluyen entre sí (...) (REYES ECHANDÍA, 2000, pp. 192).

La distinción entre imputables e inimputables no compromete el que puedan ser responsables, pero sí las consecuencias de dicha responsabilidad, la incapacidad de comprender estar yendo contra la norma es lo que hace de una persona inimputable.

En apoyo afirmó Fernández, (...) A nadie resulta extraño, tampoco, en el actual estado de la teoría del delito, que los inimputables sean capaces de realizar un tipo de injusto, es decir, sean capaces de acción, capaces de tipo (como diría el Dr. CARLOS JARAMILLO "realizadores del tipo") y capaces de antijuricidad. Las acciones de los inimputables pueden ser injustas; prueba

67 Lo cual corresponde con la vicisitud procesal que facultaba la producción de sentencias con transposición de personas. Según esto uno era el demandado, pero otro era el condenado. Por ejemplo, cuando un esclavo hacía un daño, el demandante lo refería en la fórmula, pero requería la condena del dueño. 
evidentísima de ello es que contra la acción de un inimputable (enajenado mental, menor de edad), cabe la legítima defensa y la legítima defensa no cabe sino contra una agresión injusta; luego, si los inimputables no actuaran antijurídicamente, contra sus actos no habría posibilidad de legítima defensa. Porque si se llegara a la conclusión de que solo la conducta de los imputables importa, entonces los inimputables quedaría por fuera del derecho penal. ¿Con base en que se someten, entonces, a una medida de seguridad? Claro que en la comisión, en la realización, dice muy técnicamente el código, de una acción o una omisión prevista como punible, es decir, de un delito o una contravención. Para eludir la responsabilidad objetiva de los inimputables, los alemanes, que definieron la imputabilidad como capacidad de culpabilidad y excluyeron a los inimputables de la culpabilidad, se inventaron la teoría del dolus naturalis, el dolo natural, el dolo sin la consecuencia de la ilicitud (...) (FERNÁNDEZ CARRASQUILLA, 1994, pp. 143-144).

Así, la teoría de cuño kantiano erigió la capacidad como condición de imputabilidad (WEEZEL, 2011), por suerte que quien se encuentre al momento de cometer su acto ilícito en incapacidad de comprender su ilicitud o, entendiéndola no pueda adecuar su comportamiento, es considerado incapaz, con ello inimputable y por lo mismo, no es susceptible de un juicio de culpabilidad -lo que en derecho civil equivale a la transposición de personas (FEDELE, 1943), o como suele decirse en derecho penal, la persona es inimputable (von FEUERBACH, 1989). Las consecuencias de su actuar típico y antijurídico son sustancialmente distintas a las de imputables, pues serán merecedores de medidas de seguridad.

En esta versión, culpabilidad y voluntad son términos interdependientes, por suerte que sólo quienes la poseen pueden ser culpables (WELZEL, Derecho Penal Alemán. Parte general, 1997).

En criterio de Velásquez la culpabilidad implica que libre y voluntariamente el individuo se disponga hacia la realización de una conducta ilícit, de donde surja la facultad por parte del Estado de sancionar al transgresor (VELÁSQUEZ VELÁSQUEZ, 2014).

Según Muñoz, en la culpabilidad, (...) se encuentran las facultades psíquicas del autor (la llamada imputabilidad o capacidad de culpabilidad), el conocimiento por parte del autor del carácter prohibido de su acción u omisión y la exigibilidad de un comportamiento distinto (...) (MUÑOZ CONDE, 2013, pp. 123).

Agregó Fernández, (...) La diferencia, pues, entre imputables e inimputables, que a nivel ontológico es de grado (y si no fuera de grado seria de esencia y si fuera de esencia tendríamos que concluir que los inimputables no son seres humanos, porque su esencia sería distinta a la nuestra), estriba en que, cuando se trata de penas, exige el código que el sujeto tenga la plena

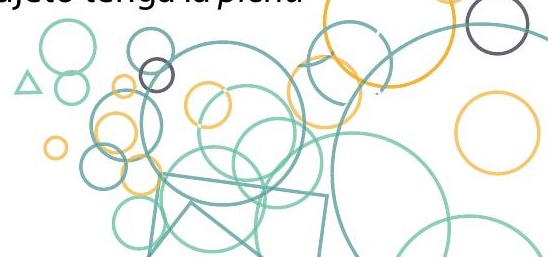


capacidad de esa advertencia y cuando se trata de medidas de seguridad se contesta con una deficiente capacidad de compresión. Esto nos indica que inimputabilidad no es, en este articulado, presupuesto de la culpabilidad, sino de la pena (...) (FERNÁNDEZ CARRASQUILLA, 1994, pp. 139).

El autor acierta a señalar cómo la existencia de una doble definición de delito, conforme con las cuales para inimputables se trata de un comportamiento típico, antijurídico y culpable, mientras que para inimputables no es sino conducta típica y antijurídica, no fundamenta realmente una base de responsabilidad, sino el pretexto penal para intervenir a la persona, es decir se trata de poderlo castigar sin satisfacer el concepto de responsabilidad. El cambio la nominación medida de seguridad por penas, lejos de protegerlos en términos reales no logra sino agudizar el sentido represivo y retributivo del derecho penal, (...) Decir que las medidas de seguridad son un recurso administrativo, no resuelve el problema. Porque los recursos administrativos, aunque sean dispensados por el juez penal, también son recursos jurídicos y representan sanciones jurídicas para los responsables. Claro que la mejor manera de eliminar la responsabilidad objetiva de los inimputables, es eliminar la responsabilidad penal de los inimputables. Pero como esto no fue lo que hizo el código y como está prohibida la responsabilidad objetiva, no queda otra salida que admitir la responsabilidad subjetiva de los inimputables. Responsabilidad subjetiva y culpabilidad son exactamente lo mismo. Responsabilidad subjetiva o por la culpabilidad, es un concepto que resiste los dos tipos de responsabilidad: por los hechos de autor imputable y reprochable, y por los del que no es imputable (...) (FERNÁNDEZ CARRASQUILLA, 1994, pp. 141).

Como es comúnmente reconocido, una de las fuentes de inimputabilidad más señaladas son las disfunciones físicas, psíquicas o mentales, fruto de lesiones o enfermedades (URRUELA MORA, 2004).

Luego, podemos afirmar que la situación de discapacidad que apareja los efectos anotados jurídicamente implican la incapacidad o inimputabilidad (MEZGER, La imputabilidad., 2006), y con ello un tratamiento jurídico diferencial, cuya orientación declarada está dirigida más hacia la protección de la persona que a una discriminación, pero paradójicamente para poder lograr ese efecto de lo primero que se valieron fue de la negación misma de la persona, ${ }^{68}$ consiste en la disminución de la condición de persona y con ello, una menos exigente demanda de exactitud y demostración de responsabilidad, como consecuencia castigos que como se sabe resultan mucho más agresivos en la práctica (MUÑOZ CONDE, La imputabilidad desde el punto de vista médico y jurídico penal, 1988).

68 Resaltamos que a nuestro juicio el derecho penal no excluye a las personas con discapacidad, sino que les reduce su condición de persona. 
Ahora bien, la opción kantiana evidencia unas ventajas importantes, bastante satisfactorias al tipo de representación social que discierne entre personas buenas y personas malas, siendo éstas las que merecen que el Estado se cierna sobre ellas de forma más violenta. Y con respecto a los inimputables, no es menos correspondiente, pues le sirve a la sociedad para no verse a sí misma cruel, sino por el contrario acogedora con los desprotegidos y hasta dadivosa con quienes precisan de su piedad.

Muñoz expresó la idea de una forma bastante clara, bien que su terreno epistemológico no ha sido el semiótico, hizo consideraciones afines que lo llevaron a sostener, (...) También fuera del derecho penal se emplean expresiones como "tener la culpa", "echar la culpa", "sentirse culpable", etc., que reflejan un sentido parecido, aunque con distinta terminología, al que se da al concepto de "culpabilidad" en derecho penal. Efectivamente, cuando se dice que "alguien tiene la culpa" o que es "culpable de algo" se está aludiendo a la responsabilidad por la realización de un hecho desaprobado. Incluso psicológicamente, la "culpa" como sentimiento es siempre muestra de un pesar por el mal cometido. Antes que la culpa, objetiva o subjetiva, hay, pues, una desaprobación previa de algo que se ha realizado y que no se debería haber realizado, o de algo que no se ha realizado, debiendo haberse realizado. En derecho penal se emplea la expresión "culpabilidad" como el conjunto de condiciones que permite declarar a alguien como culpable o responsable de un delito (...) (MUÑOZ CONDE, Teoría General del Delito, 2013, pp. 119).

Es decir, el sentido social precede al más austero estimado técnico de la responsabilidad basada en la culpabilidad. Lo que es tanto como afirmar, primero es necesario ser socialmente culpable.

Al desconocer este aspecto, esencial a la responsabilidad sancionatoria, la teoría kantiana a un nivel praxiológico cae en la oscuridad. Así lo expresó Muñoz, (...) (...) La norma penal se dirige a individuos capaces de motivarse en su comportamiento por los mandatos normativos. Lo importante no es que el individuo pueda elegir entre varios haceres posibles; lo importante es que la norma penal le motiva con sus mandatos y prohibiciones para que se abstenga de realizar uno de esos varios haceres posibles, que es precisamente el que la norma prohíbe con la amenaza de una pena. A partir de un determinado desarrollo mental, biológico y cultural del individuo, se espera que este pueda motivarse por los mandatos normativos. La evolución cultural y los conocimientos sociológicos, psicológicos y biológicos han permitido fijar en la legislación unos criterios para determinar los casos en los que, a partir de un determinado grado de desarrollo biológico, psíquico y cultural, es posible atribuir al individuo el hecho cometido 


\section{OPPCF}

y hacerle responsable del mismo. El fundamento común a estos criterios que englobamos en el concepto de culpabilidad se encuentra, por tanto, en aquellas facultades que permiten al ser humano participar con sus semejantes, en condiciones de igualdad, en una vida en común pacífica y justamente organizada. La "motivabilidad", la capacidad para reaccionar frente a las exigencias normativas es, según creemos, la facultad humana fundamental que, unida a otras (inteligencia, afectividad, etc.), permite la atribución de una acción a un sujeto $y$, en consecuencia, la exigencia de responsabilidad por la acción por él cometida. Cualquier alteración importante de esa facultad -cualquiera que sea el origen de la misma- deberá determinar la exclusión o, si no es tan importante, la atenuación de la culpabilidad. En estos casos, la tarea del Estado social y democrático de derecho no consiste en castigar a los que no están en posición de poder participar en condiciones de igualdad en la configuración de la vida social, sino en promover las condiciones para que la libertad y la igualdad del individuo y de los grupos en que se integran sean reales y efectivas; remover los obstáculos que impidan o dificulten su plenitud y facilitar la participación de todos los ciudadanos en la vida política, económica y social (art. 9,2 de la Constitución). En una democracia que aspira a ser verdadera y real es necesario desarrollar también un concepto de culpabilidad material, y no puramente formal. Igual que no es suficiente el reconocimiento formal de unos derechos fundamentales si estos careen de contenido (si la mayoría de la población es analfabeta, ¿de qué le sirve el derecho a la información?), tampoco puede ser suficiente, para constatar la culpabilidad de un individuo por el hecho cometido que este haya podido obrar en teoría de una manera distinta a como lo hizo, si no se analizan las razones para entender por qué actuó de una determinada manera y no de otra (...) (2013, pp. 125-126).

Al punto es difícil no sólo una satisfactoria demostración del dolo (MORA NARVÁEZ, 2012), sino el ser o no capaz de entender y adecuar el comportamiento a dicha comprensión, lo cual se resuelve en tramitarlo como algo que opera por cognición más que por indagación, por lo que la demostración termina siendo minimizada y la deducción a instancia del juez o, a quien corresponda declarar la condición de inimputable, maximizada en sustitución de lo que la ciencia difícilmente puede acreditar de forma verificable.

Precisamente, (...) los problemas sistemáticos que plantea la responsabilidad penal de los inimputables, es decir, deja a la teoría jurídica de las medidas de seguridad por fuera del sistema teórico del delito, con algo de candor, como si no existieran, o como si sus problemas se pudieran resolver intuitivamente y caso por caso en un plano pre-dogmático y por ende inseguro y movedizo. Esa primera vía no logra resolver armónicamente la responsabilidad subjetiva de los inimputables, escamoteando el problema con la exigencia de una acusación 
síquica entre la enfermedad y el delito (...) causación que de existir, en el mejor de los casos es indemostrable; presuponiendo una separación ontológica entre imputables e inimputables, de tal alcance que los primeros, y solamente ellos, pueden ser culpables, porque únicamente a ellos les es dado vivir en el reino histórico de la libertad, en tanto que los segundos serían, como dice BETTIOL, "fragmentos de la naturaleza tarada" (...) entes marginados de la historia, privados de la libertad, carentes de voluntad final, incapaces de toda valoración, inidóneos para cometer delitos. (...) (FERNÁNDEZ CARRASQUILLA, 1995, pp.: 198-199).

Dicha fundamentación no es la única que sirve de piso a una cierta versión de la responsabilidad jurídica, como lo sostuvimos, y sus deficiencias han entreabierto la puerta en favor de la opción paralela que fue precisamente la pensada por Hegel, en donde el conocimiento y la voluntad, es decir el dolo y la culpa no son más que condiciones normativas que sirven para concretar la imputación, mientras que cuanto tiene que ver con las personas, dado su rol social, se atiende que tanto se atuvieron a las reglas que lo regulan, y si crearon un riesgo antijurídico controlable o no, y si ello se concretó en un daño penalmente relevante (REYES ALVARADO, 2005).

Tendencia que resulta al menos teóricamente más favorable al tender a atenuar el paralelismo entre personas imputables e inimputables. Al reconocer la discapacidad cognitiva, los roles atribuidos deben ser correspondientes, lo que no conlleva a que sean menos importantes socialmente hablando, y el resquebrajamiento de las expectativas sociales respectivas, implican o pueden implicar la responsabilidad sin importar otro tipo de consideración (OSPINA RAMÍREZ, 2010).

De donde la capacidad de controlarse a sí mismo sea el elemento de la culpabilidad (ROXIN, 1981). Al fin y al cabo, el inimputable es entendido como construcción social y con ello las consecuencias de sus actos. Tal y como lo dijera Zafaroni, (...) comprobada la existencia de un delito, corresponde requerir de la agencia judicial la habilitación de cierto poder punitivo sobre la persona identificada como su sujeto activo. Frente a este requerimiento la agencia tiene la posibilidad de proporcionar una respuesta punitiva (posibilidad de responder o responsabilidad). Al responder con la habilitación del poder punitivo, la agencia judicial se hace responsable por la criminalización del agente. En la perspectiva reductora que se viene desarrollando, se produce una inversión del planteo de responsabilidad: responsable es el estado que, a través de la agencia judicial, responde habilitando poder punitivo y por ende, en términos jurídicos que presuponen los correspondientes límites éticos que le impiden habilitar un poder punitivo intolerablemente irracional es responsables por esta habilitación (...) $(2002$, pp. 875). 
Habiendo "incapaces sanos y capaces enfermos" (ESTRADA SALTOS, 2014), sólo cuando la incapacidad es de tal envergadura que inhabilita la incursión de la agencia judicial, hay propiamente inimputabilidad (ZAFARONI, 2002).

No pondríamos entre dicho que la culpabilidad en tanto concepto es una creación jurídica, así como también los son la responsabilidad, la imputabilidad y la inimputabilidad. Es decir, son signos, hechos institucionales. (...) La culpabilidad no es un fenómeno individual sino social. No es una cualidad de la conducta sino una característica que se le atribuye para poder imputársela a alguien como su autor y hacerle responder por ella.

Es, pues, la sociedad o mejor su Estado representante, producto de la correlación de fuerzas sociales existentes en un momento histórico determinado, quien define los límites de lo culpable y de lo no culpable, de la libertad y de la no libertad.

De ahí se deriva que el concepto de culpabilidad tiene un fundamento social, antes que psicológico, y que no es una categoría abstracta o ahistórica al margen o incluso, como algunos creen, contraria a las finalidades preventivas del derecho penal, sino la culminación de todo un proceso de elaboración conceptual destinado a explicar por qué y para qué, en un momento histórico determinado, se recurre a un medio defensivo de la sociedad tan grave como la pena y en qué medida debe hacerse uso de ese medio (...) (MUÑOZ CONDE, Teoría General del Delito, 2013, pp. 123).

Pero que se trate de signos no puede hacer perder de vista que, en tanto hechos institucionales, son a condición de la vigencia de la creencia social en que descansan. Es decir, la representatividad propia del signo no se satisface porque el derecho los declare como tal, aquí no tienen lugar las transferencias en cuanto a la entidad de verdad del signo.

Es aquí en donde juega un papel determinante la sociedad, pues lo que Searle llamó creencia social, que es lo que llamamos nosotros sentido de justicia, tiene que sostener el signo, y lo que deducimos es que el derecho sancionatorio a través de la construcción sintagmática de los inimputables, lo que hace es otorgarle entidad institucional a un cierto sentido social de justicia que señala la necesidad de reducir la condición de persona a quienes tiene discapacidad cognitiva.

Esto para poder intervenirlos con mayor violencia, sobre la base aparente de protegerlos, lo que hace es realmente protegerse de ellos, y trae rabiosamente todos aquellos casos en que no pudo reducirlos por la vía penal, como eventos de verdaderas bestias, en otro tiempo bárbaros, respecto de quienes no queda otra vía que la autocomposición (El Tiempo, 2019). 


\subsection{CONCRECIÓN DE UN ABORDAJE SEMIÓTICO Y SU INFLUENCIA SOBRE LA JUSTICIA FISCAL}

La responsabilidad es tal vez el signo más distinguido en todo el sistema en que reposan las relaciones entre los individuos de una comunidad. Aun cuando podría decirse que corresponde al derecho, la semiótica se ha encargado de evidenciar que existe una especie de intercambio entre la comunidad en general, y los espacios sociales especializados, entre los que se encuentran el derecho, efectivamente, pero también otros estrechamente ligados como el del control y vigilancia fiscal.

El punto de contacto o sinapsis específica es la justicia. En unos casos, la justicia penal, por ejemplo, en otros, la justicia fiscal. Aun cuando muy recurrentemente fusionadas, emergiendo como un mismo espectro.

Sin duda la responsabilidad es un signo de naturaleza conceptual, vinculado a otros mediante los cuales se logra su semiotización. Es decir, la operación de su función representativa, forjando la construcción específica de realidad social que le corresponde. Es, en palabras de Peirce, correspondería a un interpretante. Lo que la teoría general identifica como polisigno, es decir, un signo hecho de otros signos.

El signo tributario de este efecto -respecto de la responsabilidad, es por antonomasia, la culpabilidad. Surgiendo de ello la llamada responsabilidad subjetiva que, como hemos verificado normativamente, caracteriza a todo el derecho sancionatorio colombiano, en particular el correspondiente a la justicia fiscal.

No obstante, la teoría de respaldo no ha generado los presupuestos de la culpabilidad fiscal, dando paso a la ausencia de una orientación específica al respecto, con el riesgo de acudir a mecanismo de justicia basados en responsabilidad objetiva. Esto es, derivada de una relación sujeto-daño, resuelta nada más que a partir de verificar la existencia del daño, sin que se considere la voluntad y la comprensión de la persona.

Precisamente lo que arroja esta investigación, son los presupuestos teóricos de la culpabilidad fiscal. La cual, semióticamente, es una construcción tanto jurídica como social.

Por ello, uno de los resultados investigativos ha sido una reconstrucción histórica de la culpabilidad, que sirva de fundamento de análisis de las normas como la analizadas en el primer aparte de texto actual.

De donde podamos predicar que, en cuanto tiene que ver con la justicia fiscal, procede de la misma fuente. Es decir, la culpabilidad fiscal debe ser entendida dentro de los límites

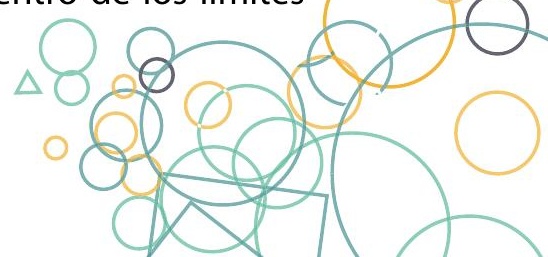




\section{OPPCF}

epistemológicos implicados en el sistema de signos que proceden de la estructura del derecho clásico. Sin duda sistémicamente en sus inicios conforme con el campo de la responsabilidad privada o de lo que hoy llamaríamos derecho privado, y a partir de los trabajos dogmáticos de Kant y de Hegel, mediante los cuales se generalizó hasta cubrir todo el derecho privado y el derecho público, muy acentuadamente el derecho sancionatorio.

El mismo que empezó a adquirir distinción científica justamente cuando se dispuso a la busca de un fundamento epistemológicamente objetivo al castigo social. La ciencia penal, como principal expresión del derecho sancionatorio, estaría inaugurada en tal perspectiva con los trabajos de Paul Johann Anselm von Feuerbach, en cuyo empeño se propuso sistematizar los modelos punitivos, acentuando la prevención general como efecto proveniente del castigo, cuya intensidad consideraba al sujeto como parte del hecho castigable.

El tratamiento hermenéutico concluyó en la muy conocida taxonomía normativa de la culpa. Facilitada sin lugar a duda por la epistemología de base cristiana que, posteriormente fue sofisticada con su identitario aristotélico, conocido comúnmente como escolástica.

Las cosas se dieron muy afortunadas para que la dogmática se apropiara de la culpabilidad, y los resultados son notorios. Fruto de lo cual existen actualmente tres posibilidades a la culpabilidad, ya que manteniendo o no necesariamente, su condición de principalidad, se la reconoce como presupuesto de responsabilidad (art. 9 L. 599/00), como condición de punibilidad (art. 12 L. 599/00) o, como criterio de dosificación: (art. 34 inc. $2^{\circ}$ y 55-61 contradictorio L. 599/00).

En Colombia la ausencia de culpabilidad implica la improcedencia de la sanción, por ello el comportamiento de la persona incapaz, adquiere una definición paralela respecto de su conducta. No obstante, es de advertirse que la posición más defendida es la del Tribunal Constitucional Federal de Alemania, el cual dedujo tratarse de un principio constitucional del modelo Estado Social Democrático y de Derecho (Bundesverfassungsgericht, 2006).

Tras modular la conducta punible por lo que antes eran formas de culpabilidad (art. $21 \mathrm{~L}$ 599/00), la ley penal colombiana implicó una vinculación entre la pena y la forma normativa. Hay una pena para el dolo, otra para la culpa y otra para la preterintención. De tal forma, la culpabilidad se integra al principio nulla poena sine legem.

Lo cual identifica así mismo a la responsabilidad derivada del ejercicio del control y vigilancia fiscal. No sólo porque así se deriva de a Constitución Política, sino porque, el artículo 5 de la Ley 610 de 2000, prescribió que el primer elemento de la responsabilidad fiscal es la demostración 
de una conducta dolosa o culposa atribuible a una persona que realiza gestión fiscal.

Sin embargo, pese a las transfiguraciones de la culpabilidad, sigue siendo un asunto jurisdiccional que, al cabo, termina adquiriendo contenido a instancia de la labor del juzgador, tanto en lo penal como en lo fiscal. ${ }^{69}$ El asunto, como se dijo es, ¿cuál es el origen de ese contenido? Y lo que halla la semiótica es que es fruto del sentido social de justicia.

Es en este punto donde la semiótica interviene. Para empezar, la semiótica reconoce el protagonismo social en materia de justicia. Por ello, es la sociedad la que da contenido a la culpabilidad.

Seguramente pueda ser una respuesta que molesta por igual a hermeneutas y dogmatistas, al sospechar del conocimiento social en materia de responsabilidad en particular, y de justicia en general.

Para explicarlo, lo primero es retornar a lo que la semiótica reconoce como entorno, trasfondo, habitus o instinto de juridicidad y, así mismo, la transvaloración o individuación y, los actos metalocucionarios.

Todo sucede en la iusphera, esto es, donde, entre otros, al semiotizar los signos y ejercer los actos de habla pertinentes, se produce un proceso de apropiación social de las instituciones, para hacer que ellas cumplan sus propias funciones sistémicamente, es decir, integradas a las restantes instituciones, en favor de la identidad y la funcionalidad de la estructura social.

La iusphera es la sociedad en su dimensión de justicia, allí donde se cumplen las funciones dispuestas a favor del sentido social de justicia que una sociedad en particular produce. Si la justicia es una de las tomas de situación mediante las cuales la sociedad hace presa del mundo, esto sucede dentro de una abstracción semiótica que llamamos así.

Precisamente la semiótica de la justicia destaca que una sociedad tiene cuerpo jurídico en la dimensión que le es propia. Se hace manifiesta a través de una de sus más complejas operaciones consistente en crear su propio sentido de justicia. Para que ello sea posible se precisa de un conjunto de capacidades de trasfondo, que hacen posible el cumplimiento de las funciones de la justicia o del derecho, si así se prefiere, y dadas hacen posible el ser jurídico, es decir el ser que procede conforme a un horizonte de sentido constituido por su propia

69 En MOYA VARGAS Manuel Fernando (2007). Los Fallos Penales por Inasistencia Alimentaria. Un desfase entre la ley y la práctica judicial, Universidad Santo Tomás. Bogotá, Colombia, el fenómeno es claramente evidenciado. Los jueces al realizar lo que es llamado, labor de interpretación y valoración probatoria, lo que fuerzan es el contenido mismo de la culpabilidad en casos concretos. Lo que implica que realmente, no demasiado lo que los dogmatistas lograron en comparación con los hermeneutas. La culpabilidad, no obstante alcanzar declaración normativa y/o e principalidad, es una especie de hoyo negro. Los jueces la completan en canto a su contenido, como se dijo. Pero la inquietud al respecto es, y ¿de dónde se extrae ese contenido?

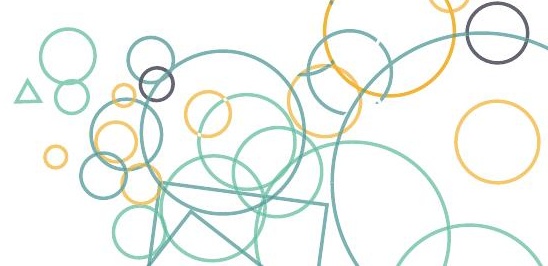


versión de la justicia.

De ahí la familiaridad de los términos empleados: habitus -propio de la teoría de los campos, trasfondo -de la filosofía del lenguaje, entorno -conforme al uso que la sociología hace de él, o instinto de juridicidad que es el acuñado en la semiótica de la justicia.

La misma condición que explica la coexistencia de dos órdenes sociales en la versión tradicional del llamado derecho romano, esto es el paralelismo ius y fas.

El instinto de juridicidad es la condición inmanente que hace posible la dimensión jurídica de la sociedad. Por ello mismo es que desafía y cuestiona la teoría de los campos, pues encuentra verificable la exploración bourdiana, nada más que en el espacio judicial, que es lo que el sociólogo francés llamó campo jurídico. Entre otras consecuencias deriva la semiótica de la justicia, que el derecho no es obra de los técnicos, sino que su función se contrae a las propuestas o a las especificaciones, producto del instinto social de justicia.

La sociedad concursa toda a la producción del sentido de justicia, no a la manera de la idealidad de un contrato social, sino de unas prácticas comunicativas a través de las cuales crea su sentido de justicia, lo transmite y lo retransmite.

En dichos procesos precisamente pone a prueba las propuestas de los técnicos, quienes formulan las instituciones jurídicas, traídas o no de otras experiencias, y la sociedad lo que hace es someterlas a su instinto de juridicidad para ajustarlas a él o rechazarlas.

A este último proceso es lo que llamamos transvaloración o individuación social de las instituciones. Dado que, frente a una institución, una comunidad de hablantes no se neutraliza o deja de ser ella, sino que juega con la institución, y sólo a partir de una especie de ajuste, hará de ésta su propia versión, o la repudiará de su iusphera.

La institución enerva el instinto de justicia y por ello siempre hará algo de la institución, algo propio, para hacer de la institución su institución.

Lo que nos preguntamos en esta ocasión es qué hace una sociedad con la institución de la culpabilidad, más precisamente de la culpabilidad fiscal. Conforme a su proceso de individuación qué implicancias compromete el ponerle su sello de propiedad, qué queda una vez individuada.

En el contexto social suele usarse como sinónimos las expresiones culpabilidad y responsabilidad, pues no es difícil desentrañar el vínculo que subyace al decir que alguien es culpable, en el entendido que debe responder. 
Y es probable que dicho uso se haya enquistado aún más como consecuencia de la oposición que se formula en los medios de comunicación entre culpable ó inocente (MOYA VARGAS, Sentido de Justicia y Proceso Penal, 2018). Pues es muy frecuente tal dicotomía en películas y en programas televisivos en que se representan causas, frecuentemente penales, entre las que suelen ser asociadas las correspondientes al control y vigilancia fiscal. En éstos el señalamiento del culpable equivale al del condenado o condenable.

Esa denotación no parece agotarse sin embargo en lo técnico o, por mejor decir, en su vínculo con la justicia, pues el remanente moral o si se prefiere, teológico redunda con tanta fuerza como lo propiamente jurídico.

De hecho, no es difícil hallar su rastro en textos sagrados, tal como sucede en Levítico 5, 1, (...) Si alguien es llamado a declarar como testigo de algo que vio o escuchó, y se niega a declarar, comete un pecado y debe cargar con la culpa (...) El mismo texto asocia a la culpa la impureza sumada al conocimiento, el error de juramento sobrevenido el conocimiento, y debe haber expiación mediante la penitencia.

Al fin y al cabo, la incomodidad de Herodes respecto del maestro de Nazaret fue, precisamente, no haber hallado culpa alguna en él. Dicha asociación se aproxima bastante a la significación de la culpabilidad, por lo menos en la historia decimonónica del derecho sancionatorio.

Aun cuando a partir del verso 14 del mismo texto, se propicia una asociación entre pecado involuntario y ser culpable de fraude, caso en el cual, es decir, en quien concurran las dos condiciones, debe igualmente expiar su culpa.

Es muy probable que al menos en las sociedades culturizadas a partir de este tipo de presupuesto - la sociedad iberoamericana es la muestra destacada de la culturización cristiana, hayan incorporado la culpa como signo de responsabilidad, más por la ruta religiosa que por la técnica y, acaso la jurídica haya sucedido a la religiosa, y con ello cargado de la significación originalmente aportada.

Y tal vez sea esta la ruta más objetiva -epistemológicamente hablando, para entender el uso social con denotación justificativa o excluyente de responsabilidad de quien, al perder control sobre su feudo intencional, produce efectos reprochables no estimados en la cobertura de su conciencia: fue sin culpa.

La culpabilidad es un signo social que representa la condición de quien debe algo, en términos de castigo. Quien carga con la mácula de culpabilidad se halla en medio de un horizonte de sentido en donde la expiación es la única salida. De hecho, ser culpable implica ser susceptible

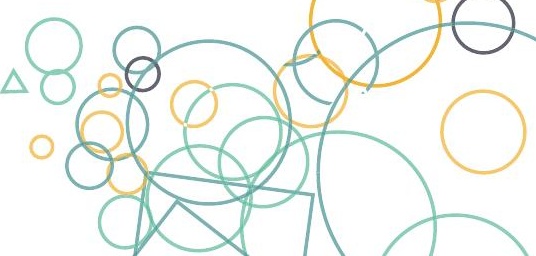


de castigo, y la burla del castigo puede librarlo de la situación estrictamente humana, pero difícilmente se libra de la ira de los dioses. Nada puede resignificar al culpable como el castigo. Con todo, el uso social del signo culpabilidad, conviene tanto a quienes por su propia maldad deben responder, como aquellos que por torpeza o por mala ventura, se encontrarán en situación similar. Es tan culpable el delincuente y el pecador, como aquel quien por la culpa de otro es así mismo responsable, como por ejemplo el padre del hijo delincuente o pecador. Desde este punto de vista, se puede ser culpable sin mayor distancia de la condición de víctima. Pero así sea por abducción, el uso social del signo culpabilidad, descansa en un sistema de relaciones, pues no se es culpable per se ni en sí. Sino que se es culpable de cara a una prohibición y con respecto a alguien, pero hay una autoridad ante la cual se debe responder. La relación sistémica siempre describe los siguientes elementos actanciales:

a. Un mandato de prohibición $(P)$

b. Un efecto de no observar la prohibición $(X)$

c. Un agente susceptible de ser resignificado negativamente $(A)$

d. Una autoridad social (V)

e. La resignificación fruto de la declaratoria de culpabilidad ( $\mathrm{C}=\mathrm{A}-$ )

f. La resignificación fruto del sufrimiento producido por el castigo $(A+)$

Las funciones distinguidas son: si $(A)$ incumple $(P)$, conlleva $(X)$, lo cual por decisión de $(V)$ se convierte en $(C=A-)$, lo que superará volviéndose $(A+)$.

Sin duda la función más contundente es la de $(C=A-)$, se observa así que la culpabilidad es un signo puesto que incorpora una carga significativa de consideración, socialmente hablando, que funciona por referencia.

Efectivamente cumple la función X cuenta como $Y$ en $C$, es decir como todo signo constituye un hecho institucional, puesto que quien es declarado culpable adquiere una significación de la cual antes carecía, consistente en adquirir el significado del responsable.

Para estos efectos, (A) es un hecho bruto en cuanto ser humano que poco o nada significa en términos de responsabilidad, pero mediante el proceso de asignación de sentido, adquiere el significado de culpable, es decir, de responsable. A partir de entonces, él mismo es el estímulus del signo culpabilidad.

Tiene por referente el que hizo $(P)$, y su apremio es el desafío de sujetarse al castigo, para 
adquirir otra resignificación, profundamente vinculada a la expiación.

Aquí el sujeto $(A)$ enfrenta dos procesos: el de convertirse en (A-) y el de convertirse en $(A+)$. Curiosamente ser sólo (A) es el refugio del anonimato -en materia de responsabilidad claro está, puesto que sólo puede llegar a ser $(A+)$ sino a condición de haberse hecho previamente $(A-)$.

Paradójicamente hay más virtud en $(A+)$ que en simplemente $(A)$, y acaso la parábola del hijo pródigo se explique mejor por esta ruta. En efecto, el hijo cumplidor de su deber es sinónimo de normalidad, es decir de aquello que no se ve porque así debe ser, no hace ruido, pues contribuye al silencio moral y al silencio de la justicia, no le importa ni a la moral ni al derecho, y muy seguramente tampoco a la ética. En tanto no interrumpe ninguno de esos estados, tampoco los hace perceptibles, y por eso ellos mismos se desentienden de él.

Pero en cambio, si los interrumpe, si hace ruido, es decir si rompe el silencio jurídico, el moral y/o el ético, los respectivos órdenes se cernirán sobre él resignificándolos conforme a su metacódigos.

El hijo pródigo es quien hace ruido moral, ruido de injusticia o ruido ético, en tanto rompió el silencio, fue resignificado a partir del ruido causado, y su virtud consiste en volver a resignificarse esta vez por encima del hijo anónimo, pues si antes hizo ruido negativo, ahora hace ruido positivo, música de justicia, moral o ética, y ello encanta, lo hace virtuosamente visible, porque lo que ahora interrumpe es lo negativo, la oscuridad, la embriaguez.

Tal vez el proceso pueda describirse como lo hiciera Nietzsche en el Origen de la Tragedia a Partir del Espíritu de la Música: de lo apolíneo se va hacia lo dionisiaco y de éste vuelve a otro orden apolíneo.

No es posible un sistema social sin función sancionatoria. Una de sus máximas autopoiéticas de las cuales depende su autoafirmación. En consecuencia, precisa poder crear sus propios culpables, para poderse restablecer de algo. Los culpables son los agentes verídicos de su autopoiesis. En esto radica la virtud del infractor, del pecador, del delincuente, del hijo pródigo. La valía del culpable arrepentido y reivindicado mediante el castigo se ofrece como ideal desde lo teológico hasta lo jurídico, pese haber propiciado una situación socialmente negativa: la violación de la norma sea en términos de daño antijurídico o simple desobediencia. Por ello la culpabilidad es un signo de negación.

Pero el continuum del culpable se resuelve de otra forma cuando es resignificado por la sociedad. En efecto lo socialmente negativo no tiene por qué serlo invariablemente todos los

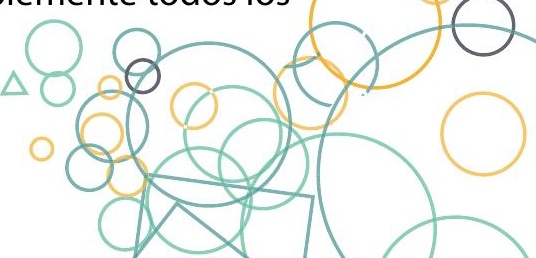




\section{OPPCF}

niveles y aspectos, como lo evidencia la semiótica de la justicia, pues al menos tratándose de culpables la carga de positividad que arrastra el mismo culpable una vez ha sido castigado -o eventualmente justificado, lo resignifica nuevamente.

Que $(A+)$ es socialmente más representativo que meramente $(A)$, lo demuestra el valor otorgado al sufrimiento, la reivindicación suele medirse en término de la intensidad del sufrimiento. No en vano la historia evidencia que cuando el sufrimiento se exacerbó, en términos de visibilidad, la identidad popular con el supliciado resulta en caldo de cultivo para propiciar un modelo de sufrimiento menos visible, más intuitivo, menos ruidoso, y que mantenga los efectos preventivos, pero al tiempo impida la identidad inmediata e inevitable del culpable -castigado, con la sociedad.

Desde luego la figura que los criminólogos designaron etiquetamiento parece desafiar tal conclusión. Por etiquetamiento, no obstante, se ha entendido socio-jurídicamente, el fenómeno mediante el cual se perpetúan los efectos de la condena más allá del término de su ejecución, entre otros mediante rechazo social al conservar asignada la condición de culpable de algo.

Semióticamente -sin embargo, se acentúan ciertos aspectos del fenómeno, pues lo que identifica es la autorreferencialidad de la sentencia, y a partir de ella como algo subsecuente e inevitable, producción de realidad social, de una muy concreta realidad social.

En efecto, la sociedad cuanto hace mediante el etiquetamiento es visibilizar, vivir, experimentar el castigo que decretó, pero que de otro modo le sería absolutamente distante y oculto permear el castigo que las instituciones sancionatorias ocultan.

El infractor es uno de los efectos de la decisión, que bien puede ser una sentencia condenatoria. Es creado a partir de ella, y obsérvese que la creación procede de la sentencia y no de la ejecución de un hecho ilícito necesariamente, pues el etiquetamiento no se condiciona a la verificación de la ocurrencia del hecho y de la participación de la persona del culpable, sino que se asume como dada (MOYA VARGAS, Fundamentos de la Semiótica Jurídica. Hacia una semiótica del derecho penal, 2018).

No por ello el culpable castigado o el culpable arrepentido, es un personaje que posiblemente no sea bienvenido en los escenarios tradicionales.

En el sistema, la culpabilidad no es sinónimo de responsabilidad sino su condición inalienable. Es decir, sólo quien es culpable puede ser responsable.

Penalmente, por ejemplo, el culpable- responsable es el interpretante dinámico respecto 
del culpable social -interpretante final, por ello el efecto preventivo general procede de la estandarización del significado, y ello sólo es posible en la dinámica social, no en la ciencia penal, pues el interpretante inmediato proviene de las afueras del derecho, y depende de la versión de responsabilidad, si es kantiana será el original mal, si es hegeliana el infractor.

Atendiendo al noema del signo original, esto es, al culpable entendido como infractor que debe expiar su culpa, la significación técnica puede o no coincidir con la social. Pues en los escenarios especializados como, por ejemplo, los procesos fiscales, o los procesos penales, son propicios a procesos comunicativos en los que se emplean signos y significados demasiado específicos.

Es decir, el culpable técnicamente hablando, puede coincidir o no con el culpable social. Y normalmente hay convergencia cuando el sentido social permea los límites de saturación de los escenarios técnicos. Sea porque el juzgador lo vehicula, porque hay representación social como en los casos de jurados de conciencia, o porque los expertos dentro de escenarios técnicos hacen uso social de la culpabilidad.

El sentido social de justicia es lo único que puede dar contenido a la culpabilidad. Esta es la incomodidad insuperable a hermeneutas y dogmatistas. No es asunto normativo, técnicamente hablando, ni de principios. Luego no es asunto jurídico. Es algo, como se dijo, metajurídico. Es social, es el producto de los actos de habla en que una comunidad de hablantes emplea el signo culpabilidad, cuya identidad icónica parece incontestable.

Como no es norma, el hermeneuta no pudo reconocerla. Como no es principio constitucional, al dogmatista no le quedó más remedio que otorgarle contenidos que, si bien satisficieron las demandas de la teoría del derecho sancionatorio, nunca han sido praxiológicamente comprobables.

Unos y otros terminaron descargando en los juzgadores la responsabilidad de darle vida a la culpabilidad, pues a través de la norma, no le dieron otra cosa que un cadáver que debían resucitar en el proceso, bajo criterios que desafían la razón y la sensatez, como el conocimiento presunto de la ley, la maldad interior, la voluntad de ilicitud, etc.

Pero no puede dejarse a un lado la solución casi mágica que se obtuvo a través de los procesos acusatorio-adversativos: el jurado de conciencia, el representante social encargado de declarar el veredicto de culpable o inocente.

Si inevitablemente la culpabilidad es de origen social, ¿por qué no reconocerloy otorgar al juezla función de hacer la lectura respectiva? De lo contrario, seguir justificando seudorracionalmente

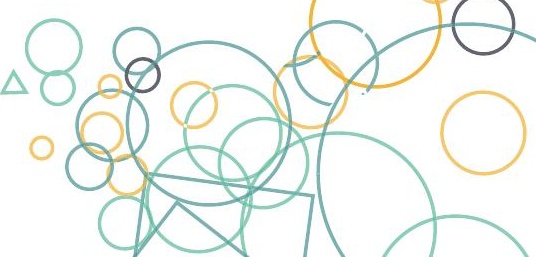


lo que es injustificable, es colocar al juez siempre al acecho de la sospecha y, mantenerlo e la confusión aparentemente superada, en que se hallaron los clásicos.

Ahora bien, como sostuvimos inicialmente, las comunidades forjan su conocimiento de la culpabilidad, al igual que de casi todo lo que es importante a ella, mediante conocimiento que no es inferencial en cuanto deductivo o inductivo. En cambio, lo hace de forma abductiva.

Lo que es el pensamiento de esta naturaleza, Peirce lo explicó en dos párrafos de forma bastante sencilla:

(...) El objeto de razonar es averiguar algo que no conocemos a partir de lo que ya conocemos. Consecuentemente, razonar es bueno si es tal que da lugar a una conclusión verdadera a partir de premisas verdaderas, y no a otra cosa. La cuestión de la validez es así algo puramente de hecho y no de pensamiento. Si A son los hechos enunciados en las premisas y B lo concluido, la cuestión es si estos hechos están relacionados de tal manera que si A entonces generalmente B. Si es así, la inferencia es válida; si no, no. La cuestión no es en lo más mínimo la de si al aceptar la mente las premisas sentimos o no también un impulso a aceptar la conclusión. Es verdad que en general por naturaleza razonamos correctamente. Pero esto es accidental; la conclusión verdadera seguiría siendo verdadera aun cuando careciéramos de todo impulso a aceptarla; y la falsa seguiría siendo falsa, aun cuando no pudiésemos resistir la tendencia a creer en ella. (...)(PEIRCE, 1988, pp. 175).

\section{En precisión del pensamiento abductivo, expuso:}

(...) Hay que adoptar un método nuevo y diferente de establecer opiniones, que no sólo produzca un impulso a creer, sino que decida también cuál es la proposición a creer. Liberemos pues de impedimentos la acción de las preferencias naturales, y que los hombres, bajo la influencia de éstas, conversando unos con otros y considerando las cuestiones bajo perspectivas diferentes, desarrollen gradualmente creencias en armonía con las causas naturales. Este método se parece a aquél mediante el cual han madurado las concepciones artísticas. El ejemplo más perfecto del mismo se encuentra en la historia de la filosofía metafísica. Usualmente los sistemas de este tipo no se han basado en hechos observados, al menos no a un cierto nivel relevante. Básicamente se han adoptado porque sus proposiciones fundamentales parecían "agradables a la razón". Es esta una expresión adecuada; no significa aquello que concuerda con la experiencia, sino aquello que nos encontramos inclinados a creer. Platón, por ejemplo, encuentra agradable a la razón que las distancias unas de otras de las esferas celestes sean proporcionales a las diferentes longitudes de las cuerdas que producen acordes armoniosos. Muchos filósofos han llegado a sus conclusiones fundamentales mediante consideraciones de este tipo; pero esta es la forma más elemental y menos desarrollada que adopta el método, pues está claro que otro puede encontrar como más agradable a su razón la teoría de Kepler de que las esferas celestes son proporcionales a las esferas inscritas y circunscritas de los diferentes sólidos regulares. Pero la contrastación de las opiniones llevará pronto a los hombres a apoyarse en preferencias de naturaleza mucho más universal. Tomemos, por ejemplo, la doctrina de que el hombre sólo actúa egoístamente, es decir, a partir de la consideración de que actuar en un sentido le reportará mayor placer que actuar en otro. Esto no se apoya en hecho alguno, $y$, sin embargo, ha tenido una amplia aceptación hasta ser la única teoría razonable. (...) (PEIRCE, 1988, pp. 179).

Abductivamente lo que hace una sociedad es crear sus propios culpables. No se trata de personas, sino de una cierta condición sígnica asignada a ciertas personas. 
Así como un ícono no sustituye el referente, sino que se predica de él, el signo de la culpabilidad es predicado de ciertas personas, pero no son ellas. Se trata de una condición sígnica adquirida.

Si bien la manifestación institucional corresponde a los jueces en general, y a quienes ejercen la vigilancia y el control fiscal en particular, éstos no pueden hacer otra cosa que tomarla de la comunidad a la cual pertenecen. Lo contrario, es decir, permitir que los jueces crean la culpabilidad, como aparentemente sucede, corre siempre el riesgo inmanente de una especie de tiranía, en la que poco o nada remedia el principio de legalidad, pues el contenido de la culpabilidad, que es el presupuesto de la responsabilidad o de la sanción, lo puede sacar del sombrero de mago una persona.

El derecho no crea expertos en justicia, ni en culpabilidad, como en las escuelas de filosofía o teología no surgen expertos en moral, sino conocedores de ciertos constructos teóricos. De la misma forma, el médico no es la salud, sino alguien que propicia las condiciones para que suceda.

Eso mismo es lo que corresponde al juez en materia de justicia. Es decir, hacer propicias las condiciones de realización en favor de algo que no depende de él.

La aproximación semiótica devela que los culpables son la némesis de la sociedad que los representa. Es así porque entendida como signo, la culpabilidad conviene a una sociedad para hacer presente a la conciencia lo que ella ha decidido no ser, aspecto éste que hace parte de su propio sentido de justicia en la media en que mediante ellos se reafirma en uno de sus valores distintivos -la justicia precisamente, a cuyo propósito se cierne sobre la representación que proyecta su propia negación.

Dicho sentido de justicia es construido y transmitido mediante aquellos procesos comunicativos que tienen por referente a los culpables como [personas]. ${ }^{70}$ Pero que el referente sea actual o potencialmente una persona, no desafía lo dicho ni emparenta las conclusiones semióticas con las hermenéuticas, las dogmáticas ni las socio-jurídicas, pues la óntica del culpable (que es una función sígnica y no una persona), expresa su autorreferencialidad, como quiera que surge de las mismas comunicaciones en que se habla de ellos: no hay culpables sino a condición que se hable de culpables y de esos actos de habla es que surgen los culpables. En suma, si no se habla de culpables, simplemente no los hay.

Semióticamente entendido culpable -antes que una persona determinada en sentido estricto alude al ruido que hace perceptible el silencio de la sociedad, y con él cierta manifestación de su sentido de justicia. La culpabilidad describe una dimensión social que, si bien no necesita

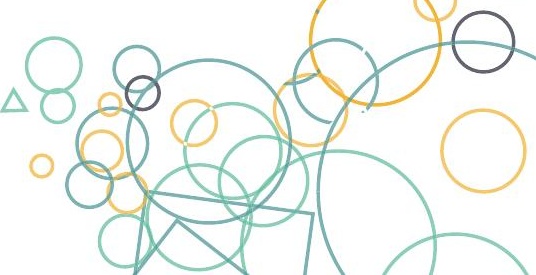




\section{OPPCF}

personalizarse en términos absolutos, en el evento de alcanzar a alguien en particular propicia su re-significación, lo cual por demás es preciso para el cumplimiento de la función de autopoiesis social.

Así que culpable no es sinónimo de persona sino de proceso funcional que revierte en una interrupción necesaria para que se haga manifiesto el sentido social de justicia. Y visto así, la justicia transicional tendría que descubrir su sentido real, y seguramente adquirir condiciones de posibilidad que no se presten a resistencias en términos de justicia material.

\subsection{CONCLUSIONES}

La conclusión más importante alcanzada a lo largo de la investigación parte del presupuesto conforme con el cual, la culpabilidad es un principio constitucional que vincula todo el derecho sancionatorio.

Con base en este presupuesto, se halló que los procesos de vigilancia y control fiscal hacen parte del sistema de derecho sancionatorio. Consecuencia de lo cual, la justicia fiscal manifiesta a través de los procesos de vigilancia y control fiscal, sólo pueden declarar responsables a los culpables fiscales, esto es, a quienes logra demostrárseles que procedieron con dolo o con culpa.

No obstante, lo que se halló es que este es un aspecto, si no ignorado, gravemente descuidado o carente de tratamiento técnico, al interior de los procesos de control y vigilancia fiscal.

Al hacer una reconstrucción de la culpabilidad, de cara a la construcción de una teoría de la culpabilidad fiscal, se halló una categoría que, respecto del derecho sancionatorio, particularmente manifiesto en el derecho penal, ha oscilado entre dos opciones conceptuales. Por una parte, la correspondiente a una condición psicológica del sujeto o agente de la conducta ilícita. Por otra parte, aquella que no encuentra más que una condición normativa.

Al tiempo la concepción del culpable ha estado basculando entre dos opciones extremas: son una creación en sí, es decir seres que "nacieron asi" como cualquier otra persona con cualquier otra característica.

O, por el contrario, son social creados, quiérase o no ver en ellos víctimas de la sociedad. Algunas veces denominados enfermos, otras, divergentes, contraculturales $y$, hasta enemigos, los culpables son seres que precisan ser intervenidos por el Estado, bien para excluirlos o bien para re-incluirlos a la sociedad.

Los métodos que han conducido a tales conclusiones han sido particularmente el hermenéutico y el dogmático. 
Lo que ha llamado la atención en favor de esta investigación, es que dicha prospección científica de la culpabilidad y los culpables, está diseñada sobre un fenómeno paradójicamente, abductivo -en el sentido de Peirce, del cual sin embargo sus métodos no dan cuenta. Es decir, ni es deductivo ni mucho menos inductivo.

Semióticamente se entiende que la abducción es una forma de pensar a partir del fenómeno hacia lo más abstracto con que se vincula el silogismo concreto, y que retorna al mismo para otorgarle una cierta condición de validez -paralela a la inducción y a la deducción, en que a partir de un suceso se forja una explicación atendible, que a su turno debe servir a explicar el fenómeno. Es una idea muy próxima, creemos, a la de instinto de juridicidad, con que hemos explicado el fundamento social de la justicia.

Pues bien, la abducción es una forma de proceder racional, basado en la constitución de explicaciones espontáneas, si se quiere basadas en el instinto social, allí donde hay muchos elementos de pensamiento simplemente dados, no deducidos, no demostrados, ni mucho menos inducidos, sino aceptados como existentes. Por ello tal vez con Peirce pueda concluirse que más que una forma de pensar paralela a la inducción y a la deducción sea más bien una función social primaria.

El presupuesto abductivo respecto a la culpabilidad y a los culpables sirve de plataforma a quien debe producir la decisión de responsabilidad, para identificar culpabilidad y culpables como seres humanos. Bajo condiciones y sólo dentro de ciertos límites jurídicos que, es precisamente lo único que puede aportar el derecho a la teoría de la culpabilidad. Ese ajustamiento ha dado bastante trabajo a los juristas, en busca de un máximo de identidad, llegando a ideas tales como que los inimputables y las personas jurídicas pueden ser responsables sin ser culpables.

Aquí el punto es que culpabilidad y culpable si bien son predicados de seres humanos, no los sustituye.

A partir de la vista semiótica lo que se postula es que esas dos construcciones antes que hacer emerger seres humanos malos o equivocados, para separarlos de los buenos o acertados, más bien se trata de funciones sígnicas sociales y jurídicas, dispuestas a producir cierto tipo de efecto dentro de un sistema social, es decir, no son personas, sino signos cuyas funciones aplicadas hacen que ciertas personas ocupen un lugar social respecto de otras.

En la tradición hermenéutica y dogmática, dichas funciones no sólo se silencian, sino que se sumen en un anonimato que sugiere su inexistencia, pero tal miopía no sólo carece de la capacidad de eliminarlas, sino que antes bien resulta propicia a su operatividad fantasmal y 
descontrolada.

Las distintas teorías en que se basan los métodos ortodoxos del derecho han propuesto fundamentos y efectos diferenciales al tratamiento de la culpabilidad, lo cual sugiere alguna inestabilidad histórica de los conceptos. Aspecto concreto que pese ser importante, no es algo que interese demasiado a esta investigación, cuya principal cualidad consiste en tomar distancia de los métodos tradicionales, y a partir de la semiótica de la justicia, descubrir lo que en cambio encubren o ignoran los demás.

Es así como se ha encontrado que culpabilidad y culpables, a diferencia de lo formulado hasta el momento, antes que personas, se trata de constructos sígnicos que cumplen unas funciones precisas, tanto jurídicas como no jurídicas, favorables -si no necesarias, al proceso de construcción social del sentido de justicia.

A esta conclusión se arriba tras verificar el uso lingüístico que de la palabra culpabilidad hace la sociedad en general y, dentro de escenarios cotidianos -normalmente no judiciales, acentuada por una denotación semántica profundamente vinculada a la de responsabilidad. Se evidencia un proceso comunicativo y de construcción de sentido, inevitablemente.

Sin duda es manifestación de un uso semióticamente considerable -el que hace la sociedad de estos signos, actuados en la realidad social que irrumpe, en las funciones eidéticas que opera $y$, en su contribución al sentido social de justicia que construye y comunica.

Este proceso no sucede necesariamente dentro del espacio judicial o, si se prefiere con Bourdieu, dentro del campo jurídico. Sin duda, hay más culpables fuera del circuito judicial que dentro de él; más responsables en las calles que en las cárceles; y todavía más culpables completamente anónimos, potenciales o virtuales, respecto de los cuales ni siquiera se sabe si se trata de personas.

Si bien esta condición sería interpretada por la hermenéutica y la dogmática como disfunción, puede servir a efectos sociales apreciables que en sí no son nada disfuncionales, conforme lo revela la semiótica de la justicia.

Claro está, el culpable técnicamente hablando no es precisa e inevitablemente el mismo culpable social, y tampoco la intensidad de la culpabilidad técnica corresponde con la intensidad de la culpabilidad social. Se encuentran en un punto sustancial: el sentido social de justicia, y es entonces donde se "compensan", o mejor, se individua lo jurídico transformándose en social, con ello en justicia.

El instinto social de juridicidad no abdica ante los técnicos del derecho, y siempre hará de 
lo jurídico algo favorable a él aun cuando el resultado desafíe lo más granado de la ciencia del derecho en su versión hermenéutica, dogmática o socio-jurídica. Prueba de lo cual es el fenómeno del etiquetamiento, que bien entendido es una expresión del proceso de individuación social del derecho penal, y en manera alguna el azar incontestable de una sociedad adolescente. No todo condenado es socialmente etiquetado, precisamente por el tipo de re-significación al que es sometida la figura en particular.

Puede haber confusión debido a que la ciencia jurídica emplea los mismos signos y además también los vincula, y a despecho de los tecnócratas, siempre sucederá el encuentro con el instinto social de justicia, como dijimos, en ese punto crucial que es el sentido de justicia. En los escenarios técnicos -como el judicial o el académico, y en los que no lo son también, responsabilidad, culpabilidad y culpables, son la expresión sintáctica de signos cuyas funciones proposicionales pueden variar de unos escenarios a otros, pero coinciden también en que se construyen y transmiten mediante procesos comunicativos, en unos técnicos y en otros no.

Las coincidencias -no pocas evidentemente, sugieren una cierta identidad, pero la realidad social desafía - performa?, la estabilidad originaria o ideal de las instituciones. La diferencia radical más que un paralelismo revela una antinomia, pues mientras el derecho asigna a la culpabilidad una función predominante de negación, la sociedad la resuelve en favor de su propia autoafirmación.

Ahora bien, la semiótica de la justicia desvanece la duda relacionada, ¿lo jurídico logra superponerse a lo social? Pues tiene claro que los procesos de individuación propician un tipo de ajuste de lo jurídico a lo social, dentro del contexto demarcado por el trasfondo jurídico o instinto de juridicidad.

Desde que se concibió la culpabilidad, pese al esfuerzo histórico por desligarla de su contenido social, ha resultado inevitable que sea la sociedad la que le otorga contenido.

Esto implica que, si la justicia fiscal se tiene que basar en la culpabilidad, para poder declarar a alguien como responsable, el contenido material de la culpabilidad, debe ser entendido socialmente.

Y ese contenido debe derivarse de lo que la sociedad entiende que deben ser y hacer los ejecutores del gasto público. Es decir, la medida de su culpabilidad conviene a una cierta representación social que, sólo puede negarse cuando intervienen circunstancias que lo hacen improbable. Como, por ejemplo, cuando se hace imposible la vigilancia y el control fiscal como consecuencia de la falta de recursos. 


\section{OPPCF}

De hecho, en desarrollo de la presente investigación, se consideró el tratamiento con que se circuló la información asociada al control y vigilancia fiscal por parte de los medios de comunicación.

Básicamente se caracterizó porque se basó en la experiencia del daño fiscal. Significando con ello, que ante todo se mostraron resultados negativos sobre el presupuesto público, derivado de delitos, negligencia, incumplimientos de obras, inexistencia de las mismas pese haber pagado, etc.

Casi todas estas expresiones fueron siendo comprimidas bajo la palabra "corrupción". Y más aún, con frecuencia se compararon datos como, por ejemplo, lo que pierde el Estado por efecto de financiamiento de la guerra contrainsurgente, de cara a la corrupción, para evidenciar que el daño más grave que sufre la sociedad, es precisamente la corrupción.

La mayor parte de las noticias, no hicieron referencia a la función de la vigilancia y el control fiscal, aun cuando a veces refirieron que la frente de información fueron las autoridades que la ejercen.

Las expresiones sociales que rodearon los fenómenos evidencian una cierta postura social que, por cierto, sugieren que la comunidad reclama un perfil específico para los ejecutores del gasto público y, en la misma medida, un nivel de exigibilidad de responsabilidad mayor.

Es este tipo de condiciones las que deben proporcionarle contenido a la culpabilidad implicada en la justicia fiscal.

Desde luego, el OPPCF debe propender por establecer las principales características, para proporcionar a los funcionarios encargados de declarar la responsabilidad fiscal, de elementos de juicio favorables a una metodología de investigación y valoración probatoria. Sin perder de vista que un proceso de vigilancia y control fiscal, inconsulto del principio constitucional de culpabilidad, cae dentro de los límites de la ilicitud y de la ilegalidad.

Debiendo demostrar la culpabilidad, se precisa de elementos teóricos de juicio que permitan orientarlos acerca del contenido de la culpabilidad, para alcanzar estándares de justicia más afines a la Constitución, al derecho internacional y, a la sociedad.

\subsection{REFERENCIAS BIBLIOGRÁFICAS}

- Bernal Torres, C. A. (2006). Metodología de la investigación para administración, economía, humanidades y ciencias sociales. Pearson Educación.

Alcaldía Distrital de Bogotá D.C. 2017. Decreto 689 de 2011. Por medio del cual se adopta 
la “Guía para la formulación e implementación de políticas públicas del Distrito.

- Haranguş, D., \& Dudă-Dăianu, D. (2013). Impact assessment of Public Relations in the Fiscal Control Management of the National Agency for Fiscal Administration. Journal Of Economics \& Business Research, 19(2), 34-43.

- DNP. (25 de Julio de 2014). Funciones DNP. Portal del Departamento Nacional de Planeación: https://www.dnp.gov.co/DNPN/la-entidad/funciones-dnp

- Auditoría General de la República. - Ossa, Carlos (2006). Reformar el Control Fiscal Territorial.

- Contraloría General de la República. Informe de gestión al Congreso y al Presidente de la República 2016-2017. Recuperado de: http://contraloria.gov.co

- Gómez Lee, I. D. (2006). Control fiscal y seguridad jurídica gubernamental. Universidad Externado de Colombia.

- Blöchliger, H.,\& King, D. (2006). Fiscalautonomy ofsub-centralgovernments. En, https://www. oecd-ilibrary.org/taxation/fiscal-autonomy-of-sub-central-governments_5k97b127pc0ten.

- Auditoría General de la República y Banco Mundial (2011). Sistema Nacional de Control Fiscal Territorial en Colombia". Imprenta Nacional.

- Auditoría General de la República - Peláez, Juan., Tuta, Guillermo y García., Gustavo (2013). La Impostergable Reingeniería del Control Fiscal Territorial. Documento para el debate sobre una política pública del control fiscal. Revista Sindéresis.

- Semana.com (14 de septiembre de 2018 ). Los retos socioeconómicos del presidente Iván Duque con el Litoral Pacífico. Recuperado: https://www.semana.com/opinion/articulo/losretos-socioeconomicos-del-presidente-ivan-duque-con-el-litoral-pacifico/582940

- Auditoría General de la República, 2002. El Nuevo Sistema de Control Fiscal Colombiano Sinopsis. Separata especial. Revista Sindéresis.

- Auditoría General de la República. - Ossa, Carlos (2006). Reformar el Control Fiscal Territorial. Necesidad inaplazable para optimizar las finanzas territoriales. Revista Sindéresis

- Auditoría General de la República. Rendón, Álvaro- Suárez, Daniel (2001). Bases para un Nuevo Modelo de Control en Colombia. Ponencias II Foro Nacional de Control.

- Base de datos: Auditoría General de la República SIREL-SIA. (2017). Generada en noviembre de 2017. 


\section{OPPCF}

- Carvajal, L. y Amaya, R. (2004). Colombia e Indonesia: lejanía geográfica, cercanía temática (un ejercicio comparativo**. Bogotá, Colombia: Embajada de Indonesia en Colombia.

- Contraloría denuncia billonarios sobrecostos en Reficar. (26 de enero de 2016) El Espectador. Recuperado de http://www.elespectador.com/

- Comisión Nacional Ciudadana para la Lucha Contra la Corrupción (2014). Cuarto Informe de la CNCLCC: «Ciudadanía califica la corrupción como uno de los problemas más graves que enfrenta el país». Bogotá, Colombia. Recuperado de: http://ciudadanoscontralacorrupcion. org

- Contraloría General de la República. Informe de gestión al Congreso y al Presidente de la República 2016-2017. Recuperado de: http://contraloria.gov.co

- DANE (2017). Resultados de la Encuesta de Cultura Política 2017. Bogotá, Colombia: DANE. Recuperado de: http://www.dane.gov.co

- Diaz, Camilo (16 de enero de 2016). La locura de vender Isagén costará \$70.000 millones. Revista Dinero. Recuperado de http://www.dinero.com

- ¿Funcionará el proyecto de pagar a quienes denuncien corrupción? (3 de marzo de 2017)

- Contraloría denuncia billonarios sobrecostos en Reficar. (26 de enero de 2016) El Pais.com. co. Recuperado de http://www.elpais.com.co

- Gómez, Iván Darío, Céspedes, Fredy (2017) Reestructuración y Fortalecimiento del Control Fiscal. Propuesta para la reforma del control fiscal en Colombia. Documento de trabajo.

- Gómez, Iván Darío, Ordóñez, Tatiana (2010). Vulnerabilidad y Sofisticada Corrupción: Desafío para la Auditoría Gubernamental en Colombia. Revista Internacional LEGIS de Contabilidad y Auditoría (44), 17-36.

- Informe de ponencia para primer debate al proyecto de acto legislativo 072 de 2013 cámara. (2013). Recuperado de http://www.imprenta.gov.co/gacetap/gaceta.indice?v_ num $=825 \&$ v_anog $=2013$

- López, Clara (2006). Control Fiscal Territorial. Realidad y propuesta de Mejoramiento. Bogotá. Universidad del Rosario-GTZ.

López, Clara (2013). Colombia, un país diferente. Las 2 orillas. Recuperado de: https://www. las2orillas.co

- Ministerio de Tecnologías de Información programa Gobierno en Línea y Auditoría 
General de la República (2012). Documento propuesta de Procesos y Procedimientos para el Nuevo Esquema de Control Fiscal en Línea.

- Naranjo, Rodrigo. (2007) Eficacia del Control Fiscal en Colombia. Derecho Comparado, Historia, Micro organizaciones e Instituciones. Universidad del Rosario.

- Ochoa, Héctor, Charris, Sandra. (2003) Propuesta de un Modelo de Control Fiscal para el Estado Colombiano: El Sistema de Control Fiscal Nacional. ICESI Estudios Gerenciales, (89)

- Olken, B. (2007). Monitoring Corruption: Evidence from a Field Experiment in Indonesia. Boston, USA: Harvard University and National Bureau of Economic Research.

- Organización Internacional de las Entidades Fiscalizadoras Superiores OLACEFS (2007). Declaración de México sobre independencia de las EFS (ISAll-10). Recuperado de http// www.intosai.org

- Organización Internacional de las Entidades Fiscalizadoras Superiores OLACEFS (2009). Declaración de Asunción Principios sobre Rendición de Cuentas. Recuperado de http// https://www.agn.gov.ar

- Organización Internacional de las Entidades Fiscalizadoras Superiores OLACEFS (2014). Buenas prácticas para el fortalecimiento de las relaciones entre las EFS y la Ciudadanía.

- Recuperado de http://www.olacefs.com

- Ordóñez, Tatiana (2007). La Responsabilidad Fiscal en Colombia y la Imposibilidad del Resarcimiento Patrimonial. Revista IUSTA Universidad Santo Tomas. 1 (26), 126

- Real Academia Española. (2001). Diccionario de la lengua española (22.aed.). Consultado en http://www.rae.es/rae.html

- Restrepo, M., Araujo, R y Tuta, G. Control Fiscal Territorial. Validación de un modelo de la gestión y los resultados de las contralorías territoriales en Colombia. Universidad del Rosario, Agencia de Cooperación Técnica Alemana GTZ, Bogotá.

- Semana en vivo (10 de febrero de 2016). ¿Cuánto fue realmente lo que se robaron en Reficar?

- Saqueo de la corrupción equivale a casi un billón de pesos por semana. (26 de febrero de 2017) El Tiempo. Recuperado de http://www.eltiempo.com/ 


\section{CAPITULO VII}

\section{ESTRUCTURA Y FORTALECIMIENTO DEL CONTROL FISCAL TERRITORIAL - DIAGNÓSTICO Y PROPUESTA ${ }^{71}$}

\section{STRUCTURE AND STRENGTHENING OF TERRITORIAL FISCAL CONTROL - DIAGNOSIS AND PROPOSAL}

Coautores:

Juan Diego Doncel Ramírez. Administrador de Empresas de la Universidad Pedagógica y Tecnológica de Colombia UPTC. Especialista en Gobierno Municipal de la Universidad Javeriana, Especialista en Control Organizacional y de Gestión de la Universidad de los Andes, Especialista en Gestión Pública de la Escuela Superior de Administración Pública ESAP. Profesional Especializado Auditoría Auxiliar AGR.

Tatiana Ordóñez Vásquez. Abogada de la Universidad del Rosario. Magister en Derecho Administrativo de la Universidad Militar, Especialista en Instituciones Jurídico-Procesales de la Universidad Nacional de Colombia y Especialista en Derecho Administrativo de la Universidad Santo Tomás. Profesional Especializado Auditoría Auxiliar AGR. Docente de posgrado, e investigadora del "Observatorio de Política Pública del Control Fiscal" adscrito -según convenioa la Auditoría General de la República y la Universidad Santo Tomás de Bogotá.

Liliana Patricia Ortiz Ospino, Ingeniera Industrial de la Universidad del Norte, Magíster en

71 Documento elaborado en diciembre de 2017 por un equipo de especialistas de la Auditoría General de la República - AGR, con la colaboración de los doctores Guillermo E. Tuta y Gustavo A. Escudero; y presentado al CONPES en desarrollo del compromiso adquirido por la entidad. 
Políticas Públicas de la Universidad de los Andes y Especialista en Gerencia y Gestión Cultural de la Universidad del Rosario. Docente investigador de pregrado y posgrado y Profesional Especializado Oficina de Estudios Especiales y Apoyo Técnico de la AGR e investigadora del "Observatorio de Política Pública del Control Fiscal" adscrito -según convenio- a la Auditoría General de la República y la Universidad Santo Tomás de Bogotá.

Ana Esther Tovar Porras. Administradora Pública de la Escuela Superior de Administración Pública ESAP, Especialista en Planeación Estratégica del Control interno de la Universidad Libre. Asesora del Despacho del Auditor General de la República.

Armando Rodríguez Ángel. Administrador Público de la Escuela Superior de Administración Pública ESAP, Especialista en Finanzas de la Universidad del Rosario, y Especialista en Presupuesto también de la ESAP. Asesor del Despacho del Auditor General de la República.

Ximena Salazar Quintero. Ingeniera industrial de la Universidad del Norte, Especialista en Gerencia de Proyectos de Ingeniería de la Universidad EAN. Asesora del Despacho del Auditor General de la República.

\section{Resumen}

Varios estudios propiciados por la academia, la Auditoría General de la República (AGR), otros órganos de control fiscal del nivel nacional y territorial, y organismos multilaterales como el Banco Mundial, además de deliberaciones y conclusiones de diversos foros y eventos técnicos, han dado cuenta de la perentoria necesidad de fortalecer el control fiscal en Colombia, particularmente, en lo atinente al control fiscal territorial como elemento fundamental de la descentralización y de la democracia local.

El objetivo de este documento fue “Desarrollar una evaluación y propuesta sobre la estructura del control fiscal territorial", compromiso adquirido por la Auditoría General de la República (AGR) en el CONPES 167 de 2013, actividad número 110 (5.20) del componente principal de la Política Pública Integral Anticorrupción (PPIA).

En consecuencia, desde una mirada eminentemente técnica, se propusieron en diciembre de 2017 estos elementos de análisis, para ordenar el debate de la agenda pública, en la medida en que la reforma sustancial en materia de control fiscal, como la que se plantea, requiere ilustración técnica, no obstante tener un carácter esencialmente político e interesar al conjunto de la sociedad. 
No obstante contener propuestas elaboradas en diciembre de 2017, cobra especial relevancia el texto dado que fue tenido como insumo para las discusiones que en el seno del Congreso de la República implicó la expedición del Acto Legislativo 04 de 18 de septiembre de 2019, por el cual se reforma el control fiscal colombiano.

En consecuencia, las 12 principales propuestas que hasta diciembre de 2017 había venido acopiando, sistematizando y propiciando la Auditoría General de la República como organismo de control fiscal de segundo nivel, en su condición de auditora de los contralores; basadas en diagnósticos recurrentes y actualizados, y que se sintetizan, a título de hipótesis, así: 1) Corregir la estructura difusa del control fiscal; 2) Otorgar la función preventiva al control fiscal; 3) Medidas para mejorar el resarcimiento del daño al patrimonio público; 4) Garantizar la autonomía de los órganos de control fiscal territorial; 5) Un nuevo modo de cálculo presupuestal para las contralorías territoriales; 6) Superar la fractura entre el control fiscal interno y el control fiscal externo; 7) Desarrollar la carrera administrativa especial en las contralorías territoriales; 8) Fortalecer la capacidad sancionatoria de las contralorías territoriales y de la AGR; 9) Medición de resultados beneficios del control fiscal; 10) Tecnología para mejorar la calidad y cobertura del control; 11) Control social para el fortalecimiento del control fiscal, y finalmente 12) Ampliación del periodo constitucional del Auditor General de la República.

\section{Abstract}

Several studies promoted by the academy, the General Audit Office of the Republic (AGR), other fiscal control bodies of the national and territorial level, and multilateral organizations such as the World Bank, in addition to deliberations and conclusions of many forums and technical events, have realized the urgent need to strengthen Colombian fiscal control, particularly as regards territorial fiscal control as a fundamental element of decentralization and local democracy.

The objective of this document was"to develop an evaluation and a proposal on the structure of territorial fiscal control", a commitment acquired by the General Audit of the Republic (AGR) in CONPES 167 of 2013, activity number 110 (5.20) of the main component of the Comprehensive Public Anti-Corruption Policy (PPIA).

Consequently, from an eminently technical perspective, these elements of analysis were proposed in December 2017, to order the debate on the public agenda, to the extent that substantial tax control reform, such as the one proposed, requires technical illustration, despite having an essentially political character and interest the whole society. 
Despite containing this proposals made in December 2017, the text is particularly relevant since it was taken as input for the discussions that within the Congress of the Republic involved the issuance of Legislative Act 04 of September 18, 2019, whereby Colombian fiscal control is reformed.

Consequently, the 12 main proposals that until December 2017 had been collecting, systematizing and propitiating the General Audit of the Republic as a second level fiscal control body, in its capacity as auditor of the comptrollers; based on recurrent and updated diagnoses, and which are synthesized, by way of hypothesis, as follows: 1) Correct the diffuse structure of fiscal control; 2) Grant the preventive function to the fiscal control; 3) Measures to improve compensation for damage to public assets; 4) Guarantee the autonomy of the territorial fiscal control bodies; 5) A new mode of budgetary calculation for territorial comptrollers; 6 ) Overcome the fracture between internal fiscal control and external fiscal control; 7) Develop the special administrative career in the territorial comptrollers; 8) Strengthen the sanctioning capacity of territorial controllers and the AGR; 9) Measuring results benefits of fiscal control; 10) Technology to improve the quality and coverage of the control; 11) Social control to strengthen fiscal control, and finally 12) Extension of the constitutional period of the Auditor General of the Republic.

\section{Palabras clave}

Control fiscal, control social, estructura del control fiscal territorial.

\section{Keywords}

Fiscal control, internal control, social control, structure of territorial fiscal control

Temario: Introducción. 7.1. Contexto y diagnóstico. 7.2. Diagnóstico y propuesta de solución 7.3. Conclusiones. 7.4. Lista de referencias

\section{Introducción}

Con el objeto de "Desarrollar una evaluación y propuesta sobre la estructura del control fiscal territorial", para atender el compromiso adquirido por la Auditoría General de la República (AGR) en el CONPES 167 de 2013, actividad número 110 (5.20) del componente principal de la Política Pública Integral Anticorrupción (PPIA); desde una mirada eminentemente técnica, se propusieron en diciembre de 2017 elementos de análisis, para ordenar el debate de la agenda pública, a título de ilustración técnica como insumo para una reforma sustancial en materia de control fiscal, que no obstante tener un carácter esencialmente político, interesa a toda la 


\section{OPPCF}

sociedad.

El 9 de diciembre de 2013, en conmemoración del día mundial de lucha anticorrupción, se expidió el Documento CONPES 167 de 2013 “Estrategia Nacional de la Política Pública Integral Anticorrupción", con el objetivo principal de fortalecer las herramientas y mecanismos institucionales para la prevención, investigación y sanción de la corrupción en el país, mediante cinco (5) estrategias:

- Mejorar el acceso y la calidad de la información pública para prevenir la corrupción.

- Mejorar las herramientas de gestión pública para prevenir la corrupción.

- Aumentar la incidencia del control social en la lucha contra la corrupción

- Promover la integridad y la cultura de la legalidad en el Estado y la sociedad.

- Reducir la impunidad en actos de corrupción.

En el numeral VIII del Documento CONPES 167 se recomendaba, entre otras acciones:

11. Sugerir a la Fiscalía General de la Nación, a la Procuraduría General de la Nación y a la Auditoría General de la República contribuir con el mejoramiento del acceso y la calidad de la información pública para la prevención de la corrupción.

12. Sugerir a la Procuraduría General de la Nación y a la Auditoría General de la República, adelantar gestiones para mejorar las herramientas de gestión pública, promover el control social, la integridad y la cultura de la legalidad en el Estado y la sociedad, conforme a lo establecido en el plan de acción. (Resaltado fuera del texto)

El Plan de Acción del CONPES 167 contenía 110 acciones concertadas con entidades y dependencias del ejecutivo nacional y órganos de control con sus respectivos indicadores de cumplimiento, metas, plazos y responsables.

En ese sentido, la Auditoría General de la República (AGR), asumió el compromiso señalado en la acción número 110 (5.20) consistente en “Desarrollar una evaluación y propuesta sobre la estructura del control fiscal territorial".

El documento contiene los resultados de la evaluación, con apoyo en diversos estudios y propuestas de la academia, organismos multilaterales y otras autoridades en el tema, así como de contralorías. Fue elaborado por especialistas de distintas disciplinas profesionales, formación y experiencias en materia de control fiscal.

Para ello, también se hizo referencia a los compromisos de otras entidades con relación al control fiscal y que han sido incorporadas al plan de acción del Documento CONPES 167, porque son fundamentales para garantizar una óptima "estructura del control fiscal territorial" 
y complementan los compromisos de la AGR frente al tema bajo su responsabilidad.

En efecto, el Plan de Acción del Documento CONPES incluyó, entre otras, las siguientes acciones, que directa o indirectamente inciden en la "estructura del control fiscal territorial", en su eficiencia y efectividad:

1.17 Desarrollar plataforma tecnológica integrada para el ejercicio de la función fiscalizadora - según lo dispuesto el artículo 126 de la Ley 1474 de 2011 (Estatuto Anticorrupción). Integración de Sistemas de Información para el control fiscal. (AGR)

2.4 Presentar un proyecto de ley para crear la carrera administrativa de las contralorías territoriales y modificar la forma de elección de los contralores territoriales, para garantizar la transparencia de dichos procesos. (Mininterior)

2.32 Promover y desarrollar estudios técnicos y metodologías para el ejercicio de control y vigilancia de los recursos públicos. (AGR)

5.3 Elaborar una ruta crítica para lograr mayor efectividad en la recuperación de activos producto de hechos de corrupción. (DAPRE-Secretaría de Transparencia)

5.15 Realizar una mesa técnica con las entidades competentes para elaborar una propuesta de articulación de sistemas de información de los procesos penales, fiscales y disciplinarios. (DAPRE. Secretaría de Transparencia)

5.20 Desarrollar una evaluación y propuesta sobre la estructura del control fiscal territorial. (AGR). Las referencias a las entidades responsables en cursiva no hacen parte del texto.

Aunque una primera lectura y estudio de la política anticorrupción incorporada en el Documento CONPES 167 permite concluir un acertado enfoque preventivo, éste es un elemento ausente en las normas que regulan los órganos de control fiscal.

Por ejemplo, el Ministerio Público dispone de facultades preventivas, mientras que el control fiscal en Colombia, por disposición constitucional es posterior y selectivo (Const., 1991, art. 267), de manera que solo puede pronunciarse una vez culminadas las diferentes actividades, operaciones y procesos, según lo ordena la Ley 42 de 1993.

Artículo $5^{\circ}$. Para efecto del artículo 267 de la Constitución Nacional se entiende por control posterior la vigilancia de las actividades, operaciones y procesos ejecutados por los sujetos de control y de los resultados obtenidos por los mismos. Por control selectivo se entiende la elección mediante un procedimiento técnico de una muestra representativa de recursos, cuentas, operaciones o actividades para obtener conclusiones sobre el universo respectivo en el desarrollo del control fiscal.

La necesidad de un enfoque preventivo del control fiscal constituye un elemento fundamental para la efectividad de esta función pública en la lucha contra la corrupción.

De persistir el enfoque actual, las contralorías del país seguirán condenadas a fungir como notarios de los descalabros patrimoniales, máxime cuando la mayoría de los casos emblemáticos de corrupción demuestran que el daño al patrimonio público en lo fundamental 
es irreparable, como se verá líneas adelante.

El tema de la estructura del control fiscal, también se enfrenta a problemas como la ausencia de autonomía presupuestal, la falta de independencia frente a los vigilados, la forma de elección de los contralores, la demora en la reglamentación de la carrera administrativa especial de los servidores públicos de las contralorías, entre otros asuntos que el presente documento aborda de manera integral y sistémica, como requisito para la construcción de un verdadero y eficiente Sistema Nacional - Territorial del control fiscal colombiano, tarea pendiente en la legislación y en la práctica de tan importante función pública.

\subsection{CONTEXTO Y DIAGNÓSTICO}

En el último trimestre de 2017 el debate público frente a las elecciones para Presidente y Congreso de la República, se ha venido centrando cada vez con mayor fuerza en el tema de la corrupción. Es claro que resulta complicado hacer aproximaciones sobre la cuantía que todos los días pasa de los presupuestos públicos a hinchar los bolsillos de los corruptos. Según el Contralor General, Edgardo Maya: "este flagelo le cuesta al país 50 billones de pesos al año: vale decir, casi un billón de pesos por semana" (El Tiempo, 2017).

Cifra que todavía estaría muy por debajo de la realidad, pues no se aclara si ese valor incluye lo que se perdió en la Refinería de Cartagena -REFICAR, que tuvo sobrecostos por encima de cuatro mil millones de dólares (El Espectador, 2016), parte de los cuales se perdió por corrupción. O lo que significó la reciente venta de ISAGEN como pérdida de un activo muy productivo para la Nación.(Revista Dinero, 2016).Tampoco se informa sobre lo que se pierde todos los días por el incuantificable daño ambiental, incluido el que genera la explotación irracional de los recursos naturales, que constituye una forma de usufructo legalizado contra el interés general, por parte de las grandes compañías transnacionales de la mega minería y también por la explotación ilegal de empresas mineras en cabeza de distintas mafias que operan en los territorios.

Hace poco más de un año, comenzaron a regir los nuevos planes de desarrollo en cada uno de los 1.102 municipios y 32 departamentos que tiene Colombia, para el período junio 2016 - mayo 2020, planes que se ejecutan a través de los presupuestos de inversión anuales, especialmente mediante la figura de la contratación pública. Y aquí también la corrupción hace su agosto, sin medidas de control efectivas en las distintas etapas del proceso de ejecución de los programas y proyectos.

Naturalmente que ese fenómeno de la corrupción es global, multidimensional y generalizado; 
abarca las distintas ramas del poder público y también a los particulares. No es un fenómeno que involucra exclusivamente causales como la ausencia de controles, entre ellos el control fiscal. Pero digamos sin temor a equivocarnos, que el modelo de control fiscal en Colombia, los organismos que lo ejercen, las normas y políticas que lo rigen son funcionales a un modelo perverso de des-administración que propicia la corrupción, pues carece de instrumentos legales preventivos y de herramientas oportunas para detectar y evitar el daño patrimonial.

En efecto, el modelo de control fiscal al manejo de los recursos públicos no es independiente de sus vigilados, no controla con eficacia, eficiencia ni efectividad porque no puede legalmente "advertir" o comunicar alertas tempranas que prevengan el daño al erario público. Ni siquiera puede operar como un sistema cohesionado con políticas que orienten su efectividad, porque ha sido ideado por quienes diseñan y adoptan las políticas públicas con el criterio de no "entorpecer" la gestión de la administración y de los particulares que manejan los recursos públicos. Y entonces, solamente puede examinar y pronunciarse tardíamente, una vez ejecutadas las distintas actividades, operaciones y procesos administrativos.

De este modelo de control se están aprovechando los intereses particulares de aquellos para quienes "todo vale" a la hora de incrementar sus ingresos, así sea de manera dolosa. Aquellos que tienen como objetivo aumentar sus tasas de ganancia, sin ningún escrúpulo ni asomo ético.

De igual forma, el modelo de "administración" del patrimonio público se ha venido deformando de manera preocupante, hasta límites insospechados, donde hoy, algunas acciones y políticas adoptadas por quienes deberían proteger los recursos públicos y el interés general -como lo ordena la Constitución- favorecen y apadrinan las más oscuras transacciones (caso Odebrecht, entre tantos otros), debilitando al máximo las instituciones del Estado. Pareciera que estuviese emergiendo una nueva política orientada a que los recursos públicos se pongan al servicio de los grandes negocios, anulando cualquier intención constitucional sobre la "libre competencia" y la "función social y ecológica de la propiedad privada". Entonces, "dejar hacer, dejar pasar", pareciera ser también la nueva consigna del actual modelo de control fiscal, modelo sobre el que no ha sido posible su reforma y fortalecimiento para evitar que sea funcional a aquellos intereses venales.

Y ni hablar del control interno, en cabeza de la misma administración. El control al manejo de los recursos públicos se cumple en primera instancia a través de la operación del control interno que le compete a cada entidad pública. Este control interno se complementa con el control fiscal externo posterior y selectivo a cargo de las contralorías. El control interno creado por la Constitución Política y reglamentado por la ley, está basado en el "autocontrol", 
la "autogestión” y la "autorregulación". Todos los servidores públicos, -incluida la alta dirección al interior de las entidades y organismos del Estado-, deberían vigilar y controlar la gestión de los recursos públicos en sus distintos momentos: de manera previa, simultánea y también posterior. Al control interno adecuadamente implementado le correspondería ofrecer a la sociedad, -como legítima propietaria de los bienes y recursos públicos-, seguridad razonable sobre el buen manejo y uso de los mismos, la garantía del cumplimiento de las políticas, de las normas y de los propósitos institucionales, así como de la información involucrada para hacer más transparente la rendición de cuentas. La sentencia C-103 de 2015 le ratificó al control interno la función de advertencia; sin embargo, a la fecha no se conocen acciones preventivas de importancia por parte de las oficinas de control interno, que hayan evitado el daño al patrimonio público, por lo que es evidente que el actual modelo de control interno, -dado los resultados examinados frente a la corrupción-, continúa en deuda con la sociedad, por su inefectividad.

Por otra parte, la recentralización del control fiscal en la Contraloría General de la República -CGR, no puede considerarse la mejor medida para lograr la eficiencia y efectividad del control fiscal y para la lucha contra la corrupción. El fortalecimiento del nivel territorial de la administración pública y del control a la misma, a partir de una verdadera descentralización, del impulso del control social y garantías de autonomía para tomar decisiones estratégicas en las regiones, constituyen requisito fundamental para la lograr la óptima inversión de los recursos públicos y consecuentemente, la superación de la desigualdad y la pobreza, aspectos centrales en la construcción de una paz estable y duradera.

En una intervención ante los contralores del país, el Auditor General de la República, Carlos Hernán Rodríguez Becerra, se pronunció frente a las tendencias re centralizadoras, así:

(...) Adicionalmente, desde un punto de vista geopolítico, Colombia es el compendio de una gran variedad de culturas y por ende en cada región se configuran diferentes territorialidades, es decir que, a manera de ejemplo, la forma de garantizar el derecho a la seguridad alimentaria, que es un derecho humano universal, no puede ser la misma en Mitú que en Palmira. Lo anterior significa que la institucionalidad debe estar en capacidad de reconocer y respetar la diferencia, la interculturalidad y no caer en el círculo vicioso de la exclusión social, abonando el terreno para la corrupción. Es allí, precisamente, en la territorialidad, en donde cobra valor fundamental, la descentralización y por ello, el papel que juega la Contraloría Territorial es determinante, para garantizar la materialización de un Estado Social de Derecho.

(...) No puede concebirse un control fiscal territorial desde el nivel central del Estado, sin lesionar gravemente el concepto de descentralización concebido por el Constituyente de 1991.

La descentralización administrativa, en palabras del Doctor Libardo Rodríguez, exconsejero de Estado, es "la facultad que se otorga a las diferentes entidades públicas del Estado para gobernarse por sí mismas, mediante la radicación de funciones en sus manos para que las 
ejerzan autónomamente".

Por lo anterior, no cabe duda que intentar eliminar las Contralorías Territoriales que hoy existen en el país para trasladarle esas funciones a la Contraloría General de la República, no solo es incongruente con la descentralización administrativa, sino que riñe con el espíritu mismo de nuestra Constitución, en especial con el postulado fundamental contenido el artículo $1^{\circ}$ que desarrolla uno de los principios de la Carta Política: "Colombia es un Estado social de derecho, organizado en forma de República unitaria, descentralizada, con autonomía de sus entidades territoriales (...)

Y continuó el señor Auditor a los contralores territoriales:

No obstante, se observa una fuerte tendencia nacional hacia el logro de este cometido de eliminación de las contralorías territoriales. Así se desprende de las líneas generales de política pública elaboradas por el DNP. Un ejemplo de ello lo constituye el documento CONPES 167 de 2013, citado al inicio de mi intervención, que identifica una serie de debilidades en el Control Fiscal Territorial, entre las que se encuentran:

- La falta de resultados efectivos en el proceso auditor

- El incumplimiento de obligaciones fiscales

- Y la no revisión de las cuentas recibidas

Esto nos lleva a preguntarse si ¿Acabando con las contralorías territoriales se soluciona el problema del control fiscal en el país y se acaba con la corrupción administrativa? Es claro que la respuesta a este cuestionamiento es negativa, por cuanto nada garantiza que, con la centralización del Control Fiscal territorial en la CGR o cualquier otro ente, se logren mejores resultados en Control Fiscal y en la gestión pública territorial.

Si la preocupación radica en los niveles de corrupción vigentes hoy en el país, la solución no puede ser la eliminación de las Contralorías Territoriales, pues esa corrupción ha alcanzado las proporciones señaladas, aún con la existencia de la Contraloría General de la República en lo nacional y en lo territorial con vigencia de sus controles excepcionales (preferente y prevalente).".

En ese contexto, surge la pregunta: ¿Qué hacer? Varios estudios propiciados por la academia, la Auditoría General de la República, organismos multilaterales como el Banco Mundial y los mismos organismos de control fiscal, así como las deliberaciones y conclusiones de diversos foros y eventos técnicos, han dado cuenta de la impostergable decisión que han de tomar las instancias correspondientes frente al necesario fortalecimiento del control fiscal en Colombia, particularmente, en lo atinente al control fiscal territorial como elemento fundamental de la descentralización y de la democracia local.

El presente documento, resume las principales propuestas que ha venido acopiando, sistematizando y propiciando la Auditoría General de la República como organismo de control fiscal de segundo nivel, en su condición de auditora de los contralores.

De manera que las siguientes propuestas de acción, basadas en diagnósticos recurrentes pero actualizados, nos permiten dar respuesta suficientemente autorizada y documentada a los 


\section{OPPCF}

interrogantes del CONPES 167 de 2013.

\subsection{DIAGNÓSTICO Y PROPUESTAS DE SOLUCIÓN}

\subsubsection{Corregir la estructura difusa del control fiscal}

Una primera mirada sobre el modelo de control fiscal en nuestro país, advierte sobre la “Difusa estructura del Sistema de Control Nacional". (AGR-Banco Mundial, 2011)

Aparentemente, no resulta razonable la existencia de 66 contralorías, a saber: Contraloría General de la República, 32 contralorías departamentales y 33 contralorías distritales y municipales. Además, como organismos de control fiscal de segundo nivel: la Auditoría General de la República y la Auditoría Fiscal ante la Contraloría de Bogotá, D.C.

Lo realmente no razonable, es la muy precaria articulación entre esa frondosa institucionalidad del control fiscal que inhibe trabajar con economías de escala y conduce a unos resultados dispersos en sus procesos misionales de auditoría y de resarcimiento efectivo del daño causado al patrimonio público.

El problema no es la existencia de contralorías en el nivel territorial. El problema radica en la política de no tomar medidas de fondo para permitir su articulación y fortalecimiento. Las dificultades para establecer un efectivo engranaje institucional, que haga práctico, seguro y eficiente el control fiscal desde y hacia los territorios, provienen lamentablemente, de algunos niveles de decisión del gobierno y de la misma CGR, que propician su estrangulamiento y por ende el riesgo de su desaparición.

Contrario a esas intenciones de propiciar la eliminación el control fiscal territorial, el primer llamado de la mayoría de propuestas de fortalecimiento apunta a la necesidad de crear formalmente un verdadero Sistema Nacional Territorial de Control Fiscal, con atribuciones para proponer políticas públicas cohesionadoras en las materias de su competencia; definir planes y programas de cobertura nacional, regional y local de mediano y largo plazo frente a la vigilancia y control a los recursos públicos; consensuar los distintos niveles de participación de las contralorías en dichos planes y programas y hacer viables los principios de complementariedad y subsidiariedad cuando corresponda.

Además de dirigir la capacitación, el desarrollo informático y proponer la distribución de cargas y beneficios generados por la operación de dicho sistema, deberá determinarse claramente un nuevo esquema de relaciones interinstitucionales en términos de roles, recursos, responsabilidades y competencias de todos los componentes del sistema: Contraloría General, contralorías departamentales, contralorías distritales y municipales, Auditoría General de la 
República, Auditoría Fiscal ante la Contraloría de Bogotá D.C., y el organismo representativo de las oficinas de control interno. Componente fundamental del nuevo sistema serán las organizaciones representativas del control social. (Restrepo, Araujo y Tuta, 2010. p89 y 90; AGR-Banco Mundial, 2011. p.82).

En este contexto, una eficiente estructura del control fiscal tiene que ver con las medidas que deberán tomarse para superar la fractura del control fiscal externo con el control fiscal interno y establecer nuevas relaciones entre estos dos niveles del control, tal y como se examina en otro acápite del presente estudio. Así mismo, tiene que ver con la reclamada autonomía presupuestal, la independencia política de los contralores frente a sus vigilados y la carrera administrativa especial para los servidores públicos de las contralorías, temas que están bajo la responsabilidad de otras autoridades en el plan de acción del CONPES 167.

La Auditoría General de la República, asume el compromiso de elaborar de manera participativa la propuesta normativa, durante el primer semestre de 2018.

\section{2.2. Otorgar la función preventiva al control fiscal}

El debate sobre la efectividad del control fiscal ha sido intenso. Las contralorías, incluida la Contraloría General de la República, fungen como notarios que solamente pueden dar fe pública del daño patrimonial causado, sin que puedan evitarlo. Y tampoco han logrado recuperar los billonarios recursos desfalcados al erario porque una vez despojada la sociedad de sus recursos, ese daño al patrimonio público deviene en irreparable.

Una buena parte de las contralorías departamentales y municipales con los recursos presupuestales prácticamente congelados desde el año 2000 por las decisiones de la ley 617 de ese año, tienen graves limitaciones tecnológicas y de talento humano que no les ha permitido abordar el control de manera eficiente, oportuna y con la cobertura y calidad requerida.

Asílas cosas, hoy el control es demasiado posterior, demasiado selectivo, y, por tanto, demasiado permisivo, y hasta ahora, han fracasado todos los intentos de reforma para fortalecerlo; por ejemplo, el de otorgarle funciones preventivas que no constituyan control previo, sino control inmediato o en tiempo real.

Para ilustrar la importancia de los instrumentos preventivos, basta analizar las intervenciones de la ex contralora Sandra Morelli y del actual contralor Edgardo Maya cuando explicaban la ausencia de control fiscal oportuno y efectivo en los sucesos de la Refinería de Cartagena: El organismo de control, no tenía, ni tiene como intervenir, o siquiera advertir sobre las irregularidades en curso, porque la ley no se lo permite a la contraloría. (Semana en vivo, 2016)

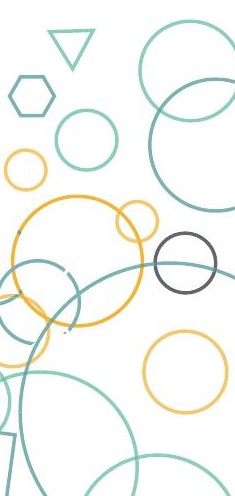




\section{OPPCF}

La función de advertencia, como un instrumento del control posterior pero inmediato que tenían las contralorías para prevenir posible daño al patrimonio público, fue declarada inconstitucional mediante sentencia C-103/2015 de la Corte Constitucional.

En consecuencia, debido a que nuestra Carta Política no dispone de un enfoque preventivo frente al posible menoscabo del patrimonio público, el tema del control y su necesario reenfoque merece un debate creativo, a fin de proponer ideas e instrumentos que conlleven a la toma de decisiones de política pública que permitan disponer, entre otras de la facultad de "advertencia" o de una figura similar, o de comunicar "alertas tempranas" como producto del ejercicio oportuno y efectivo del análisis de riesgos que realizan las contralorías en desarrollo del control fiscal posterior pero inmediato.

La nueva legislación al respecto, deberá disponer medidas preventivas, tales como solicitar dentro del ámbito de sus competencias la suspensión de procedimientos administrativos, actos, contratos o su ejecución, para que cesen los efectos y se eviten los perjuicios, cuando existan indicios graves que permitan inferir la vulneración inminente del patrimonio público.

Esta medida solo podría ser decretada por el respectivo contralor, quien no podrá delegar su ejercicio, y la misma conservará su vigencia hasta un plazo máximo de dos meses, término durante el cual el organismo de control deberá promover las acciones judiciales pertinentes.

Igual que en el punto anterior, relativo a la estructura del control fiscal, la Auditoría General de la República, asume el compromiso de elaborar de manera participativa la propuesta normativa referida a la facultad preventiva del control fiscal, tema que desarrollará y culminará durante el primer semestre de 2018.

\section{2.3. Medidas para mejorar el resarcimiento del daño al patrimonio público}

Axiomático es que, medir en términos de eficiencia y eficacia la gestión de las contralorías territoriales con base en los resultados de recuperación de activos, o recaudo que es lo mismo, no es ni técnica ni justamente adecuado. Aseverar que su gestión se concreta al recaudo del daño patrimonial, es desconocer la naturaleza, función y operación del control fiscal.

Concluir costo beneficio, comparando simplemente lo que cuesta una contraloría (presupuesto) con lo que recauda, es un desacierto cuyos resultados han sido siempre, y seguirán siendo, desafortunados y desalentadores; y un errado y débil argumento de quienes promueven las intenciones de centralización del control fiscal.

Para identificar estrategias y desarrollar herramientas que sirvan para luchar contra la impunidad en actos de corrupción, y en particular los que implican detrimento patrimonial al 
Estado, hay que entender necesariamente, que la gestión de control fiscal de las contralorías territoriales es, y debe medirse como un todo, de manera integral, incluyendo, como se explica adelante, los beneficios cuantificables y no cuantificables del ejercicio de control fiscal de las contralorías territoriales, que no siempre implican recaudo, sino que trascienden esa noción.

Es en este contexto y teniendo en cuenta que la problemática del control fiscal territorial ha sido históricamente identificada con los pobres e inefectivos resultados de los procesos de responsabilidad fiscal y de cobro coactivo; cuya normatividad hace casi que nugatoria la posibilidad de resarcimiento del daño, debilitando aún más el proceso; se proponen en este documento, medidas concretas que faciliten y aseguren alcanzar los niveles de eficiencia y eficacia en la recuperación de activos que busca la Estrategia Nacional de la Política Pública Integral Anticorrupción.

\section{- El carácter de juez y parte.}

El doble carácter de investigadores y jueces de las contralorías territoriales desnaturaliza su función técnica de vigilancia; y hace que converja en un mismo organismo, las funciones de recolección de pruebas, denuncia, instrucción de procesos, fallos y cobro de dineros ${ }^{72}$, restándole imparcialidad y objetividad; sin que se garantice el recurso de alzada ante organismos diferentes al que identificó el hallazgo. (Rendón, 2001; AGR Sindéresis, 2002; Ochoa y Charris, 2013).

(...) Otras situaciones adversas se reflejan en la debilidad de las garantías de defensa de los implicados en los procesos de responsabilidad fiscal, en una situación de incertidumbre y desconcierto en la sociedad, a partir de casos específicos analizados o nulidades que produce la justicia a los fallos de las contralorías. Para el individuo, el control es sancionatorio y punitivo, no es reparador ni preventivo; es amenazante de sus derechos humanos fundamentales como la dignidad humana, la libertad de empresa, el buen nombre, el derecho al trabajo y otros derechos. Predomina la desconfianza mutua en los organismos de control hacia los actores de la gestión pública y la gestión contractual, que no comprenden los escenarios de incertidumbre y dificultad para tales gestores fiscales. En reciprocidad, los sujetos vigilados tampoco confían en tales organismos. (...) (Gómez y Céspedes, 2017)

\section{- La naturaleza administrativa y cuasi jurisdiccional de las contralorías.}

En el trámite de los procesos de responsabilidad fiscal y de cobro coactivo, las contralorías fungen como una jurisdicción más, deben disponer de una infraestructura y recursos profesionales ${ }^{73}$ necesarios para judicializar también los hallazgos fiscales que identifican, desdibujando su papel estrictamente técnico y restándole eficacia en la vigilancia de la gestión fiscal que le corresponde a los órganos de control fiscal (Naranjo, 2007). Ese ejercicio cuasi jurisdiccional implica, lo que se puede calificarse como desgaste operativo de las contralorías, y ha exigido que tales órganos de control hagan ingentes esfuerzos económicos para la mejora y automatización de los procesos de responsabilidad fiscal y de cobro coactivo, esfuerzos que hoy no solo están dispersos, sino que no están estandarizados y el nivel de madurez de buena parte de ellos sigue siendo muy bajo (MINTIC Gobierno en

72 Afirmación que es más evidente en las contralorías territoriales con pocos funcionarios, que exige que algunos tengan ese carácter dual reprochado.

73 El número de funcionarios de las contralorías territoriales - sin contar la de Bogotá- destinados a adelantar los procesos fiscales para la vigencia 2016 fue de 380 .

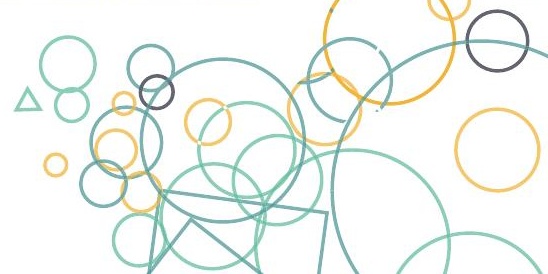


Línea-AGR, 2012, p.22).

Sobre esa función, se encontró que: “En muchos países no se encomiendan a las contralorías funciones sancionatorias; su labor se limita a constatar la existencia de procedimientos, a evaluar los resultados, pero toda sospecha de manejos inadecuados o negligentes debe ser remitida a autoridades judiciales". (Ochoa y Charris, 2013) Negrilla fuera del texto.

\section{- La ocurrencia frecuente de prescripción de la responsabilidad fiscal, de la caducidad de la acción fiscal y la baja recuperación de cartera.}

En buena parte de los procesos fiscales, por impericia, inactividad, inexperiencia, falta de recursos físicos, humanos, técnicos, de infraestructura, oportunidad o debilidades de autocontrol, se obliga a la declaratoria de la caducidad de la acción fiscal ${ }^{74}$ porque no se abrió proceso dentro de los cinco años siguientes a la ocurrencia del daño investigado; o nulidades procesales que demoran el trámite de los procesos; hasta el punto tal que llegan a imposibilitar totalmente el resarcimiento del daño patrimonial en unos casos, o a obtener una baja recuperación de cartera en otros; o a la declaratoria de ocurrencia de la prescripción de la responsabilidad fiscal ${ }^{75}$, porque por dilación, falta de pericia, herramientas o recursos, no fue posible fallar de fondo dentro de los cinco años siguientes al auto de apertura del proceso.

Estudios muestran que los resultados de este proceso, para cuales la vía judicial está abierta, no son satisfactorios. Los procesos duran años (hay cifras que hablan de un promedio de trece años), con pocos éxitos en cuanto a sanciones y/o la recuperación de recursos malversados o de la reparación del daño económico causado. Desde el punto de vista de la política anticorrupción el proceso tampoco es satisfactorio, porque muestra que finalmente el riesgo para ser sancionado y responsabilizado por un acto corrupto, después de un proceso largo, es mínimo para un funcionario mal intencionado. (López, 2006)

\section{- El proceso de responsabilidad fiscal es permisivo.}

Con la sentencia C-619 de 8 de agosto de 2002, la Corte Constitucional impuso al funcionario instructor del proceso de responsabilidad fiscal la necesidad de probar culpa grave para responsabilidad fiscal, en lugar de culpa leve que se equipara a la negligencia, tal como estaba previsto originariamente por el legislador al expedir la Ley 610 de 2000. Esta decisión de la Corte trajo como resultado un obstáculo que impide la recuperación del patrimonio público calificado con culpa leve y en lugar de atacar la corrupción, es un anuncio de tolerancia frente a la impunidad. (Ordóñez, 2007).

Consecuencia de lo afirmado es, que el alto número de autos de archivo y de fallos sin responsabilidad fiscal, cuya cuantía se contabiliza en las estadísticas como presunto daño patrimonial investigado, corresponde en muy buena parte a casos en los que se verificó la existencia de un daño patrimonial al Estado, y en los que por alguna razón no se logró probar la culpa grave de los gestores fiscales. Incluso, están en ese presupuesto los

74 Según lo reportado en la rendición de cuentas realizada por las contralorías a la Auditoría General de la República, entre 2012 y 2016 se archivaron por caducidad de la acción fiscal 233 procesos de responsabilidad fiscal tramitados por procedimiento ordinario, y un valor total de 176.943.654.010 pesos.

Según lo reportado en la rendición de cuentas realizada por las contralorías a la Auditoría General de la República, entre 2012 y 2016 se archivaron por prescripción de la responsabilidad fiscal 662 procesos de responsabilidad fiscal tramitados por procedimiento ordinario, y un valor total de 186.604.913.276 pesos. 
procesos que se abrieron con base en deficiencias administrativas, del error consecuencia del descuido, la ignorancia, la negligencia, la indolencia o el desgreño de los gestores fiscales, que existiendo, no fueron suficientes para enmarcarse en el grado de culpa grave que exige la referida sentencia (Gómez y Ordóñez, 2010).

En ese contexto general, se propone como medida para obtener una eficiente y eficaz recuperación de daño patrimonial causado al erario, la de liberar a las contralorías territoriales de la función de adelantar y tramitar hasta su culminación los procesos de responsabilidad fiscal y de cobro coactivo, y radicarla en una jurisdicción real, como la de lo Contencioso Administrativo, adicionando los procesos de responsabilidad fiscal y jurisdicción coactiva en los listados del artículo 104 de la Ley 1437 de 2011, eliminando la simbiosis innecesaria entre dos funciones perfectamente diferenciables, una de las cuales es más propia de la Rama Judicial, superando una de las más grandes atrofias del sistema de control fiscal (AGR Sindéresis, 2002), con lo cual, las contralorías ganarían fortaleza como órganos de auditoría pública (Naranjo, 2007).

Con la implementación de ésta medida, se propendería por un restablecimiento real y oportuno del daño patrimonial causado al patrimonio público, con fallos jurídicos adecuados, minimizando los riesgos de caducidad, de prescripción, de nulidades y dilaciones procesales, además de evitar que los responsables fiscales se insolventen corruptamente para evadir las consecuencias de su indebida y dañina gestión. En este escenario, se prevé que los fallos se multiplicarían, se garantizaría aún más el derecho defensa y la segunda instancia, se decretarían y ejecutarían medidas cautelares por quien tiene la infraestructura y las herramientas para hacerlo, y se evitaría tener que remitir, de todas formas, a la jurisdicción de lo contencioso administrativo por el uso de medios de control como el de nulidad y restablecimiento del derecho, los fallos con responsabilidad fiscal ejecutoriados, que siempre son demandados ante esa jurisdicción, haciendo menos complejo y gravoso el proceso de responsabilidad.

Todo lo anterior conllevaría en consecuencia, a lograr una efectiva recuperación de los recursos públicos, y disminuir el nivel de impunidad de los gestores fiscales que con su acción u omisión lo dañan. La mencionada propuesta no es nueva, viene exponiéndose en distintos escenarios y por distintos estudiosos del tema, entre ellos (Suarez, 2001), (Rendón, 2001) (Ochoa y Charris, 2003) (López, 2006) (Ossa, 2006) (Gómez y Céspedes, 2017).

Ahora bien, como propuesta alternativa, está la de fortalecer el proceso de responsabilidad fiscal eliminando la exigencia de culpa grave para responsabilizar fiscalmente; aumentar las presunciones del Estatuto Anticorrupción; hacer que la investigación de bienes y el decreto

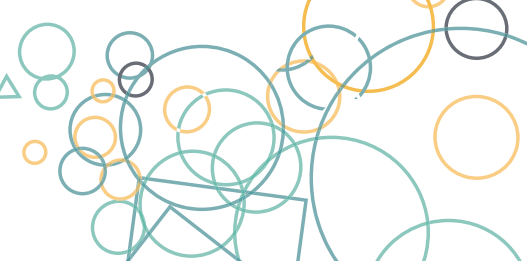




\section{OPPCF}

de medidas cautelares no sea facultativo del operador jurídico, sino obligatorio desde que se suscribe el auto de apertura en procesos de responsabilidad tramitados por el procedimiento ordinario, y el auto de apertura e imputación en los procesos tramitados por procedimiento verbal; establecer convenios con entidades internacionales y nacionales para la identificación y ubicación de bienes y propiedades de los investigados, como por ejemplo las Oficinas de Registro, el Instituto Geográfico Agustín Codazzi, las Oficinas de Catastro autónomas, el Fondo Nacional del Ahorro, Ecopetrol, entre otras instancias, que faciliten acceder a bases de datos nacionales sobre la información de bienes de los presuntos responsables, evitando el desgaste que implica para las contralorías territoriales. tantos trámites engorrosos de oficiar a todo el país, con las demoras que esto conlleva, lo que afecta la oportunidad del decreto y práctica de medidas cautelares (MINTIC Gobierno en Línea-AGR, 2012, p.22).

Finalmente, reglamentar la remisibilidad de deudas fiscales -como ocurre con las tributarias-, para que las contralorías territoriales y en general los órganos de control fiscal puedan dejar de cargar grandes sumas de fallos con responsabilidad fiscal y resoluciones sancionatorias, que son incobrables por la práctica perversa de los gestores fiscales que se han insolventado para evitar pagar el daño patrimonial causado al Estado, lo que ha constituido durante años, una carga pesada que afecta en gran parte las estadísticas de recaudo de las contralorías, y que deberán seguir cargando indefinidamente, mientras no haya orientación, reglamentación y unidad de criterio a nivel nacional para eliminar de la cartera por cobrar, lo realmente incobrable.

\section{2.4. Garantizar la autonomía de los órganos de control fiscal territorial}

El mandato Superior en su artículo 267 determina que la Contraloría es una entidad de carácter técnico, con autonomía administrativa y presupuestal. A su vez, la INTOSAI (Organización Internacional de las Entidades Fiscalizadoras Superiores -EFS), en su Declaración de México -mayo de 2007- estableció:

Los principios básicos de la independencia de las EFS son las siguientes:

1. La existencia de un marco constitucional, reglamentario o legal apropiado y eficaz, así como de disposiciones para la aplicación de facto de dicho marco

2. La independencia de la autoridad superior de la EFS, y de los "miembros" (para el caso de instituciones colegiadas), incluyendo la seguridad en el cargo y la inmunidad legal en el cumplimiento normal de sus obligaciones.

3. Un mandato suficientemente amplio y facultades plenamente discrecionales en el cumplimiento de las funciones de la EFS

4. Acceso irrestricto a la información 
5. El derecho y la obligación de informar sobre su trabajo

6. Libertad de decidir el contenido y la oportunidad (momento) de sus informes de auditoría, al igual que sobre su publicación y divulgación

7. La existencia de mecanismos eficaces de seguimiento de las recomendaciones de la EFS

8. Autonomía financiera y gerencial/administrativa, al igual que disponibilidad de recursos humanos, materiales y económicos apropiados

Las disposiciones para la aplicación de estos principios sirven para ilustrarlos y se consideran como el ideal para una EFS independiente. (INTOSAI, 2007)

En nuestro país, no ha sido posible garantizar una verdadera autonomía presupuestal ni la necesaria independencia de los organismos de control fiscal, frente a sus vigilados. En efecto, uno de los problemas que afecta la autonomía y la independencia del control fiscal consiste en que los gobernantes a vigilar en el nivel territorial son elegidos para un período de cuatro años el último domingo del mes de octubre y se posesionan el $1^{\circ}$ de enero del año siguiente.

Durante el tiempo que transcurre a partir de la elección del gobernante, se realiza la campaña de los aspirantes a ocupar los cargos de contralor departamental, distrital o municipal, en la respectiva entidad territorial, campaña en la que resulta inevitable la injerencia de los gobernantes elegidos, que serán objeto de control fiscal por el contralor a elegir por las asambleas y concejos.

Todo ello a pesar del mandato constitucional ${ }^{76}$ que ordena sujetar dicha elección a una convocatoria pública "conforme a la ley" y sometida a principios de transparencia, objetividad, publicidad, participación ciudadana y equidad de género. La reforma constitucional es de 2015 y la ley que regula la convocatoria pública no ha sido expedida.

El procedimiento de convocatoria pública no parece resolver el problema planteado frente a las garantías de transparencia, objetividad e independencia, dado que los puntajes otorgados en las entrevistas por las corporaciones públicas pueden primar frente a los resultados de los exámenes sobre conocimientos técnicos, experiencia y otras variables para medir la idoneidad de los elegidos. De manera que, sigue primando la posible injerencia de los gobernantes en la elección de sus controladores, así como los posibles intereses indebidos de diputados y concejales.

De manera que se impone la adopción de medidas más efectivas y asertivas en el proceso de selección y elección de quienes tendrán a su cargo la vigilancia de la gestión fiscal en los

76 Acto Legislativo 2 de 2015, que modificó el artículo 272 de la Constitución Política 


\section{OPPCF}

departamentos, distritos y municipios, que incluya modificar la forma y requisitos para la designación de los contralores y los cuerpos directivos de las contralorías.

El procedimiento idóneo es el concurso de méritos, con exigencias precisas de experiencia sobre control fiscal demostrable y altos niveles de probidad para quienes aspiren a ocupar dichos cargos, entre otros.

Adicionalmente, los contralores serán escogidos para períodos de cuatro años, que deberán iniciar a la mitad del período del gobernante de turno y terminar a la mitad del siguiente, sin que puedan ser reelegidos.

De manera complementaria, debe resolverse el grave problema de recursos presupuestales de las contralorías, como se explica líneas adelante. Así las cosas, se posibilita la construcción de nuevas relaciones de independencia y autonomía frente a los vigilados.

La tarea de "Presentar un proyecto de ley para crear la carrera administrativa de las contralorías territoriales y modificar la forma de elección de los contralores territoriales, para garantizar la transparencia de dichos procesos", contenida en el plan de acción del Documento CONPES 167 , a cargo del Ministerio del Interior, es fundamental para consolidar una estructura eficiente y efectiva del control fiscal.

\subsubsection{Un nuevo modo de cálculo presupuestal para las contralorías territoriales}

Las normas que rigen los presupuestos de los organismos de control en los territorios son muy rígidas. Fueron diseñadas hace 17 años para superar una situación de crisis fiscal en los municipios y departamentos, pero han permanecido invariables desde entonces, a pesar de haberse superado las causas que originaron esas medidas restrictivas. Según la Ley 617 de 2000 , las medidas de ajuste fueron transitorias para todos los organismos del nivel ejecutivo, pero no así, para los organismos de control fiscal, generando una nefasta asimetría entre las capacidades de gestión de los vigilados frente a la de los vigilantes en claro detrimento de éstos últimos. Y es a la postre, la sociedad -en los territorios- la que ha visto afectada su capacidad de controlar a los gobernantes. Pareciera que, de manera deliberada, se debilitara el ejercicio del control fiscal para facilitar el accionar de la des-administración. Adicionalmente, las diferencias presupuestales entre las contralorías y su capacidad de gestión son muy diferentes y en la actualidad no existen políticas para su fortalecimiento.

Para corregir esta situación, es hora de suprimir aquellos artículos de la Ley 617 de 2000 que ahogan y extinguen paulatinamente el presupuesto de las contralorías, así como derogar el artículo 15 de la Ley 330 de 1996, en cuanto a la prohibición a las contralorías departamentales 
de contratar por prestación de servicios. Resulta imperativo otorgar la posibilidad legal para que las contralorías realicen inversión en tecnología y demás elementos efectivos de modernización institucional para aumentar su capacidad de gestión y de resultados.

Por disposición del artículo 267 constitucional, la Contraloría es una entidad de carácter técnico con autonomía administrativa y presupuestal. En igual sentido, en relación con las contralorías departamentales y municipales el artículo 272 de la Carta Política dispone que corresponde a las asambleas y a los concejos Distritales y Municipales organizar las respectivas contralorías como entidades técnicas dotadas de autonomía administrativa y presupuestal.

En desarrollo de estos preceptos constitucionales, el Legislador, atendiendo el espíritu de las normas constitucionales, estableció en el artículo 54 de la Ley 42 de 1993 lo siguiente:

En ejercicio de la autonomía presupuestal la Contraloría General de la República elaborará cada año su proyecto de presupuesto de gastos o de apropiaciones para ser presentado a la Dirección General de Presupuesto, quien lo incorporará al respectivo proyecto de ley de presupuesto que se someterá a la consideración del Congreso de la República.

Además, la Ley 106 de 1993 en el artículo $4^{\circ}$ dispone que en desarrollo de la autonomía presupuestal la Contraloría General de la República, maneja, administra y fija su presupuesto en concordancia con la Ley Orgánica del Presupuesto.

A nivel territorial, la Ley 136 de 1994 en su artículo 165, señala lo siguiente en relación con el tema:

Los contralores distritales y municipales, tendrán, además de lo establecido en el artículo 272 de la Constitución Política, las siguientes atribuciones: (...) 12. Elaborar el proyecto de presupuesto de la Contraloría y presentarlo al alcalde, dentro de los términos establecidos en esta Ley, para ser incorporadas al proyecto de presupuesto anual de rentas y gastos. El alcalde no podrá modificarlo. (...) Una vez aprobado el presupuesto no podrá ser objeto de traslados por decisión del alcalde.

Por otra parte, la noción de autonomía presupuestal fue aclarada por el Consejo de Estado en concepto de octubre 9 de 1995, de la siguiente manera:

La autonomía presupuestal se manifiesta en la iniciativa de elaboración del proyecto de presupuesto; en la existencia de un mecanismo legal de no reducción de la partida presupuestal y de actualización monetaria de la misma; en la imposibilidad de modificación del proyecto por el alcalde o de realizar traslados administrativos, así como en la capacidad para ordenar el gasto y celebrar contratos en función de la ejecución del respectivo presupuesto.

De lo anterior se concluye:

- Que la autonomía presupuestal de las contralorías territoriales, les permite a estas elaborar en forma independiente el proyecto de presupuesto de rentas y gastos de la respectiva contraloría, con el fin de que éste sea incorporado por parte del alcalde o gobernador, 


\section{OPPCF}

según corresponda, en el proyecto de presupuesto anual del respectivo departamento o municipio.

- Que la autoridad administrativa local, no puede modificar el proyecto de presupuesto presentado por la Contraloría, y no está facultada para realizar modificaciones en el presupuesto, una vez este haya sido aprobado.

Con la expedición de la Ley 617 de 2000 se fijaron límites para los gastos de funcionamiento de las Contralorías Distritales, Municipales y Departamentales, de tal forma que dichos gastos, a partir de la vigencia de la Ley, deberían financiarse con los ingresos corrientes de libre destinación de la correspondiente entidad territorial, esto es, excluyendo renglones importantes como la participación de los municipios en los ingresos corrientes de la Nación de forzosa inversión, los ingresos percibidos en favor de terceros, los recursos del balance, los recursos de cofinanciación, las regalías y compensaciones, las operaciones de crédito público y la sobretasa al ACPM.

Adicionalmente, la ley estableció que a partir del año 2005 los gastos de las contralorías no podrían crecer por encima de la meta de inflación establecida por el Banco de la República.

No cabe duda que esta decisión afectó de manera grave el funcionamiento de los Organismos de Control Fiscal territorial del país y redujo de manera drástica el campo de acción funcional de las contralorías, desconociendo los postulados básicos de la descentralización administrativa consagrados en la Constitución Política, creando un mecanismo perverso de aniquilamiento institucional a partir del decrecimiento real de los presupuestos de estos Organismos de Fiscalización, en relación con el aumento paulatino de los gastos de funcionamiento, en especial en la remuneración de los servicios personales y de nómina, con lo que la autonomía de las entidades territoriales quedó reducida a un mero formalismo y la sostenibilidad del proceso de descentralización no se garantizó.

En efecto, la variación acumulada en el IPC a partir del año 2005 es significativamente menor al aumento mostrado en los salarios y prestaciones sociales de los funcionarios de las contralorías territoriales y en general de los gastos de funcionamiento, situación que ha generado un desequilibrio financiero importante que afecta de manera grave el normal funcionamiento de las contralorías territoriales.

Este desfinanciamiento de tipo presupuestal genera además la imposibilidad real que tienen estos organismos de control de contar con un rubro específico de inversión que les permita adelantar proyectos importantes para la aplicación del Control Fiscal como el desarrollo de 
tecnologías de la información y las comunicaciones, programas avanzados de formación y capacitación de funcionarios, entre otros. De contar con un adecuado financiamiento, se posibilitaría el avance en el diseño y aplicación de nuevos y mejores procedimientos y técnicas de auditoría, como elemento fundamental en lucha contra la corrupción.

Es por ello, que se requiere con urgencia modificar la forma en que se fija en la actualidad, el presupuesto que se destina a las contralorías territoriales, mediante la adopción de una fórmula que permita, tanto la sostenibilidad presupuestal de las mismas, como la actualización monetaria anual de las partidas presupuestarias fijadas, sin que se desborden los gastos de funcionamiento de los organismos de control fiscal territorial.

\section{2.6. Superar la fractura entre el control fiscal interno y el control fiscal externo}

No existe una verdadera complementariedad entre el Sistema de Control Fiscal y el Sistema de Control Interno, principalmente con las oficinas evaluadoras, encargadas de realizar la evaluación y asesoría de manera independiente a los diferentes procesos de las entidades del Estado.

La gran cantidad de hallazgos administrativos que se identifican en las auditorías realizadas por las contralorías, asociados a las debilidades del sistema de control interno de las entidades vigiladas, distraen el verdadero ejercicio de control fiscal y no permiten enfocarlo a la identificación y análisis de riesgos fiscales.

Según lo reportado en la rendición de cuentas realizada por las contralorías a la Auditoría General de la República, en el periodo 2012 - 2016, las contralorías territoriales identificaron en sus informes 166.521 hallazgos administrativos y la Contraloría General de la República, para el mismo periodo, 32.072. Es decir, durante los últimos 5 años, los organismos de control fiscal en Colombia identificaron 198.599 hallazgos de naturaleza administrativa.

En Colombia, los organismos de control fiscal y las Oficinas de Control Interno desempeñan roles diferentes, claramente definidos en la ley. Sin embargo, los dos tienen un propósito común que consiste en garantizar el adecuado uso de los recursos públicos, a través de una administración pública transparente, eficiente, efectiva y económica.

La diferencia entre los dos sistemas, radica en que las contralorías realizan control fiscal posterior y selectivo, mientras que las oficinas de control interno lo hacen de forma previa, concomitante y/o posterior. Al respecto la Corte Constitucional desde la sentencia C-534 de 1993 y en consideración a la atribución del artículo 268 numeral $6^{\circ}$ de la Constitución, ha dicho: 
(...) Al colocarse en cabeza de la administración (sic) la obligación de conceptuar la calidad y eficiencia del control fiscal interno de las entidades y organismos del Estado, como lo prevé la propia Constitución (art. 268 numeral 6o.), se logra una distinción esencial entre los contenidos, fines y responsabilidades propios del control interno, que debe organizarse en las entidades públicas y las del control fiscal externo ejercido por la Contraloría General de la República y las contralorías departamentales, distritales y municipales a nivel territorial.

Se confiere así forma real a la diferenciación entre las tareas administrativas y las de control fiscal, de donde el control interno se entiende como parte del proceso administrativo y corresponde adelantarlo a los administradores; teniendo oportunidades propias en todos los momentos del cumplimiento de la función administrativa, pudiendo serlo previo, concomitante y/o posterior, lo que permite que el funcionario cumpla su función, asumiendo la responsabilidad por sus actuaciones y resultados; sin perjuicio de la independencia de los organismos de control fiscal, no coadministradores, que cumplirán sus funciones de manera posterior y selectiva, sin ocuparse de funciones administrativas distintas de las inherentes a su propia organización (artículo 267 C.N.). Por eso, la Carta atribuye al Contralor General de la República, la facultad de conceptuar sobre la "calidad" y "eficiencia" del control fiscal interno de las entidades y organismos estatales, evaluación que ha sido definida por la ley como el análisis de los sistemas de control interno de las entidades sujetas a la vigilancia, con el fin de determinar la calidad de los mismos, el nivel de confianza que se les puede otorgar y si son eficaces y eficientes en el cumplimiento de sus objetivos (...) (artículo 18 Ley 42 de 1993).

En consecuencia, en materia de control interno se requieren nuevos desarrollos normativos que permitan diseñar mecanismos de coordinación y cooperación, enfocados a fortalecer la vigilancia oportuna de los recursos públicos.

La creación del Sistema de Control Fiscal, debe vincular, como un actor fundamental para su activación, a las Oficinas de Control Interno.

Respecto a la falta de complementariedad entre el control fiscal y el control interno, la AGR, en el documento titulado la Impostergable Reingeniería del Control Fiscal Territorial, señala:

(...) Problemática: Los eslabones de la cadena de valor del control fiscal interno y externo se encuentran fracturados. Ninguno de estos controles ha producido los resultados esperados.

En consecuencia, condición básica para el ejercicio de un control efectivo anticorrupción, la constituye el fortalecimiento de los sistemas de control interno y externo de las entidades vigiladas y de las propias contralorías.

El fortalecimiento, comienza por la forma de provisión de los responsables de las oficinas coordinadoras o evaluadoras, de modo que éstos no deban sus lealtades a los nominadores de cada entidad, sino que su independencia sea garantizada y obedezca a un ingreso por méritos, con estabilidad y período determinados. Este tema fue resuelto parcialmente por el Estatuto Anticorrupción, al determinar que en el nivel central del gobierno, serán el Presidente, los alcaldes y gobernadores quienes seleccionarán por méritos a los jefes de las oficinas de control interno de sus respectivas jurisdicciones. Pero quedó pendiente resolver esos nombramientos en los demás organismos de las demás ramas del poder público y en los mismos organismos de control.

Igualmente, el fortalecimiento del sistema de control, tanto interno como externo, implica otorgar mayores herramientas y autonomía a las oficinas coordinadoras o evaluadoras de control interno, para realizar control preventivo, sin que ello implique autorización alguna 
para validar actuaciones, actividades, operaciones o procesos. El control interno, en esencia, tiene funciones preventivas, que deben ejercerse con independencia e imparcialidad y con posibilidades legales de comunicar advertencias cuando se vislumbren riesgos de pérdida de patrimonio público y también, a nuestro juicio, los jefes de las oficinas coordinadoras deben disponer de capacidad legal para aplicar sanciones (...). (Peláez, Tuta y Gutiérrez, 2013, p.156)

Adicionalmente, la Corte Constitucional en Sentencia C-103 de 2015, declaró inexequible el numeral $7^{\circ}$ del artículo $5^{\circ}$ del Decreto 267 de 2000, en lo relacionado con la función de advertencia, señalando:

(...) En definitiva, de acuerdo con la jurisprudencia de esta Corporación, una de las manifestaciones del carácter amplio e integral del modelo constitucional de vigilancia fiscal de los recursos públicos la constituye la coexistencia de dos niveles de control: el primero, constituido por los mecanismos de control interno, de naturaleza previa y administrativa; el segundo nivel corresponde al control fiscal externo, de carácter posterior y selectivo, que compete realizar a una entidad autónoma e independiente como es la Contraloría, y cuya efectividad depende de su adecuada articulación con el primer nivel de control (...).

\subsubsection{Desarrollo de la carrera administrativa especial en las contralorías territoriales}

Mediante Sentencia C-073 de 2006, la Corte Constitucional fijó el alcance de los artículos 268-10 y 272 de la Carta Política y concluyó que el régimen de carrera administrativa en las contralorías es de carácter especial por disposición del Constituyente. A la fecha, el Congreso de la República no ha expedido las normas que desarrollen el régimen especial de carrera administrativa aplicable a las contralorías territoriales.

La Comisión Nacional del Servicio Civil en cumplimiento del parágrafo 2 del artículo 3 de la Ley 909 de 2004, aplicó en vigencias anteriores, de manera transitoria, el régimen general de carrera y desarrolló los concursos de carrera administrativa para las contralorías territoriales.

Según la cuenta rendida a la AGR, por las contralorías territoriales, al cierre de la vigencia 2016, estas contaban en sus plantas de personal con un total de 3182 servidores públicos, de los cuales: 62 (2\%) son funcionarios de periodo, 718 (22\%) son de libre nombramiento y remoción, 1974 (62\%) son de carrera administrativa, 402 (13\%) son provisionales y 26 (1\%) figuran como supernumerarios.

En consecuencia, es imperativo que el Congreso de la República expida las normas que desarrollen el régimen de carrera administrativa especial de las contralorías territoriales.

Los procesos de selección de los funcionarios que conforman el Sistema de Control Fiscal, principalmente quienes asumen funciones misionales, deben contar con criterios diferentes a los del régimen general de carrera, para demostrar que objetivamente cumplen y cuentan con las competencias requeridas para ejercer funciones especializadas en control fiscal. 
Se propone que los concursos de carrera administrativa para los servidores públicos de las contralorías territoriales, incluyan requisitos que exijan altos estándares en experiencia relacionada, niveles de probidad demostrables y la realización de cursos-concursos, similares a los que hoy se aplican en la Rama Judicial.

Respecto al tema, la AGR, ha expresado que:

(...) 1. Dentro del proceso de reingeniería del control fiscal, liderado por la Auditoría General de la República, en coordinación con los diferentes sectores interesados, (trabajadores, contralores, ciudadanía, gobierno), es fundamental contar con un sistema de vinculación de personal que garantice, por una parte, el mayor grado de idoneidad en el personal vinculado, y por otro, el reconocimiento de todas las garantías y prerrogativas en pro del bienestar de los trabajadores.

2. La carrera administrativa se constituye en el mecanismo más idóneo en la consecución y aplicación de los principios de la función administrativa, particularmente, en términos de excelencia en el desempeño de quienes desarrollen la labor de vigilancia fiscal.

3. Dado que el tema tratado tiene vocación de reserva legal, es necesaria la presentación de un proyecto de ley, en el que se vean claramente las bondades y beneficios de aplicar un sistema de carrera administrativa, eminentemente técnico, (Contraloría General de la República).

4. Para el efecto, es preciso promover el diseño y elaboración de un documento bajo los parámetros del consenso entre los diferentes actores, de manera que no solamente se esté contribuyendo al mejoramiento continuo en el ejercicio de la función administrativa, sino que, sea reconocida en su integridad, y con todas las garantías, la labor de quienes participan desde diferentes escenarios en el desarrollo del control fiscal (...). (Peláez, Tuta, García, 2013, p.153)

Como se señaló líneas atrás, esta tarea de "Presentar un proyecto de ley para crear la carrera administrativa de las contralorías territoriales y modificar la forma de elección de los contralores territoriales, para garantizar la transparencia de dichos procesos", contenida en el plan de acción del Documento CONPES 167, a cargo del Ministerio del Interior, es fundamental para consolidar una estructura eficiente y efectiva del control fiscal.

\subsubsection{Fortalecer la capacidad sancionatoria de las contralorías territoriales y de la AGR.}

Dada la frecuente ocurrencia de situaciones irregulares de forma reiterada, relacionadas con las cuentas e informes rendidos por los sujetos vigilados, la práctica ha demostrado la necesidad de ampliar las causales establecidas en los artículos 100 y 101 de la ley 42 de 1993 y otorgarle a los organismos de control fiscal, la competencia para sancionar aspectos que, por no tener hoy consecuencias sancionatorias, se han convertido en un resultado frecuente del ejercicio de auditoría, generando desinterés por parte de los sujetos vigilados, lo cual le resta contundencia a la labor del control fiscal, tales como: 
- El no fenecimiento de una cuenta.

- La reiteración de conceptos no favorables como producto de la evaluación de la calidad y eficiencia del control fiscal interno en la entidad vigilada.

- Obtener estados contables con dictamen de no razonabilidad o con abstención de opinión.

Sobre este punto:

“(...) La Auditoría General de la República considera conveniente incluir dentro de las causales de sanción establecidas por la ley 42 de 1993, el no fenecimiento de una cuenta y, además, el impedimento legal del responsable, para hacer parte de otra entidad pública, mientras persista la no aprobación. Igualmente, solicitamos incluir como causal de sanción la reiteración de conceptos no favorables como producto de la evaluación de la calidad y eficiencia del control fiscal interno en la entidad vigilada. (...) El incumplimiento parcial o total de los compromisos incluidos en los planes de mejoramiento, será causal de acciones sancionatorias por parte de los organismos de control fiscal. (...)" (Peláez, Tuta, García, 2013)

\subsubsection{La medición de resultados y los beneficios del control fiscal}

El Plan Estratégico de la Organización Internacional de Entidades Fiscalizadoras Superiores INTOSAI- que culminó en 2016, incluyó seis prioridades estratégicas, dentro de las cuales una se relaciona directamente con los beneficios, así:

- Ayudar a asegurar la independencia de las Entidades Fiscalizadoras Superiores - EFS

- Implementación de estándares Internacionales para Instituciones Fiscalizadoras Superiores ISSAI (s)

- Fortalecer la creación de capacidades de las EFS

- Demostrar el Valor y Beneficios de las EFS

- Promover la lucha contra la corrupción

- Mejorar las comunicaciones de la INTOSAI

A propósito, en el año 2010 en los Acuerdos de Johannesburgo, la INTOSAI afirmó:

(...) Las Entidades Fiscalizadoras Superiores fungen como importantes pilares de sus respectivos sistemas democráticos nacionales y juegan un rol fundamental en el mejoramiento del desempeño del sector público, destacando la importancia de los principios de buena gobernanza, transparencia y responsabilidad. Teniendo en cuenta el creciente interés de partes interesadas -internas y externas- así como, la también creciente gama de servicios de auditoría proporcionados por las EFS; la INTOSAI reconoce la necesidad progresiva de demostrar los valores y beneficios que generan las EFS.

(...) El objetivo general de las auditorías independientes es, por lo tanto, generar una diferencia en las vidas de los ciudadanos, al contribuir a la confianza, la eficiencia y la efectividad. EFS independientes y efectivas, son precondición necesaria para la democracia. Esto implica que el mandato de un auditor independiente en el sector público va más allá de la tradicional definición de la auditoría externa, porque trata también con temas de interés público - el interés de los ciudadanos -. 
(...) En nuestro país, el artículo 129 de la ley 1474 de 2011, Estatuto Anticorrupción, determinó como uno de los criterios orientadores de la planeación estratégica de las contralorías territoriales la "Medición permanente de los resultados e impactos producidos por el ejercicio de la función de control fiscal".

Acorde con lo afirmado, y con el texto del artículo 127 de la Ley 1474 de 2011:

La AGR constatará la medición efectuada por las Contralorías de los beneficios generados por el ejercicio de su función, para lo cual tendrá en cuenta que se trate de acciones evidenciadas debidamente comprobadas, que correspondan al seguimiento de acciones establecidas en planes de mejoramiento o que sean producto de observaciones, hallazgos, pronunciamientos o advertencias efectuados por la contraloría, que sean cuantificables o cualificables y que exista una relación directa entre la acción de mejoramiento y el beneficio.

A las contralorías las reconocen los ciudadanos fundamentalmente por los resultados de su gestión y por la efectividad de su trabajo.

Todos los procesos misionales de las contralorías deben medirse, no solamente en términos de la gestión realizada, sino principalmente, por los resultados y efectos de la labor integral del control fiscal. Para esos efectos, la Contraloría General de la República ha diseñado y aplica una metodología para el reporte de los beneficios del control fiscal. A su vez, las contralorías territoriales han adaptado y adoptado metodologías similares.

Para el efecto, la siguiente definición de beneficios del control fiscal:

(...) La determinación de los beneficios del control fiscal es el instrumento que cuantifica o cualifica el valor agregado generado por el impacto de las actuaciones de control y vigilancia ejercidas por la Contraloría General de la República, a través de funciones de seguimiento a los planes de mejoramiento, observaciones, hallazgos y pronunciamientos. Los beneficios se enmarcan en los conceptos de ahorro y recuperación, en donde ahorro es la erogación dejada de hacer o de pagar por la Entidad o asunto vigilado al realizar una acción preventiva o correctiva, y recuperación es el valor de los bienes o derechos devueltos o reembolsados a la Entidad (...). (CGR, 2017, p.52).

Lo anterior significa que a las contralorías no solamente se les debe medir por el grado de recuperación efectiva del daño patrimonial causado, sino también y con mucho énfasis, por los ahorros y recuperaciones que logren en su función de vigilancia y control, tal como se aludió anteriormente, en el acápite dedicado a las medidas para mejorar el resarcimiento del daño al patrimonio público.

Para ilustrar los efectos e impactos del control fiscal en los últimos años, a continuación, se presentan algunos resultados obtenidos como beneficios del control fiscal.

Tabla 4. Beneficios del control fiscal - total contralorías del país - presupuesto 


\begin{tabular}{llrll}
\hline & \multicolumn{2}{c}{ Total beneficios reportados } & \multicolumn{2}{l}{ Presupuesto contralorías } \\
\hline 2012 & $\$$ & 2.332 .993 .356 .684 & $\$$ & 827.436 .804 .338 \\
\hline 2013 & $\$$ & 3.966 .425 .030 .904 & $\$$ & 832.062 .532 .705 \\
\hline 2014 & $\$$ & 1.561 .439 .867 .657 & $\$$ & 778.148 .942 .004 \\
\hline 2015 & $\$$ & 1.448 .228 .993 .838 & $\$$ & 903.293 .171 .409 \\
\hline 2016 & $\$$ & 279.757 .733 .048 & $\$$ & 873.619 .730 .216 \\
\hline
\end{tabular}

Tabla 5. Beneficios del control fiscal - total contralorías territoriales presupuesto

\begin{tabular}{lllll}
\hline & \multicolumn{3}{l}{ Total beneficios reportados } & \multicolumn{2}{l}{ Presupuesto contralorías } \\
\hline 2012 & $\$$ & 849.731 .919 .381 & $\$$ & 299.247 .874 .506 \\
\hline 2013 & $\$$ & 697.254 .878 .465 & $\$$ & 234.263 .532 .705 \\
\hline 2014 & $\$$ & 1.106 .637 .345 .244 & $\$$ & 244.267 .667 .800 \\
\hline 2015 & $\$$ & 747.052 .781 .357 & $\$$ & 254.760 .877 .433 \\
2016 & $\$$ & 132.996 .560 .080 & $\$$ & 273.365 .758 .663 \\
\hline
\end{tabular}

\subsection{Las tecnologías para mejorar la calidad y cobertura del control}

La Declaración de Asunción, expedida en el encuentro de la Organización Latinoamericana y del Caribe de Entidades Fiscalizadoras Superiores - OLACEFS, celebrado en 2010, en la capital paraguaya, acordó adoptar y difundir entre otros, los siguientes principios de la rendición de cuentas, importantes para un buen gobierno:

“(...) 4. Transparencia de la información.

La publicidad de las actuaciones públicas es premisa fundamental de la transparencia, por lo que la información presentada para los efectos de la rendición de cuentas debe ser confiable, relevante, clara, accesible, comprensible, completa, medible, verificable, oportuna, útil y pública para el ciudadano, promoviéndose el uso de diferentes medios para su comunicación, con el objeto de lograr una adecuada difusión a los actores interesados. Los órganos de control deberán impulsar que la información presentada por las instituciones y funcionarios públicos cuenten con las mencionadas características.

(...) Además, las EFS promoverán un uso intensivo de la tecnología y novedosas formas de comunicación, no sólo para lograr el acceso a la información sino también para efectos

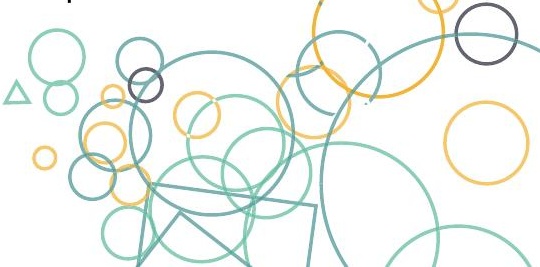




\section{OPPCF}

transaccionales que permitan una gestión pública mucho más eficiente y transparente. Así mismo las EFS promoverán el desarrollo e implementación de normativa, sistemas y, metodologías e indicadores, que permitan realizar mediciones y evaluaciones permanentes de la gestión pública y de la rendición de cuentas (...). (OLACEFS, 2010)

Con ocasión de la expedición de la Ley 1474 de 2011 - Estatuto Anticorrupción -, en la que en su artículo 126 hace referencia a los Sistemas de información en las Entidades de control fiscal, estableció que la Contraloría General de la República, las Contralorías territoriales y la Auditoría General de la República, a través del Sistema Nacional de Control Fiscal - Sinacof, levantarán el inventario de los sistemas de información desarrollados o contratados hasta la fecha de la entrada en vigencia de la ley por parte de las contralorías territoriales para el ejercicio de su función fiscalizadora y propondrán una plataforma tecnológica unificada que procure la integración de los sistemas existentes y permita la incorporación de nuevos desarrollos previamente convenidos y concertados por los participantes de dicho sistema.

De tal forma que, en cumplimiento de lo dispuesto, por su parte la Auditoría General de la República, elaboró un informe como resultado de la encuesta sobre software realizada en octubre de 2011 a las Contralorías territoriales del país, en la que se evidencia que todas las entidades han realizado esfuerzos para mejorar su labor misional. En efecto, el documento señalado logró establecer que en todos los procesos existen aplicaciones, pero el grado de madurez y de estandarización de los mismos es muy bajo; incluso se trata también de esquemas metodológicos y conceptuales, pues existen dos fuertes tendencias en la manera de ejecutar el control fiscal: una orientada al control de gestión y resultados y otra enfocada netamente en los aspectos presupuestales y financieros.

Posteriormente, se adelantó una labor conjunta con el Ministerio de las Tecnologías de la Información y Comunicaciones - MINTIC y algunas contralorías territoriales con el propósito de establecer un sistema único de control fiscal. Al respecto, la línea de acción propuesta se soporta en la heterogeneidad, no tanto en función de los procesos, sino más bien de los sujetos de control a cargo de las contralorías y de la AGR.

El objetivo de dicha actividad, fue presentar una propuesta de procesos y procedimientos en el marco de una futura implementación tecnológica de la solución de Control Fiscal en Línea e identificar las mejores prácticas en cuanto al diseño de aplicativos y los sistemas informáticos encontrados en uso en las Contralorías.

De conformidad con los lineamientos establecidos por las entidades participantes, los ejes temáticos propuestos se desarrollaron en los siguientes procesos: 
- Rendición de cuentas (Incluye la descripción del eje de control a la contratación).

- Proceso Auditor (Incluye la descripción del eje Plan General de Auditoría).

- Responsabilidad fiscal.

- Cobro coactivo.

- Administrativo sancionatorio.

- Participación ciudadana

Al respecto se destacan las conclusiones (MINTIC, AGR 2012) de las cuales se extracta que:

(...) Para la operación del modelo es necesario que el proceso propuesto sea flexible y acorde a la realidad e infraestructura; no solo, de cada contraloría sino de cada sujeto de control. Por lo tanto, deben suponerse niveles de integración medio y bajo que permitan a todos los actores cumplir con sus tareas independientemente del grado de automatización con las que se ejecuten; pues no es obligatorio que la interoperabilidad deba surtirse en esquemas de automatización plena.

(...) Todas aquellas tareas que no puedan ser ejecutadas por el sistema, deben ser remitidas a un back office en el que se fijen estándares de tiempo y resultado.

(...) El equipo de implementación de la estrategia debe tener en cuenta que, en la actualidad, todos los procesos se caracterizan por ser de carácter interinstitucional pero que tal y como se evidenció en el trabajo de campo, hoy día se ejercen actividades aisladas, en cierta medida desordenadas.

(...) Este ejercicio implicaría el desarrollo de mesas técnicas para revisar el grado de madurez del CHIP y del SECOP e identificar las variables y campos de información adicionales; así mismo, el tipo de validación que se realiza durante el cargue. Se hace alusión específica a estos dos sistemas porque en el trabajo de campo, se pudo tener conocimiento de su funcionamiento y porque soporta información clave para la rendición de cuentas en materia presupuestal contable y contractual.

(...) En lo que concierne a requerimientos específicos para las funcionalidades del sistema que soportará los procesos de control fiscal en línea, se considera pertinente reconocer que el diseño de la plataforma debe ser parametrizable de tal suerte que, por cada una de las actividades de los procesos, se permita fijar reglas por cada contraloría y por cada sujeto de control (...).

Finalmente, después de cinco (5) años de presentado el anterior documento, la puesta en marcha de las propuestas allí elaboradas no se habían materializado. Una de las situaciones que afectó el avance de este importante trabajo, fue la posición de la Contraloría General de la República, la que en su momento no concibió que la labor se estuviera realizando por parte de la AGR y las contralorías territoriales, sino que dicha acción debería tener su liderazgo, bajo los parámetros técnicos que ella determinara. En conclusión, es mínimo el avance frente al cumplimiento de ese mandato legal y mucho menor el de consolidar la estructura de un verdadero control fiscal en línea. 


\section{OPPCF}

\subsubsection{Control social para el fortalecimiento del control fiscal.}

Con relación a este tema, la Organización Latinoamericana y del Caribe de Entidades Fiscalizadoras Superiores - OLACEFS, se ha pronunciado acerca de la incidencia ciudadana en el ejercicio del control fiscal:

(...) Este mecanismo de participación ciudadana en el control fiscal está orientado a generar espacios de diálogo y deliberación para influir en la formulación de políticas públicas para el mejoramiento del control fiscal, la gestión pública y la rendición de cuentas institucionales a la ciudadanía. La puesta en marcha de este mecanismo debe partir del reconocimiento de la naturaleza pública de los problemas sobre los cuales desea promoverse la incidencia, así como de la disponibilidad de marcos normativos que facilitan la participación ciudadana en la definición, formulación, implementación, seguimiento y evaluación de las políticas públicas.

El desarrollo de este mecanismo requiere de la movilización de importantes sectores institucionales y sociales además del liderazgo nacional de las EFS. (...) (OLACEFS, 2014, p.10)

Los diagnósticos elaborados sobre la situación del control fiscal territorial en Colombia han evidenciado de forma común, la baja o insuficiente participación por parte de la ciudadanía en el control de los recursos públicos (Ochoa y Charris, 2003; López, 2006; Restrepo, Araujo y Tuta, 2010; Matute, 2011; Peláez, Tuta y García, 2013). En este sentido, se manifiesta una problemática asociada no solo al cumplimiento del mandato establecido en el artículo 270 de la Carta Política, sino también al deber que tienen todos los ciudadanos de ejercer el control social para contribuir a la eficiente y eficaz destinación de los recursos públicos.

Según los reportes de los procesos de responsabilidad fiscal en curso, solo el $2 \%$ de estos tienen su origen en las denuncias realizadas por la ciudadanía (AGR SIREL-SIA, 2017), porcentaje que se encuentra por debajo del promedio de otras participaciones de acuerdo con la Encuesta de Cultura Política del DANE 2017, la cual reporta una participación en acciones comunitarias de $13,5 \%$; en recreación, cultura y deporte de $11,7 \%$ y en actividades de tipo espiritual o religioso de 74,5\% (DANE, consultado en diciembre de 2017). Estos hechos indican que la ciudadanía colombiana, a pesar de reconocer la problemática en relación con la desviación de recursos públicos y la necesidad de realizar control social sobre el erario, no participa de estas con el mismo interés que en otro tipo de actividades (en promedio 25\%, DANE, 2017).

La baja participación en el control social por parte de la ciudadanía puede estar explicada por varias razones: desconocimiento de los instrumentos para ejercer control social y control fiscal (DANE, 2017), indiferencia frente a la problemática nacional (López, 2013), falta de credibilidad frente a las instituciones del Estado (CNCLCC, 2014), riesgos en la integridad o seguridad personal y familiar (El País, 2017); sin embargo, Olken (2007), en sus estudios sobre corrupción demuestra que la participación ciudadana tiene impacto, bajo un conjunto limitado de 


\section{circunstancias:}

(...) La evidencia empírica sugiere que el monitoreo ciudadano puede ser efectivo en circunstancias en las que hay poca libertad o intereses privados involucrados. Por ejemplo, los programas que proporcionan bienes privados, como alimentos subsidiados, educación o atención médica, donde los ciudadanos tienen un interés personal en garantizar que se entreguen los productos y se minimice el desvío de recursos, pueden ser candidatos apropiados para el monitoreo de base. Para los bienes públicos en los cuales los incentivos para monitorear son mucho más débiles, como los proyectos de infraestructura, los resultados muestran que el uso de auditores profesionales puede ser mucho más efectivo (...) (Olken, 2007, p. 244).

En este sentido, el impacto de la participación ciudadana en el ejercicio de control social, es limitado en ciertas circunstancias y sus efectos no son los mismos en la totalidad de sectores y categorías en que se dividen los recursos públicos. Por esta razón, las propuestas en las que se involucre la participación de la ciudadanía deben contemplar estas restricciones y contener la focalización de los mecanismos utilizados hacia las áreas o sectores en donde se evidencian mayores impactos.

\section{De otra parte, la Comisión Nacional Ciudadana para la Lucha Contra la Corrupción (CNCLCC) en} su informe de 2014 destacó:

(...) la importancia del control ciudadano para la construcción de paz en Colombia, teniendo en cuenta que la corrupción y los obstáculos a la participación ciudadana podrían afectar la implementación de los acuerdos de paz. La CNCLCC resaltó la necesidad de lograr mayor apertura por parte de las autoridades nacionales y locales para proporcionar información a la ciudadanía y rendir cuentas sobre el uso de recursos públicos, así como promover la participación efectiva de grupos ciudadanos afectados por el conflicto armado (...) (CNCLCC, 2014).

Dicha Comisión además indica que:

(...) Es urgente que durante los próximos años se logren resultados efectivos y evidentes para la ciudadanía en materia de prevención y sanción de corrupción en ámbitos como las inversiones públicas del Estado, en los cargos públicos de alto nivel en todas las ramas del poder, en el sistema judicial, en el sistema electoral y los partidos políticos, entre otros campos. Para esto, resulta fundamental una mayor coordinación entre distintas instancias del Estado para combatir la impunidad de los casos de corrupción que afectan a toda la sociedad y de esta manera empezar a generar confianza en la misma (...) (Olken, 2007, p. 244).

En consecuencia, habrá que fortalecer la participación ciudadana con las siguientes medidas:

- Convocar a la ciudadanía para el ejercicio de control social, focalizando su participación en los sectores donde están involucrados los intereses privados de la ciudadanía como: salud, educación, vivienda, servicios públicos domiciliarios, entre otros.

- Diseñar e implementar un programa de pedagogía en control social impulsando redes con distintos actores de la sociedad civil (Peláez, Tuta y García, 2013), en los que se generen 


\section{OPPCF}

estrategias conjuntas con los organismos de control (Fiscalía General de la Nación, Procuraduría General de la República, Contraloría General de la República, Auditoría General de la República y Contralorías Territoriales).

- Diseñar e implementar políticas públicas de participación ciudadana para la lucha contra la corrupción en el ámbito territorial, de acuerdo con las políticas nacionales actuales: Ley 1474 de 2011 (Estatuto Anticorrupción), CONPES 167 de 2013 (Política Anticorrupción), Ley 1712 de 2014 (Ley de Transparencia), Ley 1757 de 2015 (Ley de Promoción y Protección de la Participación Ciudadana), entre otras.

- Brindar información a los ciudadanos, mediante la elaboración de aplicativos informáticos de fácil acceso en la que se superpongan datos georreferenciados de la ejecución de contratos o intervenciones con recursos públicos (planes, programas, proyectos) en los sectores de salud, educación, vivienda, servicios públicos domiciliarios, entre otros, con sus objetos y montos. En ese sentido, se buscaría fortalecer los desarrollos e iniciativas del MINTIC, utilizando como punto de partida las políticas públicas territoriales de lucha contra la corrupción.

- Diseñar e implementar con el sector privado programas de responsabilidad social, que impulsen procesos de formación de la ciudadanía en identificación de riesgos en la prestación de servicios y mecanismos de monitoreo de recursos públicos en los sectores de mayor impacto.

- Generar estudios especializados, guías o instructivos elaborados especialmente para el monitoreo ciudadano, con herramientas de análisis y argumentación que puedan ser verificados en los contextos locales.

- Implementar en el ámbito territorial mecanismos para el fortalecimiento de veedurías ciudadanas en articulación con las políticas nacionales.

- Diseñar e implementar proyectos de cooperación y alianzas estratégicas con los actores involucrados en la lucha contra la corrupción (sector privado, academia, sector público, organismos de control, organizaciones no gubernamentales, entre otros) para que, con el apoyo de la ciudadanía, se construyan redes de alertas tempranas anticorrupción.

\subsubsection{Ampliación del periodo constitucional del Auditor General de la República}

Este tema ha sido ampliamente debatido en diferentes instancias a nivel nacional, es así que, en el informe de ponencia para primer debate al proyecto de acto legislativo 072 de 2013, presentado ante la Cámara de Representantes, por medio del cual se propuso la modificación 
del artículo 274 de la Constitución Política de Colombia, se tuvieron en cuenta entre otras las siguientes consideraciones:

- Actualmente el periodo constitucional del Auditor General de la República es de dos (2) años, mientras que el periodo de los contralores es de cuatro (4) años. Es importante señalar que la Constitución de 1991 estableció periodos para las autoridades públicas así: cuatro (4) años para el Presidente de la República, Procurador General de la Nación, Defensor del Pueblo, y Fiscal General de la Nación. En el ámbito territorial los Gobernadores, Alcaldes y Personeros, también cuentan con un periodo de (4) cuatro años.

- Los planes y programas proyectados por los Contralores se desarrollan en períodos de cuatro (4) años establecidos por la Constitución y la Ley, el seguimiento y evaluación a que está sometida su gestión, también debería realizarse en un período similar, lo que permitiría efectuar evaluaciones globales al vencimiento del período, verificando el grado de cumplimiento de las metas trazadas por las Contralorías y su contribución a la lucha contra la corrupción y la ineficiencia e ineficacia en la gestión fiscal.

- El periodo de dos (2) años, previsto en la actual Constitución no es suficiente para poder ejecutar proyectos sólidos para la mejora del control fiscal, máxime cuando la principal misión de la Auditoría General es la coadyuvancia para la mejora del control fiscal, lo cual conlleva una serie de estrategias a mediano y largo plazo que no es posible ejecutarlas en un periodo tan corto.

- Con el actual esquema, el ejercicio del control fiscal por parte de la AGR, está condicionado por un criterio cortoplacista que en nada contribuye al desarrollo y mejoramiento de las Contralorías como órganos de control que combaten la corrupción y buscan el resarcimiento al daño patrimonial al Estado.

- El periodo del Auditor General de la República ampliado, permitirá que sus funciones se desarrollen en la forma requerida y arrojen los resultados esperados por la ciudadanía, garantizando que los recursos públicos asignados a las Contralorías se administren de manera eficiente y se destinen a la satisfacción del cometido estatal, para el cual fueron creadas.

Por lo anterior, es pertinente insistir en la necesidad de ampliar el período del Auditor General de la República a cuatro años, como el de los demás organismos de control. Igualmente se propone que el inicio del periodo no coincida con el del Contralor General de la República.

\subsection{CONCLUSIONES}

En los párrafos precedentes se ha expuesto lo que, a juicio de la AGR, constituyen temas fundamentales que deben ser abordados por las instancias correspondientes, el Congreso de la República, el Gobierno Nacional, las Contralorías y la misma Auditoría General de la República, para definir el futuro inmediato de los organismos de control fiscal y su efectividad en la lucha contra la corrupción. 
Para ello se han tratado los requerimientos legales y técnicos que posibilitarían una reforma que permita una eficiente y efectiva estructura del control fiscal territorial. En consecuencia, las medidas que han de adoptarse en cada caso serían de orden constitucional, legal y también aquellas que pueden y deben abordarse por parte de los mismos organismos de control sin necesidad de reforma jurídica.

\section{Propuestas de reforma constitucional:}

1.1. Fortalecimiento y articulación de la actual estructura del control fiscal. Creación Constitucional de un Sistema Nacional Territorial de Control Fiscal, que amplíe, mejore e institucionalice el SINACOF de la CGR; integrado por todas las instituciones de control fiscal de primer y segundo nivel y por las instituciones representativas del control interno y representantes de la sociedad civil organizada.

1.2. Elevar a rango constitucional el control fiscal preventivo establecido en el Estatuto Anticorrupción. Retomar la función de advertencia o su equivalente, como producto del ejercicio inmediato del control fiscal posterior, frente al riesgo de pérdida de patrimonio público.

\subsection{Crear una jurisdicción especial para los procesos de responsabilidad fiscal.}

1.4 Ampliar a cuatro años el periodo del Auditor General de la República.

\section{Propuestas de reforma legal:}

2.1 Supresión o modificación de la Ley 617 de 2000 en lo relacionado con los presupuestos de las contralorías y supresión del artículo 15 de la Ley 330 de 1996, en cuanto a la prohibición a las contralorías departamentales de contratar por prestación de servicios. Adoptar una nueva metodología para calcular el presupuesto de las contralorías, estableciendo para todas, la posibilidad legal de incluir en el presupuesto el rubro de inversión.

\subsection{Reglamentar la carrera administrativa del control fiscal territorial.}

2.3 Independencia y autonomía de los organismos de control fiscal territorial. La meritocracia, como requisito único para la selección de contralores territoriales y sus equipos directivos. La elección por cuatro años, con periodos no coincidentes con los de los gobernantes vigilados.

2.4 Liberar a las contralorías territoriales de la función de adelantar y tramitar hasta su culminación los procesos de responsabilidad fiscal y de cobro coactivo, y trasladar tal función en una jurisdicción real, como la de lo Contencioso Administrativo, adicionando los procesos de responsabilidad fiscal y jurisdicción coactiva en los listados del artículo 104 de la Ley 1437 de 2011.

2.5. Fortalecimiento de las contralorías territoriales, dotándolas de los recursos técnicos, tecnológicos, presupuestales y de talento humano calificado, de manera que dispongan de la suficiente capacidad gerencial para cumplir con la misión constitucional asignada.

2.6 Establecer sanciones adicionales a las señaladas en la Ley 42 de 1993, para los gestores de recursos públicos por el no fenecimiento de cuentas; conceptos desfavorables sobre la calidad y eficiencia de control fiscal interno y por la no razonabilidad de los estados contables.

2.7 Articular el sistema de control interno y el control fiscal y establecer nuevas atribuciones a oficinas de control interno.

\section{Otras acciones para la eficacia del control fiscal que no requieren reforma jurídica:}

3.1 Implementación del ejercicio inmediato del control posterior. 
3.2 Fortalecimiento de la evaluación de la gestión y resultados a través del control al Plan de Desarrollo.

Finalmente, por su importancia la AGR recomendó con base en los anteriores análisis, en el mismo documento de respuesta al CONPES 167, que a la hora de un gran debate sobre la reforma al Sistema de Control Fiscal, se tuviera muy en cuenta las recomendaciones de la Misión de Expertos (AGR y Banco Mundial, 2011), y que se dejara abierta la puerta para desarrollar los contenidos normativos de una reforma legal que posibilitara el control preventivo y una nueva estructura del control fiscal.

Efectivamente, el documento atrás compartido, elaborado por la Auditoría General de la República en desarrollo de la actividad número 110 (5.20) del componente principal de la Política Pública Integral Anticorrupción (PPIA), del CONPES 167 de 2013, a título de propuesta sobre la estructura del control fiscal territorial, fue tenido como insumo en las distintas mesas de discusión del Proyecto de Acto Legislativo 39 de 2019 Senado, 355 de 2019 Cámara "Por medio del cual se reforma el régimen de control fiscal" (Primera vuelta), cuyo texto definitivo fue publicado por Decreto 1275 de 18 de julio de 2019 y que culminó con el Acto Legislativo 004 de 18 de septiembre de 2019, cuyas principales reformas se exponen en el capítulo II de este mismo libro, denominado "Generalidades sobre la trayectoria legal, jurisprudencial y de regulación, del control fiscal en Colombia".

En consecuencia, los análisis elaborados en el documento de diciembre de 2017 y expuestos atrás, no solo mantienen su vigencia sino que constituyen elementos de análisis sustancial, para tener en cuenta al momento de la construcción de políticas públicas de control fiscal en el país.

\subsection{BIBLIOGRAFÍA}

- Auditoría General de la República y Banco Mundial (2011). Sistema Nacional de Control Fiscal Territorial en Colombia". Imprenta Nacional.

- Auditoría General de la República - Peláez, Juan., Tuta, Guillermo y García., Gustavo (2013). La Impostergable Reingeniería del Control Fiscal Territorial. Documento para el debate sobre una política pública del control fiscal. Revista Sindéresis.

- Auditoría General de la República, 2002. El Nuevo Sistema de Control Fiscal Colombiano Sinopsis. Separata especial. Revista Sindéresis.

- Auditoría General de la República. - Ossa, Carlos (2006). Reformar el Control Fiscal Territorial. Necesidad inaplazable para optimizar las finanzas territoriales. Revista Sindéresis 


\section{OPPCF}

- Auditoría General de la República. Rendón, Álvaro- Suárez, Daniel (2001). Bases para un Nuevo Modelo de Control en Colombia. Ponencias II Foro Nacional de Control.

- Base de datos: Auditoría General de la República SIREL-SIA. (2017). Generada en noviembre de 2017.

- Carvajal, L. y Amaya, R. (2004). Colombia e Indonesia: lejanía geográfica, cercanía temática (un ejercicio comparativo)*. Bogotá, Colombia: Embajada de Indonesia en Colombia.

- Contraloría denuncia billonarios sobrecostos en Reficar. (26 de enero de 2016) ElEspectador. Recuperado de http://www.elespectador.com/

- Comisión Nacional Ciudadana para la Lucha Contra la Corrupción (2014). Cuarto Informe de la CNCLCC: «Ciudadanía califica la corrupción como uno de los problemas más graves que enfrenta el país». Bogotá, Colombia. Recuperado de: http://ciudadanoscontralacorrupcion. org

- Contraloría General de la República. Informe de gestión al Congreso y al Presidente de la República 2016-2017. Recuperado de: http://contraloria.gov.co

- DANE (2017). Resultados de la Encuesta de Cultura Política 2017. Bogotá, Colombia: DANE. Recuperado de: http://www.dane.gov.co

- Diaz, Camilo (16 de enero de 2016). La locura de vender Isagén costará \$70.000 millones. Revista Dinero. Recuperado de http://www.dinero.com

- ¿ ¿Funcionará el proyecto de pagar a quienes denuncien corrupción? (3 de marzo de 2017)

- Contraloría denuncia billonarios sobrecostos en Reficar. (26 de enero de 2016) El Pais.com. co. Recuperado de http://www.elpais.com.co

- Gómez, Iván Darío, Céspedes, Fredy (2017) Reestructuración y Fortalecimiento del Control Fiscal. Propuesta para la reforma del control fiscal en Colombia. Documento de trabajo.

- Gómez, Iván Darío, Ordóñez, Tatiana (2010). Vulnerabilidad y Sofisticada Corrupción: Desafío para la Auditoría Gubernamental en Colombia. Revista Internacional LEGIS de Contabilidad y Auditoría (44), 17-36.

- Informe de ponencia para primer debate al proyecto de acto legislativo 072 de 2013 cámara. (2013). Recuperado de http://www.imprenta.gov.co/gacetap/gaceta.indice?v num $=825 \&$ v anog $=2013$

- López, Clara (2006). Control Fiscal Territorial. Realidad y propuesta de Mejoramiento. Bogotá. 
Universidad del Rosario-GTZ.

- López, Clara (2013). Colombia, un país diferente. Las 2 orillas. Recuperado de: https://www. las2orillas.co

- Ministerio de Tecnologías de Información programa Gobierno en Línea y Auditoría General de la República (2012). Documento propuesta de Procesos y Procedimientos para el Nuevo Esquema de Control Fiscal en Línea.

- Naranjo, Rodrigo. (2007) Eficacia del Control Fiscal en Colombia. Derecho Comparado, Historia, Micro organizaciones e Instituciones. Universidad del Rosario.

- Ochoa, Héctor, Charris, Sandra. (2003) Propuesta de un Modelo de Control Fiscal para el Estado Colombiano: El Sistema de Control Fiscal Nacional. ICESI Estudios Gerenciales, (89)

- Olken, B. (2007). Monitoring Corruption: Evidence from a Field Experiment in Indonesia. Boston, USA: Harvard University and National Bureau of Economic Research.

Organización Internacional de las Entidades Fiscalizadoras Superiores OLACEFS (2007). Declaración de México sobre independencia de las EFS (ISAll-10). Recuperado de http//www. intosai.org

Organización Internacional de las Entidades Fiscalizadoras Superiores OLACEFS (2009). Declaración de Asunción Principios sobre Rendición de Cuentas. Recuperado de http// https:// www.agn.gov.ar

Organización Internacional de las Entidades Fiscalizadoras Superiores OLACEFS (2014). Buenas prácticas para el fortalecimiento de las relaciones entre las EFS y la Ciudadanía.

Recuperado de http://www.olacefs.com

Ordóñez, Tatiana (2007). La Responsabilidad Fiscal en Colombia y la Imposibilidad del Resarcimiento Patrimonial. Revista IUSTA Universidad Santo Tomas. 1 (26), 126

Real Academia Española. (2001). Diccionario de la lengua española (22. ${ }^{\mathrm{a} e d .}$.). Consultado en http://www.rae.es/rae.html

Restrepo, M., Araujo, R y Tuta, G. Control Fiscal Territorial. Validación de un modelo de la gestión y los resultados de las contralorías territoriales en Colombia. Universidad del Rosario, Agencia de Cooperación Técnica Alemana GTZ, Bogotá.

Semana en vivo (10 de febrero de 2016). ¿Cuánto fue realmente lo que se robaron en Reficar?

Saqueo de la corrupción equivale a casi un billón de pesos por semana. (26 de febrero de 2017) El Tiempo. Recuperado de http://www.eltiempo.com/ 


\title{
CAPÍTULO VIII
}

\author{
LA DESIGUALDAD, LOS HALLAZGOS, LAS BRECHAS SOCIO ECONÓMICAS Y SU \\ RELACIÓN CON LAS POLIITICAS PÚBLICAS DEL CONTROL Y VIGILANCIA FISCAL
THE INEQUALITY, FINDINGS, SOCIO-ECONOMIC GAPS AND THEIR RELATIONSHIP WITH PUBLIC POLICIES OF FISCAL CONTROL AND \\ SURVEILLANCE
}

\author{
Leyner Mosquera Perea77
}

\section{Resumen}

En el presente capítulo, se abordan elementos que aportan elementos, para la construcción y puesta en marcha de políticas públicas eficientes, efectivas y eficaces, acorde a las características regionales de Colombia. Se analiza el modelo actual de control y vigilancia fiscal, desde el punto de vista de la normatividad actual. A su vez se estudia de forma descriptiva el panorama de las políticas públicas en Colombia. A su vez se examina el contexto económico y social de Colombia, y a nivel de subregiones mediante un estudio de caso sobre el litoral Pacífico. Finalmente se desarrolla un análisis económico, con el propósito de comprender la existencia de aspectos sociales diferentes al rol de las Contralorías territoriales como: la desigualdad, las brechas sociales y económicas, las cuales pueden estar correlacionadas con los hallazgos, la corrupción y el detrimento patrimonial. Lo anterior permite aportar al debate actual de Colombia sobre el enfoque de las políticas públicas para mitigar problemas del control y vigilancia fiscal.

\section{Abstract}

In this chapter, elements that contribute elements are addressed, for the construction and implementation of efficient, effective and specific public policies, according to the regional characteristics of Colombia. The current fiscal control and surveillance model is analyzed, from the point of view of current regulations. In turn, the panorama of public policies in Colombia is

$77 \quad$ Leyner Mosquera Perea. Ingeniero de Producción Industrial del Instituto Tecnológico Metropolitano ITM - Medellín y actual Asesor de la Dirección Nacional de la Escuela Superior de Administración Pública ESAP; Candidato a Magister en Economía Aplicada de la Universidad de los Andes. Investigador del Semillero Pacífico de la Facultad de Economía de la Universidad de los Andes, e investigador del "Observatorio de Política Pública del Control Fiscal" adscrito -según convenio- a la Auditoría General de la República y la Universidad Santo Tomás de Bogotá. 
descriptively studied. In turn, the economic and social context of Colombia is examined, as well as a sub-region level through a case study on the Pacific coast. Finally, an economic analysis is developed, with the purpose of understanding the existence of social aspects different from the role of the territorial Comptrollers such as: inequality, social and economic gaps, which may be correlated with the findings, corruption and property detriment. This allows us to contribute to Colombia's current debate on the approach of public policies to mitigate fiscal control and surveillance problems.

\section{Palabras claves:}

Hallazgos, políticas públicas, Pacífico, Colombia, desigualdad.

\section{Key words:}

Findings, public policies, Pacific, Colombia, inequality

Temario: 8.1 Contexto. 8.2. Metodología y descripción de datos. 8.3. Resultados y análisis. 8.4. Conclusiones. 8.5. Referencias bibliográficas.

\section{Introducción}

El interés por los estudios de políticas públicas en todo el mundo, son cada vez mayores, la producción académica sobre estos temas ha incrementado de forma sustancial en las últimas décadas, lo cual ha permitido que hoy se disponga de elementos científicos y técnicos para desempeñar un mejor análisis, diseño y evaluación de las políticas públicas. (Parsons, 1995).

Las políticas públicas se refieren a la forma en cómo se definen y contribuyen cuestiones y problemas, y a la forma en que llegan a la agenda política y a la agenda de las políticas públicas. A su vez, estudian: “cómo, por qué y para qué los gobiernos adoptan y actúan o no actúan" (Parsons, 1995)

Bajo el diseño e implementación de una política pública deriva que el gobierno establezca una relación horizontal con la sociedad civil (Benavente, 2014) fundamental contar con la participación activa de los ciudadanos para el diseño e implementación de una política pública que atienda las necesidades de la población. La Procuraduría General de la Nación (2013) señala que:

La política pública es el resultado de un proceso social, no de un mandato jurídico ni de una decisión administrativa, es, por el contrario, la concreción de unos ideales que se construyen a partir de unas dinámicas sociales que requieren ser interpretadas y llevadas a una toma de decisiones capaces de ser administradas y continuamente revisadas.

Por otra parte, la constitución Política de Colombia en los artículos, 1, 2 y 3 hace referencia a la

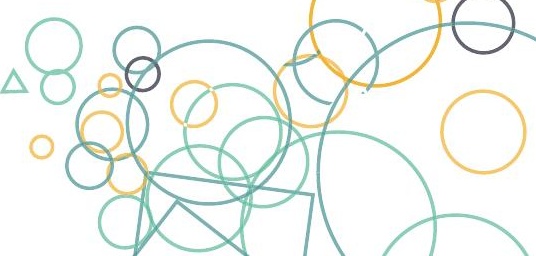


política pública de la siguiente manera:

Artículo 1. Colombia es un Estado social de derecho, organizado en forma de República unitaria, descentralizada, con autonomía de sus entidades territoriales, democrática, participativa y pluralista, fundada en el respeto de la dignidad humana, en el trabajo y la solidaridad de las personas que la integran y en la prevalencia del interés general.

Artículo 2. Son fines esenciales del Estado: servir a la comunidad, promover la prosperidad general y garantizar la efectividad de los principios, derechos y deberes consagrados en la Constitución; facilitar la participación de todos en las decisiones que los afectan y en la vida económica, política, administrativa y cultural de la Nación; defender la independencia nacional, mantener la integridad territorial y asegurar la convivencia pacífica y la vigencia de un orden justo.

Las autoridades de la República están instituidas para proteger a todas las personas residentes en Colombia, en su vida, honra, bienes, creencias, y demás derechos y libertades, y para asegurar el cumplimiento de los deberes sociales del Estado y de los particulares.

Artículo 3. La soberanía reside exclusivamente en el pueblo, del cual emana el poder público. El pueblo la ejerce en forma directa o por medio de sus representantes, en los términos que la Constitución establece.

De acuerdo con lo anterior se puede establecer que la política pública exhibe un programa concreto que asocia estrategias, decisiones, acciones y evaluaciones, sobre la base de unos indicadores apropiados al seguimiento de una o varias situaciones que deben impactarse en consideración a unos objetivos claramente establecidos (Torres, 2006)

De acuerdo con la visión de la Alcaldía Distrital de Bogotá que a través de la "Guía para la formulación e implementación de una política pública del Distrito" define la política pública como: La Política Pública se inscribe como;

(...) un proceso de planeación que define una visión de largo plazo que sobrepasa los periodos de administración de los gobiernos y orienta el proceso de cambio frente a realidades sociales relevantes. Es un instrumento de planeación orientado a la acción para lograr objetivos prioritarios, fruto de un proceso de concertación intersectorial y co-creación, en el que participa la administración distrital, la ciudadanía, la sociedad civil, los gremios, la academia, etc.

Este proyecto colectivo, como instrumento que favorece la cooperación entre diferentes sectores de la sociedad, exige un trabajo intersectorial por parte de las entidades del Gobierno Distrital y de éstas con la ciudadanía, para establecer de forma conjunta la manera de abordar las necesidades más importantes de la ciudad, los enfoques de derechos humanos, género, poblacional, diferencial y territorial, así como sus alternativas de solución.

También es un proceso que demanda un conocimiento sobre la situación desde diferentes perspectivas, contemplar alternativas de solución y la identificación de tensiones entre las personas involucradas, para llegar a acuerdos sobre: las metas que se quieren alcanzar, la manera para lograrlo, la inversión requerida y el tiempo proyectado para generar el cambio.

Es fundamental destacar las formas como las entidades del estado colombiano conciben las políticas públicas, El Departamento Nacional de Planeación - DNP es una entidad 
eminentemente técnica que impulsa la implantación de una visión estratégica del país en los campos social, económico y ambiental, a través del diseño, la orientación y evaluación de las políticas públicas colombianas, el manejo y asignación de la inversión pública y la concreción de las mismas en planes, programas y proyectos del Gobierno. Los departamentos administrativos son entidades de carácter técnico encargadas de dirigir, coordinar un servicio y otorgar al Gobierno la información adecuada para la toma de decisiones. Tienen la misma categoría de los Ministerios, pero no tienen iniciativa legislativa.

De acuerdo al papel del DNP es fundamental contar con su perspectiva de la política pública: El seguimiento y la evaluación de las políticas públicas adquieren especial relevancia en la práctica de gobierno.

El cual, inspirado en los modelos del sector privado, parte de definir a los administradores públicos como gerentes responsables de hacer eficiente el gasto y maximizar el valor público de las intervenciones estatales.

Teniendo en cuentas las visiones presentadas en las líneas anteriores se puede concluir que, las políticas públicas es un mecanismo importante donde el gobierno Nacional genera un relacionamiento con la población civil, debido a que a través de la política pública se plantean soluciones concretas que buscan atender las necesidades de la población. La correcta implementación de las mismas, pueden derivar o no en un eficiente gasto de los recursos públicos y en la atención oportuna, efectiva y eficiente de las necesidades de una Nación.

Un error frecuente que se presenta en contextos de formulación y puesta en marcha de políticas públicas en Colombia, es la falta de entendimiento de las dinámicas locales, muchas veces estas políticas no funcionan de forma correcta debido a que carecen de realidad de los territorios.

En el presente capítulo, se busca aportar elementos que promuevan la discusión para la formulación de políticas públicas para la vigilancia y el control fiscal sólidas en términos de eficiencia, eficacia y efectividad, acorde a las realidades de los territorios de un país tan diverso

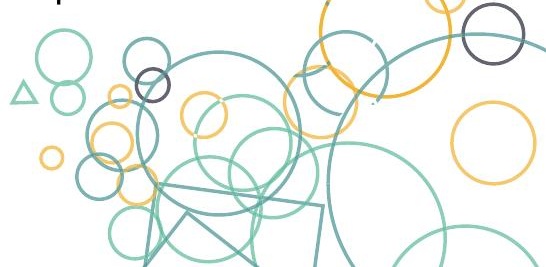


como lo es Colombia.

Colombia es un país heterogéneo en términos de diversidad cultural, económica, costumbres y social (Sánchez, 2012). Esto es muy importante tenerlo presente cuando se proponen políticas públicas de estas características, incluso hay diversidad en una misma región, como lo es el caso del Pacífico Colombiano, donde existe una gran diversidad, no sólo en términos culturales, sino también en condiciones socioeconómicas y desigualdad entre el Pacífico Andino y el litoral Pacífico. A pesar de ser la misma región, existen brechas muy amplias en términos de indicadores socioeconómicos (Cárdenas, 2018), un buen ejemplo es Buenaventura, solo está ubicada a dos horas y media de tiempo de viaje a la ciudad de Cali en el departamento del Valle y las brechas entre ambas ciudades son abismales. De acuerdo a lo anterior, se analizará mediante un estudio de caso las dinámicas socioeconómicas del litoral Pacífico, para entender a manera de ejemplo, las realidades del país en las regiones.

Otro aspecto importante es analizar las políticas públicas del control y vigilancia fiscal desde el punto de vista, de los hallazgos por parte de las contralorías territoriales en los procedimientos de vigilancia fiscal, con el propósito de estudiar la correlación entre estos hallazgos y su relación con el desempeño fiscal de los departamentos. La desigualdad, y el comportamiento de los indicadores socioeconómicos de los departamentos, podrían jugar un papel importante en cuento a este fenómeno.

Procesar, analizar y comprender los datos disponibles de corrupción, datos macroeconómicos, de desigualdad (coeficiente Gini), demográficos, de desempeño fiscal es vital para aportar evidencia científica a la discusión y considerar de forma integral otros aspectos sociales y económicos que podrían estar jugando un papel preponderante en las políticas públicas de control y vigilancia fiscal en Colombia.

De acuerdo con la Constitución Política de Colombia de 1991, el artículo 267 señala que

"el control fiscal es una función pública que ejercerá la Contraloría General de la República, la cual vigila la gestión fiscal de la administración y de los particulares o entidades que manejen fondos o bienes de la Nación.

Dicho control se ejercerá en forma posterior y selectiva conforme a los procedimientos, sistemas y principios que establezca la ley. Esta podrá, sin embargo, autorizar que, en casos especiales, la vigilancia se realice por empresas privadas colombianas escogidas por concurso público de méritos, y contratadas previo concepto del Consejo de Estado.

La vigilancia de la gestión fiscal del Estado incluye el ejercicio de un control financiero, de gestión y de resultados, fundado en la eficiencia, la economía, la equidad y la valoración de los costos ambientales. En los casos excepcionales, previstos por la ley, la Contraloría podrá ejercer control posterior sobre cuentas de cualquier entidad territorial" 
El Artículo 267 de la CPC: Define el control Fiscal como una función pública e indica que este se realiza en forma posterior y selectiva.

El artículo 268 de la Constitución Política de Colombia: Le otorga atribuciones al contralor para prescribir los métodos y la forma de rendir cuentas y la revisión y su fenecimiento para lo siguiente:

1. Prescribir los métodos y la forma de rendir cuentas los responsables del manejo de fondos o bienes de la Nación e indicar los criterios de evaluación financiera, operativa y de resultados que deberán seguirse. 2. Revisar y fenecer las cuentas que deben llevar los responsables del erario y determinar el grado de eficiencia, eficacia y economía con que hayan obrado. 3. Llevar un registro de la deuda pública de la Nación y de las entidades territoriales. 4. Exigir informes sobre su gestión fiscal a los empleados oficiales de cualquier orden y a toda persona o entidad pública o privada que administre fondos o bienes de la Nación. 5. Establecer la responsabilidad que se derive de la gestión fiscal, imponer las sanciones pecuniarias que sean del caso, recaudar su monto y ejercer la jurisdicción coactiva sobre los alcances deducidos de la misma. 6. Conceptuar sobre la calidad y eficiencia del control fiscal interno de las entidades y organismos del Estado. 7. Presentar al Congreso de la República un informe anual sobre el estado de los recursos naturales y del ambiente. 8. Promover ante las autoridades competentes, aportando las pruebas respectivas, investigaciones penales o disciplinarias contra quienes hayan causado perjuicio a los intereses patrimoniales del Estado. La Contraloría, bajo su responsabilidad, podrá exigir, verdad sabida y buena fe guardada, la suspensión inmediata de funcionarios mientras culminan las investigaciones o los respectivos procesos penales o disciplinarios. 9. Presentar proyectos de ley relativos al régimen del control fiscal y a la organización y funcionamiento de la Contraloría General. 10. Proveer mediante concurso público los empleos de su dependencia que haya creado la ley. Esta determinará un régimen especial de carrera administrativa para la selección, promoción y retiro de los funcionarios de la Contraloría. Se prohíbe a quienes formen parte de las corporaciones que intervienen en la postulación y elección del Contralor, dar recomendaciones personales y políticas para empleos en su despacho. 11. Presentar informes al Congreso y al Presidente de la República sobre el cumplimiento de sus funciones y certificación sobre la situación de las finanzas del Estado, de acuerdo con la ley. 12. Dictar normas generales para armonizar los sistemas de control fiscal de todas las entidades públicas del orden nacional y territorial. 13. Las demás que señale la ley.

Ley 42 de 1993: Por medio de la se reglamenta la organización del sistema de control fiscal financiero y determina los organismos que lo ejercen.

Los artículos 1 y 2 establecen: "Artículo $1^{\circ}$ : La presente Ley comprende el conjunto de preceptos que regulan los principios, sistemas y procedimientos de control fiscal financiero; de los organismos que lo ejercen en los niveles nacional, departamental y municipal y de los procedimientos jurídicos aplicables." Mientas que el Artículo $2^{\circ}$ :

Son sujetos de control fiscal los órganos que integran las ramas legislativa y judicial, los órganos autónomos e independientes como los de control y electorales, los organismos que hacen parte de la estructura de la administración nacional y demás entidades nacionales, los organismos creados por la Constitución Nacional y la ley que tienen régimen especial, las sociedades de economía mixta, las empresas industriales y comerciales del Estado, los particulares que manejen fondos o bienes del Estado, las personas jurídicas y cualquier otro

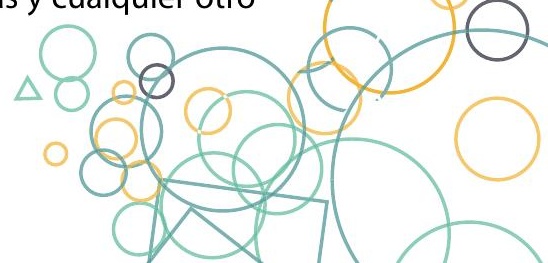




\section{OPPCF}

tipo de organización o sociedad que maneje recursos del Estado en lo relacionado con éstos y el Banco de la República.(....)

La Resolución Orgánica 7350 de 2013: Por medio de la cual se define la forma de presentación de rendición de cuentas - SIRECI. Resolución Orgánica 012 del 24 de marzo de 2017: Auditorias financieras Resolución Orgánica 014 de junio 14 de 2017: Auditorias de cumplimiento Resolución orgánica 015 de junio 21 de 2017: Auditorias de Desempeño Cuando una economía es saludable y con el propósito de comprender que no se debe coincidir las políticas públicas de Colombia como el resto de países de la región. Fue asignada institucionalmente, siguiendo la tradición, a la Contraloría General de la República, cuyo objeto es la vigilancia de la ejecución del fisco, tanto en su condición matemática como en su versión material o sustancial, es decir, el direccionamiento del gasto público, lo cual coincide con las tendencias de la doctrina (Lee, 2006)

Según la versión constitucional el control y vigilancia fiscal es posterior. Concepción que arraiga en la tendencia que previene obstaculizar la ejecución del gasto, lo cual se sigue considerando que tiene efectos macroeconómicos adversos, fuera de ser más afín a presupuestos axiológicos como la eficacia, eficiencia y modulación de la acción pública, así como a presumir la buena fe, no sólo del ciudadano sino del funcionario público (Blöchliger, 2006)

Si una Nación no cuenta con una política pública eficiente y efectiva para Control y vigilancia fiscal, esto podría derivar en un déficit fiscal, de acuerdo a lo anterior, el control y vigilancia fiscal se podría considerar como un mecanismo institucional del Estado por el cual se le pueden hacer seguimiento al correcto gasto de los recursos públicos ejecución. Una buena gestión de la vigilancia y el control fiscal, podría derivar aspectos claves para una democracia como la gobernabilidad y la eficiencia de los recursos públicos lo cual garantiza un mayor bienestar en la sociedad.

Según cifras de la Contraloría General de la Nación, las Contralorías Territoriales, tan solo recuperan el $0,04 \%$ de lo que cuesta mantener el funcionamiento las estructuras de las Contralorías Territoriales. En primera instancia este pareciera ser un dato desalentados si se observa desde el punto de vista de rentabilidad financiera, pero en términos de impactos sociales y económicos, los hallazgos juegan un papel importante en la sociedad colombiana, incluso así no se recupere todo el dinero que se debería recuperar, debido a que generan externalidades positivas sobre la sociedad, el hecho de realizar auditorías rigurosas.

Encontrar hallazgos, así estos no hayan derivado en detrimento patrimonial ya estaría generando un cambio de comportamiento de los individuos o entidades que son auditadas. 
No se trata de generar incentivos perversos en las Contralorías, en cuento a que sean medidas de acuerdo a la cantidad de dinero que recuperen, o de acuerdo a la cantidad de casos de corrupción que encuentren, o al número de funcionarios o entidades que sancionen. Este incentivo podría ser perjudicial para el control fiscal en Colombia, debido a que se podría generar más corrupción en lugar de prevenirla y/o detenerla.

Es fundamental buscar los mecanismos técnicos y tecnológicos que permitan mejorar la eficiencia, eficacia y efectividad del control fiscal en Colombia para de este modo contar con un sistema sólido que permita obtener los resultados que requiere el país en esta materia.

Para lograrlo es importante tener en cuenta factores tan claves como, entender el contexto del país y las regiones y tratar de implementar políticas públicas que tenga en cuenta la información cuantitativa y cualitativa disponible y se focalice de acuerdo a las características de los territorios, dado que los retos que afronta el Valle en términos de control fiscal no son los mismo de Nariño, o los problemas fiscales de Chocó no son los mismo de Cauca, teniendo en cuenta que estos cuatro departamentos están ubicados en la región del Pacífico.

La hipótesis principal de este estudio plantea que los departamentos más rezagados en términos socioeconómicos en Colombia, presentan mayor número de hallazgos y dinero perdido a raíz de la corrupción. Las bajas capacidades de desempeño fiscal podrían estar correlacionadas con los hallazgos. A modo de especulación de hipótesis se plantean los siguientes escenarios: i) Los departamentos con mayor desigualdad (Gini) cuentan con menor número de hallazgos. ii) En cuanto incrementa el número de hallazgos, los departamentos mejoran el índice de desempeño fiscal. iii) Los ingresos los habitantes de un departamento medidos en términos de PIB per cápita podrían estar correlacionados con el número de hallazgos que realizan las contralorías territoriales. iv) Los departamentos más rezagados que menos reportan hallazgos podrían contar con niveles de corrupción más altos. v) El problema de vigilancia fiscal, no solo se aborda desde la perspectiva del incremento del presupuesto de las contralorías territoriales, sino que también es necesario fortalecer otros aspectos sociales a nivel departamental que generarían un efecto positivo sobre el control y vigilancia fiscal en Colombia.

En el presente capitulo, realiza un estudio descriptivo, en cuanto al contexto, del control y vigilancia fiscal, lo que incluye un breve contexto de las políticas públicas en Colombia, luego se aborda un análisis económico de Colombia y se hace un estudio de caso en la región del Pacífico para entender las dinámicas socio económicas del país. Luego se aborda la metodología y descripción de los datos, donde se estima con econometría, la existencia de correlaciones

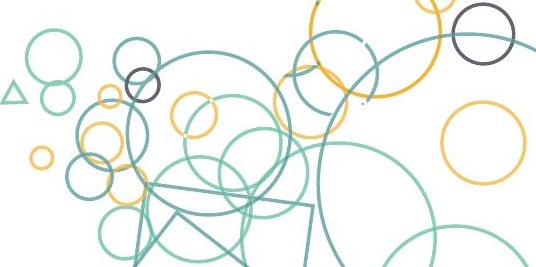


entre variables, como: desempeño fiscal, corrupción, hallazgos por parte de las contralorías departamentales, datos económicos, de desigualdad y demográficos de los departamentos de Colombia. Posteriormente se analizan los resultados, basados las estimaciones econométricas y finalmente se plantean las conclusiones.

\subsection{CONTEXTO}

\subsubsection{Análisis económico de Colombia}

Antes de hacer un análisis empírico y abordar propuestas de políticas públicas para el Control y Vigilancia Fiscal en Colombia, como eje transversal para vigilar los recursos públicos y satisfacer las necesidades de la población colombiana, mediante mecanismos como el uso eficiente de los recursos públicos, es fundamental contar con un entendimiento y comprensión de los diferentes fenómenos económicos que de una otras formas afectan a la población colombiana, el desempeño fiscal también tiene fuertes implicaciones monetarias, por lo que es fundamental abordar este tema con una mirada macroeconómica.

Entender las dinámicas macroeconómicas de Colombia en los aspectos fundamentales, es un buen punto de partida para comprender las dinámicas locales de los territorios del país.

Para medir la importancia de diferentes ramas de la actividad económica en una economía podemos utilizar la contribución de cada una de estas ramas al PIB mediante el cálculo del valor agregado. Las ramas de la actividad económica de un país como Colombia se pueden dividir en:

i. La agricultura que incluye la caza, la pesca, la silvicultura y la ganadería.

ii. La industria que incluye la producción manufacturera, la minería, la construcción y el suministro de electricidad, agua y gas.

iii. Los servicios que incluyen el transporte, comercio, servicios financieros y servicios personales.

iv. Los ingresos del gobierno por conceptos de impuestos menos las subvenciones.

En Colombia para el año 1965 la agricultura representó aproximadamente el 30\% de PIB. En 2016 en Colombia la agricultura representó aproximadamente el 7\% del PIB, De 1995 hasta el 2016 la industria en Colombia representó un crecimiento, siendo en 1988 y 2012 las más altas de Colombia con aproximadamente un 35\%, de participación.

Cuando se calcula el PIB, por el lado del gasto se dice que cada peso gastado entra a alguna de las siguientes categorías: consumo, inversión, gasto del gobierno y exportaciones netas (exportaciones menos importaciones). En las cuentas nacionales la formación bruta de capital 
corresponde a la inversión realizada por los agentes privados más la inversión realizada por el gobierno. Revisando los datos de capital como porcentaje del PIB se encuentra que la inversión en formación bruta de capital en Colombia ha presentado mucha variación a lo largo del tiempo. En 1999 Colombia realizó la inversión más baja en términos porcentuales, mientras en 2015 con casi el 30\% fue la más alta.

En términos generales, la economía de Colombia ha sido estable y siempre ha mantenido un crecimiento anual sostenido alrededor de los 2 puntos.

EI PIB per cápita es igual al PIB dividido el total de la población nacional. Usualmente es una medida del estándar de vida en un país porque mide el ingreso promedio de un habitante y puede ser comparado fácilmente entre países. Pero el PIB, podría ser una medida de bienes que pueda no estar teniendo en cuenta factores no observables con alta reverencia en una economía, como lo es el bienestar social, por ejemplo; puede que el PIB disminuya en términos monetarios en una región cuya dependencia sea mayoritariamente de la minería ilegal, pero en términos de bienestar las condiciones salud de los habitantes mejoren, así como los recursos naturales que ya no son devastados a raíz de esta actividad económica. Por lo que tendría mucho más sentido analizar el PIB teniendo en cuenta otros indicadores como lo es el Gini, el cual mide el índice de desigualdad en una sociedad, esto se explica a continuación luego de abordar el PIB per cápita.

\section{La desigualdad en Colombia}

Como se mencionó en líneas anteriores el coeficiente de Gini es una medida de la desigualdad dentro de un país, en este caso se mira este indicador en términos de ingresos. Un índice de Gini de 0 representa una equidad perfecta, mientras que un índice de 100 representa una inequidad perfecta.

De acuerdo con el cuadro 1, se evidencia que Colombia es el segundo país más desigual de Sudamérica, esto es un dato desalentador.

Tabla 1. Índice Gini de Colombia en Sudamérica en 2017

Desigualdad en países de América Latina - Índice de Gini (de mayor a menor)

\begin{tabular}{ll}
\hline Brasil & 53,3 \\
Colombia & 49,7 \\
Paraguay & 48,8 \\
Chile & 46,6
\end{tabular}




\section{OPPCF}

\begin{tabular}{lc} 
Ecuador & 44,7 \\
Bolivia & 44,0 \\
Perú & 43,3 \\
Argentina & 40,6 \\
Uruguay & 39,5 \\
\hline
\end{tabular}

De acuerdo con lo anterior y teniendo en cuanta el PIB per cápita, Colombia es un país con un PIB per cápita alto, pero a su vez es el segundo país más desigual de América Latina, esto significa que la riqueza está concentrada en una parte pequeña de la población, lo cual conlleva un gran problema social y económico, dado que un PIB per cápita muy alto, no necesariamente está mostrando bienestar a toda la sociedad, esto nos lleva a pensar que si Colombia quiere salir del sub desarrollo, debe comenzar a orientar políticas públicas que le permita cerrar brechas en cuento a los altos niveles de desigualdad.

\section{Consumo, inflación e IPC en Colombia}

Con el propósito de entender el desempeño de Colombia en términos del deflactor del PIB, formación bruta de capital, consumo final del gobierno, consumo de los hogares, IPC e inflación, de acuerdo con la gráfica 1 se pueden sacar las siguientes conclusiones:

- Formación Bruta de Capital: La Formación Bruta de Capital es la serie que presenta mayor variación con un crecimiento negativo hasta de -20 para el I trimestre del año 2004, esto se asocia a que hubo muy baja inversión en bienes y servicios de la economía en ese periodo, lo cual incluye la formación bruta de capital fijo, la variación de existencias y la adquisición menos disposición de objetos valiosos y la más alta en el trimestre siguiente del mismo año.

- Consumo Final del Gobierno: El Consumo Final del Gobierno, se refiere al total del gasto corriente del Gobierno, para la compra de bienes y servicios, para el funcionamiento del mismo, en este sentido, aunque con una curva mucho más suavizada, el consumo final del gobierno reportó la segunda variación más alta siendo el IV trimestre del año 2012 la más baja y el I trimestre de 2006 la más alta, siendo más alta un consumo mayor y siendo bajo un menor consumo.

- Consumo de los hogares: El consumo de los hogares se entiende como la cantidad final de bienes y servicios que consumieron los hogares de una economía, en el caso colombiano, es positivo y estable el consumo de hogares, debido a que según la gráfica 7 este fue la que menos variación tuvo, permaneciendo constante en la mayor cantidad del tiempo, cuando el consumo de los hogares incrementa, esto también dinamiza la economía. 


\section{Gráfico 1. Consumo de los hogares, el consumo del gobierno y Formación Bruta de Capital}

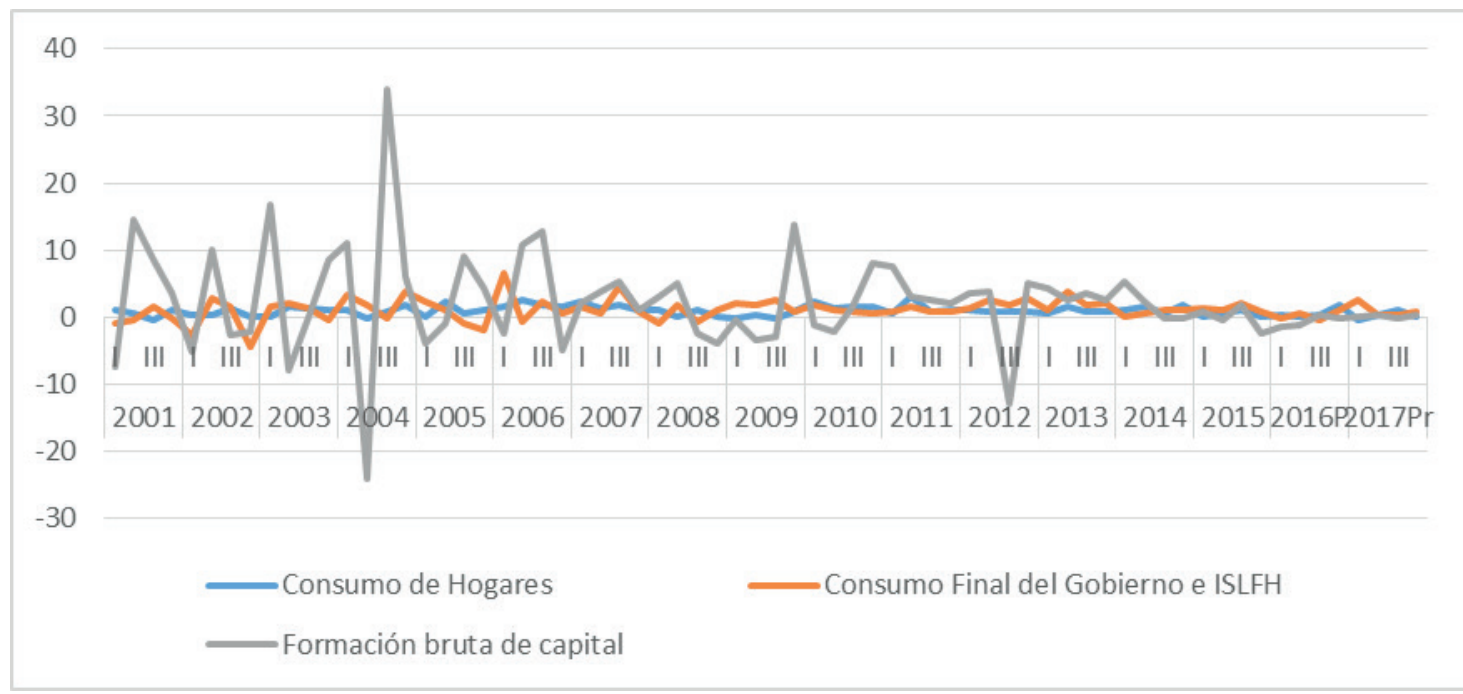

Fuente: Elaboración Propia a partir de datos del DANE

Una medida del tamaño del comercio de un país es la suma de importaciones y exportaciones como proporción del PIB. Usando los datos del PIB a precios constantes a continuación se calcula la serie a partir de valores trimestrales.

De acuerdo con la gráfica 2, en promedio el comercio de Colombia (las suma de las importaciones y exportaciones) en el periodo de 2000 al 2017 representó entre el 30\% y 45\% del PIB, mostrando una tendencia estable y al alza en la mayor cantidad del tiempo, para el IV trimestre del 2017 fue de aproximadamente el 40\%.

\section{Gráfico 2. Suma de importaciones y exportaciones como proporción del PIB}

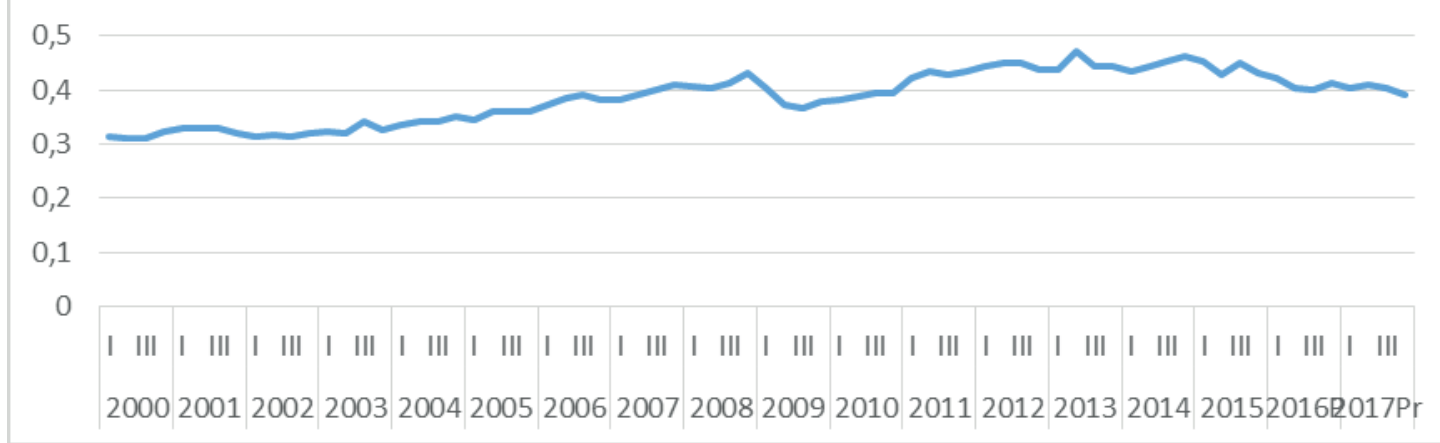

Fuente: Elaboración Propia a partir de datos del DANE 


\section{OPPCF}

El deflactor del PIB es un índice de precios que calcula la variación de los precios de una economía en un periodo determinado utilizando para ello el Producto Interior Bruto (PIB). El deflactor del PIB se utiliza para conocer la parte del crecimiento de una economía que se debe al aumento de precios. En este ejercicio de comprender la macroeconomía de Colombia, el deflactor del PIB se calcula con el fin de suavizar el incremento de precios en una economía y, por tanto, permite corregir las estimaciones del crecimiento de ésta, ya que, si no se utilizara, el crecimiento no sería real, dado que se podría llegar a sobrevalorar. De acuerdo con la gráfica 3 se evidencia que el deflactor del PIB en Colombia ha crecido de forma constante, esto significa que los precios agregados de toda la economía del país (todos los bienes y servicios que conforman el PIB) han incrementado de forma constante en el tiempo.

Gráfico 3. Deflactor del PIB en Colombia

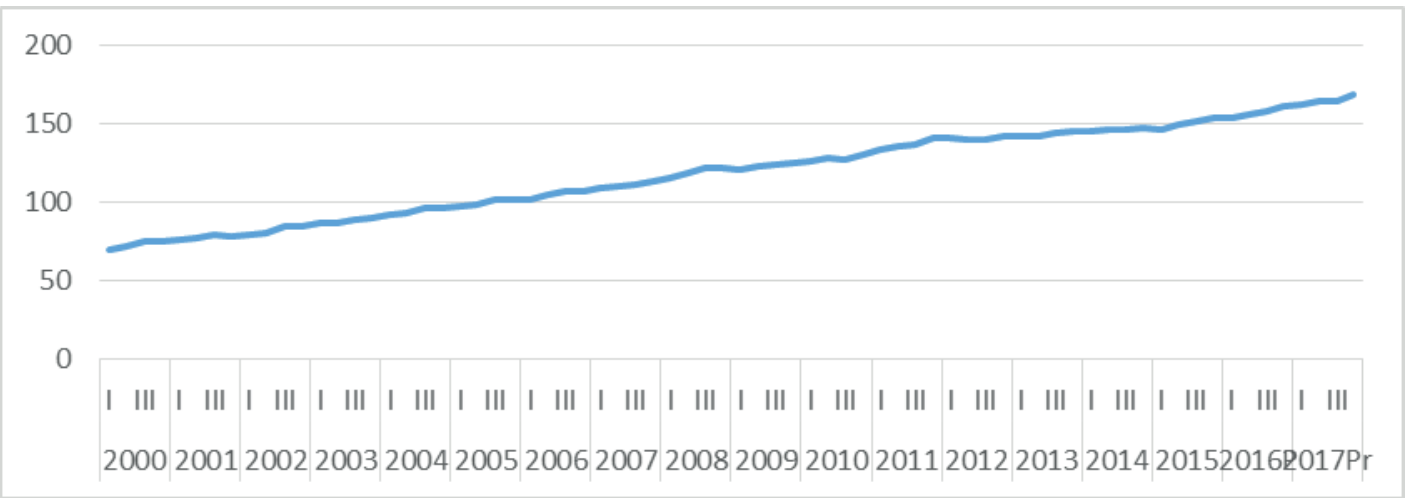

Fuente: Elaboración Propia a partir de datos del DANE

Calculando la serie trimestral del cambio porcentual del IPC y usando los resultados del numeral anterior, se calcula la serie del cambio trimestral del deflactor del PIB para el mismo periodo. Graficando estas dos series en la misma gráfica se muestra en la gráfica 4: El cambio porcentual del PIB presenta picos más altos y bajos en la variación con respecto al Cambio porcentual del IPC, pero en términos generales, ambos presentan una tendencia similar. De 2003 al 2017 la inflación en Colombia osciló entre al 0,2\% y 3 \% pero en general permanece constante. En conclusión, se podrían interpretar que la Inflación ha mantenido un comportamiento regular, lo cual es positivo para una economía.

\section{Gráfico 4. Cambio porcentual del IPC y Cambio porcentual del PIB}




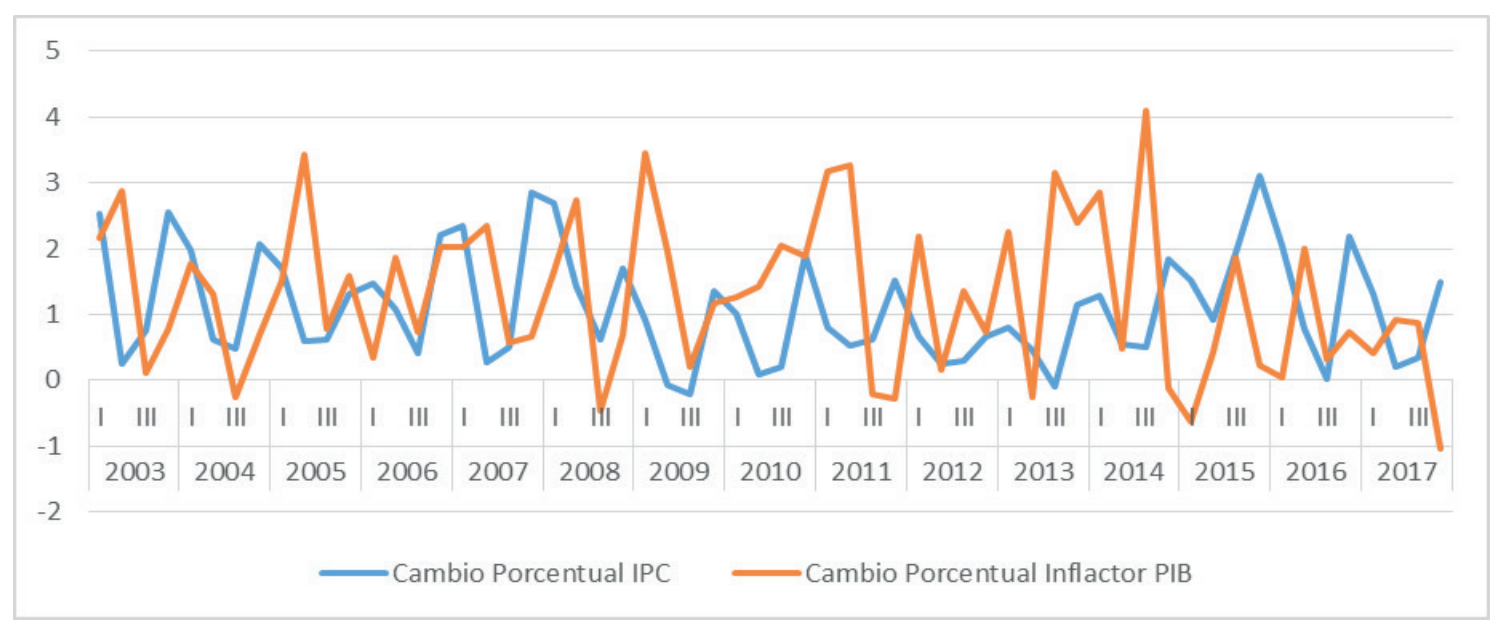

Fuente: Elaboración Propia a partir de datos del DANE

En el año 1991 empiezan los cambios estructurales en la política monetaria del país al otorgarse la independencia al Banco de la República, y el enfoque se deriva hacia el manejo de las variables monetarias, crediticias y cambiarias para "preservar el valor adquisitivo de la moneda". Desde octubre de 1999 se cambió el esquema de inflación objetivo, hacia una inflación baja y estable donde se fija una meta cuantitativa y un rango de control. En 2001 se creó por primera vez la meta de largo plazo, $3 \%$, estableciendo rangos entre $2 \%$ y $4 \%$. Por lo tanto, de acuerdo con el gráfico 5.

\section{Gráfico 5. Inflación anual del consumidor}

GRÁFICO 1 | Inflación anual al consumidor |

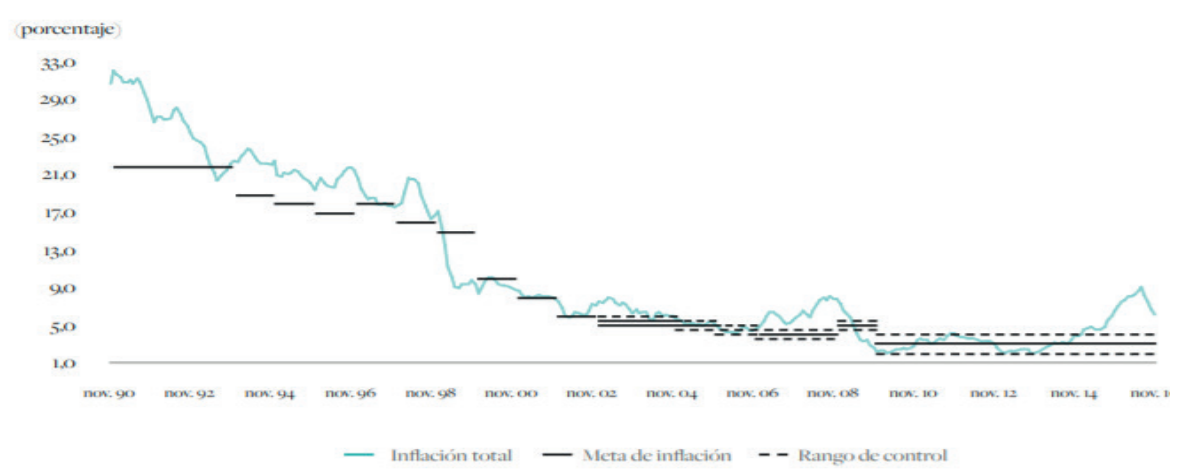

Fuente: DANE y Banco de la República

Los datos de inflación que tienen un comportamiento cercano a la nueva realidad de la 


\section{OPPCF}

economía colombiana puede tomarse a partir de 1999-2001 con un cambio estructural derivado de este enfoque de metas de inflación, el comportamiento actual responde a una tendencia consistente desde 2002 como se puede ver en el gráfico 6.

\section{Gráfico 6. Variación inflación}

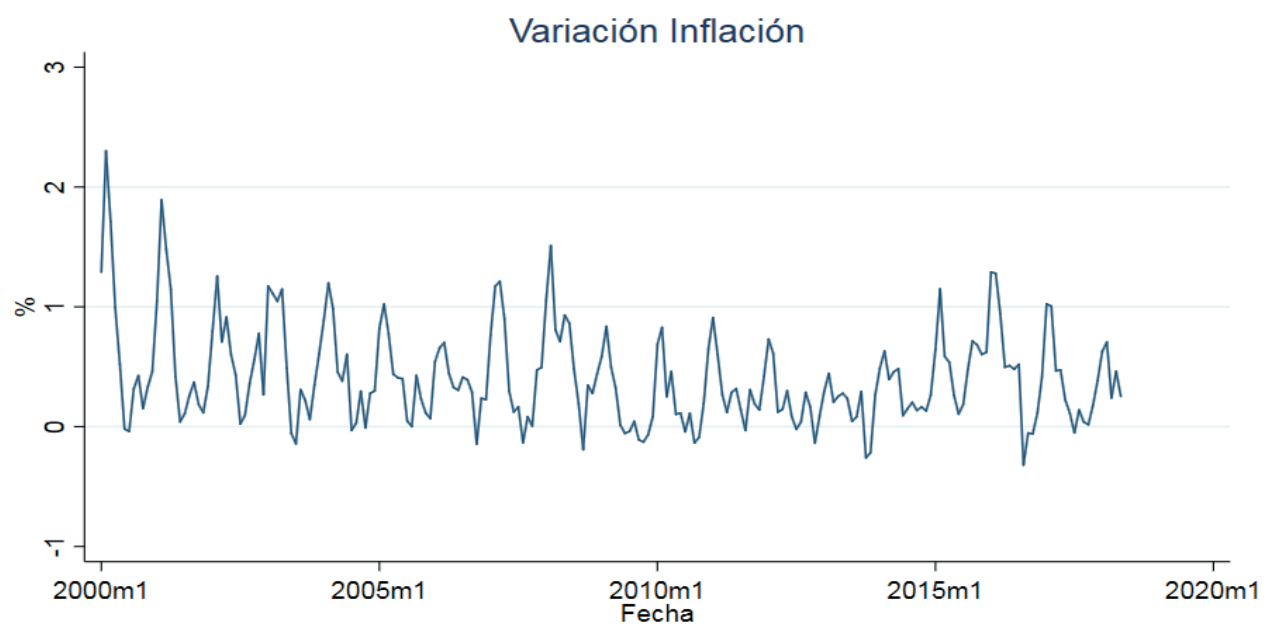

Fuente: DANE

Calculando la serie trimestral del cambio porcentual del IPC y usando los resultados del numeral anterior, se calcula la serie del cambio trimestral del deflactor del PIB para el mismo periodo. Graficando estas dos series en la misma gráfica se muestra: El cambio porcentual del PIB presenta picos más altos y bajos en la variación con respecto al Cambio porcentual del IPC, pero en términos generales, ambos presentan una tendencia similar. De 2003 al 2017 la inflación en Colombia osciló entre al 0,2\% y 3 \%. En conclusión, la Inflación ha mantenido un comportamiento regular, lo cual es positivo para una economía.

Colombia es un país con una economía estable, incluso teniendo en cuenta la recisión económica mundial de 2008, la economía colombiana permaneció sólida y tuvo un buen desempeño, la inflación ha sido bien manejada por el banco central del país. Aún hay retos grandes en cuento al desempleo, y a la desigualdad, Colombia sigue siendo un país muy desigual y esto podría estar generando una situación complicada a la hora de pensar políticas públicas efectivas y eficientes.

Eentender las dinámicas del país y proponer una política pública para el control y vigilancia fiscal acorde a las características sociales y económicas de Colombia es un primer paso, luego 
es importante comprender las dinámicas socioeconómicas de las regiones de Colombia, en cuento a los niveles de desigualdad y como esto puede tener algún tipo de relación con la corrupción y el desempeño fiscal de los departamentos del país, todo este contexto permite conocer mejor el país y ayuda a aterrizar la presente investigación y aportar a la discusión del diseño de una política pública de control fiscal efectiva y eficiente.

\subsubsection{Entendiendo las dinámicas socioeconómicas de las regiones de Colombia: un estudio de caso en el Pacífico}

Hablar del Pacífico es un buen ejemplo para ilustrar y entender las dinámicas socioeconómicas de Colombia, lo cual es un factor clave en la estructuración y puesta en marcha de políticas Públicas eficaz, eficientes y con gran probabilidad de funcionamiento.

El Pacífico colombiano es una región geográfica y natural que abarca los territorios de cuatro departamentos: Chocó, Valle del Cauca, Cauca y Nariño (Romero, 2009). Esta región, con sus 8'410.059 habitantes, abarca un territorio de $83.170 \mathrm{~km} 2$ y equivale al $7 \%$ del territorio nacional. Mientras que el litoral Pacífico es una subregión geográfica y natural que se encuentra dentro de la región del Pacífico y que abarca el cien por ciento del departamento de Chocó, solo Buenaventura en el Valle del Cauca, parte del Cauca y Nariño donde hay una gran variedad de ecosistemas, especies, fauna y flora endémicas. Esta zona está habitada por más de 1'910.957. A Pesar de su riqueza natural y endémica, la economía del litoral es una de las más rezagadas del país; sus indicadores sociales y de bienestar son muestra del enorme rezago relativo del litoral, frente a la región del no litoral pacífico, pese a estar dentro de la misma región.

\section{Ilustración 1: Mapa del litoral Pacífico con Colores y NO litoral sin Colores ${ }^{78}$}

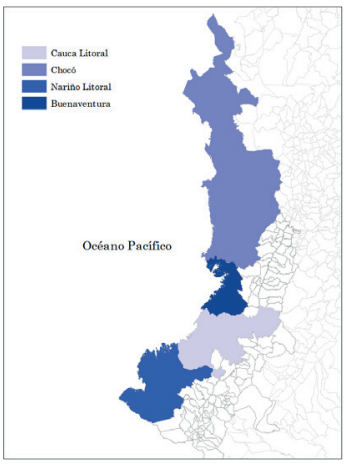

Fuente: Elaboración Propia

78 La figura 1 muestra de forma gráfica la región del Pacífico Colombiano. El litoral es la zona coloreada y el no litoral es la zona en relieve. En el norte el departamento del Chocó, y sus 30 municipios coloreado con un tono azul claro, seguido de Buenaventura con el tono azul más oscuro, luego el litoral cauca compuesto por los Municipios: Balboa, Buenos Aires, Caldono, Caloto, Corinto, El Tambo, Guachené, Guapi, Jambaló, López, Miranda, Morales, Padilla, Puerto Tejada, Santander de Quilichao, Suárez, Timbiquí, Toribio y Villa Rica. Finalmente, el litoral Nariño compuesto por los municipios: Barbacoas, El Charco, La Tola, Magüi, Mosquera, Olaya Herrera, Francisco Pizarro, Roberto Payán, Santa Bárbara, San Andres de Tumaco. 


\section{OPPCF}

Para estudiar la pobreza en el litoral Pacífico se analizarán tres indicadores: línea de pobreza o incidencia de Pobreza Monetaria, Índice de Pobreza Multidimensional (IPM) y Necesidades Básicas Insatisfechas (NBI).

El primero se refiere únicamente a la privación monetaria, por lo que se calcula la proporción de personas que se encuentran debajo del mínimo ingreso que se considera necesario para satisfacer necesidades vitales. Sin embargo, este indicador puede ser muy impreciso, dado que el ingreso necesario para cumplir con este objetivo depende de la edad, condiciones de salud, género, ubicación, atmosfera epidemiológica, tradiciones de la familia y enfermedades crónicas. Por ende, un único valor para toda la población colombiana puede no ser adecuado para todas las personas del litoral Pacífico. Por consiguiente, para lograr un análisis más directo y acertado, se pueden utilizar otros índices como el NBI y el IPM. EI NBI mide la pobreza de la privación de uno de los siguientes indicadores: viviendas sin hacinamiento crítico, condiciones físicas propias para el alojamiento humano, servicios adecuados, baja dependencia económica y niños en edad escolar que asisten a la escuela. No obstante, este índice no tiene en cuenta la privación a las buenas condiciones de salud, ni la de nutrición. Por lo tanto, para esto se analiza el IPM, el cual tiene en cuenta 15 privaciones en las que se incluyen las dimensiones de: educación en el hogar, bienestar de niños y jóvenes, salud, trabajo, vivienda y acceso a servicios públicos. Si no se cumplen con cinco de estas, el hogar se considera pobre. Por ende, se podrían presentar diferencias entre los tres índices si los ingresos mínimos para sobrepasar la línea de pobreza no son suficientes para que una persona cumpla con los requisitos del IPM y NBI. Por lo cual es importante hacer un análisis con estas tres medidas. A continuación, se realizará un análisis de estos índices en el Litoral Pacífico vs el no litoral Pacífico (este último, Pacífico Andino) y el promedio Nacional.

\section{Pobreza Monetaria y desigualdad}

La pobreza en el litoral Pacífico era de 62,4\% en 1993 y de 64,1\% en 2005, frente a valores de $55,8 \%$ y $51,2 \%$ en los mismos años para el total nacional.

Sin embargo, al observar los datos departamentales que incluye el litoral como Chocó, Cauca, Nariño y Valle del Cauca, la tendencia del indicador de Incidencia de la Pobreza Monetaria desde el 2002 hasta el 2016 sí presenta una tendencia a la baja pasando de 57,5\% (2002) a 44,7\% (2016) frente a un paso de la incidencia nacional del 55,1\% (2002) al 34,9\% (2016). No obstante, la región Pacífico sigue teniendo niveles de pobreza mucho más altos que el resto del país. Particularmente, en 2015 el Chocó era el departamento con mayor incidencia de la pobreza de la región, seguido por Cauca y Nariño. Este último departamento mejoró 
significativamente sus indicadores, superando a Cauca y acercándose a la media nacional.

Valle ha presentado valores de pobreza monetaria significativamente más bajos a los de la región y a la media nacional en el periodo estudiado. Esto puede deberse a la presencia de Cali en el departamento que tiene mejores indicadores que el resto de los municipios de Valle.

En cuanto al Índice de Pobreza Extrema, los valores departamentales de la región pasan del $24,7 \%$ (2002) al 19,9\% (2016) mientras que los nacionales pasan del $21,4 \%$ (2002) al 11,6\% (2016). Sin embargo, es el departamento de la región que presenta mejores niveles de pobreza extrema, los cuales fueron de 6,2\%. En cuanto a Chocó y Cauca, las diferencias entre 2002 y 2016 son mínimas y en el caso de ambos departamentos, se está por encima de la media nacional en todos los años.

En cuanto al Gini, el litoral también presenta niveles más altos que el total nacional. De hecho, una gran parte de los indicadores de Gini de 1993 de los municipios del litoral son más altos que la media nacional, o en todo caso, no están muy lejos de ella. Más allá, cuando hablamos de los indicadores del año 2005, se encuentra que todos los municipios del litoral Pacífico presentan un indicador de desigualdad más alto que la media nacional. Además, hay varias observaciones que están por encima de ambas medidas.

\section{Necesidades Básicas Insatisfechas (NBI)}

Para entender el NBI el Pacífico también se tiene en cuenta en el análisis a la ciudad de Medellín (Antioquia), y el promedio nacional, como se evidencia en la gráfica 7, la cual hace palpable la gran brecha que representan las ciudades capitales del no litoral Pacífico y Antioquia respecto a las ciudades más representativas del Litoral en cuanto a las NBI de 1993 hasta el 2011. Mientras la pobreza, medida en término de NBI, cayó en todas las ciudades capitales evaluadas, en la ciudad del litoral las privaciones de NBI han persistido o han empeorado. Los casos más alarmantes son Guapi y Quibdó en los que este indicador muestra una disminución en la calidad de vida, de manera contraria a la tendencia nacional. En particular, Quibdó, a pesar de ser una de las 13 ciudades principales del país, no ha tenido mejorías en las condiciones de bienestar de sus habitantes. 
Gráfico 7. NBI litoral vs NO litoral Pacífico

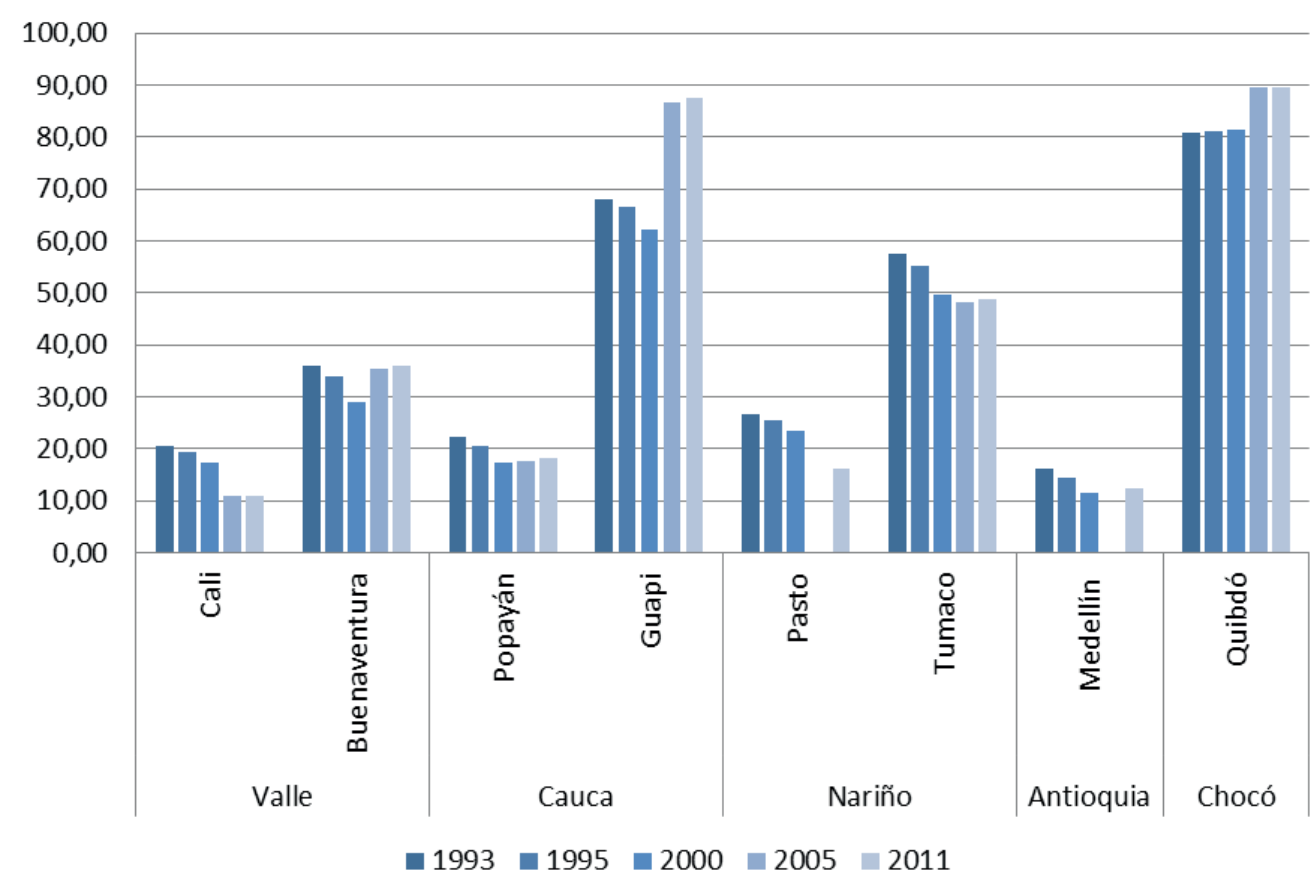

Fuente: Elaboración propia a partir del artículo de Juan Camilo Cárdenas ${ }^{79}$

Si la tendencia en los indicadores de la calidad de vida de los habitantes de cada uno de estos municipios continúa como hasta ahora, a Buenaventura le faltan 4.129 años para alcanzar las condiciones de vida de Cali y eso que están tan solo a dos horas y media de Cali y, a Tumaco, 138 años para alcanzar a Pasto. Mientas que para Guapi y Quibdó alcanzar a Popayán y a Medellín respectivamente no sería posible debido a que empeoraron, el reto de estos municipios es revertir la tendencia que han tenido en los últimos años (Mosquera, 2018).

Este rezago entre la calidad de vida del litoral Pacífico y el no litoral Pacífico; es una alerta para reducir estas brechas entre la periferia y el centro del País. A su vez es una muestra de los altos niveles de desigualdad que enfrenta Colombia, lo cual es necesario tenerlo en cuenta a la hora de pensar las políticas públicas para el control y vigilancia fiscal en Colombia.

\section{Pobreza Multidimensional}

Los indicadores del Índice de Pobreza Multidimensional, el litoral presentan una vez más, valores más altos a los de la media nacional. Particularmente para el año 2005, la media nacional indicaba que el $69,5 \%$ de las personas tenían privación en cinco o más indicadores 79 Revista portafolio:http://m.portafolio.co/opinion/juan-camilo-cardenas/desarrollo-con-desde-y-para-el-pacifico-analisis-516746 
que pertenecen a las dimensiones de educación, niñez y juventud, vivienda, salud y trabajo. Este valor era del $88 \%$ en el litoral Pacífico.

El litoral Pacífico muestra privaciones más altas que el promedio nacional en 14 de 15 indicadores. Particularmente, los indicadores que muestra mayores niveles de privación en el Pacífico son empleo formal con $97,61 \%$ de privación (2005), logro educativo con $87,40 \%$ (2005) y acceso a agua mejorada con 67,06\% (2005).

Luego del anterior análisis de coyuntura económica en del litoral Pacífico vs el no litoral, se puede observar las brechas que existen en departamentos de una misma región del país, esto nos da una idea del nivel de desigualdad que existe al interior de Colombia, estos elementos deben ser tenido en cuenta para la formulación de políticas públicas para el control y vigilancia fiscal en el país, comprender las realidades locales el vital.

A modo de conclusión, haciendo un análisis meramente económico en términos de indicadores de pobreza y desigualdad, se evidencia las brechas tan abismales que se pueden encontrar en una misma región de Colombia, estos elementos son claves para considerarlos en la estructuración de políticas públicas, estas circunstancias pueden aportar a la discusión de tratar de entender las razones por las cuales una política funciona mejor en un departamento u otro, o en un municipio u otro, siendo ambos vecinos, como es el caso de Buenaventura y Cali.

\subsection{METODOLOGÍA Y DESCRIPCIÓN DE DATOS}

El modelo será construido a partir de los datos y teniendo en cuenta el contexto descriptivo del panorama de Colombia y la región del Pacífico, en términos de corrupción, información socio económica y desigualdad. Las variables seleccionadas para dicho análisis, se especifican a lo largo de esta sección, luego de una motivación a raíz de las estadísticas descriptivas. Posteriormente se explicará el modelo econométrico a estimar.

\subsubsection{Datos}

En la presente investigación se consolidó un panel de datos con las siguientes bases:

1. Consolidado de los hallazgos de los reportes de rendición de cuenta que reportan las Contralorías Territoriales al sistema interno de la Auditoría General de la República. Estas bases cuentan con datos desde el 2014 hasta el 2017 con información de los hallazgos y la cuantía de los hallazgos.

2. Índice desempeño fiscal: De Terridata del Departamento Nacional de Planeación DNP, esta información está disponible desde el año 2014 hasta el 2017.

3. Índice Transparencia por Colombia: Estos datos muestran información sobre el índice de transparencia de los 32 departamentales y las 32 gobernaciones del país, de 2014 y 2015. 
4. Estadísticas por temas DANE: Del DANE se obtuvo información de varias bases de datos de variables como, población, PIB per cápita, pobreza extrema y Gini por departamento. En algunas ocasiones se tiene información desde 2014 hasta 2017 y en otras oportunidades se cuenta con menos cantidades de años.

La unidad de observación de los datos de esta investigación son los departamentos de Colombia.

\subsubsection{Estadísticas descriptivas}

Antes de ver los resultados de las regresiones, se presenta de forma gráfica el análisis de la base de datos, mediante estadísticas descriptivas y la representación gráfica de las variables de interés en los modelos.

En el análisis descriptivo de las variables se encontró que en algunos departamentos que cuentan con altas tasas de pobreza extrema, como los casos de Chocó, Cesar, La Guajira, podría existir una correlación entre el índice de desempeño fiscal y la cantidad de hallazgos. En el caso de Chocó, se nota un incremento en los hallazgos y en el índice de empeño fiscal de forma simultánea, como muestra la gráfica 8.

\section{Gráfico 8. Hallazgos vs índice de desempeño fiscal Chocó}

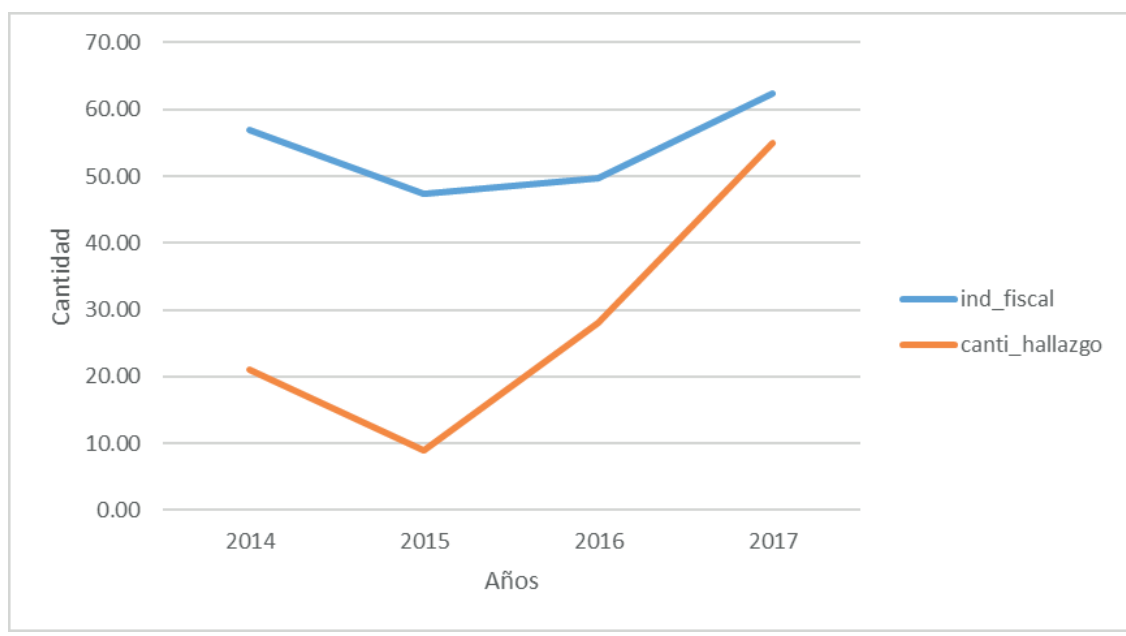

Fuente: Elaboración propia

Este es un dato importante, lo cual nos lleva a pensar que de forma descriptiva habría una correlación entre el número de hallazgos y el índice de desempeño fiscal de los departamentos. De acuerdo con la gráfica 9, se observa que, en el caso de Cesar, aunque no tan pronunciado con el caso de Chocó, pareciera estar sucediendo una situación similar, de forma descriptiva una correlación entre el índice de desempeño fiscal y la cantidad de hallazgos, al caer los 
hallazgos se evidencia una leve caída en el desempeño fiscal del departamento.

Gráfico 9. Hallazgos vs índice de desempeño fiscal Cesar.

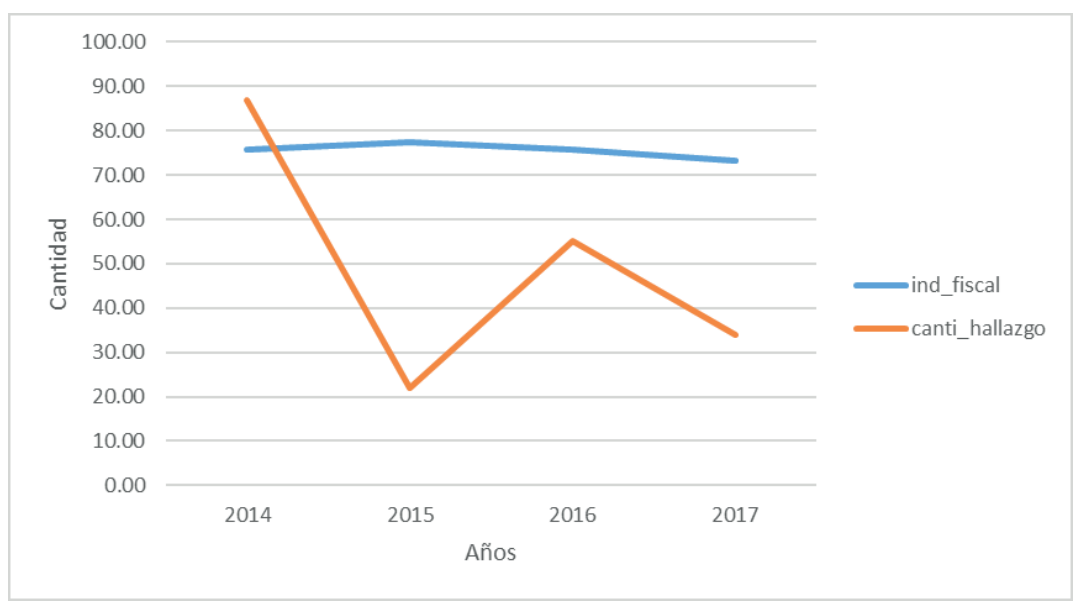

Fuente: Elaboración propia

En el caso de la guajira, se evidencia un comportamiento parecido a lo vistos en el caso de Cesar, como muestra el gráfico 10.

\section{Gráfico 10. Hallazgos vs índice de desempeño fiscal Guajira.}

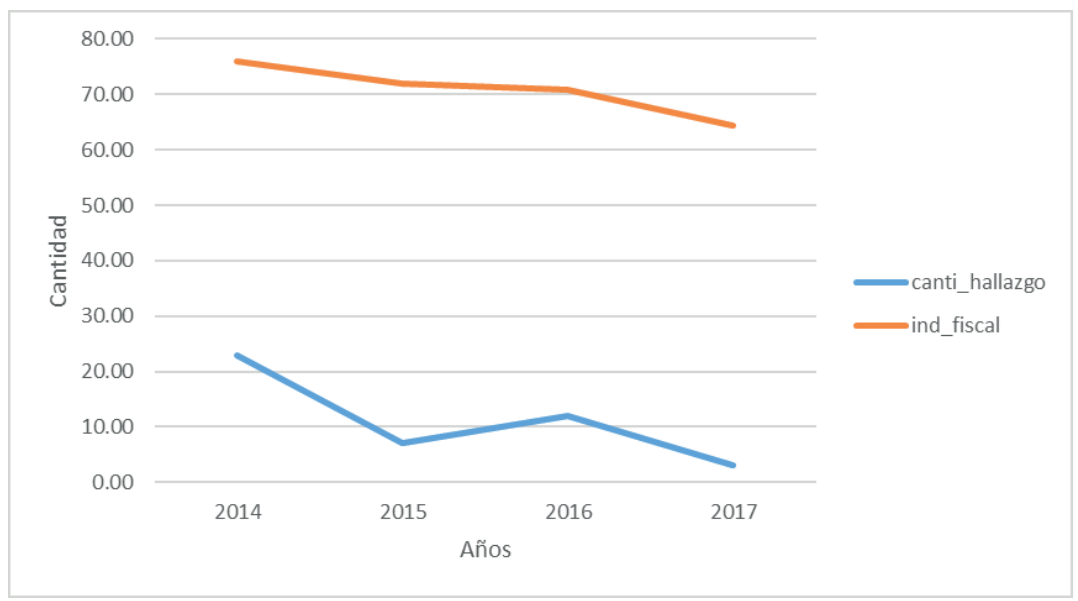

Fuente: Elaboración propia

Mirando Guainía se nota el mismo efecto que las gráficas anteriores, tal como se muestra en la gráfica 11 
Gráfico 11. Hallazgos vs índice de desempeño fiscal Guainía.

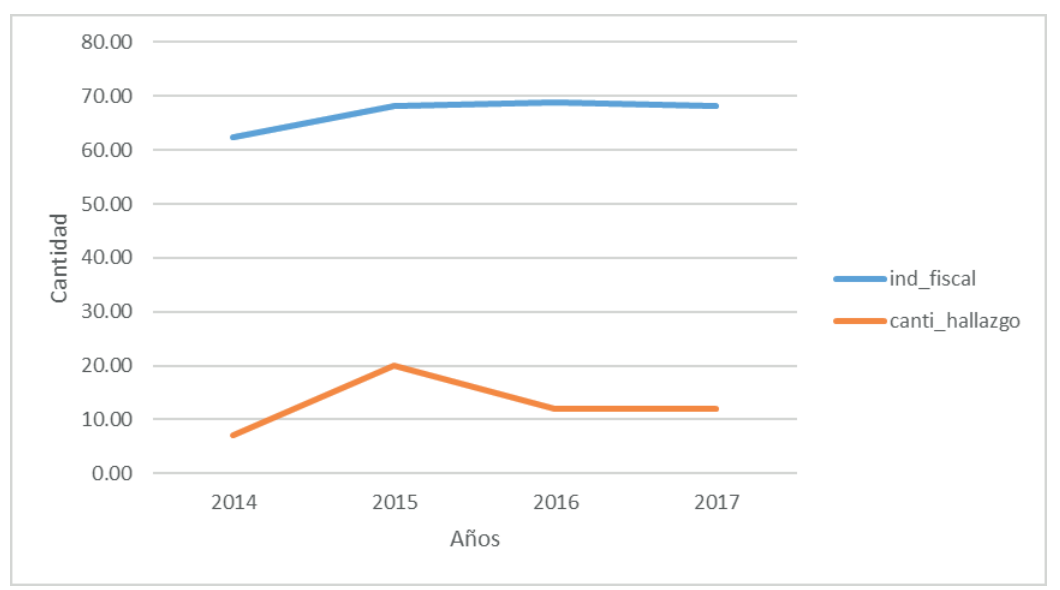

Fuente: Elaboración propia

De acuerdo con la muestra anterior, pareciera que los departamentos cuyo rango de calificación, riesgoso y vulnerable, el comportamiento del índice de desempeño fiscal es parecido al número de hallazgos que se generan. Mientras que en el caso de departamentos que cuentan con un rango de calificación sostenible en el índice de desempeño Fiscal, pareciera no está correlacionado el número de hallazgos. Como los son los casos de Atlántico y Cundinamarca. En el caso de Cundinamarca, se puede ver en el gráfico 17 el cual pareciera no mostrar una relación entre el incremento en los hallazgos y el índice de desempeño fiscal, sino todo lo contrario.

\section{Gráfico 12. Hallazgos vs índice de desempeño fiscal Cundinamarca.}

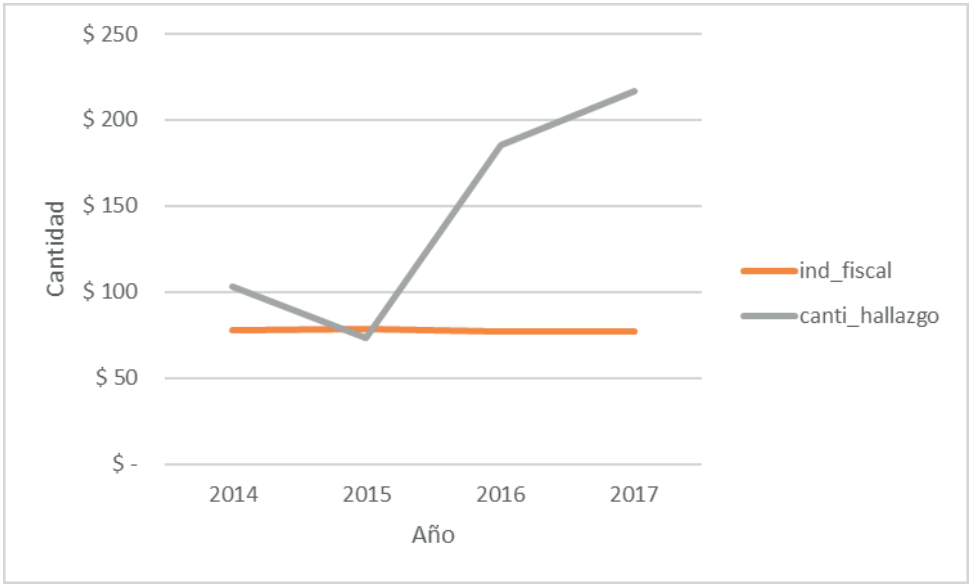

Fuente: Elaboración propia 
La misma situación de Cundinamarca, pareciera estar ocurriendo en Atlántico, como se muestra en el gráfico 12.

Gráfico 12. Hallazgos vs índice de desempeño fiscal Atlántico.

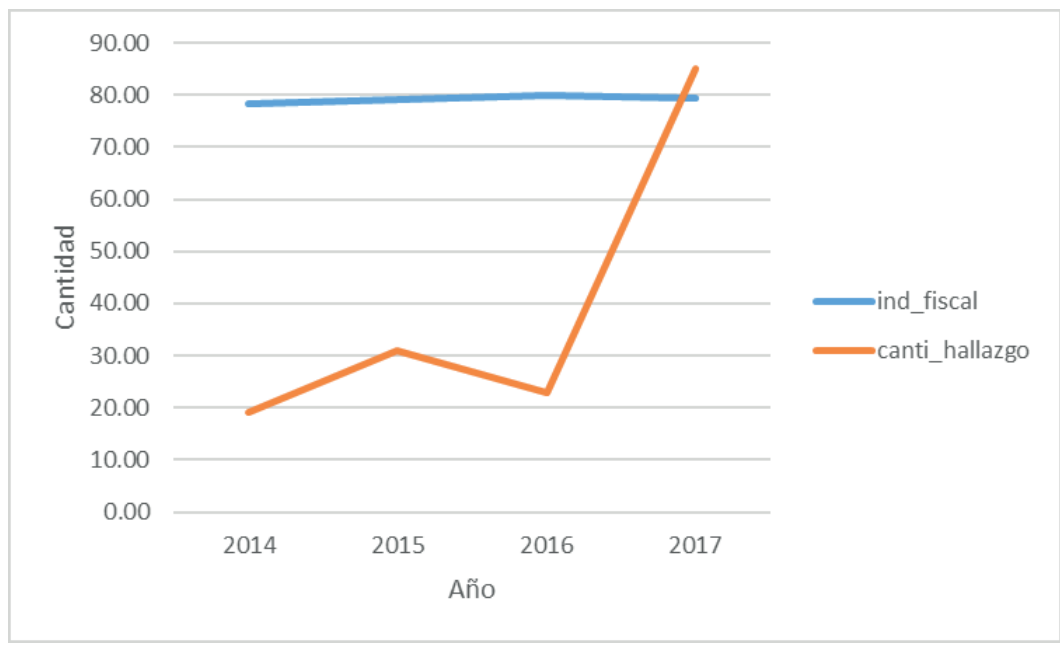

Fuente: Elaboración propia

Con el propósito de conocer las estadísticas descriptivas de las variables de interés de análisis en el presenta estudio, a continuación de presentan: Los valores mínimos, el primer cuartil, la mediana, la media, el tercer cuartil y el valor máximo de los datos de cada una de las variables, como se muestra en la tabla 2.

Tabla 2: Descriptivas de variables relevantes en el análisis de los datos

\begin{tabular}{|c|c|c|c|c|c|}
\hline \multicolumn{6}{|c|}{ Variable índice de desempeño Fiscal } \\
\hline Mínimo & Primer Cuartil & Mediana & Media & Tercer Cuartil & Máximo \\
\hline 47.46 & 67.80 & 73.21 & 71.16 & 76.20 & 81.23 \\
\hline \multicolumn{6}{|c|}{ Variable Gini } \\
\hline Mínimo & Primer Cuartil & Mediana & Media & Tercer Cuartil & Máximo \\
\hline 43.00 & 47.00 & 49.00 & 49.21 & 51.00 & 60.00 \\
\hline \multicolumn{6}{|c|}{ Cantidad de Hallazgos } \\
\hline Mínimo & Primer Cuartil & Mediana & Media & Tercer Cuartil & Máximo \\
\hline 0.00 & 35.93 & 45.74 & 42.74 & 54.61 & 70.01 \\
\hline \multicolumn{6}{|c|}{ Índice Transparencia departamental. } \\
\hline Mínimo & Primer Cuartil & Mediana & Media & Tercer Cuartil & Máximo \\
\hline 30.19 & 50.72 & 62.51 & 60.31 & 72.10 & 85.61 \\
\hline \multicolumn{6}{|c|}{ Pobreza extrema } \\
\hline Mínimo & Primer Cuartil & Mediana & Media & Tercer Cuartil & Máximo \\
\hline
\end{tabular}


2.20 6.57 9.45 11.47 12.92 39.10

\begin{tabular}{cccccc|}
\hline \multicolumn{7}{c|}{ PIB Per cápita } \\
\hline Mínimo & Primer Cuartil & Mediana & Media & Tercer Cuartil & Máximo \\
$\$ 5.033 .354$ & $\$ 7.941 .495$ & $\$ 12.153 .310$ & $\$ 13.632 .858$ & $\$ 16.381 .465$ & $\$ 47.647 .257$ \\
\hline \hline
\end{tabular}

De acuerdo con la gráfica 13, la mayoría de los departamentos reportan un índice de desempeño fiscal de superior a 70 puntos, esto es un dato alentador, debido a que la mayoría de departamentos presentan, teniendo en cuentan con una situación fiscal sostenible, aunque también vale la pena mencionar que hay una buena parte que se encuentran ubicados en un rango de 70 hacia abajo, los posiciona en una situación de vulnerabilidad y riesgo. La gráfica de dispersión pareciera mostrar una leve tendencia al alza del índice de desempeño fiscal en el rango de número de departamentos de 80 a 120 en el eje $x$. Gráfico 13. Índice desempeño fiscal de los departamentos
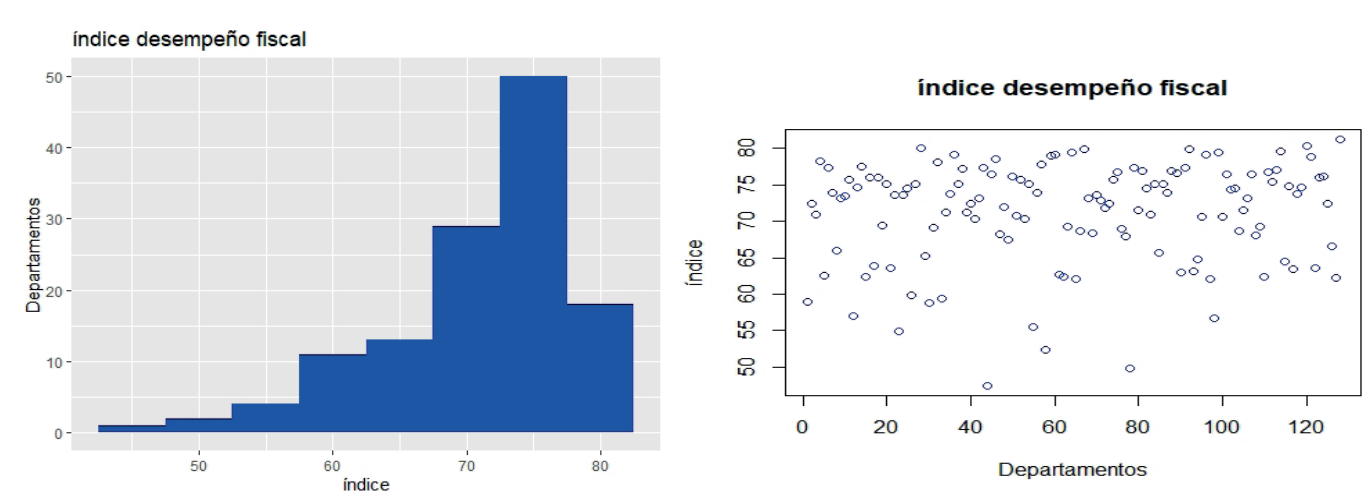

Fuente: Elaboración propia

De acuerdo con el gráfico 14, referente al índice Gini de desigualdad, se nota que la mayoría de departamentos se concentran entre el 45 y 60 , es decir, Colombia a nivel interno es un país muy desigual En el gráfico de dispersión, el gini, muestra una leve disminución a medida que incrementan las observaciones de departamentos, se nota una caída del gini acercándose más hacia los valores 50 hacia abajo, esto nos indica que la desigualdad podría estar disminuyendo levemente, lo cual Ilama la atención si contrastamos estos datos con los resultados de la gráfica 20, debido a que parecería haber una correlación gráfica, descriptiva de que si presenta un incremento en el índice de desempeño fiscal, cuando disminuye la desigualdad. 


\section{Gráfico 14. Índice de desigualdad Gini por departamentos}
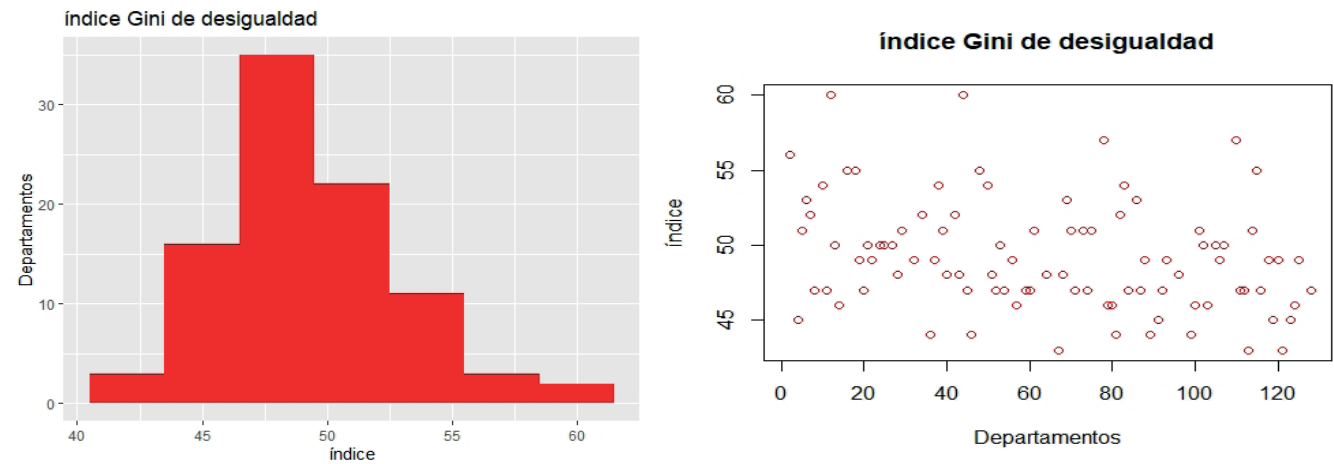

Fuente: Elaboración propia

De acuerdo con el gráfico 15 se evidencia que la pobreza extrema se concentrado mayoritariamente en rangos de 20 puntos hacia abajo, es un dato que nos permite afirmar que la pobreza extrema ha disminuido en Colombia, esto también obedece una tendencia mundial. La mayoría de los departamentos presentan un índice de pobreza monetaria extrema, entre el $5 \%$ y el $20 \%$ mayoritariamente. El gráfico de dispersión, pareciera no mostrar ninguna tendencia.

\section{Gráfico 15. Índice de pobreza extrema por departamentos}
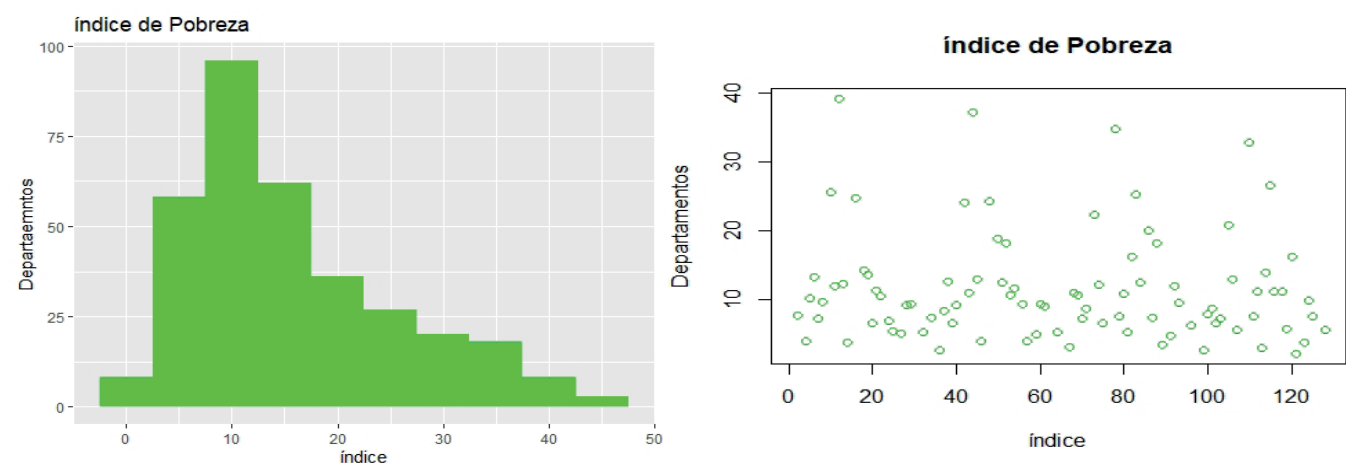

Fuente: Elaboración propia

El gráfico 16 muestra que la mayoría de los departamentos reportan un número de hallazgos inferior a 200, mientras que solo unos pocos tienen un número de hallazgos superior a 400. En el gráfico de dispersión, se nota que los hallazgos incrementan a medida que aumentan el número de observaciones de departamento, esto es un dato interesante, porque permite ver de forma descriptiva a nivel agregado de forma gráfica la correlación entre el incremento

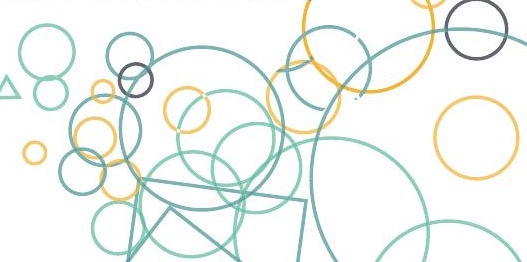


del número de hallazgos, incremento del índice de desempeño fiscal y disminución en la desigualdad.

\section{Gráfico 16. Cantidad de hallazgos por departamento}
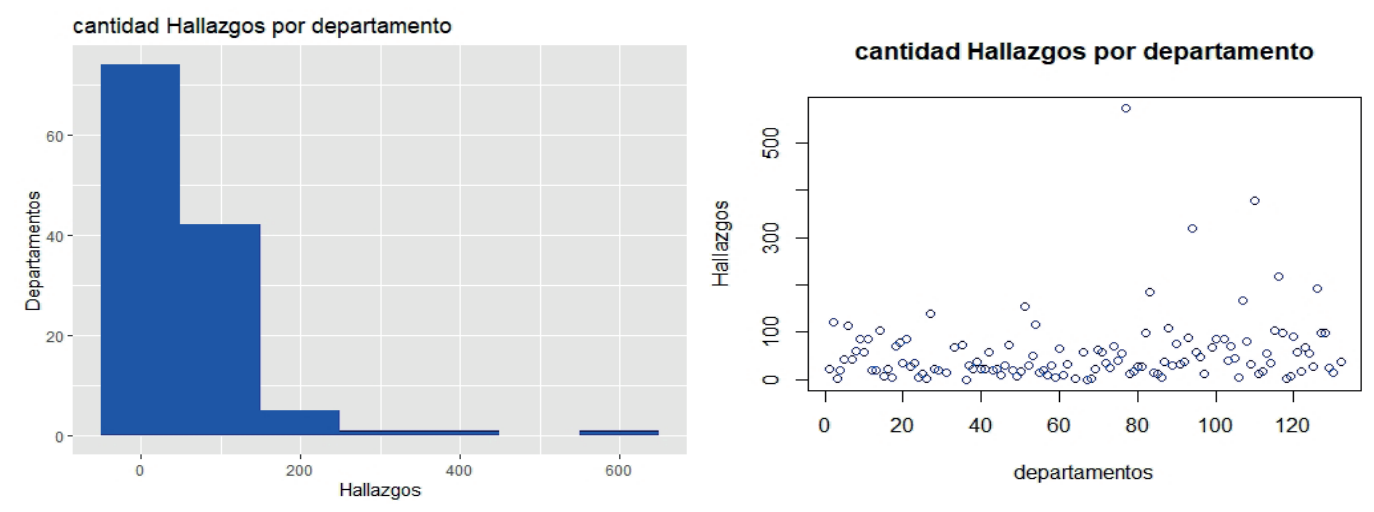

Fuente: Elaboración propia

Volviendo a los casos de Chocó y Cesar, revisando los hallazgos vs las otras variables, de la base de datos en el periodo 2014 a 2017 para mirar la relación entre los hallazgos, el índice de transparencia por Colombia y las otras variables.

\section{Gráfico 17. Descriptiva de las 5 variables de interés para Cesar}

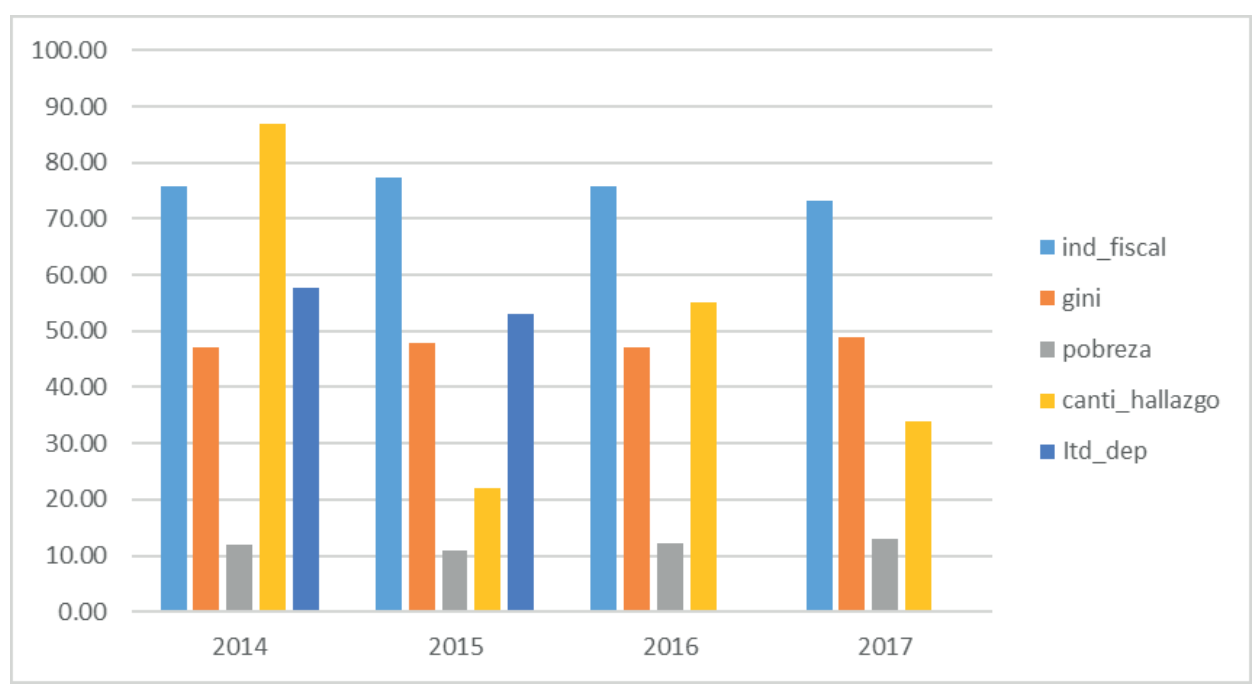

Fuente: Elaboración propia

De acuerdo con la gráfica 17 y 18, se observa que los hallazgos disminuyeron y el índice departamental de transparencia también disminuyó a lo largo del tiempo y a su vez aumentó el desempeño fiscal de los departamentos, este es un dato importante para analizar y estudiarlo 
más afondo. Otro dato importante de forma descriptivo que vale la pena resaltar, es que a medida que disminuye la desigualdad disminuye levemente la pobreza.

\section{Gráfico 18. Descriptiva de las 5 variables de interés para Cesar}

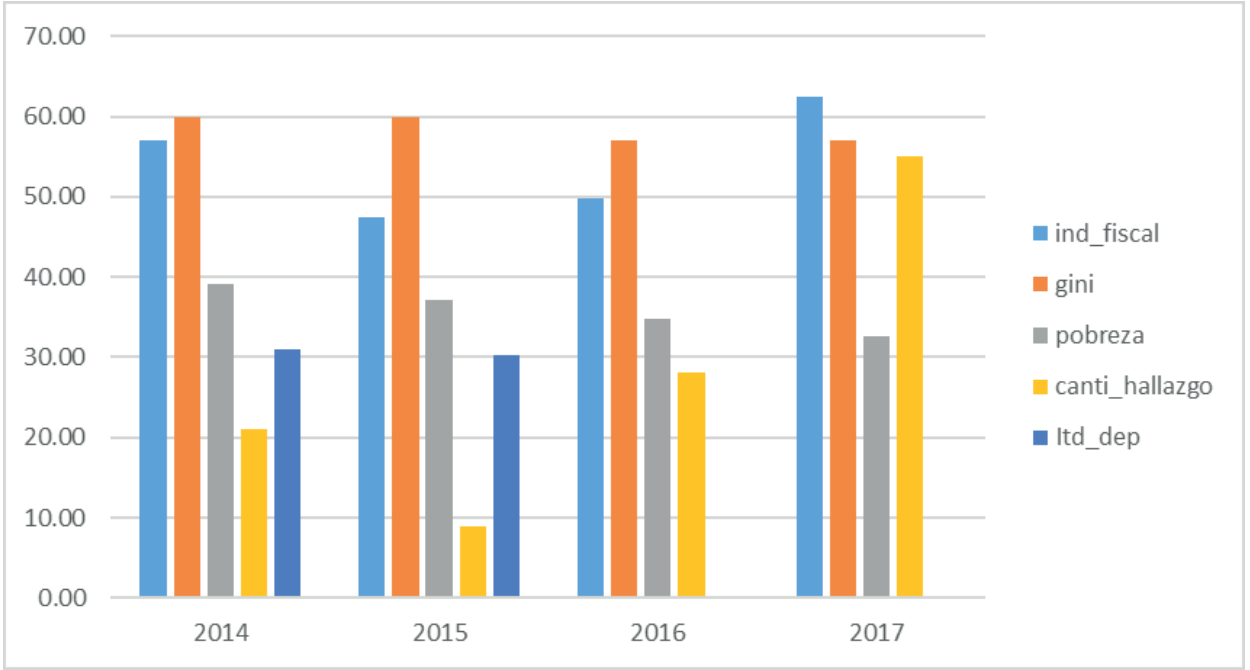

Fuente: Elaboración propia

\subsubsection{Metodología}

Para estimar la relación entre la existencia de correlación del número de hallazgos por parte de las contralorías departamentales en Colombia, las siguientes variables: indicadores de desempeño fiscal de los departamentos, índice de pobreza extrema, el índice Gini, PIB per cápita de los departamentos y variables demográficas. Se plantea la estimación de regresiones lineales con efectos fijos, aplicando la metodología de panel, usando la variable hallazgos como variable respuesta. En general para las estimaciones se consideran las siguientes variables:

Variables de interés:

- Número de hallazgos por departamentos

- Gini: índice que mide la desigualdad en un departamento

- Pobreza extrema: Porcentaje de personas en pobreza extrema en un departamento

- $\quad$ Índice de corrupción departamental de Transparencia por Colombia.

Otras variables:

- PIB Per Cápita: A nivel de departamentos

- Población: Número de habitantes por departamento 
- Departamentos

$$
\begin{gathered}
\text { Modelo econométrico 1: } \\
Y_{i t}=\beta_{0}+\beta_{1} X_{i t}+\mu_{i t}(1) \\
Y_{i}=\text { Número de hallazgos por departamento } \\
\text { El subíndice } i=\text { Hace referencia a los Departamentos }
\end{gathered}
$$

El subíndice $\mathrm{t}=$ Hace referencia al tiempo en años (2014 a 2017)

$$
\begin{gathered}
\beta_{0}=\text { Término constante del regresor (Intercepto) } \\
\beta_{1} X_{i t}=\text { vector índice Gini } \\
\mu_{i t}=\text { vector de errores o variables omitidas }
\end{gathered}
$$

Modelo econométrico 2:

$$
Y_{i t}=\beta_{0}+\beta_{1} X_{i t}+\mu_{i t}(1)
$$

$Y_{i}=$ Número de hallazgos por departamento

El subíndice $i=$ Hace referencia a los Departamentos

$$
Y_{i}=\text { Número de hallazgos por departamento }
$$

El subíndice $\mathrm{t}=$ Hace referencia al tiempo en años (2014 a 2017)

$$
\begin{gathered}
\beta_{0}=\text { Término constante del regresor (Intercepto) } \\
\beta_{1} X_{i t}=\text { vector índice desempeño fiscal } \\
\mu_{i t}=\text { vector de errores o variables omitidas } \\
\text { Modelo econométrico 3: } \\
Y_{i t}=\beta_{0}+\beta_{1} X_{i t}+\mu_{i t}(1) \\
Y_{i}=\text { Número de hallazgos por departamento } \\
\text { El subíndice } i=\text { Hace referencia a los Departamentos }
\end{gathered}
$$




$$
Y_{i}=\text { Número de hallazgos por departamento }
$$

El subíndice $t=$ Hace referencia al tiempo en años (2014 a 2017)

$$
\begin{gathered}
\beta_{0}=\text { Término constante del regresor (Intercepto) } \\
\beta_{1} X_{i t}=\text { vector logaritmo natural del PIB per cápita } \\
\mu_{i t}=\text { vector de errores o variables omitidas }
\end{gathered}
$$$$
\text { Modelo econométrico 4: }
$$$$
Y_{i t}=\beta_{0}+\beta_{1} X_{i t}+\mu_{i t}(1)
$$$$
Y_{i}=\text { Número de hallazgos por departamento }
$$

El subíndice $\mathfrak{\imath}=$ Hace referencia a los Departamentos

$$
Y_{i}=\text { Número de hallazgos por departamento }
$$

El subíndice $\mathrm{t}=$ Hace referencia al tiempo en años (2014 a 2017)

$$
\begin{gathered}
\beta_{0}=\text { Término constante del regresor (Intercepto) } \\
\beta_{1} X_{i t}=\text { vector índice de transparencia departamental } \\
\mu_{i t}=\text { vector de errores o variables omitidas }
\end{gathered}
$$

Modelo econométrico 5:

$$
Y_{i t}=\beta_{0}+\beta_{1} X_{i t}+\mu_{i t}(1)
$$

$Y_{i}=$ Número de hallazgos por departamento

El subíndice $i=$ Hace referencia a los Departamentos

$$
Y_{i}=\text { Número de hallazgos por departamento }
$$

El subíndice $t=$ Hace referencia al tiempo en años (2014 a 2017) 


$$
\begin{gathered}
\beta_{0}=\text { Término constante del regresor (Intercepto) } \\
\beta_{1} X_{i t}=\text { vector índice de pobreza extrema por departamento } \\
\mu_{i t}=\text { vector de errores o variables omitidas }
\end{gathered}
$$

Dato que se cuenta con datos panel del periodo de 2014 hasta 2017 en todas las variables excepto a variable índice de transparencia a nivel departamental, al cual solo cuenta con dos periodos: 2014 y 2015, la estimación de regresiones lineales por efectos fijos, busca controlar por otras variables que no cuenta el panel, esto permite tener unos resultados mucho más robustos y de mayor credibilidad. Para esto se correrán cinco regresiones para ver si existe correlación entre los hallazgos y otras variables observables del panel. Adicionalmente esta información cuantitativa se complementará el análisis con información cualitativa que permita comprender mejor este estudio y brindar información precisa para la toma de decisiones y recomendaciones de políticas públicas.

Adicionalmente se realiza un análisis descriptivo gráfico y numérico de las variables relacionadas en la base de datos.

Limitaciones de la metodología: En cuento a las limitaciones de la Metodología, es importante resaltar que, para realizar este tipo de estimaciones, siempre es preferible contar con un panel del dato de muchas observaciones, dado que se cuenta con datos a nivel departamental debido a que no fue posible construir una base de datos a nivel municipal, tan solo se cuenta con 128 observaciones en el caso de la variable índice de transparencia departamental, solo se cuenta con 64 observaciones. El poco número de observaciones podría estar limitando el modelo en cuento a la varianza, lo cual no permitiría mostrar significancia en los betas.

\subsection{RESULTADOS Y ANÁLISIS}

Luego de hacer las estimaciones a los 5 modelos econométricos planteados en la metodología, se encuentra significancia al 10\% entre la variable hallazgo y las variables Gini y PIB per cápita, lo que indica que hay correlación entre esas variables, como muestran las tablas 3 . Mientras que luego de correr la regresión entre la variable hallazgos y las variables, pobreza extrema, índice de desempeño fiscal e índice de transparencia por Colombia, que los coeficientes no son estadísticamente significativos, por lo que nos permite afirmar que en esta instancia no hay correlación entre estas variables.

Siguiendo con la información de la tabla 3, la regresión del modelo (1) arroja significancia 
conjunta con un F de 5.39912 que permite que rechacemos la hipótesis nula de que los coeficientes sean iguales a cero. Por otra parte, la variable Gini arroja significancia individual al $90 \%$ de confianza. En cuanto a la interpretación de los coeficientes podemos afirmar que ante el incremento de $1 \mathrm{pp}$ en el gini genera un efecto promedio sobre la variación de los hallazgos de 0.02301 unidades.

Los resultados de la regresión del modelo (2) no arrojan significancia conjunta en el $\mathrm{F}$ de 1.93637, lo cual no nos permite rechazar la hipótesis nula de que los coeficientes sean iguales a cero. Por otra parte, la variable índice de desempeño fiscal por departamento no es significativa. Lo cual nos permite afirmar que no existe correlación entre la variable hallazgos y el índice de desempeño fiscal, sin embargo, sería importante seguir explorando mecanismos que permitan testear con otro tipo de metodología, si hay correlación entre ambas variables, dado que de forma gráfica como lo vimos en numerales anteriores, si existía correlación por lo menos de forma descriptiva.

Así mismo, los resultados de la regresión del modelo (3) arrojan significancia conjunta con un $\mathrm{F}$ de 4.07053 que permite que rechacemos la hipótesis nula de que los coeficientes sean iguales a cero. Por otra parte, la variable logaritmo natural del PIB per cápita arroja significancia individual al 90\% de confianza. En cuanto a la interpretación de los coeficientes podemos afirmar que ante el incremento de $1 \%$ en el PIB per cápita, genera un efecto sobre la variación de los hallazgos de 0.04662 unidades.

Los resultados de la regresión del modelo (4) no arrojan significancia conjunta en el F de 0.000348 , lo cual no nos permite rechazar la hipótesis nula de que los coeficientes sean iguales a cero. Por otra parte, el índice de trasparencia departamental no es significativo. Lo cual nos permite afirmar que no existe correlación entre la variable hallazgos y el Índice de trasparencia departamental, sin embargo, hay que mencionar que esta variable solo tiene dos periodos de tiempo, lo cual hace no se cuente con muchas observaciones, lo que hace que no haya mucha variabilidad para encontrar significancia conjunta. Sería interesante testear esta variable cuando surjan más datos y así poder hacer una estimación más sólida.

Finalmente, los resultados de la regresión del modelo (5) no arrojan significancia conjunta en el $\mathrm{F}$ de 0.01502 , lo cual no nos permite rechazar la hipótesis nula de que los coeficientes sean iguales a cero. Por otra lo que el índice de pobreza extrema por departamento no es significativo. Lo cual nos permite afirmar que no existe correlación entre la variable hallazgos y el índice de pobreza extrema por departamento. 


\section{OPPCF}

Tabla 3. Estimación lineal por efectos fijos del número de hallazgos por departamento

\begin{tabular}{|c|c|}
\hline Variables & Número de Hallazgos por departamento \\
\hline Gini & $\begin{array}{c}0,02301^{*} \\
(4,6572)\end{array}$ \\
\hline Índice desempeño fiscal & $\begin{array}{c}0,1674 \\
(17,366)\end{array}$ \\
\hline Logaritmo natural del PIB per cápita & $0.04662 *$ \\
\hline & $(59,493)$ \\
\hline Índice de trasparencia departamental & 0,9852 \\
\hline Índice de pobreza extrema por departamento & $\begin{array}{c}0.833586 \\
0,9028 \\
(3,89388)\end{array}$ \\
\hline
\end{tabular}

\subsection{CONCLUSIONES}

Teniendo en cuenta los resultados obtenido en el presente capítulo, a modo de conclusiones se resaltan los siguientes aspectos:

El marco legal de Colombia, en cuanto a las políticas públicas y en cuento a la vigilancia del control fiscal en Colombia es bastante amplio, entonces, la solución no es crear más normas ni leyes, sino que el gran reto es hacer que funcionen bien las leyes que están establecidas actualmente. Sin embargo, diseñar y poner en marcha mecanismo que permitan hacer seguimiento y evaluación de la normatividad actual, es clave para un verdadero proceso de transformación, con el propósito de que la autoridad actúe más rápido, esto podría ayudar para que la actual normatividad sea más eficiente y efectiva.

Teniendo en cuenta el marco fiscal de mediano plazo de Colombia, la economía del país, no tendría un decrecimiento extraordinario, debido a que la inflación seguirá teniendo un comportamiento estable, y la economía del país no crecerá de forma abrupta, debido a que no se tienen nichos de mercado que muestren esa tendencia. Lo que sí es claro es que Colombia tiene una economía estable, y en momentos donde hubo recesión económica en todo el mundo, Colombia no tuvo una caída significativa, sino que se mantuvo estable, esto es una buena noticia para el país. Implementar políticas públicas que permita combatir la corrupción, podría ser viable para el país.

Las políticas públicas no funcionan de la misma manera en todo el territorio nacional. La desigualdad es un factor importante para las políticas públicas locales. De acuerdo con 
las características sociales, culturales y económicas, se deberían priorizar los programas y proyectos.

Se puede evidenciar la importancia de comprender las dinámicas regionales de Colombia, para la implementación y puesta en marcha de políticas públicas, efectivas, eficaces y eficientes que permitan cerrar brechas en la sociedad.

La desigualdad, podría estar profundizando el problema de la corrupción en Colombia, los departamentos con mayor debilidad fiscal, y mayor desigualdad, podrían estar presentando mayores casos de hallazgos y detrimento patrimonial. Por lo que para estructurar políticas públicas para el control y vigilancia fisca, no solo basta con enfocarse en reformar las Contralorías territoriales per se, sino también se deben pensar, programas que permitan generar un fortalecimiento social y económico a las regiones más rezagadas del país, entonces se trata de pensar una política pública integral que abarque otros escenarios de la sociedad.

Finalmente, y como se ha venido reiterado a lo largo del presente capítulo, se hace un llamado al gobierno nacional y a todos los órganos e instancias involucradas, a desarrollar y pensar políticas públicas que fortalezcan el control y vigilancia fiscal teniendo en cuenta aspectos como la desigualdad, la debilidad institucional, los índices de corrupción, características, sociales, económicas y basados en las realidades de los territorios colombianos, a su vez, se requiere fortalecer paralelamente las instituciones con el propósito de que estas tengan un mejor desempeño.

\subsection{REFERENCIAS BIBLIOGRÁFICAS}

- Benavente, M. C. (2014). Políticas públicas para la igualdad de género. Santiago de Chile: CEPAL.

- Blöchliger. (2006). Fiscal autonomy of sub-central governments. OECDiLibrary, https://www. oecd-ilibrary.org/taxation/fiscal-autonomy-of-sub-central-governments_5k97b127pc0ten.

- $\quad$ Alcaldía Distrital de Bogotá D.C. 2017. Decreto 689 de 2011. Por medio del cual se adopta la “Guía para la formulación e implementación de políticas públicas del Distrito.

- DNP. (25 de Julio de 2014). Funciones DNP. Portal del Departamento nacional de Planeación: https://www.dnp.gov.co/DNPN/la-entidad/funciones-dnp

- Contraloría General de la República. Informe de gestión al Congreso y al Presidente de la República 2016-2017. Recuperado de: http://contraloria.gov.co 


\section{OPPCF}

- Foros Semana (30 de mayo de 2019). Hacia un nuevo modelo de control fiscal en Colombia, recuperado de:

- https://www.forossemana.com/evento/id/38780/hacia_un_nuevo_modelo_de_control_ fiscal_en_colombia

- Cárdenas, J. C. (2018). Desarrollo con, desde y para el Pacífico. Portafolio, https://www. portafolio.co/opinion/juan-camilo-cardenas/desarrollo-con-desde-y-para-el-pacificoanalisis-516746.

- Lee, G. (2006). Control fiscal y seguridad jurídica gubernamental. Bogotá: Universidad Externado de Colombia.

- Mosquera, L. (2018). Los Retos Socioeconómicos del Presidente Iván Duque con el litoral Pacífico. Revista Semana, https://www.semana.com/opinion/articulo/los-retossocioeconomicos-del-presidente-ivan-duque-con-el-litoral-pacifico/582940.

- Parsons, W. (1995). Public Policy: An Introduction to the Theory and Practice of Policy. Aldershot, UK: Brookfield.

- Romero, J. (2009). Geografía económica. Cartagena: Banco de la República.

- Sánchez, J. A. (2012). Biodiversidad, Conversación y Desarrollo. Bogotá: Ediciones Uniandes.

- Torres, B. (2006). Metodología de la investigación para administración, economía, humanidades y ciencias sociales. Pearson Educación.

- Base de datos: Auditoría General de la República SIREL-SIA. (2017). Generada en noviembre de 2017.

- Public Data (15 de mayo de 2019). Política Económica y Deuda: https://www.google.com/ publicdata

- DANE. (17 de mayo de 2019). Estadísticas por tema recuperado de: http://www.dane.gov.co/

- Banco de la República (2019). Resultados de estadísticas de Coyuntura económica de Colombia 2018. Bogotá, Colombia: BANREP: Recuperado de: http://www.banrep.gov.co/ es/publicaciones/informe-del-gerente-abril-2017

\section{(Footnotes)}

Número de hallazgos por departamento: Errores estándar en paréntesis. ${ }^{* * *} p<0.01,{ }^{* *} p<0.05,{ }^{*} p<0.1$

Las tres estrellas indica que es significativo al $1 \%$, las dos estrellas indica que es significativo al $5 \%$ y una estrella, implica que es significativo al $10 \%$. 


